LBNL-44203

\title{
Coupled Thermohydromechanical Analysis of a Heater Test in Unsaturated Clay and Fractured Rock at Kamaishi Mine
}

\author{
Jonny Rutqvist, Jahan Noorishad and Chin-Fu Tsang \\ Earth Sciences Division \\ Ernest Orlando Lawrence Berkeley National Laboratory \\ University of California \\ Berkeley, Ca 94620 USA
}

August 1999

This work was supported by a grant from the Swedish Nuclear Power Inspectorate. Work is also partially supported by the Office of Science, Office of Basic Energy Sciences, Engineering and Geosciences Division of the Department of Energy, under contract No. DE-AC03-76SF00098 and by the National Energy Research Scientific Computational Center (NERSC) through Contract DE-AC03-76SF00098. 


\section{DISCLAIMER}

This report was prepared as an account of work sponsored by an agency of the United States Government. Neither the United States Government nor any agency thereof, nor any of their employees, make any warranty, express or implied, or assumes any legal liability or responsibility for the accuracy, completeness, or usefulness of any information, apparatus, product, or process disclosed, or represents that its use would not infringe privately owned rights. Reference herein to any specific commercial product, process, or service by trade name, trademark, manufacturer, or otherwise does not necessarily constitute or imply its endorsement, recommendation, or favoring by the United States Government or any agency thereof. The views and opinions of authors expressed herein do not necessarily state or reflect those of the United States Government or any agency thereof. 


\section{DISCLAIMER}

Portions of this document may be illegible in electronic image products. Images are produced from the best available original document. 


\section{Summary}

The recent interest in coupled thermohydromechanical (THM) processes associated with geological disposal of spent nuclear fuel, and in particular the issue of resaturation of a clay buffer around a waste canister, has encouraged major development of the finite element computer program ROCMAS in the past three years. The main objective is to develop a tool for analysis of THM processes in practical field scale, including fractured rock masses and detailed behavior of the near-field, nonisothermal and unsaturated system composed of rock fractures and clay buffer. In this report, the ROCMAS code is presented and applied for modeling of coupled THM processes in small laboratory samples of bentonite clay as well as a large in situ THM experiment in fractured rocks, at Kamaishi Mine, Japan.

The fundamental responses of a bentonite clay material were investigated in a number of laboratory tests, including suction tests, infiltration tests, thermal gradient tests, and swelling pressure tests. These laboratory tests are modeled with ROCMAS for determination of material properties and for validation of the newly implemented algorithms. The ROCMAS code is also applied for modeling of a 3-year in situ heater experiment conducted in fractured hard rock, which consists of a heater-clay buffer system and simulates a nuclear waste repository. The temperature of the heater was set to $100{ }^{\circ} \mathrm{C}$ during 8.5 months followed by a 6 -month cooling period. The bentonite and the rock surrounding the heater were extensively instrumented for monitoring of temperature, moisture content, fluid pressure, stress, strain, and displacements.

An overall good agreement between the modeling and measured results, both against the laboratory experiments and the in situ heater test, indicates that the THM responses in fractured rock and bentonite are well represented by the coupled numerical model, ROCMAS. In addition, robustness and applicability of ROCMAS to practical scale problems is demonstrated. Further studies are needed, however, on in situ properties of main rock fractures, modeling of hydromechanical behavior of the bentonite under low saturation, and modeling of the rock-bentonite interface during the resaturation process. 


$\begin{array}{lll}\text { Notations } & \\ C_{v S}= & \text { Volumetric specific heat capacity of solid } \\ C_{w w}= & \text { Volumetric specific heat capacity of water } \\ C_{P_{v}}= & \text { Volumetric specific heat capacity of vapor } \\ C_{i j k l}= & \text { Stress-deformation matrix } \\ C_{s}= & \text { Moisture capacity } \\ D_{a t m}= & \text { Molecular diffusion for water vapor in air } \\ D_{p v}= & \text { Thermal vapor diffusion coefficient } \\ D_{T v}= & \text { Isothermal vapor diffusion coefficient } \\ D_{v}= & \text { Effective molecular diffusion of water vapor in air for a porous media } \\ e & = & \text { Elastic volumetric strain } \\ e_{k l}= & \text { Components of the strain tensor } \\ f & = & \text { Body force per unit mass } \\ f_{T v}= & \text { Thermal enhancement diffusion factor } \\ g & = & \text { Acceleration of gravity } \\ h & = & \text { Relative humidity } \\ K_{w}= & \text { Hydraulic conductivity } \\ K_{w S}= & \text { Saturated hydraulic conductivity } \\ k_{w v}= & \text { Permeability } \\ k_{w S}= & \text { Saturated permeability } \\ K_{M}= & \text { Thermal conductivity } \\ k_{r}= & \text { Relative permeability } \\ L & = & \text { Latent heat of vaporization of water } \\ L_{0} & = & \text { Latent heat of vaporization of water at } T_{0} \\ P & = & \text { Fluid pressure } \\ q_{w}= & \text { Liquid mass water flow } \\ q_{v}= & \text { Vapor mass water flow } \\ R & = & \text { Specific gas constant } \\ S & = & \text { Saturation } \\ S_{0}= & \text { Reference saturation } \\ t & = & \text { Time } \\ T & = & \text { Temperature } \\ T_{a b s}= & \text { Absolute temperature } \\ T_{0}= & \text { Reference temperature } \\ z & = & \text { Elevation } \\ \alpha & = & \text { Biot's coupling constant } \\ \beta_{P}= & \text { Fluid compressibility } \\ \beta_{T}= & \text { Fluid thermal expansion coefficient } \\ \Gamma & = & \text { Isotropic linear solid thermal expansion coefficient } \\ \gamma_{w} & = & \text { Fluid weight density } \\ \delta_{i j}= & \text { Kronecker delta function } \\ \xi & = & \text { Coefficient of swelling } \\ \eta_{w}= & \text { Dynamic fluid viscosity } \\ \mu_{v} \lambda= & \text { Lame's elasticity constants } \\ v_{v}= & \text { Mass flow factor } \\ & & \end{array}$




$\begin{array}{lll}\bar{\rho}_{s} & = & \text { Average solid mass density } \\ \rho_{s} & = & \text { Solid mass density } \\ \rho_{v} & = & \text { Vapor mass density } \\ \rho_{v S} & = & \text { Saturated vapor mass density } \\ \rho_{w} & = & \text { Water mass density } \\ \rho_{w}^{0} & = & \text { Reference water mass density } \\ \tau_{i j} & = & \text { Components of the total stress tensor } \\ \tau_{v} & = & \text { Tortuosity factor } \\ \phi & = & \text { Porosity } \\ \varphi & = & \text { Matric potential } \\ \theta & = & \text { Volumetric water content } \\ \omega & = & \text { Gravimetric water content }\end{array}$




\section{Contents}

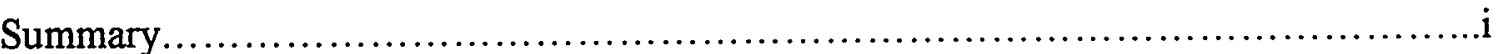

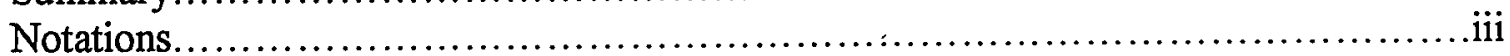

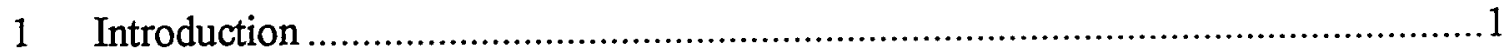

2 A model for coupled THM analysis of unsaturated media .......................................2

2.1 Approach for extension into unsaturated media ...............................................

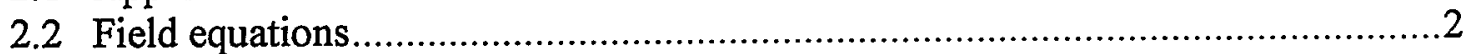

2.2.1 Mass conservation and flow of water and vapor .......................................

2.2.2 Conservation of energy and heat flow.......................................................

2.2.3 Momentum conservation and mechanics ................................................

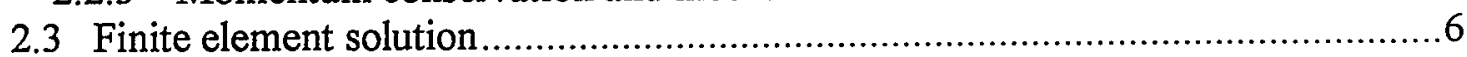

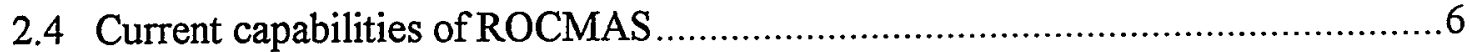

3 Coupled modeling of laboratory experiments on bentonite ...................................

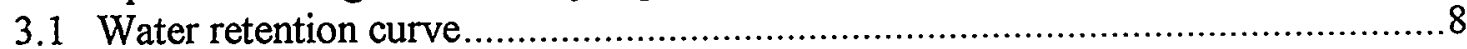

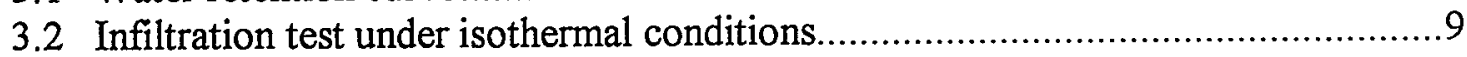

3.3 Properties for water flow under thermal gradient ............................................. 18

3.4 Properties for swelling of the bentonite ……..................................................23

3.5 Overall agreement between laboratory experiments and ROCMAS .....................26

4 Kamaishi Mine Heater Test ........................................................................27

5 Overview of the experimental data set at Kamaishi Mine .....................................29

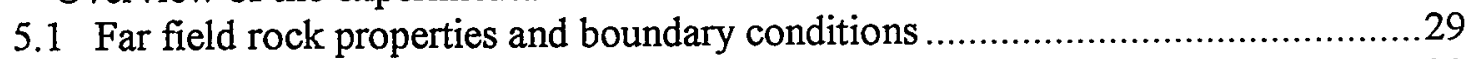

5.2 Near field rock properties and fracture geometry .............................................30

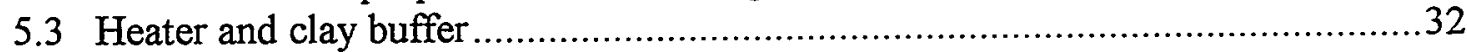

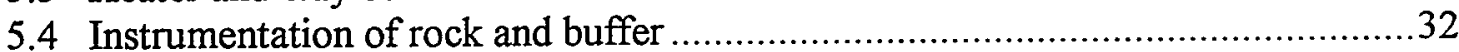

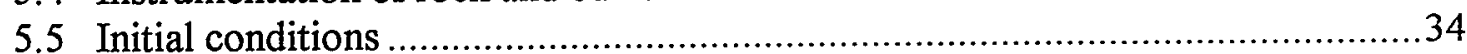

6 Modeling conceptualization of the rock at Kamaishi Mine ....................................35

6.1 Alternative modeling approaches .....................................................................35

6.2 Preliminary modeling of mechanical effects of fractures .....................................35

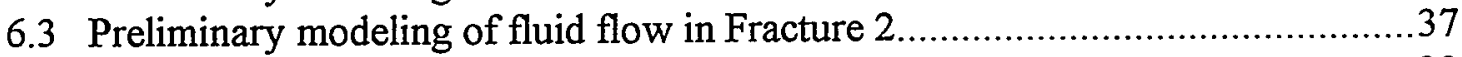

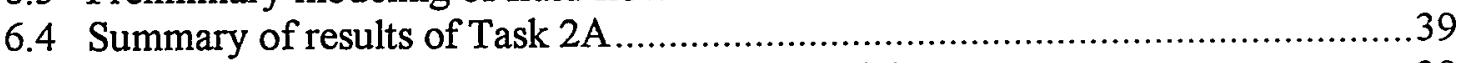

6.5 Conceptualization for a three-dimensional model ...............................................39

7 Calibration of rock mass properties at Kamaishi Mine ...........................................44

7.1 Finite-element model and boundary conditions …..........................................44

7.2 Material properties and calibration method...................................................46

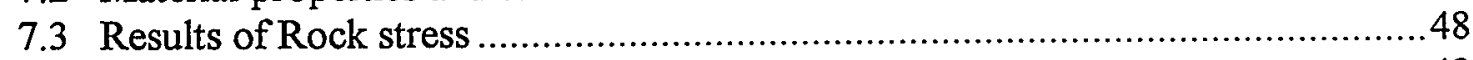

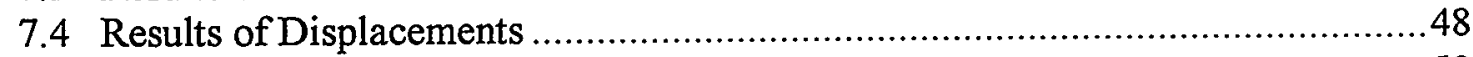

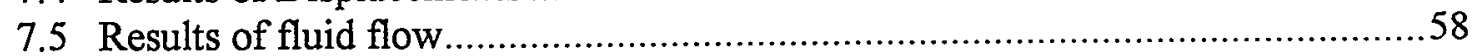

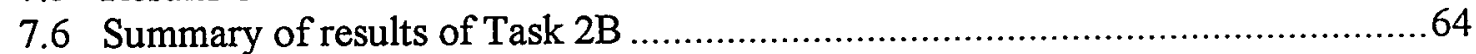

8 Coupled modeling of the in situ heater test at Kamaishi Mine ................................65

8.1 Finite element model and boundary conditions.................................................65

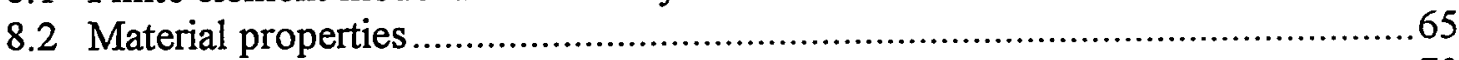

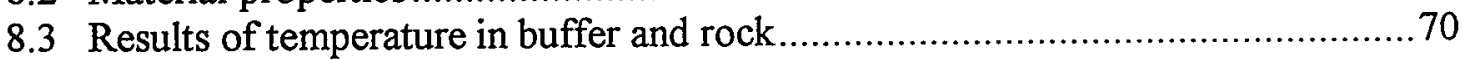

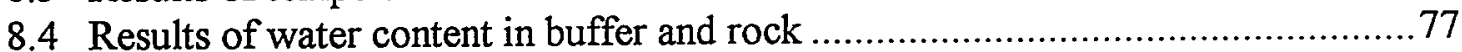

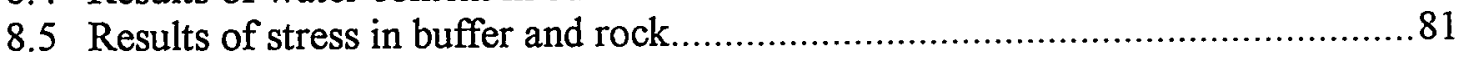

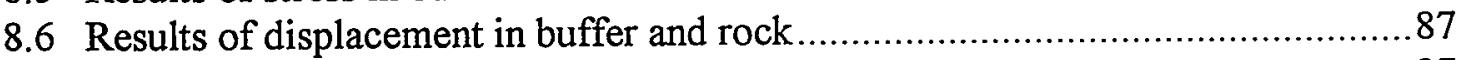

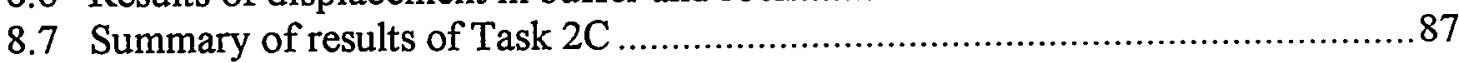


9 Overview of Coupled THM processes at Kamaishi Mine .................................93

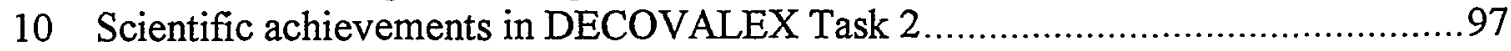

11 Lessons learned from modeling of Kamaishi Mine Heater Test ..........................98

12 Suggestions for future in situ heater tests ............................................ 99

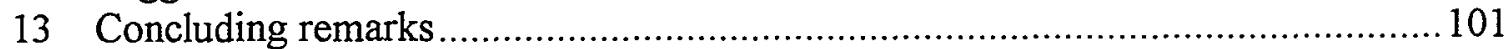

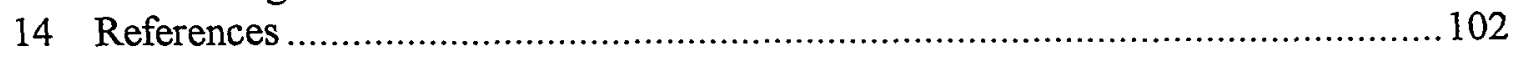




\section{Introduction}

The Swedish KBS-3 concept (SKB, 1983) for safe disposal of spent nuclear fuel is based on multiple barriers for protection of the environment against the radioactive nuclides. The spent fuel assemblies will be encapsulated in copper canisters, which will be placed in deposition holes at about 500 meters depth in the bedrock, and the holes will be filled with bentonite clay embedding the canisters. The clay buffer should prevent water from flowing around the canister and protect the canister against external mechanical movements. The bedrock at the site should provide a stable mechanical and chemical environment. If some radioactive substances get out into the groundwater, the rock should act as a filter and absorb the substances.

The performance assessment of the KBS-3 nuclear waste repository concept requires coupled THM analysis of a system comprising the canister, clay, and rock barriers. In this environment, the temperature, groundwater flow and mechanical deformation are linked processes that cannot be analyzed independently of each other. For example, the elevated temperature and thermal expansion of the rock leads to closure of existing fractures, which changes the permeability of the rock. The temperature gradient is also one of the main forces to drive the water within the clay buffer by diffusion. At the same time, the clay swells or shrinks as a function of its water content, causing mechanical deformation and stress changes.

A three-dimensional finite element model for analysis of coupled THM processes in fractured rocks, called ROCMAS is extended towards modeling of unsaturated media, and in particular toward application on the canister-buffer and rock system in a nuclear waste repository. The newly developed unsaturated version of the program is applied to a 3-year in-situ heater experiment conducted by the Japan Nuclear Cycle Development Institute (JNC) at Kamaishi Mine in Japan. It was carried out at a depth of 250 meters and simulates the conditions at a potential future nuclear waste repository in fractured hard rocks, with a design similar to the Swedish KBS-3 concept. The experiment is a major test case in the international co-operative project DECOVALEX (Jing et al., 1999) for the development of coupled THM models and their validation against field experiments. The test case is modeled separately by four research teams within DECOVALEX. This report presents the ROCMAS code and the modeling of the Kamaishi Mine heater test by Lawrence Berkeley National Laboratory (LBNL), supported by a grant from the Swedish Nuclear Power Inspectorate (SKI). 


\section{A model for coupled THM analysis of unsaturated media}

ROCMAS is a finite-element program developed at LBNL for analysis of coupled THM processes in fractured rocks (Noorishad and Tsang (1996). It is continuum-based, capable of THM modeling ubiquitously fractured rock masses, with an option for representing discrete fractures. The coupling of the fluid flow and mechanical deformation is based on an extension of Biot's general effective stress theory (Biot, 1941) for the response of a porous elastic medium to nonlinear fracture behavior. Recently, ROCMAS has been extended to handle coupled THM behavior of clay buffer material under unsaturated conditions. The theoretical development and present capabilites of ROCMAS is presented in this section, and thereafter the new algorithm is tested against laboratory experiments and applied to a in situ heater test in fractured rock.

\subsection{Approach for extension into unsaturated media}

The recent extension of the computer code toward THM processes in unsaturated media is made in the light of existing theories for moisture and heat transport in hysteretic, inhomogeneous porous media, presented by Milly (1982). Milly's work is based on theoretical developments by Phillip and de Vries (1957), but uses matric-potential and temperature as dependent variables. The matric-potential is readily translated to liquid fluid pressure, which is one of the dependent variables in ROCMAS (together with displacement and temperature). ROCMAS considers liquid water flow as well as vapor flow in air-filled pores due to molecular diffusion, and both are coupled with temperature and mechanical deformation. The liquid flow is driven by the pressure gradient and depends on the relative permeability, $k_{r}$, which is a function of saturation. The vapor flow is driven by the vapor density gradient and depends on an effective molecular diffusion coefficient $D_{\nu}$. Air flow and convection of vapor with bulk air flow are not considered. Thus, this approach may be limited to relative low temperature (weakly nonisothermal) or low-permeability systems where the steam convection can be neglected.

\subsection{Field equations}

The basic governing equations in ROCMAS for coupled thermohydroelasticity in weakly nonisothermal, variably saturated media are:

1) Mass conservation of water and vapor

2) Energy conservation

3) Momentum conservation

These equations are presented in next sections and the symbols are explained in the nomenclature list of this report.

\subsubsection{Mass conservation and flow of water and vapor}

The mass conservation of liquid water and vapor was derived separately and then combined to the following equation total water mass conservation: 


$$
\begin{aligned}
& \alpha\left[S \rho_{w}+(1-S) \rho_{v}\right] \frac{\partial e}{\partial t}+\left[\phi S \rho_{w}^{0} \beta_{p}+\phi\left(\rho_{w}-\rho_{v}\right) C_{s}+\phi(1-S) \frac{\rho_{v}}{\rho_{w} R T}\right] \frac{\partial P}{\partial t} \\
& +\left[\phi S \rho_{w}^{0} \beta_{T}+\phi(1-S)\left(h \frac{\partial \rho_{v S}}{\partial T}+\frac{\rho_{v} P}{R T^{2}}\right)\right] \frac{\partial T}{\partial t} \\
& =\nabla \cdot\left[\left(\frac{\rho_{w} k_{w}}{\eta_{w}}+D_{P v}\right) \nabla P+\frac{\rho_{w} k_{w}}{\eta_{w}} \gamma_{w} \nabla z\right]-\nabla \cdot\left(f_{T v} D_{T v} \nabla T\right)
\end{aligned}
$$

The left-hand side of Equation (1a) represents the mass of water and vapor stored within a unit volume element, and the right-hand side represents the divergence of water mass from the element. The first term on the left side is water storage due to transient expansion (volumetric strain, e) of the solid skeleton. Expansion of the solid implies increased porosity that provides more space for both liquid and vapor. The expression within the second square bracket in Equation (1a) is water storage as a result of transient pressure changes. For unsaturated conditions, the moisture capacity $\mathrm{C}_{s}$ is here the most important parameter determined by the water retention curve of the material as:

$$
C_{s}=\frac{\partial S}{\partial P} \rho_{w} g \phi
$$

where $\partial S / \partial P$ is obtained from the water retention curve. The third term on the left side of Equation (1a) is water storage from thermal expansion of the liquid water mass and a change in vapor density in the air-filled part of the pores.

The right-hand side of Equation (1a) is due to water flow in both liquid and vapor form. The liquid mass flow can be written as:

$$
q_{w}=-\frac{\rho_{w} k_{w}}{\eta_{w}}\left(\nabla P+\gamma_{w} \nabla z\right)
$$

For a fracture, the permeability $k_{w}$ depends on the current fracture aperture and can be calculated using the "cubic law". The permeability of a fracture can easily change several orders of magnitude because of mechanical fracture-aperture changes accompanied by stress changes. Another important parameter is the relative permeability $k_{r}$, which is included in the absolute permeability $k_{w}$ :

$$
k_{w}=k_{w S} \cdot k_{r}
$$

where $k_{w S}$ is the permeability at saturated conditions. Under unsaturated conditions, the relative permeability may change several orders of magnitude as a function of saturation, which implies that permeability is much smaller in a dry material than in a fully saturated material. In addition, the viscosity and density of water ( $\eta_{w}$ and $\rho_{w}$ in Equation 1a) are temperature dependent through empirical functions. 
The equation for vapor mass flow is:

$q_{v}=-D_{P v} \nabla P-f_{T_{v}} D_{T_{v}} \nabla T$

$D_{p v}$ and $D_{T v}$ are diffusion coefficients for diffusion of vapor in air-filled pores as a result of the vapor density gradient. In ROCMAS, the vapor diffusion has been split into one part related to pressure gradient and one part related to thermal gradient according, to Phillip and de Vries (1957). One advantage of this partition is that it can correctly, take account of the fact that diffusion under thermal gradient is frequently larger than what can be explained by the 'simple' diffusion theory (Phillip and de Vries, 1957). Therefore, a thermal diffusion enhancement factor $f_{T_{v}}$ is multiplied to $D_{T v}$ in Equation (1d). The diffusion coefficients are dependent on an effective molecular diffusion coefficient $D_{v}$ according to:

$D_{p v}=\frac{D_{v} \rho_{v}}{\rho_{w} R T_{a b s}}$

$D_{T v}=D_{v}\left[h \frac{\partial \rho_{v S}}{\partial T}-\frac{\rho_{v} P}{\rho_{w} R T_{a b s}^{21}}\right]$

where $\mathrm{h}$ is the relative humidity according to:

$h=e^{P / \rho_{w} R T_{a b s}}$

and $\rho_{v S}$ the saturated vapor density computed according to:

$\rho_{v S}=1 \cdot 10^{-3} \cdot e^{19.891-\left[4975.9 / T_{a b s}\right]}$

and where vapor density $\rho_{v}$ is:

$$
\rho_{v}=h \cdot \rho_{v S}
$$

The last three equations are standard thermodynamic relations for vapor in air and are default functions in ROCMAS.

\subsubsection{Conservation of energy and heat flow}

The energy conservation equation is derived by equating the change in stored energy to the sum of the convergence of heat flux. The final equation is: 


$$
\begin{aligned}
& {\left[(1-\phi) \rho_{s} C_{v s}+\rho_{w} C_{w s} \phi S+\rho_{v} C_{p v} \phi(1-S)+H_{1}\left(h \frac{\partial \rho_{v s}}{\partial T}-\frac{\rho_{v} P}{R T^{2}}\right)\right] \frac{\partial T}{\partial t}+} \\
& H_{2} \frac{\partial(\phi S)}{\partial t}+\left(H_{1} \frac{\rho_{v}}{\rho_{w} R T}+H_{2} \frac{\partial(\phi S)}{\partial P}\right) \frac{\partial P}{\partial t}+\beta T_{0} \frac{\partial e}{\partial t} \\
& =\nabla \cdot\left[\left(K_{M}+L D_{T_{v}}\right) \nabla T+L D_{P_{v}} \nabla P+\left(C_{v w} q_{w}+C_{p v} q_{v}\right) \nabla T\right]
\end{aligned}
$$

The first three terms on the left side of Equation (2a) is the heat capacity of the partially saturated media where $C_{v s}, C_{w s}, C_{p v}$ are the specific heat capacity of vapor, water, and solid respectively. The terms including $H_{1}$ and $H_{2}$ are derived from the latent heat of vaporization of water, and the last term on the left side is the heat produced by the mechanical dissipation. The right hand side is the divergence of energy resulting from heat conduction (first term), latent heat transport with vapor diffusion (second and third term), and the convection of heat with liquid and vapor flow. The latent heat of vaporization $L$ is calculated as;

$$
L \quad=\quad L_{0}+\left(C_{p_{\nu}}-C_{v w}\right)\left(T-T_{0}\right)
$$

and the two parameters $\mathrm{H}_{1}$ and $\mathrm{H}_{2}$ are defined as:

$$
\begin{aligned}
& H_{1}=\phi(1-S)\left[L_{0}+C_{P_{v}}\left(T-T_{0}\right)\right] \\
& H_{2}=\left(C_{v w} \rho_{w}-C_{P_{v}} \rho_{v}\right)\left(T-T_{0}\right)-\rho_{v} L_{0}
\end{aligned}
$$

\subsubsection{Momentum conservation and mechanics}

The momentum conservation equation is:

$$
\frac{\partial}{\partial x_{j}}\left[C_{i j k l} e_{k l}-\delta_{i j} \beta\left(T-T_{0}\right)-\delta_{i j} \zeta\left(S-S_{0}\right)-\delta_{i j} \alpha S \bar{P}\right]+\bar{\rho}_{s} f=0
$$

The expression for the total stress (tension positive) lies within the square bracket:

$$
\tau_{i j}=C_{i j k l} e_{k l}-\delta_{i j} \beta\left(T-T_{0}\right)-\delta_{i j} \zeta\left(S-S_{0}\right)-\delta_{i j} \alpha S \bar{P}
$$

The second term on the right hand side of Equation $3 b$ is the effective stress from skeletal deformation of the rock, under influence of temperature (second term), moisture swelling (third term), and fluid pressure (fourth term). In this equation, $\beta$ and $\zeta$ are defined as:

$$
\begin{aligned}
& \beta=(2 \mu+3 \lambda) \cdot \Gamma \\
& \zeta=(2 \mu+3 \lambda) \cdot \xi
\end{aligned}
$$


where $\Gamma$ is the linear thermal solid expansion coefficient and $\xi$ is a coefficient of swelling.

Sound representation of rock mechanical behavior at different scales is accommodated in ROCMAS through the stress-deformation matrix $C_{i j k l}$. For discrete fractures, $C_{i j k l}$ is derived from rock mechanical constitutive relations of normal and shear deformation in rock fractures. Fracture normal closure deformation is based on Bandis' or Goodman's joint models (Ohnishi et al., 1996), which implies that the normal deformation, mechanical, and hydraulic aperture is a nonlinear function of the current local normal stress across the fracture. Shear is accommodated by a dilating, strain-softening, elastoplastic model where shear failure is triggered by Mohr-Columb criteria (Ohnishi et al., 1996).

Ubiquitously fractured media through an anisotropic $C_{i j k l}$ can represent the mechanical behavior of large-scale rock masses. The underlying assumption is that the existing ubiquitous fracture sets in geologic material lead to a continuum-type elastoplastic behavior along the prevalent fracture direction. As a result, each well-defined fracture set is represented by a failure surface. Through this approach of oriented plasticity, the development of massive shear band failure in large-scale rock masses can be simulated. The fractures can either be homogeneously distributed with random orientation or oriented in multiple sets of ubiquitous fractures. In addition to these models developed for fractured rock, a cap-plasticity failure model has been implemented into ROCMAS for analysis of clay-type materials.

\subsection{Finite element solution}

Equations (1) to (3), along with the initial and boundary conditions, define a mixed initial boundary value problem for fluid flow and heat transport in deformable, porous, and variable saturated media. It is solved using galerking and variational finite element formulation, finite difference time discretization, incremental formulation, and NewtonRaphson linearization (Noorishad and Tsang, 1996). The result is a three-dimensional version of the ROCMAS code, which is tested and applied within this study.

\subsection{Current capabilities of ROCMAS}

The present capabilities of various versions of ROCMAS are summarized in Table 2.1. Because of the complexity of the THM phenomena, only a limited number of analytical solutions are available for verification purposes. However, by verifying various single phenomena on the one hand, and code to code verification on the other, the soundness and robustness of the ROCMAS code has been verified. In addition to verification, the code has been validated by a number of laboratory tests and large-scale field, tests. Its hydromechanical capability has been validated against field tests of high-pressure injection and hydraulic fracturing stress measurements in fractured crystalline rocks at two field sites, Luleå and Äspö in Sweden (Rutqvist et al., 1992, 1995, 1996, 1998). The code runs on PC, and UNIX platforms and on the CRAY-J90 super-computer cluster at the National Energy Scientific Research Computational Center (NERSC), and is interfaced to a pre- and post-processor for mesh generation and graphical presentation. 
Table 2.1. Present Capabilities of ROCMAS.

\begin{tabular}{|c|c|}
\hline \multirow[t]{3}{*}{ General } & 3D-Finite element model \\
\hline & Discrete fractures embedded in continua \\
\hline & Coupled temperature, fluid flow and mechanical deformations \\
\hline \multirow[t]{12}{*}{ Continua } & Linear elastic solid \\
\hline & Associated and non-associated strain softening elastoplasic \\
\hline & Sandler/Demagio cap plasticity \\
\hline & Oriented plasticity in ubiquitously fractured medium \\
\hline & Shear banding failure \\
\hline & No tension continuum \\
\hline & $\begin{array}{l}\text { Darcy fluid flow and anisotropic permeability in ubiquitously fractured } \\
\text { medium }\end{array}$ \\
\hline & Variable saturation \\
\hline & Water vapor flow through molecular diffusion \\
\hline & Heat conduction and convection \\
\hline & Thermal expansion \\
\hline & Moisture swelling \\
\hline \multirow[t]{4}{*}{ Fractures } & Non-linear aperture-normal stress relation \\
\hline & Elasto-plastic dilating strain softening shear \\
\hline & Parallel plate fluid flow \\
\hline & Heat convection \\
\hline
\end{tabular}




\section{Coupled modeling of laboratory experiments on bentonite}

In this section, material parameters of bentonite are evaluated for use in the ROCMAS code for modeling of the large scale heater test described in Section 8 of this report. JNC has performed a number of experiments to determine thermo-hydro-mechanical properties of the bentonite, and the results are presented in Fujita el al. (1997b). Some of the material parameters cannot be determined directly from the experiments due to lack of analytical solutions for the complex processes involved, and are therefore backcalculated by a model calibration. Figure 3.1 presents an overview of the calibrations performed on four laboratory experiments, and each experiment is individually described in the following sections.

\subsection{Water retention curve}

When a clay sample is dried, a very high negative (suction) pressure develops. This suction pressure is a major force for water flow and mechanical deformation of the bentonite clay under partially saturated conditions. The relation between the suction pressure and the water content, called the water retention curve, was determined on a 13 $\times 9-\mathrm{mm}$ sample by wetting and oven drying. The water potential (and water pressure) was determined from the relative humidity; the water content was determined by the weigh loss during a subsequent oven drying. The results of the experiments are presented in Figure 3.2 in terms of suction versus liquid saturation, where the liquid saturation $S$ is related to the water content $\omega$ as:

$$
S=\frac{\omega}{\phi} \frac{\rho_{d}}{\rho_{w}}
$$

where $\phi$ is the porosity, $\rho_{d}$ the dry density of the bentonite, and $\rho_{w}$ is the density of water. In this case, the porosity is 0.39 and the dry density is $1,6 \mathrm{~kg} / \mathrm{m}^{3}$.

\begin{tabular}{|c|c|c|}
\hline$\underline{\text { Laboratory experiment }}$ & & Determined parameters \\
\hline 1) Suction test & Haxp & $\begin{array}{l}\text { Water retention curve: } \\
\text { Pressure vs Saturation } \\
\Longrightarrow \mathrm{dS} / \mathrm{dP} \Rightarrow \mathrm{C}_{\mathrm{s}}=\text { moisture capacity }\end{array}$ \\
\hline 2) Infiltration test & $\Rightarrow$ & $\begin{array}{l}\text { Relative permeability, } \mathrm{kr} \\
\text { Isothermal vapor diffusivity, } D_{p v}\end{array}$ \\
\hline $\begin{array}{l}\text { 3) Thermal gradient test } \\
\text { (KID-BEN) }\end{array}$ & $\Rightarrow$ & $\begin{array}{l}\text { Thermal vapor diffusivity, } D_{T_{v}} \text { or } \\
\text { Thermal diffusion enhancement factor, } f_{T_{v}}\end{array}$ \\
\hline 4) Swelling pressure test & $\Rightarrow$ & Swelling pressure vs Saturation \\
\hline
\end{tabular}

Figure 3.1. An overview of calibration of bentonite properties by modeling of four laboratory tests. 

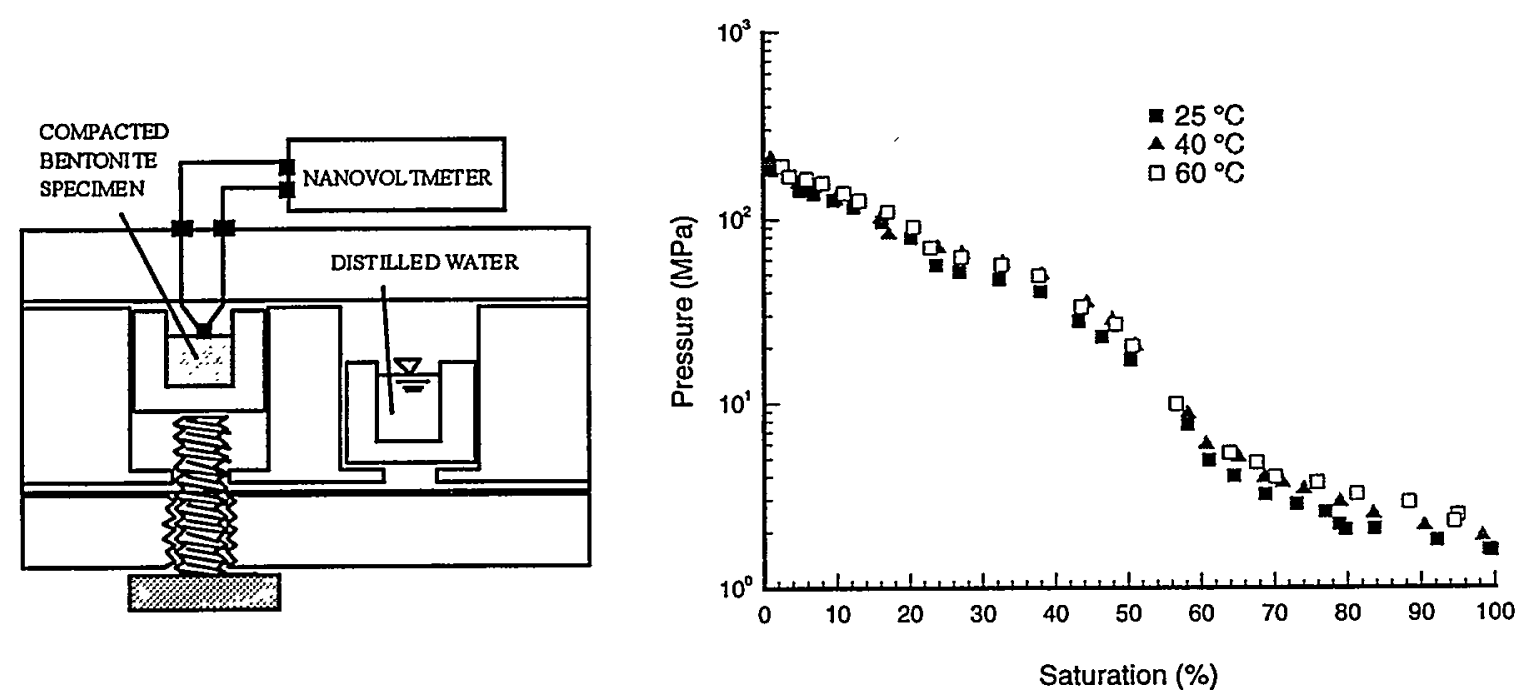

Figure 3.2. Measurments of water retention curve by JNC: (a) Equipment and (b) Results (Fujita et al., 1997b).

The results in Figure 3.2 show that the water retention is essentially independent of the temperature and has a kink at about 50 to $60 \%$ saturation. The shape of the curve, including the kink, cannot be captured by any of the known standard functions for water retention. Consequently, in this modeling, the exact experimental curve in Figure 3.2 for $40^{\circ} \mathrm{C}$ is tabulated into the ROCMAS code, except at full saturation where the suction pressure is set to zero.

\subsection{Infiltration test under isothermal conditions}

The isothermal infiltration experiment was carried out in order to understand the behavior of water movement in unsaturated bentonite. It is used for determination of two material parameters of the bentonite: the relative permeability and the isothermal vapor diffusivity. The experiments were conducted on compacted bentonite specimens of $20 \times$ 20-mm set in stainless steel cells (Figure 3.3a). Water for infiltration was supplied to the specimens through a metal filter at the bottom. After various infiltration periods, the specimen was sliced into $2-\mathrm{mm}$ sections for measurements of the water content. Figure $3.3 \mathrm{~b}$ presents the results of the infiltration test at $25^{\circ} \mathrm{C}$. From the results of these experiments, JNC evaluated the total water diffusivity, $D_{\theta}$ (including both liquid and vapor flow), using an analytical solution, where the water flux $Q$ is given by:

$$
Q=-K_{w} \frac{\partial \varphi}{\partial \theta} \frac{\partial \theta}{\partial z}=-D_{\theta} \frac{\partial \theta}{\partial z}
$$

where $K_{w}$ is the hydraulic conductivity, $\theta$ is the volumetric water content, and $\varphi$ is the

- water potential. The results are presented in Figure $3.3 \mathrm{c}$ as water diffusivity versus saturation. 


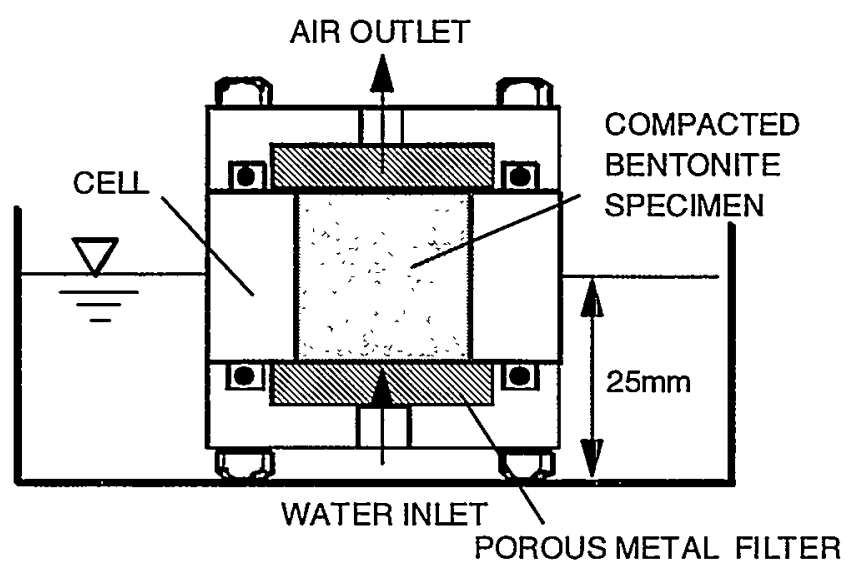

Test 1: $\mathrm{T}=25^{\circ} \mathrm{C}$ Test 2: $\mathrm{T}=40^{\circ} \mathrm{C}$ Test 3: $\mathrm{T}=60^{\circ} \mathrm{C}$

(a)

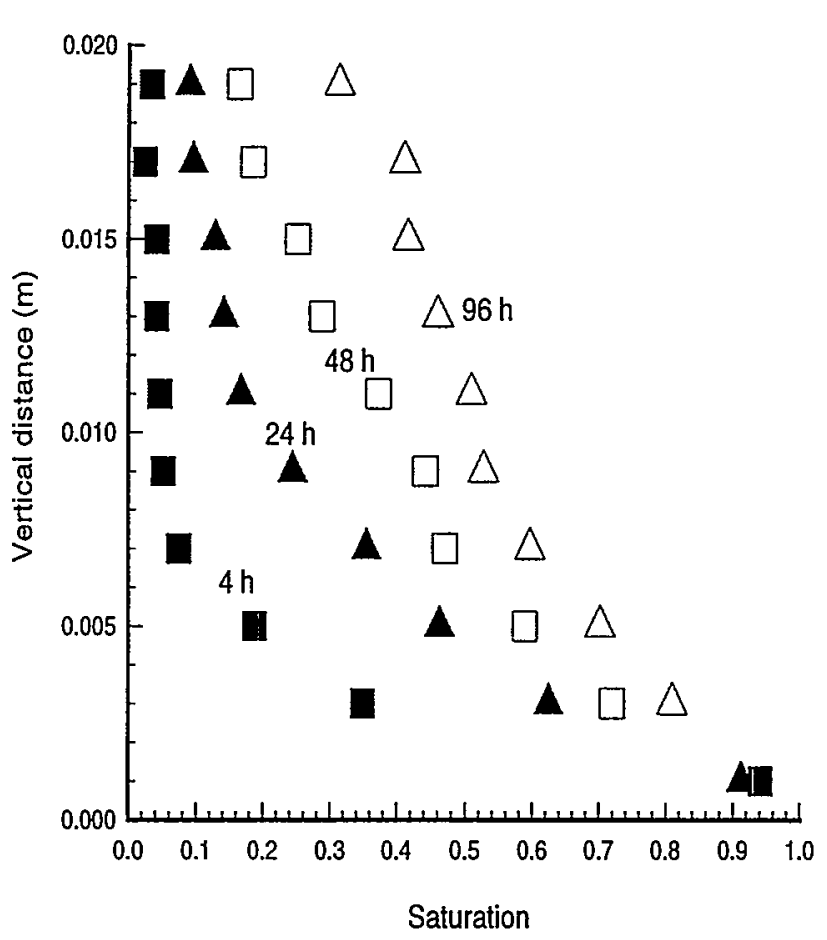

(b)

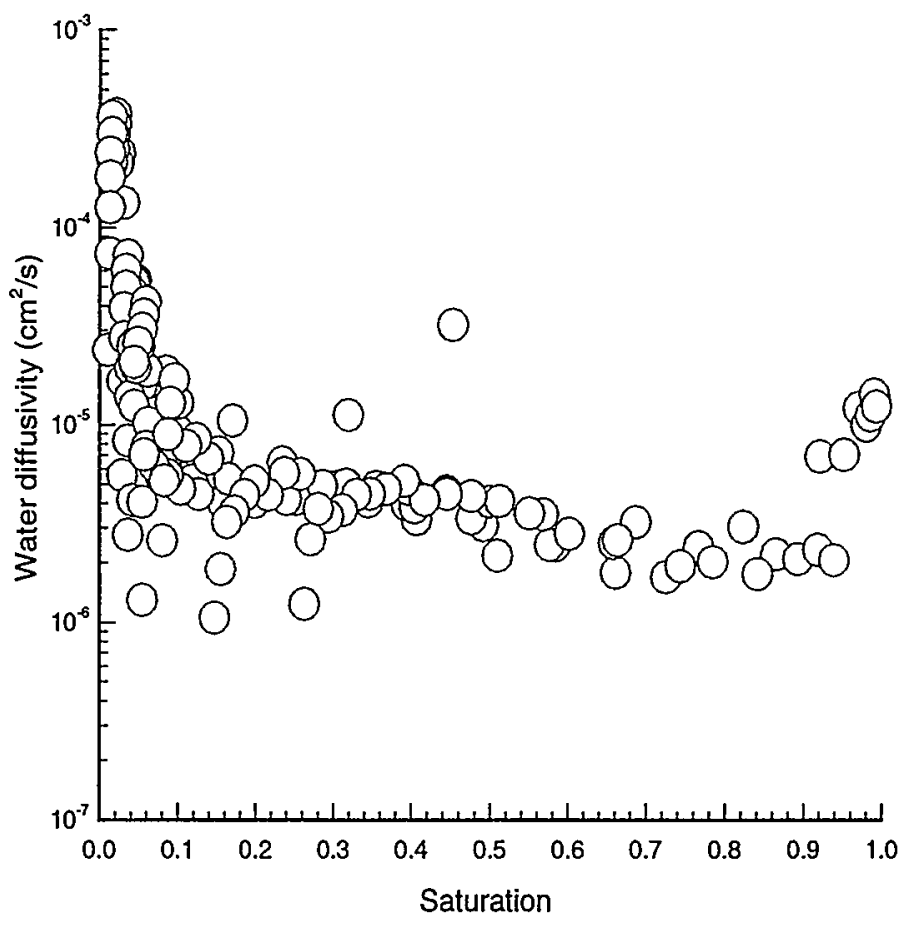

(c)

Figure 3.3. Infiltration test: (a) Principal of the test setup; (b) Results of saturation versus vertical distance from the bottom of the sample at an ambient temperature of $25^{\circ} \mathrm{C}$; (c) Results of the same experiment presented as water diffusivity versus saturation. 
The flux $Q$, and therefore also $D_{\theta}$, includes diffusion of water in liquid form as well as vapor diffusion in air-filled pores. The rate of liquid flow depends on the hydraulic permeability and relative permeability of the soil; the vapor flow depends on an effective molecular diffusion for vapor in the air-filled pores. In general, for this type of material, the liquid flow should be dominating at high degree of saturation, with the vapor diffusion perhaps becoming important at dryer conditions.

From the experimental results, properties for isothermal water flow are estimated and back-calculated by modeling the experiment with ROCMAS. The parameters were determined according to the following steps:

1) From the total diffusivity, $D_{\theta}$ in Figure $3.3 \mathrm{c}$, estimate the relative permeability, $k_{r}$ and an effective molecular diffusion coefficient $D_{v}$ in the bentonite;

2) Check and calibrate this estimate by modeling of the actual experiment in Figure 3.3b

At very wet conditions, the isothermal vapor flow may be neglected, and the total water diffusivity can be approximated as:

$D_{\theta}=\frac{K_{w}}{C_{s}} \quad$ (vapor flow neglected)

where $C_{s}$ is the moisture capacity of the soil. In terms of pressure and saturation, the moisture capacity can be calculated as:

$C_{s}=\frac{\partial \theta}{\partial \varphi}=\frac{\partial S}{\partial P} \rho_{w} g \phi$

where $\partial S / \partial P$ is obtained by taking the derivative of the water retention curve. Figure 3.4 presents the moisture capacity as a function of saturation obtained from the water retention curve in Figure 3.2. The hydraulic conductivity, $K_{w}$ is given by:

$K_{w}=k_{r}(S) \cdot K_{w S}(T)$

where $k_{r}$ is the relative permeability and $K_{w S}$ is the hydraulic conductivity at full saturation. The saturated hydraulic conductivity is a function of temperature and is defined as:

$K_{w S}=\frac{k_{w S} \rho_{w}(T) g}{\eta_{w}(T)}$

where $k_{w S}$ is saturated permeability and $\eta_{w}$ is the dynamic viscosity. The saturated permeability has been determined by PNC to be independent of temperature and equal to $1.6 \cdot 10^{-20} \mathrm{~m}^{2}$ (Fujita el al., 1997b). In the ROCMAS code, the fluid density, $\rho_{w}$, and 
viscosity, $\eta_{w}$, is made a function of temperature according to well-established thermophysical formulas. The resulting temperature dependent saturated hydraulic conductivity is compared to the measured in Figure 3.5.

From Equation (6) and (8), the relative permeability function can be calulcated according to:

$k_{r}(S)=\frac{D_{\theta}(S)}{K_{w S} C_{s}(S)} \quad$ (vapor flow neglected)

All the parameters of the right hand side of Equation (10) are known because $D_{\theta}$ is given from the experimental values in Figure 3.3c, $C_{s}$ from Figure 3.4, and $K_{w s}$ from Figure 3.5. Figure 3.6 (dashed line) presents the relative permeability function calculated with Equation (10) for the entire saturation range from wet to dry medium. The relative permeability is equal to 1.0 for saturation down to $85 \%$, but decreases dramatically for saturation values from $85 \%$ down to $60 \%$. Below $60 \%$, the relative permeability appears to be approximately constant, and at zero saturation it increases to 1.0 again (Figure 3.6, dashed line). The apparent increase in relative permeability at low saturation is not realistic, resulting from the neglect of vapor flow in Equations (10).

The isothermal water diffusivity, $D_{p v}$, can be calculated from Equation (1f) with a standard thermo-physical function of vapor density $\rho_{v}$, and with the effective molecular diffusion coefficient $D_{v}$, estimated according to (Phillips and de Vries, 1957):

$D_{v}=v_{v} \tau_{v} \phi(1-S) D_{a t m}$

where $D_{a t m}$ is the molecular diffusion coefficient for vapor flow in air, $v_{v}$ is the mass flow factor, and $\tau_{v}$ is a tortuosity factor. These factors can only be estimated, but shows that $D_{v}$, which reflects the diffusion in a porous media, is considerably smaller than $D_{a t m}$, which represents diffusion in an air-filled medium with porosity one. Experimental results show that $D_{a t m}$ can be evaluated according to Vargaftik (1975) as:

$D_{a t m}=2.16 \cdot 10^{-5}\left(T_{a b s} / 273\right)^{1.8} \quad$ (air pressure $\left.=1 \mathrm{~atm}\right)$

Figure 3.7 (dashed line) presents a matching of the vapor diffusivity $D_{p v}$ to the experimental values (symbols) of the total water diffusivity. $D_{p v}$ is calculated from Equation (1f), where $D_{v}$ is obtained from Equation (11) and $v_{v} \times \tau_{v}$ is assumed to be 0.67 . The good match between the calculated vapor diffusivity and experimental data at the lower saturation range in Figure 3.7 shows that the estimation of the mass flow factor (about 1) and the tortuosity factor (about 2/3) by Phillip and de Vries (1957) is appropriate for this clay material. Figure 3.7, also presents the water diffusivity resulting from liquid flow, assuming the relative permeability function depicted in Figure 3.6. The results show that the water flow in liquid form dominates in wet conditions, but as the saturation decreases below $30 \%$, the vapor flow by molecular diffusion is dominating. 


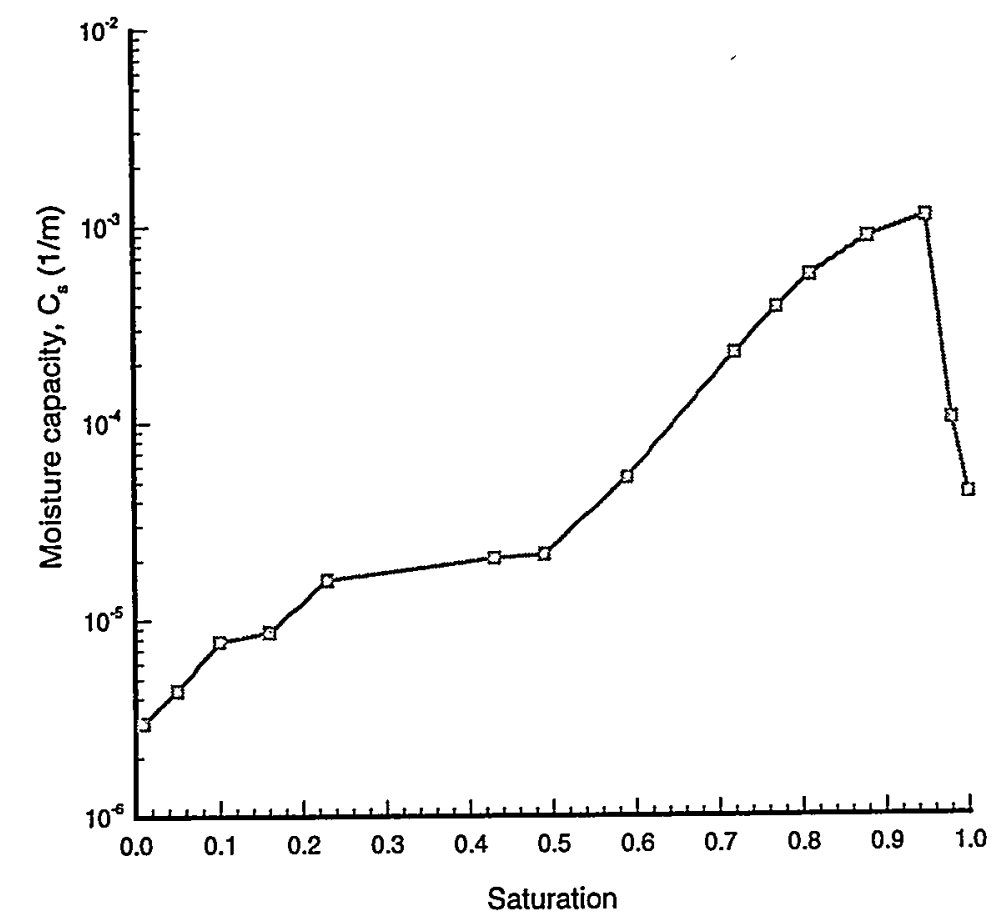

Figure 3.4. Moisture capacity calculated from the water retention curve in Figure $3.2 \mathrm{~b}$ using Equation (7).

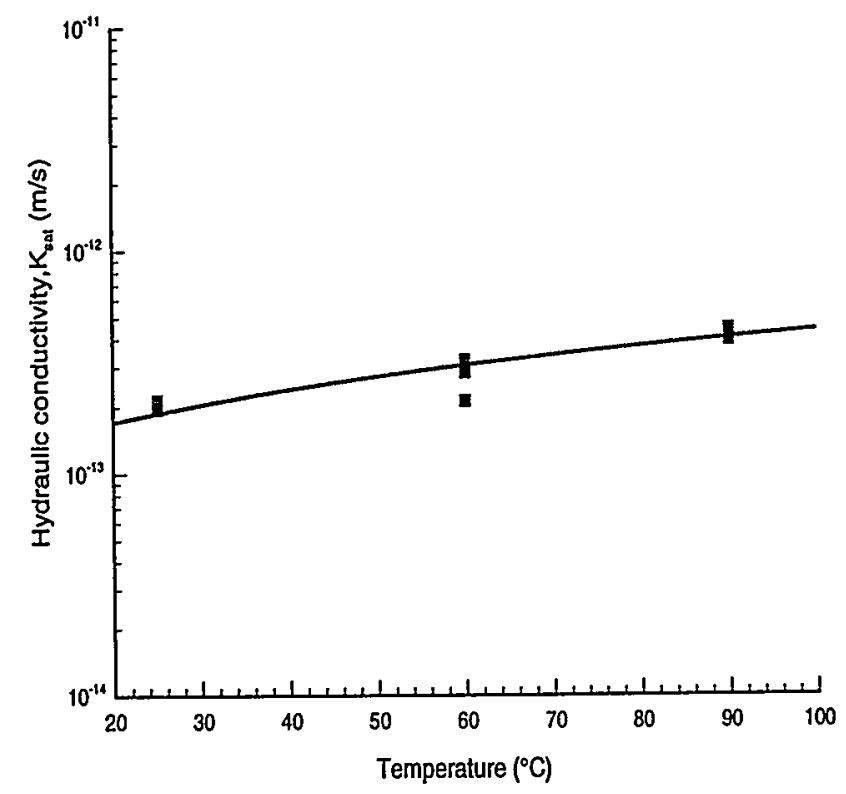

Figure 3.5. Saturated hydraulic conductivity measured by PNC (squares) and function used in ROCMAS (line). 


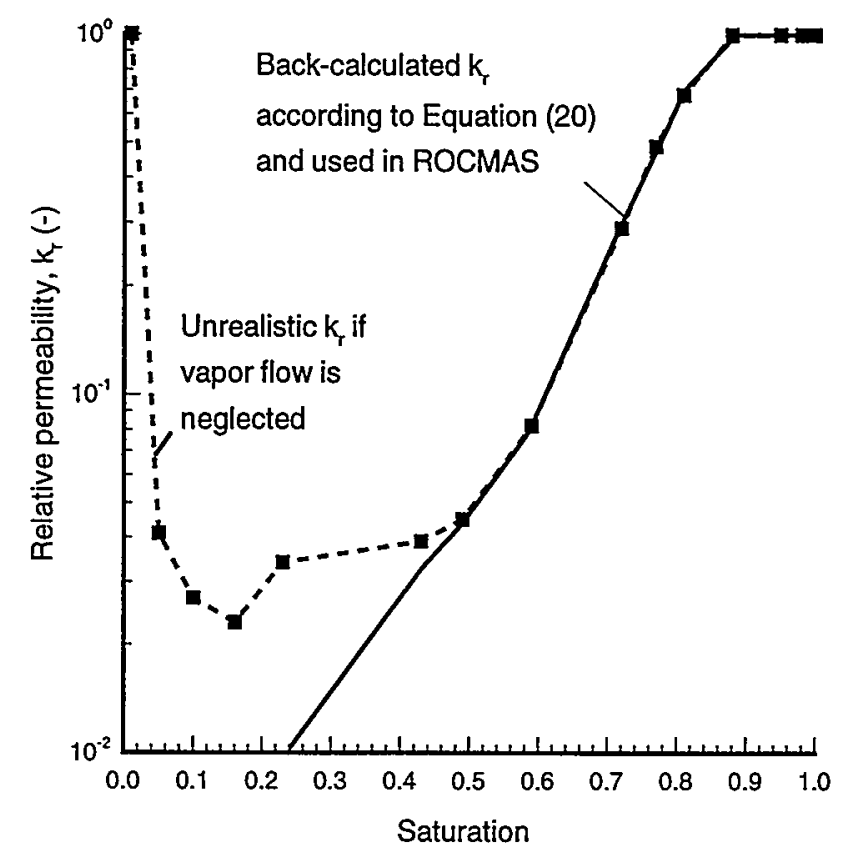

Figure 3.6. Relative permeability back-calculated with Equation (10) to match the experimental diffusivity in Figure 3.3c. Dashed line shows a relative permeability calculated with the assumption that all water diffusion takes place in liquid form. Solid line is the function that will be used in ROCMAS and considers that part of the total diffusion take place by vapor transport.

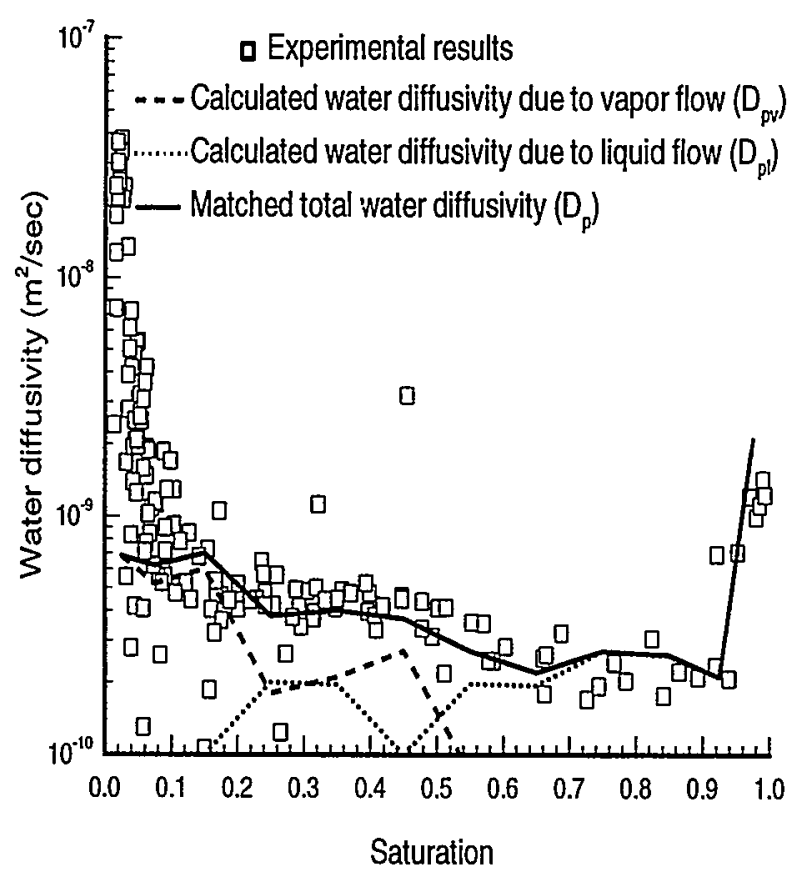

Figure 3.7. Experimental results of water diffusivity at $25^{\circ} \mathrm{C}$ (symbols), matched total water diffusivity (solid line), and diffusivity due to liquid flow (dotted line) and vapor flow in air (dashed line) to be used in ROCMAS. The vapor flow is calculated according to Equation (1f), (10) and (11) with $\nu_{v} \times \tau_{v}=0.67$. 

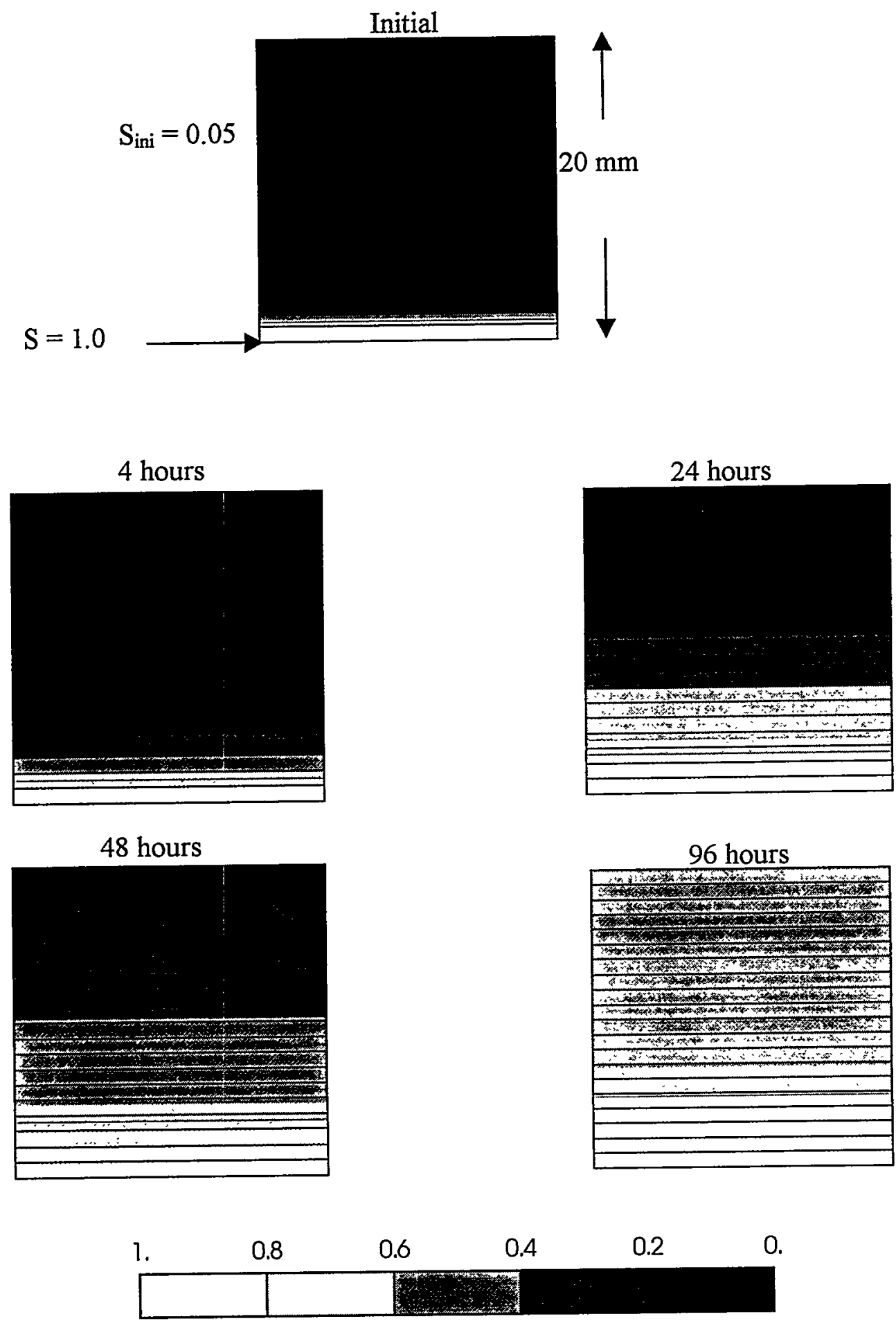

\section{Saturation}

Figure 3.8. Modeling of infiltration test: Model setup and results of Test 1 with contours of saturation at initial stage and after $4,24,48$ and 96 hours of infiltration. 
Two parameters, the relative permeability and the effective molecular diffusion, have been estimated. The actual infiltration tests leading to those estimates are then simulated using ROCMAS to check the estimates and validate the performance of the code. The three infiltration tests are simulated using a model of 20 elements, with element thickness of $1 \mathrm{~mm}$ (Figure 3.8). The modeling results in Figure 3.8 show that the water is slowly sucked upwards into the bentonite from the lower fully saturated boundary, and at 96 hours, the saturation increases to about 30 to $40 \%$ at the upper boundary. Figure 3.9 to 3.11 presents a detailed comparison of the modeling and experiments conducted at ambient temperatures of $25^{\circ}, 40^{\circ}$, and $60^{\circ} \mathrm{C}$, respectively. Some discrepancies occur at both the upper and lower boundary of the test sample, which apparently are imperfectly modeled. Away from the boundaries, the match is excellent and even captures kinks of saturation curves, which are results of the kinks that can be seen in the water retention curve in Figure 3.2. The results of the modeling show that the estimated relative permeability function (Figure 3.6) and the estimated $v_{v} \times \tau_{v}=0.67$ are accurate.

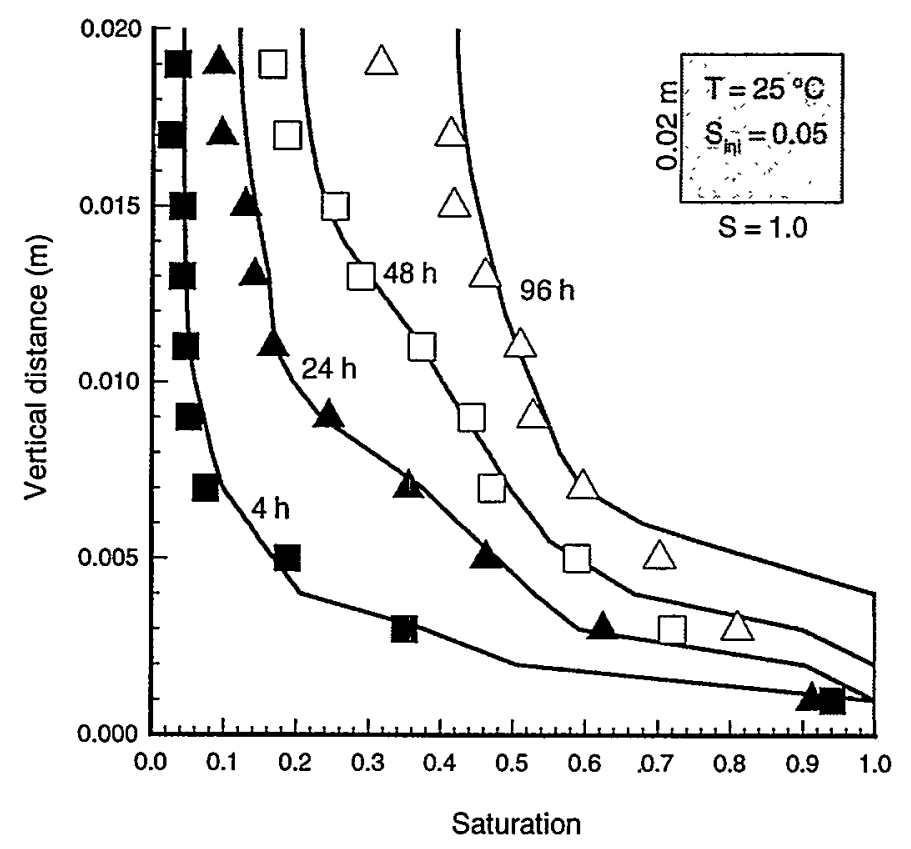

Figure 3.9. Comparison of modeling (lines) and experimental results (symbols) of infiltration Test 1 conducted at an ambient temperature of $25^{\circ} \mathrm{C}$. 


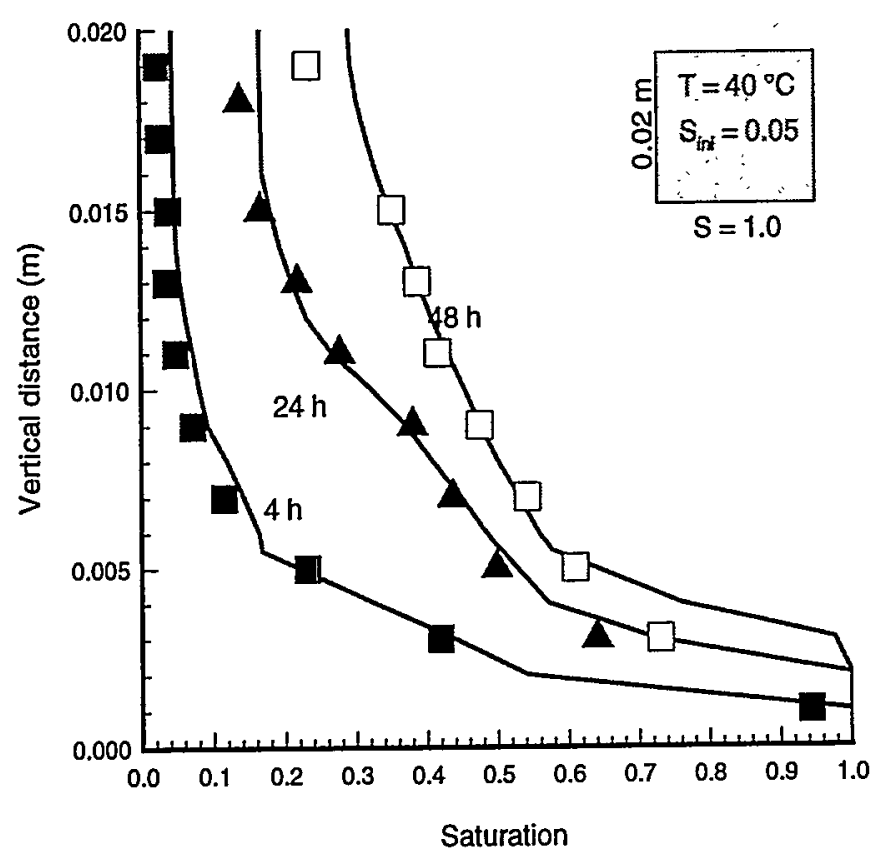

Figure 3.10. Comparison of modeling (lines) and experimental results (symbols) of Infiltration Test 2 conducted at an ambient temperature of $40^{\circ} \mathrm{C}$.

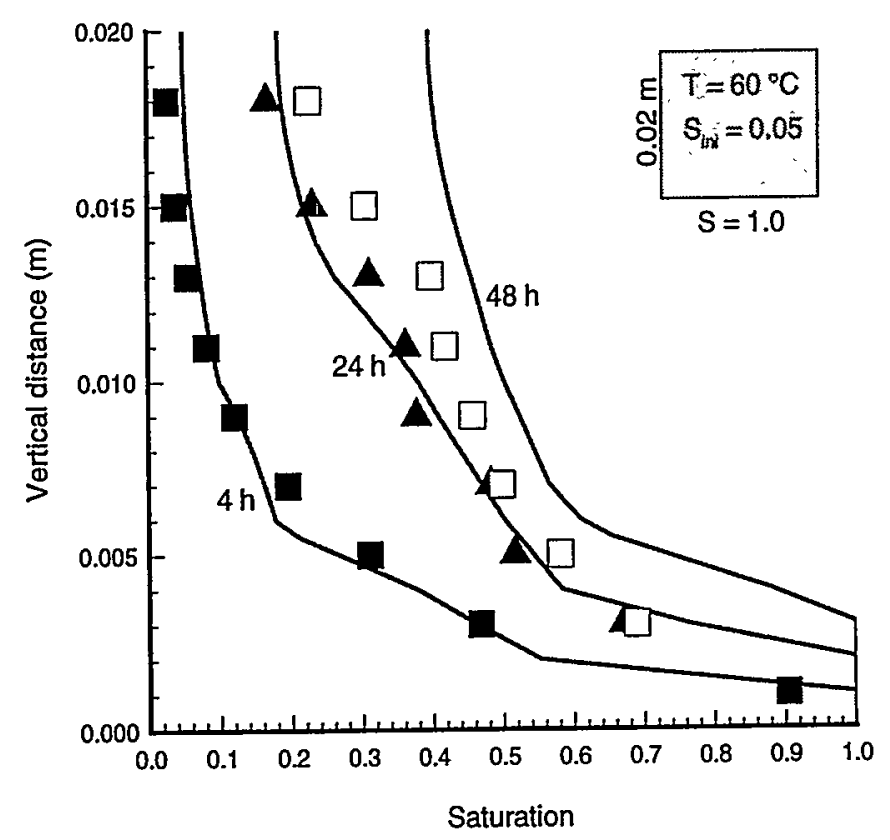

Figure 3.11. Comparison of modeling (lines) and experimental results (symbols) for Infiltration Test 3 conducted at an ambient temperature of $60^{\circ} \mathrm{C}$. 


\subsection{Properties for water flow under thermal gradient}

A number of tests to understand water movement under thermal gradient, were conducted on compacted bentonite samples of $50 \mathrm{~mm}$ diameter and $100 \mathrm{~mm}$ height, which were placed in an apparatus named KID-BEN. Applying an elevated constant temperature on the lower boundary of the specimen (Figure 3.12a) creates a thermal gradient, resulting in an upward water movement along the gradient. The temperature was monitored at various distances along the sample, and the water content was measured from the weigh loss during subsequent oven drying. Three original tests with 96 hours of heating presented in Fujita et al. (1997), was thereafter complemented by a fourth test with 400 hours of heating (Figure 3.12a). The experimental results after 400 hours of Test 4 is presented in Figure 3.12b and c.

The dominating water transport mechanics under thermal gradient is the vapor flow as a result of molecular diffusion of vapor in air caused by an increased vapor density at the hot end. The vapor is transported towards the cooler regions where the vapor density is lower. In ROCMAS, the vapor mass flow, $q_{v}$, along the vapor density gradient, is spit into two terms; one driven by the pressure gradient and one by the thermal gradient, respectively (Phillip and de Vries, 1957):

$$
q_{v}=-D_{p v} \nabla P-f_{T v} D_{T \nu} \nabla T
$$

where $D_{p v}$ is the isothermal vapor diffusivity, $D_{T v}$ is thermal vapor diffusivity, and $f_{T v}$ is a thermal diffusion enhancement factor. Both $D_{p v}$ and $D_{T v}$ are calculated internally in ROCMAS according to Equation (1f) and (1g), respectively, and are dependent on the effective molecular diffusion coefficient $D_{v}$. Because $D_{v}$, has been determined in the infiltration test, $D_{T v}$ is already fully defined through Equation $(1 \mathrm{~g})$. Therefore, the KIDBEN experiment is used to determine the only remaining unknown, which is $f_{T v}$. This factor was included to the equations by Phillip and de Vries (1957) because experiments have frequently shown that the vapor flow under thermal gradient can be considerably larger then what can be explained by "simple" diffusion theory.

Figure 3.13 presents the modeling of the KID-BEN Test 3 at the initial stage and after 96 hours of heating. The model consists of 20 elements, which are $5 \mathrm{~mm}$ thick along the flow direction. The matching of the modeling results are presented in Figures 3.14 to 3.17 for the final stage at 96 hours for Test 1 to 3 , and at 400 hours for Test 4 . The strongly nonlinear temperature profile in the experiments can only be matched by assuming that heat-loss occurred though the wall of the test container. The temperature profiles where matched by applying a heat transfer coefficient of $3.0 \mathrm{~W} / \mathrm{m}^{2}{ }^{\circ} \mathrm{C}$ across the boundary and assuming an environment temperature of $25^{\circ} \mathrm{C}$. The result in Figure 3.14 to 3.17 is obtained by calibrating the thermal diffusion enhancement factor, $f_{T v}$, and assuming all other parameters to be the same as in the infiltration test. The factor $f_{t v}$ is calibrated to 1.0 in Test 1 to 3 and 1.7 in Test 4 . The saturation can be matched at the two boundaries of the 


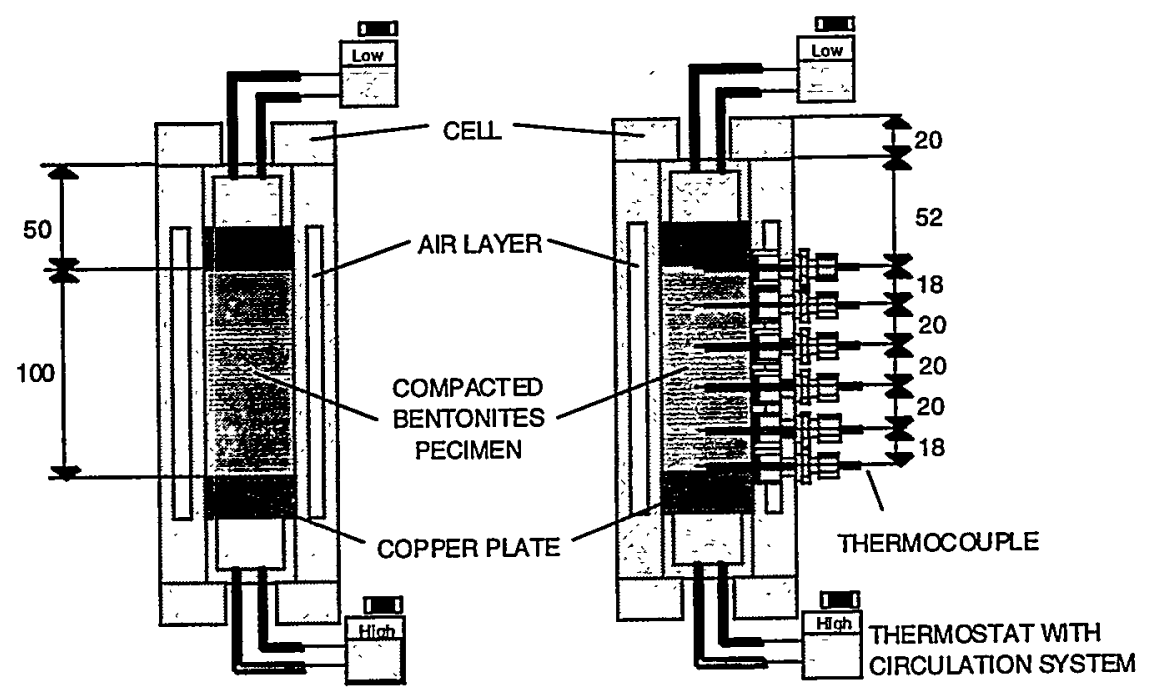

Test 1: $\mathrm{T}_{1}=35^{\circ} \mathrm{C}, \mathrm{T}_{2}=25^{\circ} \mathrm{C}, 96$ hours of heating Test 2: $\mathrm{T}_{1}=55^{\circ} \mathrm{C}, \mathrm{T}_{2}=25^{\circ} \mathrm{C}, 96$ hours of heating Test 3: $\mathrm{T}_{1}=75^{\circ} \mathrm{C}, \mathrm{T}_{2}=25^{\circ} \mathrm{C}, 96$ hours of heating Test 4: $\mathrm{T}_{1}=60^{\circ} \mathrm{C}, \mathrm{T}_{2}=40^{\circ} \mathrm{C}, 400$ hours of heating

(a)

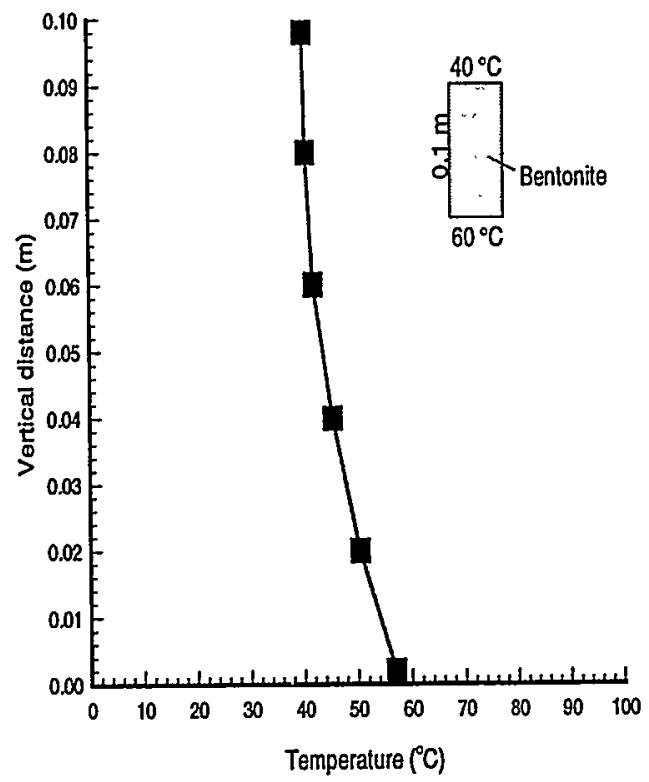

(b)

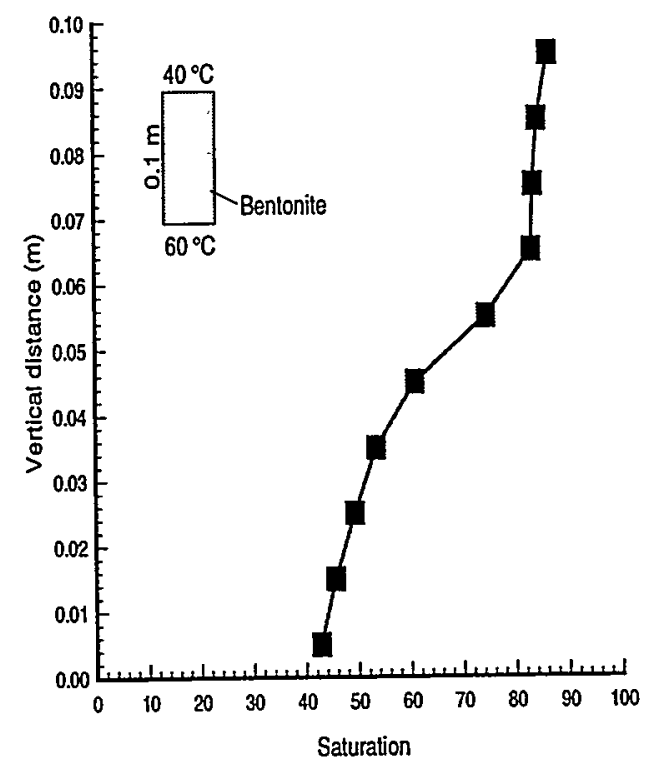

(c)

Figure 3.12. Thermal gradient test (KD-BEN): a) Test equipment and setup; (b) Temperature versus vertical distance for Test 4 after 400 hours of heating; (c) Saturation versus vertical distance after 400 hours of heating. 

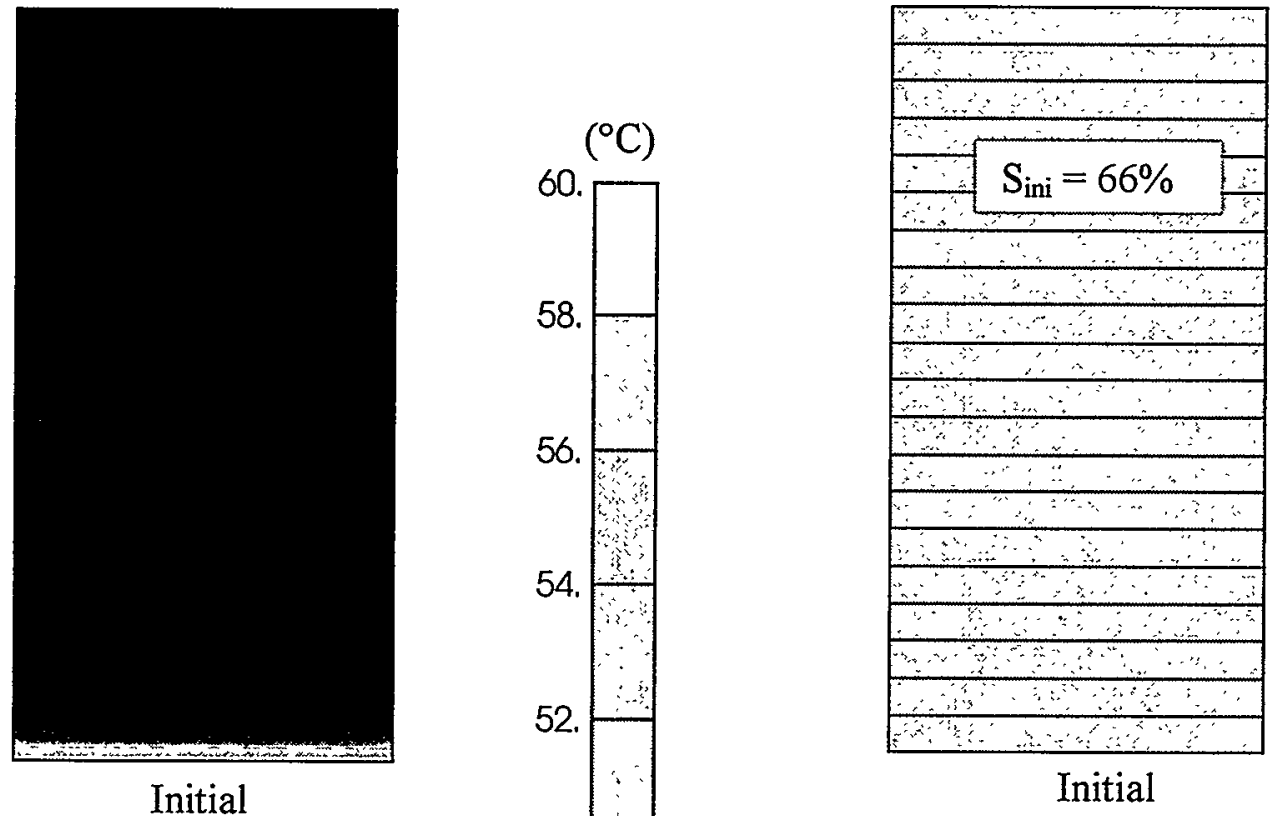

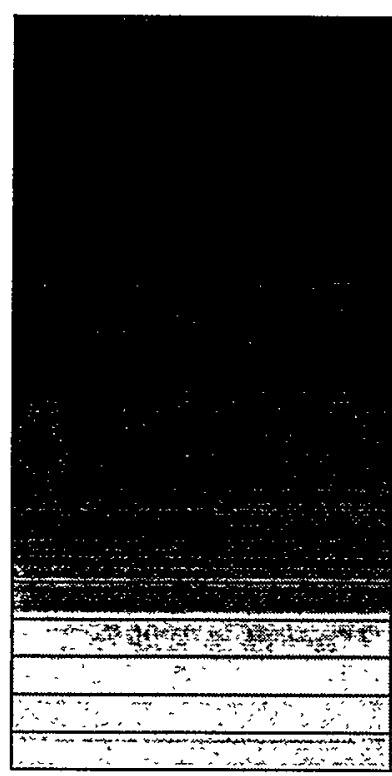

400 hours
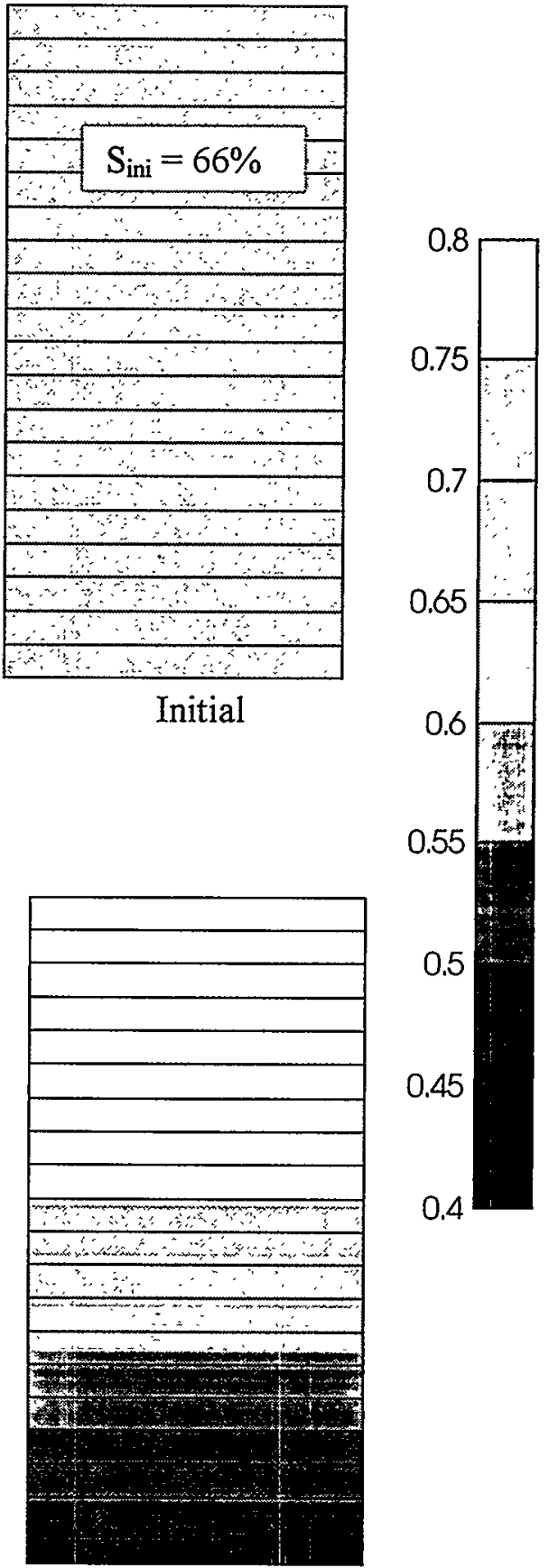

400 hours

Figure 3.13. Modeling of thermal gradient test: Model setup and results of Test 4 with contours of temperature and saturation at initial stage and after 400 hours of heating. 

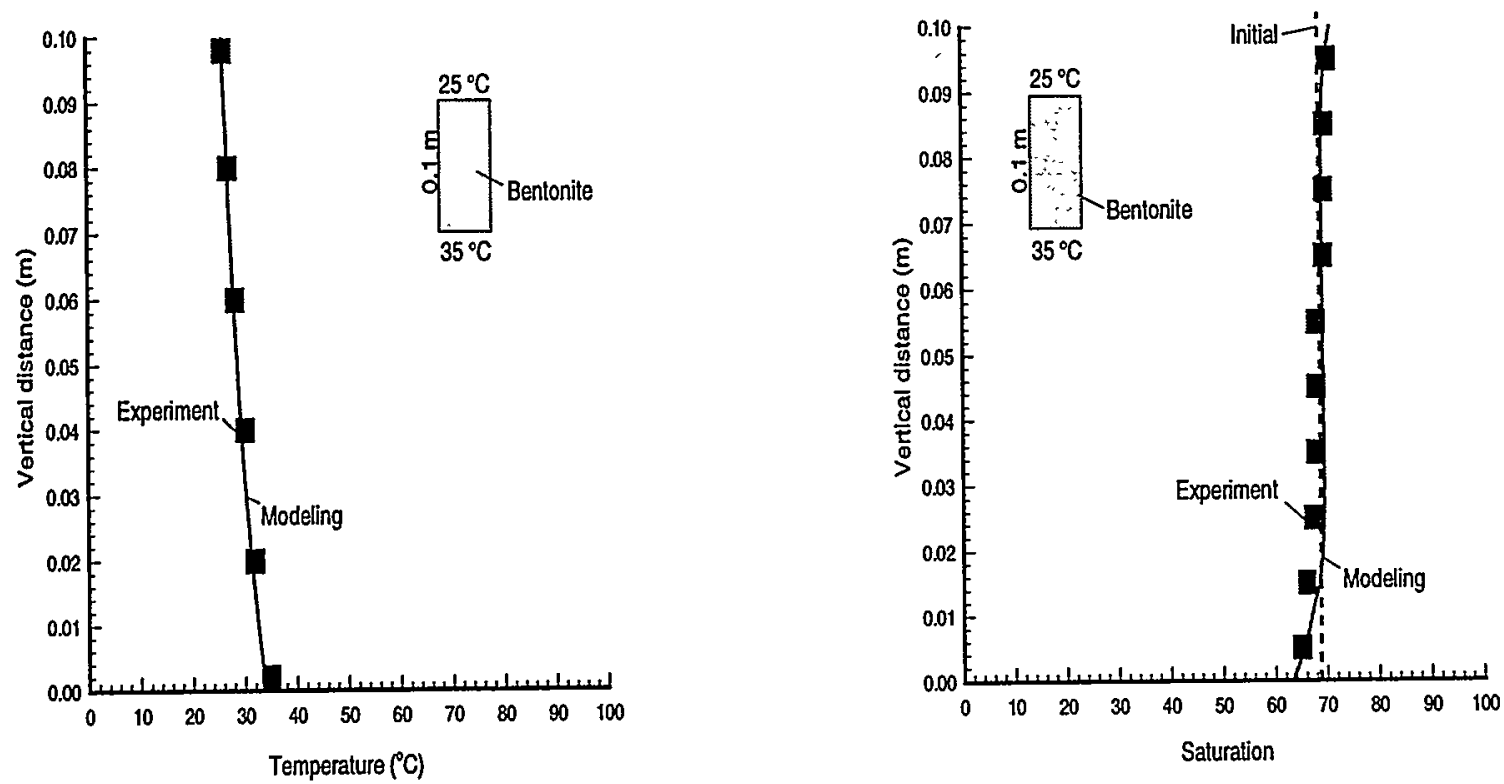

Figure 3.14. Comparison of modeling and experimental results for the Thermal Gradient Test 1 after 96 hours of heating, assuming the same material properties as in the infiltration test. (a) Temperature and (b) Saturation versus vertical distance from the bottom of the sample.
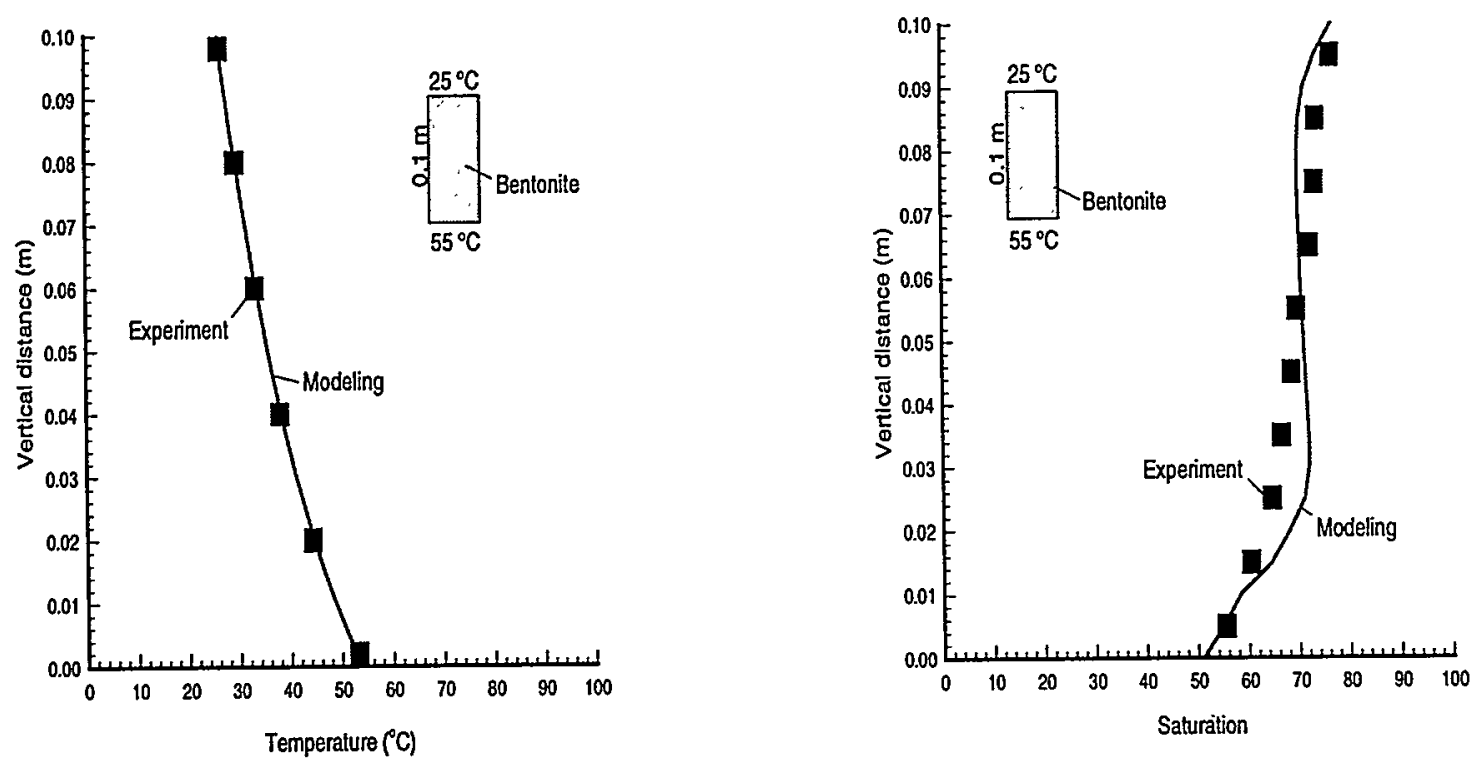

Figure 3.15. Comparison of modeling and experimental results for the Thermal Gradient Tèst 2 after 96 hours of heating, assuming the same material properties as in the infiltration test. (a) Temperature and (b) Saturation versus vertical distance from the bottom of the sample. 

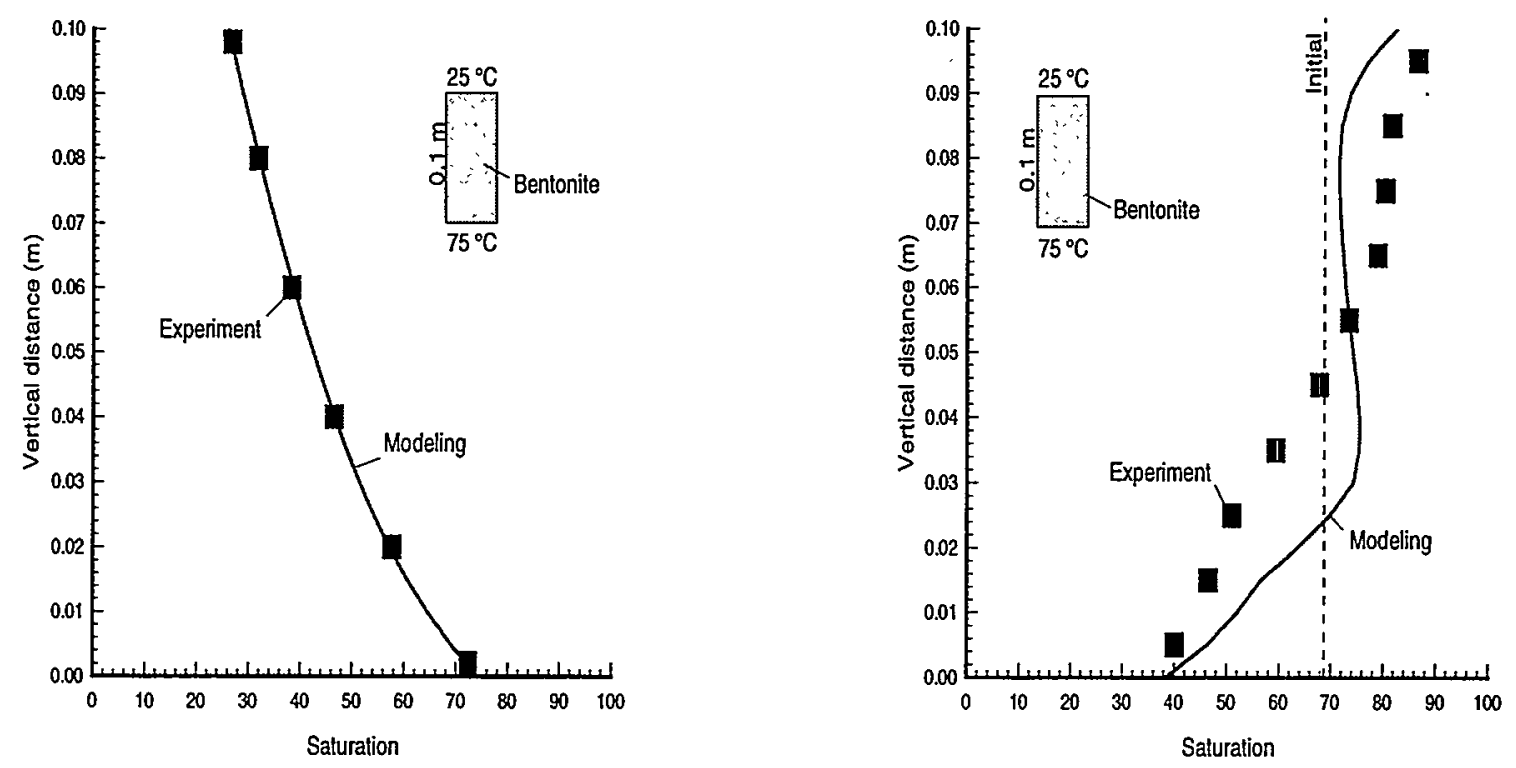

Figure 3.16. Comparison of modeling and experimental results for the Thermal Gradient Test 3 after 96 hours of heating, assuming the same material properties as in the infiltration test. (a) Temperature and (b) Saturation versus vertical distance from the bottom of the sample.
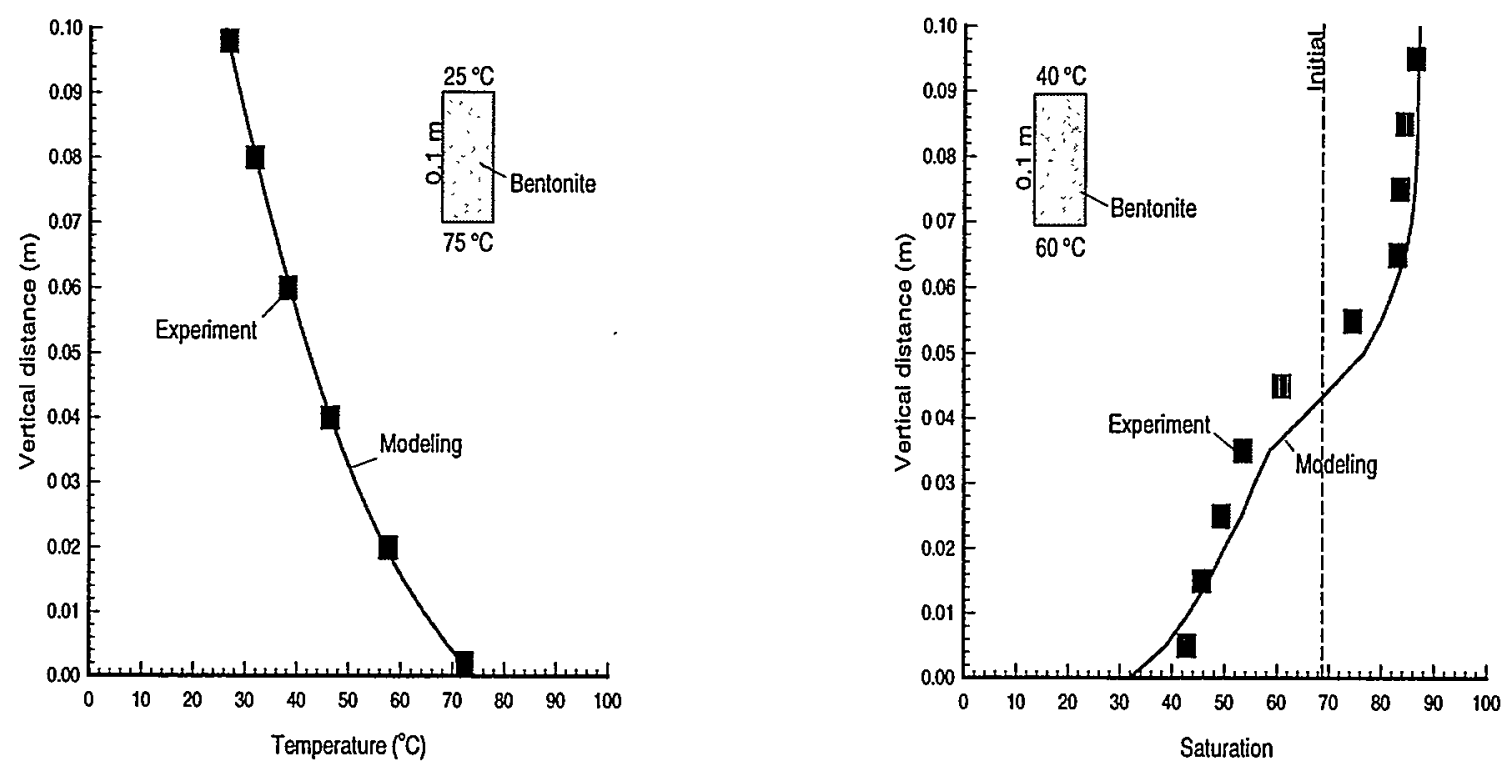

Figure 3.17. Comparison of modeling and experimental results for the Thermal Gradient Test 4 after 400 hours of heating, assuming the same material properties as in the infiltration test. (a) Temperature and (b) Saturation versus vertical distance from the bottom of the sample. 
test sample, but the saturation profile over the sample tends to be sharper in the modeling compared to the experiments, which have a more flattened profile. The match of the results of Test 4 (Figure 3.17) is, however, satisfactory. This test runs for about 400 hours, four times longer than in Test 1 to 3 . At 400 hours, the saturation profile has reached closer to a steady condition, and the rate of change is smaller. A better agreement for Test 1 to 3 could possible be obtained by a more detailed treatment of the enhancement factor $f_{T v}$ according to Phillip and de Vries (1957), where $f_{T v}$ is a function of saturation and a critical saturation, when fluid continuity breaks down. However, this was not attempted in this study.

\subsection{Properties for swelling of the bentonite}

A compacted bentonite sample swells with water uptake. If the sample is restrained from expanding, a swelling pressure will build up in the same fashion as thermal stress buildup stemming from thermal expansion. The swelling pressure test was conducted on a 20 $\times 20-\mathrm{mm}$ sample placed in a rigid cell of stainless steel (Figure 3.18). The initial saturation was about $66 \%$, and water was supplied through a metal filter at the bottom of the sample, like the infiltration test. During the infiltration, the bentonite gradually swells as a function of the increasing saturation, and a swelling pressure develops. The swelling pressure reaches a maximum value of about $1 \mathrm{MPa}$ after about 2 days of infiltration, when the sample is fully saturated.

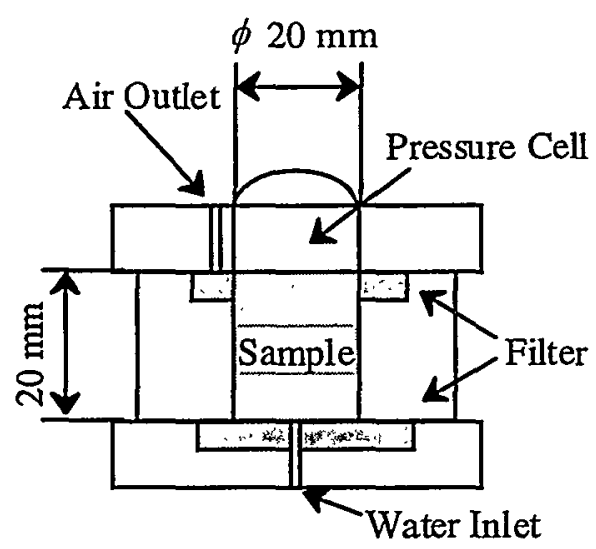

(a)

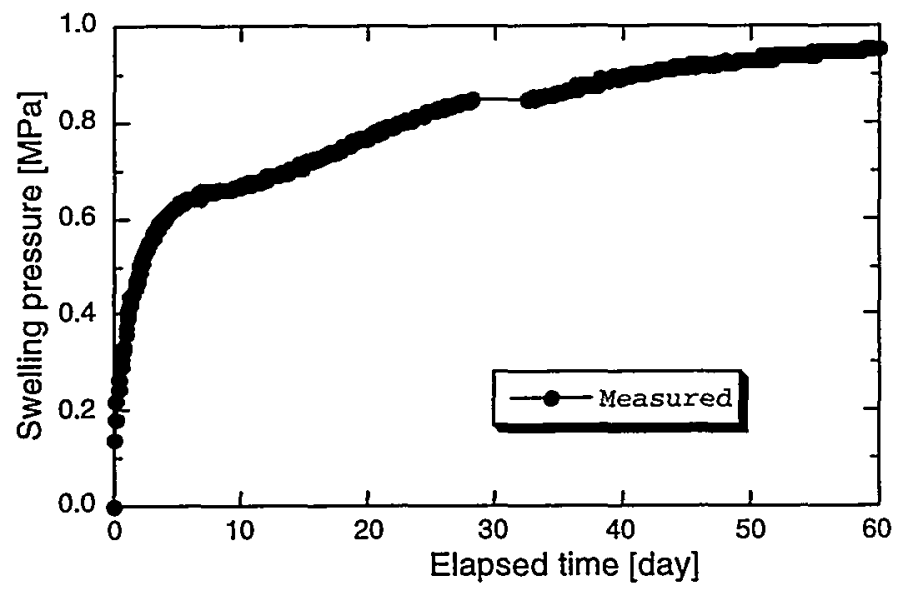

(b)

Figure 3.18. (a) Equipment for swelling pressure measurement and (b) Time history for swelling experiment. 


\section{$\underline{\text { Saturation }}$}
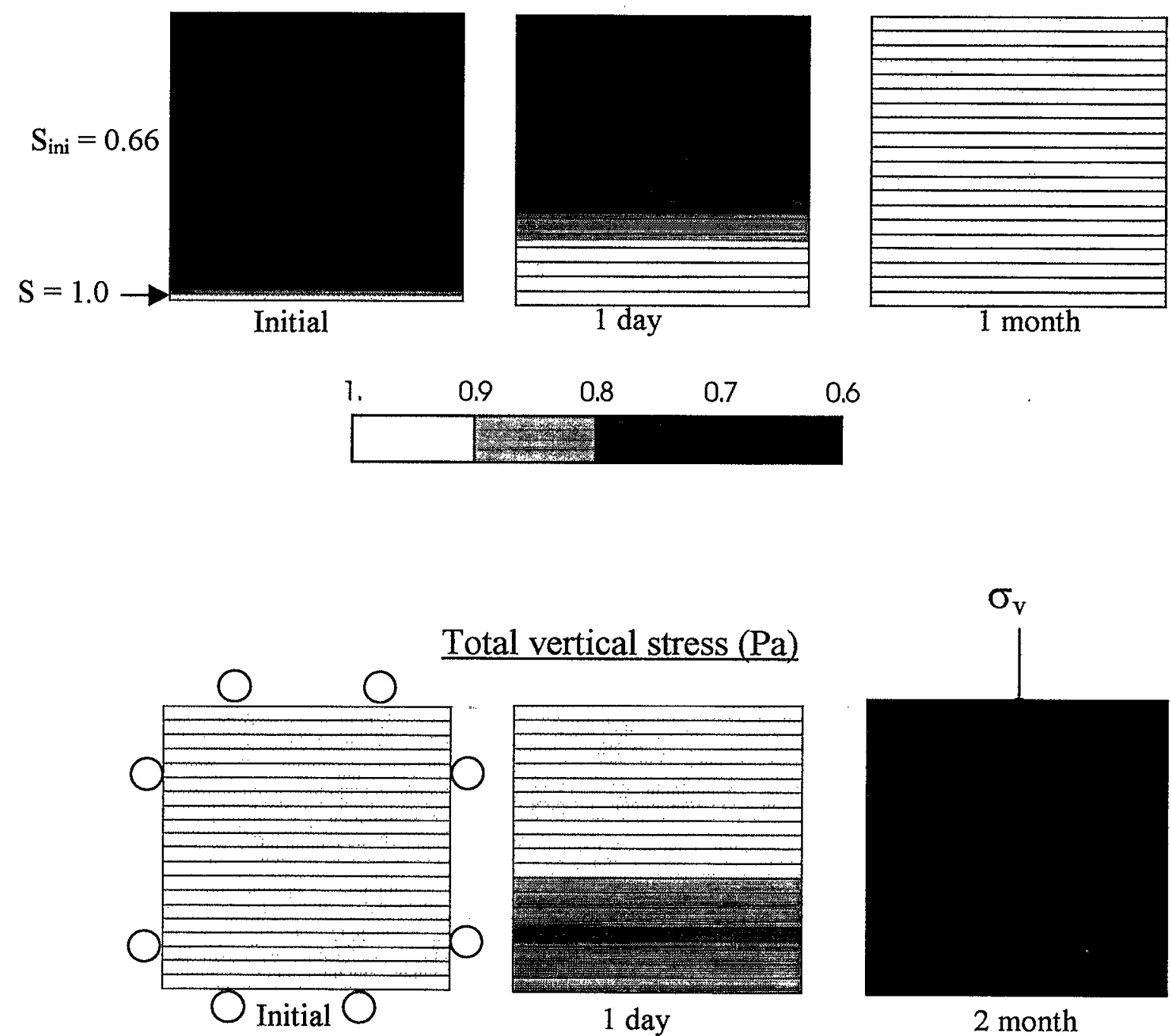

Total vertical stress $(\mathrm{Pa})$
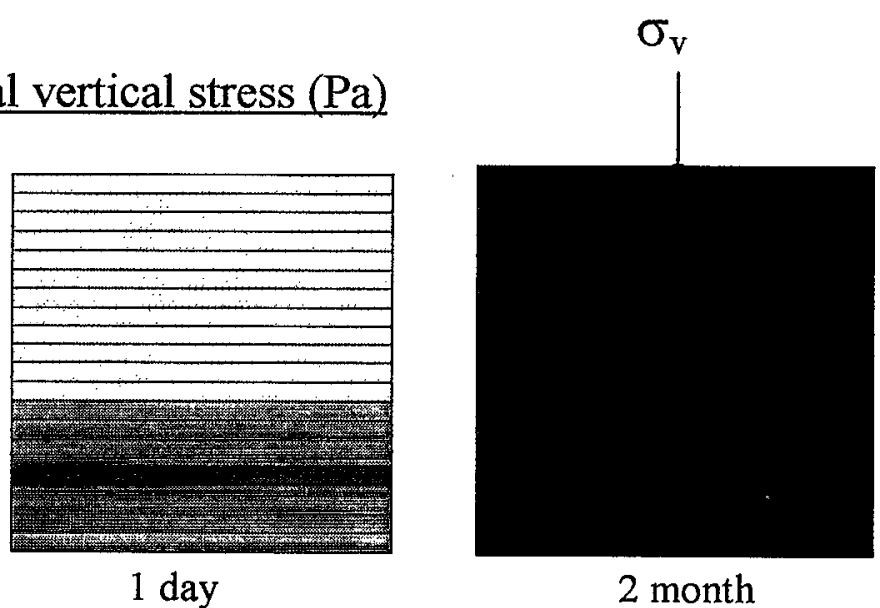

0. $-200000 .-400000 .-600000,-800000 .-1000000$.

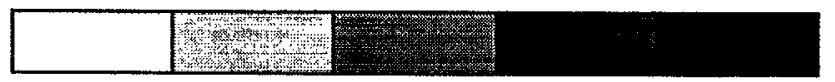

Figure 3.19. Modeling of swelling pressure test: Model setup and results of saturation and total vertical stress at initial stage and after 1 month of infiltration. 


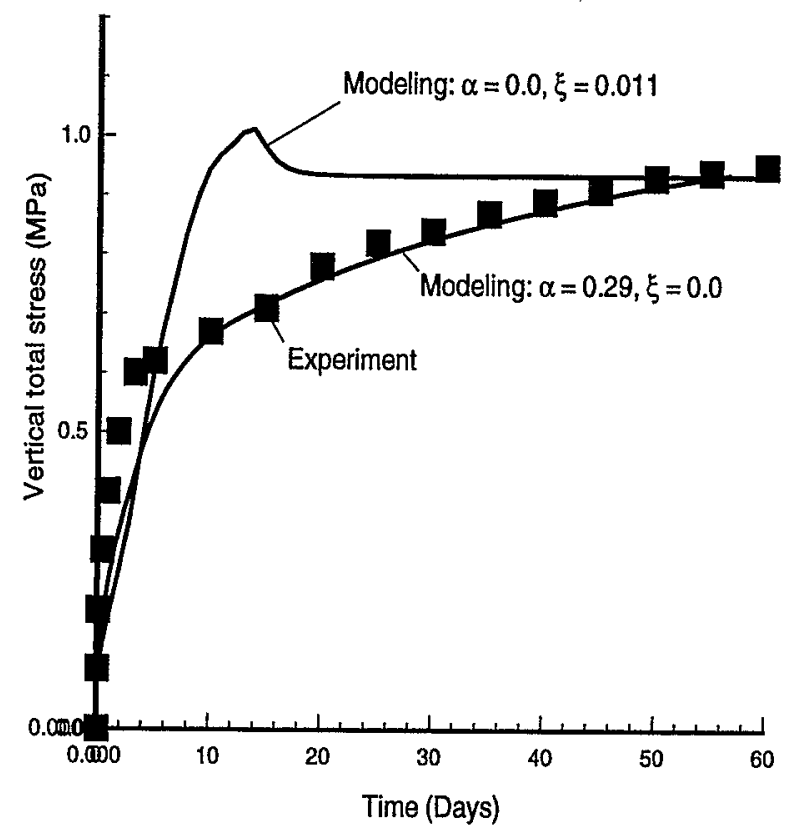

Figure 3.20. Comparison of modeling and experimental result (compressive stress positive) for the swelling pressure test. Two different approaches are used for modeling of the swelling pressure according to Equation (3b).

The modeling is conducted on the same finite element model as in the infiltration test, but with the initial saturation set to $66 \%$ (Figure 3.19). The nodes on all eight sides of the cube are restricted to moving only along the boundary by applying rollers. The total vertical stress is recorded at the top element as a function of time and is compared to the measured results. In this study, two methods for modeling of swelling pressure are considered, according to Equation (3b). The first is through a Bishop's type of effective stress law, calibrating the Biot's effective stress parameter, $\alpha$. The second method is to assume $\alpha$ equal to zero and calibrate the coefficient of swelling, $\xi$. The best matches of the two methods are compared in Figure 3.20. The first method gives a much better agreement in the transient response while the second method only agrees with respect to the final stress value. However, a separate modeling showed that if the saturation is decreasing rather than increasing, the first method $(\alpha=0.26, \xi=0.0)$ gives extremely high tension (in the order of tens of MPa) and may therefore not be realistic due to problems with the effective stress law. Therefore, the second method with $\alpha=0.0$ and $\xi$ $=0.011$ will be used in the final model of the heater test. This is an uncertain parameter estimate, since the experimental conditions are limited to saturation values above $66 \%$, while the final heater test may have much lower saturation. 


\subsection{Overall agreement between laboratory experiments and ROCMAS}

The agreement between the laboratory experiment and the calibrated numerical modeling is excellent regarding the isothermal water flow, and satisfactory regarding thermal vapor flow and swelling pressure. The back-calculated parameters of relative permeability and the diffusion coefficient are reasonable. For example, the molecular-diffusion coefficient is close to what could be predicted using the simple theory of diffusion porous media (Equation (11)). The general agreement between the data and simulated results indicates that the THM responses of the bentonite under these experimental conditions are well represented by the new algorithms of ROCMAS. Furthermore, the results indicate that the approach of Phillip and de Vries is appropriate for the bentonite material and under the circumstances of these experiments. Thus, convection of vapor with gas flow seems to be minor in comparison to the molecular diffusion. However, uncertainties exist in modeling of the mechanical behavior of the bentonite, especially at low saturation. 


\section{Kamaishi Mine Heater Test}

The Kamaishi Mine Heater Test is a major test case named Task 2 in the DECOVALEX project (Fujita et al., 1995). The experiment was conducted in a $5 \times 7$-meter alcove excavated from an existing drift located at a depth of about 250 meters (Figure 4.1a). In 1995, a vertical test pit, 1.7 meters in diameter and 5 meters in depth, was drilled in the floor of the alcove. The hole was drilled with a gentle shot boring method, using a large diameter boring machine to avoid mechanical disturbance of the rock.

In 1996, an electric heater was installed into the Test Pit and surrounded by a buffer of bentonite-clay. Bentonite was placed into the Test Pit in layers of 0.5 meters with compaction of each layer to a dry density of about $1.6 \mathrm{~kg} / \mathrm{m}^{3}$ (Figure $4.1 \mathrm{~b}$ ). After the entire Test Pit was filled with bentonite, a watertight concrete lid was placed on the drift floor, which in turn was supported by steel bars from the ceiling of the drift. Because the rock was not fully saturated immediate around the Test Pit, a flooding pool was set up on the drift floor above the Test Pit.

At the end of 1996 , the heater was turned on and the temperature was set to $100^{\circ} \mathrm{C}$ for 8.5 months followed by a 6 -month cooling period. System responses-including temperature, moisture content, fluid pressure, stress, strain and displacement-were measured in both the bentonite and surrounding rock mass. The experiment was completed in the beginning of 1998, and thereafter the monitoring sensors were calibrated.

The task for the DEOCALEX research teams was to predict the THM effects in the buffer material inside the Test Pit and in the surrounding rock, both during excavation of the Test Pit and the heater test.

The test case was divided into three main tasks: Task $2 \mathrm{~A}$, Task $2 \mathrm{~B}$ and Task $2 \mathrm{C}$. Task $2 \mathrm{~A}$ was to predict the H-M effects in the rock caused by the excavation of the Test Pit.

Geometry, mechanical and hydraulic rock properties, and hydraulic conditions before the excavation are given to the research teams. Task $2 \mathrm{~B}$ was a model calibration of rock and fracture properties, and the hydromechanical boundary conditions based on the measurements in Task $2 \mathrm{~A}$. Task $2 \mathrm{C}$ was to predict the THM effects in the rock and buffer during the heating experiment. The rock model was presumed to have properties based on the calibration in Task $2 \mathrm{~B}$, with correct permeability distribution in the near-field rock.

All the model predictions were done before completion of the respective test and before the experimental data were presented. Thereafter, the model results were compared to the experimental results as well as to modeling results of other research teams within the DECOVALEX project. 


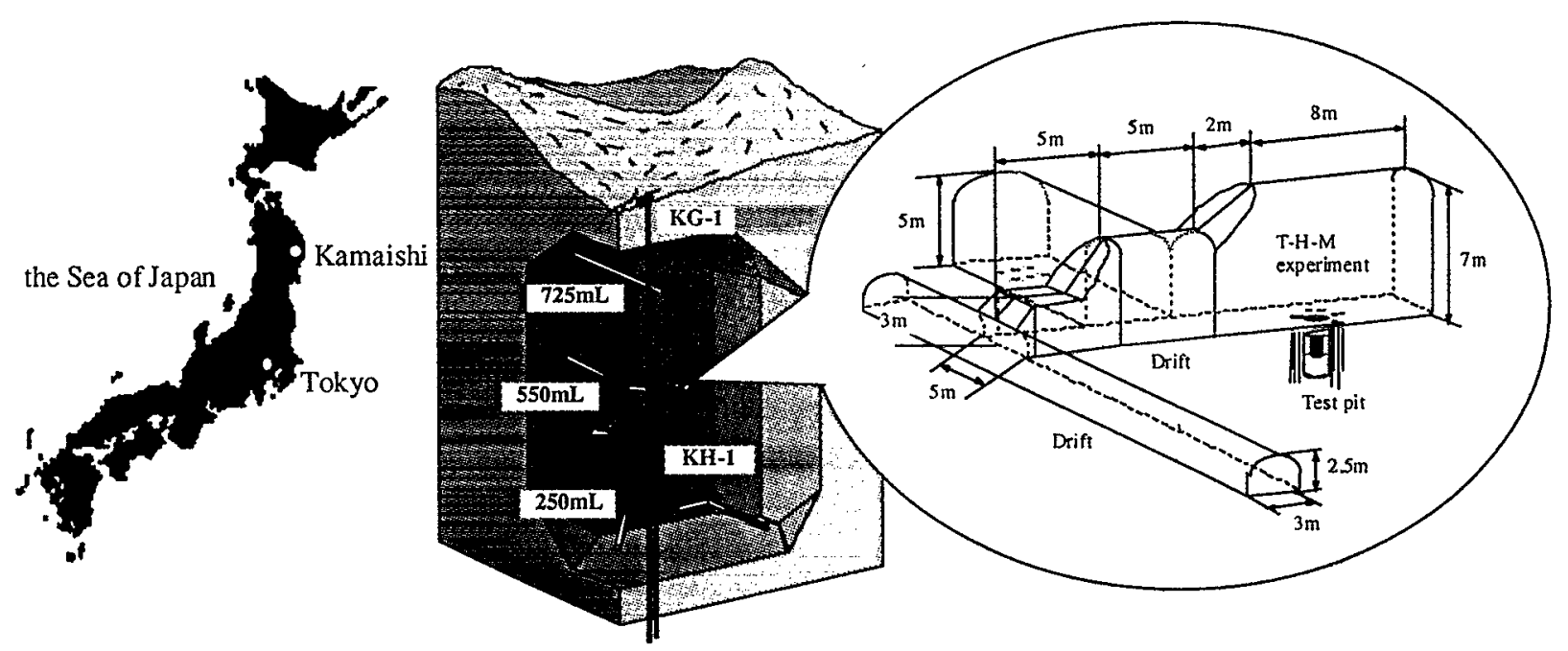

(a)

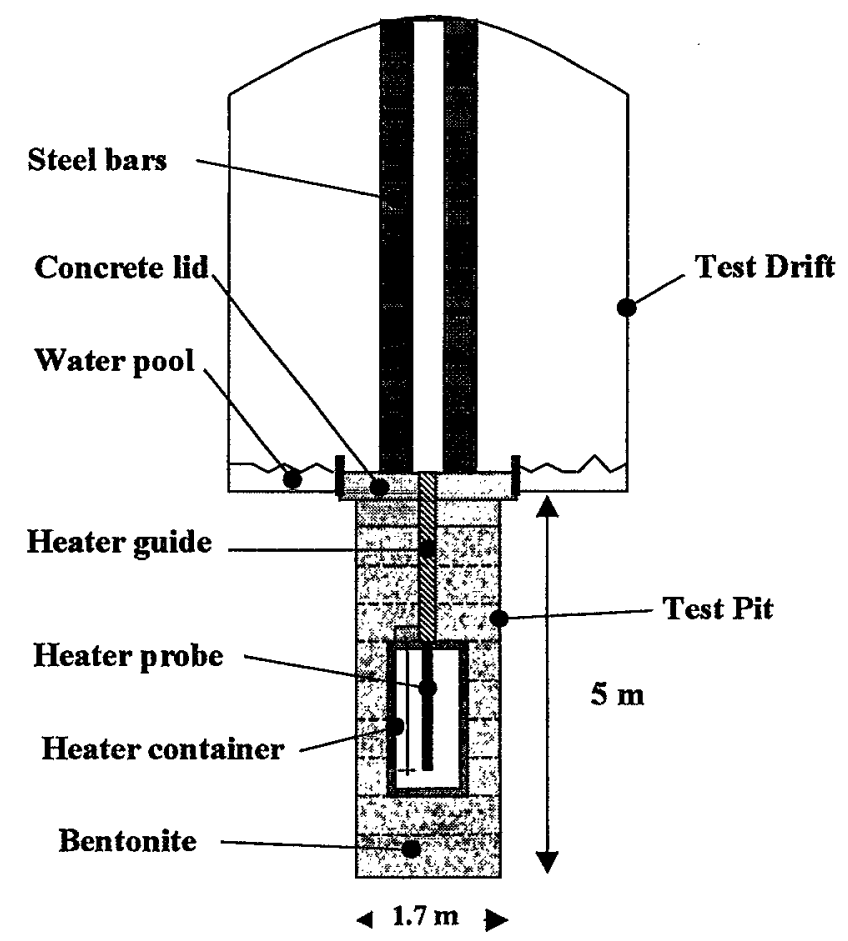

(b)

Figure 4.1. The Kamaishi Mine Heater Test (Fujita el al., 1995): (a) Location of the heater test at 250 meters depth and nearby drift system; (b) Heater and bentonite emplaced into the Test Pit. 


\section{Overview of the experimental data set at Kamaishi Mine}

A comprehensive data set with site characteristics and material properties were reported by Fujita et al. (1996a-c, 1997b) and Chijimatsu et al. (1996a-d, 1997). These reports included raw-data and result of measurements of thermal, hydraulic and mechanical material properties and site-specific initial conditions. This section presents an overview of the data in light of our THM modeling of the heater test.

\subsection{Far field rock properties and boundary conditions}

The far field properties and boundary conditions are important because they affect nearfield responses of (for instance) fluid pressure and stress. At Kamaishi Mine, on the level of the Test Drift, many fractures are striking NE with a steep dip (Figure 5.1b). The minimum principal stress is subvertical; the maximum principal stress is oriented $\mathrm{N}$ to NW (Figure 5.1c).

(a)

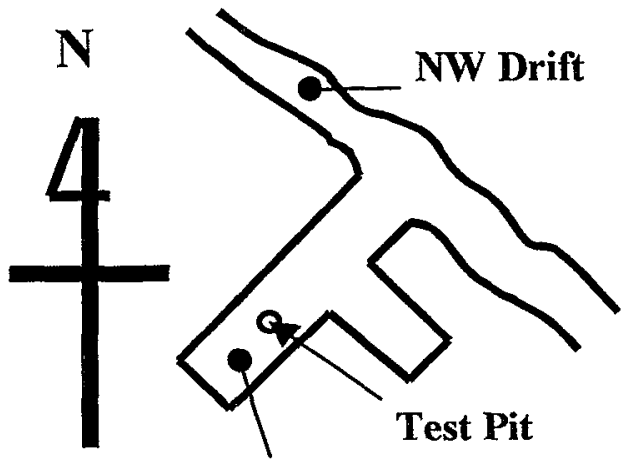

Test Drift

(c)

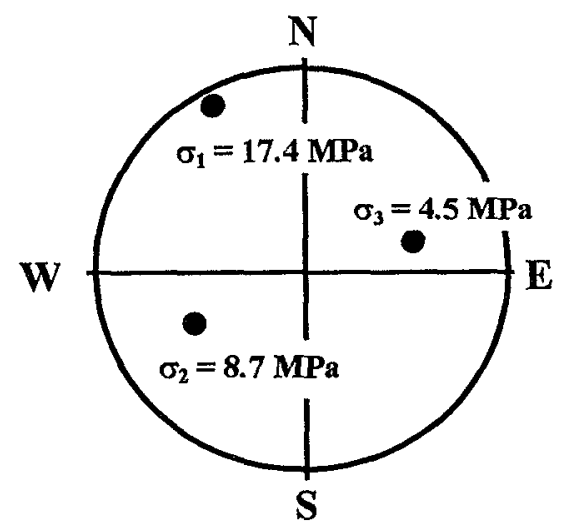

(b)

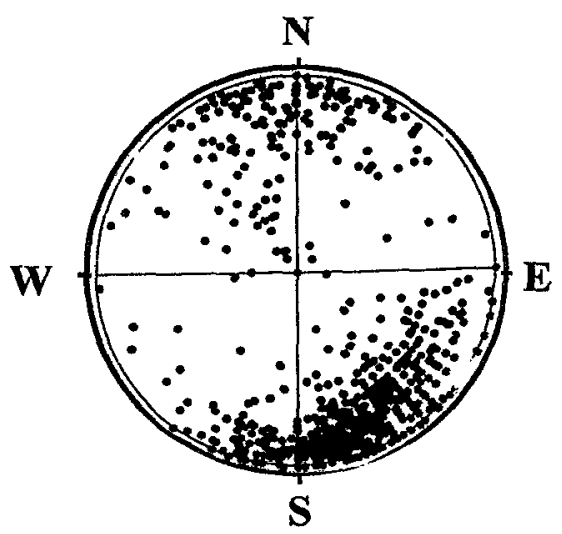

(d)

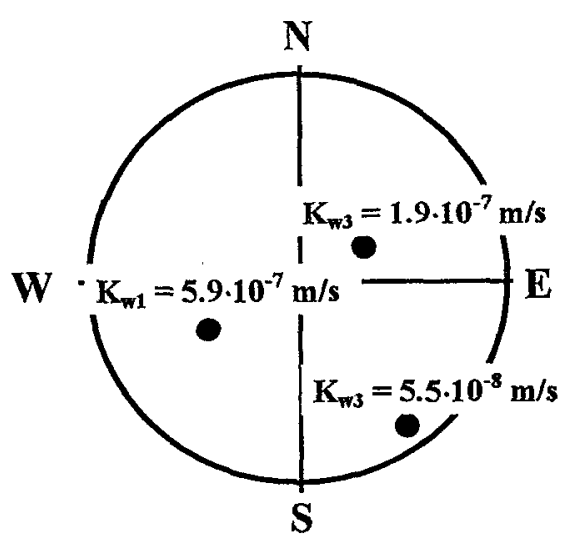

Figure 5.1. Orientation of test drift, fractures, stress and hydraulic conductivity at the test site: (a) Plane view showing the orientation of the Test Drift; (b) Equal area lower hemisphere projection of 886 fracture normals at NW drift (reproduced from Fujita el al, 1995); (c) In situ stress at 550-meter level measured with hydraulic fracturing (reproduced from Chijimatsu et al., 1996b); (d) Sketch of the principal hydraulic conductivity measured at the KD-90 drift. 
The hydraulic conductivity tensor of the rock mass is estimated at the $\mathrm{KD}-90$ drift about 100 meters away from the heater test area. These measurements show that the maximum hydraulic conductivity (Figure 5.1d) is oriented parallel to the dominating fracture orientation and perpendicular to the maximum principal stress orientation, indicating that the far-field hydraulic conductivity is correlated to the fracture orientation rather than to the in situ stress.

At Kamaishi Mine, as a result of the continuous drainage pumping in the existing drift system, the fluid pressure distribution along the vertical depth does not correspond to a hydrostatic pressure gradient. At the level of the THM test, the fluid pressure in the nearby 100 meters varies between 0.1 and $0.4 \mathrm{MPa}$, with an average pressure of about 0.3 $\mathrm{MPa}$.

\subsection{Near field rock properties and fracture geometry}

In the near field, individual fractures affect the distribution of mechanical deformability and hydraulic permeability and are therefore important for the prediction of flow, fluid pressure, mechanical strain, and displacements. These fractures (as well as the fractures in the nearby NW drift) are striking preferably NE with a steep dip (Figure 5.2a). On the floor of the Test Drift, too many fractures exist to include discretely in a finite-element model. The average fracture spacing is 0.1 to 0.4 meters. However, there are three large distinguished shear fractures adjacent to the Test Pit striking approximately EW (Fracture 1,2 and 3 in Figure 5.2b).

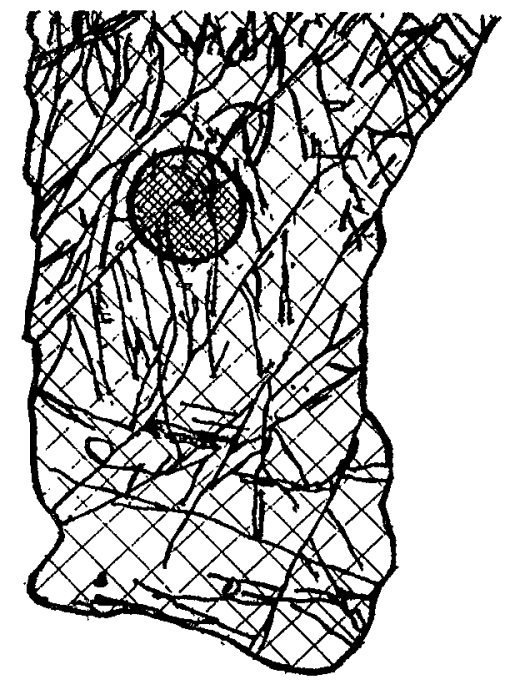

(a)

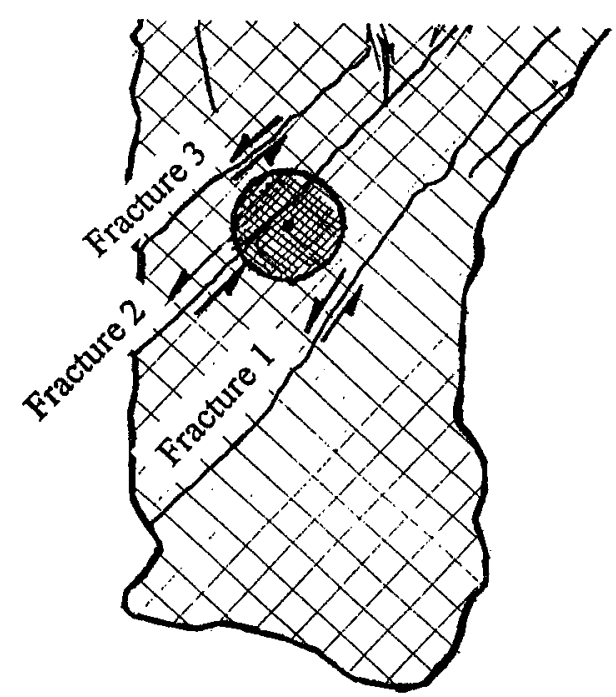

(b)

Figure 5.2. Sketch of fractures and the Test Pit on the floor of the Test Drift: (a) Fracture traces longer than 0.5 meters; (b) Fractures with observed displacement (Fujita et al., 1996c). 
These fractures have been sheared and are reported as the most open fractures on the floor, containing soft mineral fillings of up to $20 \mathrm{~mm}$ in thickness, and hence may be considerably softer and more conductive than other fractures in the near field. Fracture 1, 2 and 3 are extensive in the horizontal direction on the floor, and similar fractures with the same strike and dip can be found on the drift ceiling, also dominating the inflow into the drift.

The mechanical, hydraulic, and thermal properties of the intact rock material have been determined in laboratory experiments (Table 5.1). A number of tests have also been conducted on fractures in the laboratory as well as in the field. Laboratory tests on clean joints indicated a normal stiffness of 200-800 GPa/m (at normal stress of 0-10 MPa) and a shear stiffness of $1-10 \mathrm{GPa} / \mathrm{m}$. However, Fractures 1,2 and 3 are sheared and partly filled with mineral filling, which implies that they may be more deformable than the above-mentioned clean joints. The fractures are curved and undulating, with some parts of the fracture surfaces in contact or filled with minerals and other parts open. This condition implies that the normal and shear stiffness is likely to be heterogeneous over the fracture area.

Before excavation of the Test Pit, the in-situ hydraulic conductivity was measured in seven boreholes located within a radius of 2 meters from the center of the (unexcavated) test pit. The results of the hydraulic tests indicate that the hydraulic conductivity in the near-field rock as a whole is small, but dominated by a few open fractures. These fractures have a hydraulic transmissivity ranging from $10^{-7}$ to $10^{-6} \mathrm{~m}^{2} / \mathrm{s}$, which represents an equivalent hydraulic aperture of about 50 to 100 microns. The hydraulic permeability varies considerable over the fracture planes and water flow takes place in channels between closed or mineral-filled parts of the fractures.

Table 5.1. Mechanical, thermal, and hydraulic properties of the intact rock material measured by laboratory experiments on drill-core samples.

\begin{tabular}{|l|l|}
\hline \multicolumn{1}{|c|}{ Property } & \multicolumn{1}{c|}{ Value } \\
\hline Unconfined compressive strength & $123 \mathrm{MPa}$ \\
\hline Young's modulus, $E$ & $61 \mathrm{GPa}$ \\
\hline Poisson's ratio, $v$ & 0.3 \\
\hline Cohesion & $22 \mathrm{MPa}$ \\
\hline Internal friction angle & $52^{\circ}$ \\
\hline Density, $\rho_{s}$ & $2700 \mathrm{~kg} / \mathrm{m}^{3}$ \\
\hline Porosity, $\phi$ & 0.0038 \\
\hline Thermal conductivity, $K_{M}$ & $2.6 \mathrm{w} /(\mathrm{m} \cdot \mathrm{k})\left(\right.$ at $\left.60^{\circ} \mathrm{C}\right)$ \\
\hline Specific heat, $C_{p S}$ & $833 \mathrm{~J} /(\mathrm{m} \cdot \mathrm{K})$ \\
\hline Thermal expansivity, $\beta_{T}$ & $8.2 \cdot 10^{-6} 1 / \mathrm{K}$ \\
\hline Hydraulic conductivity, $K$ & $1 \cdot 10^{-13} \mathrm{~m} / \mathrm{s}($ at $10 \mathrm{MPa}$ confining pressure) \\
\hline
\end{tabular}




\subsection{Heater and clay buffer}

The heater container, $104 \mathrm{~cm}$ in diameter and $195 \mathrm{~cm}$ in height, is made of $50-\mathrm{mm}$ thick carbon-steel and contains an electric heater probe and a stirrer. The temperature is controlled to be constant at about $100{ }^{\circ} \mathrm{C}$ at the surface of the heater container. Properties of the heater and the concrete lid were given by JNC and are presented within this report in Section 8, Table 8.1.

JNC performed a number of experiments to determine THM properties of the buffer material, which is a granulated bentonite, BENTONITE OT-9607 (Fujita et al., 1997b). These experiments includes:

1. Compaction test

2. Saturated hydraulic permeability test

3. Suction test

4. Infiltration test

5. Thermal gradient test

6. Thermal conductivity test

7. Unconfined compression test

8. Swelling pressure test

9. Drying shrinkage test

Some of the properties could not be determined directly from the experimental results because of the lack of analytical solutions for the complex processes involved. Instead, these properties were back-calculated by a numerical modeling calibration. The experimental results of Laboratory test 2,3,4,5 and 8 were presented earlier in this report, Section 3 together with the numerical modeling of these tests.

\subsection{Instrumentation of rock and buffer}

Many boreholes were drilled around the Test Pit to monitor the hydraulic, mechanical, and thermal responses of the rock during excavation of the Test Pit and during the heater test (Figure 5.3). These boreholes were located within two meters from the center of the Test Pit and were drilled to a depth of about 8 meters. During the entire experiment, pore pressure and temperature were monitored at several levels in $\mathrm{KBH} 1$ to 6 , and mechanical displacement and strain were monitored in KBM1 to 5.

The bentonite buffer was extensively instrumented with sensors chiefly along three monitoring sections (O-DDA, O-BBC and $\mathrm{O}-\mathrm{CD}$ ), which are shown in Figure 5.3. Figure 5.4 presents the location of the sensors, which consist of hygrometers, pressure cells, heat flux sensors, strain gauges, psychrometers, pore-pressure transducers, and thermocouples. The measured quantities are temperature, water content, heat flux, strain, and total stress (pressure). In addition, core samples were extracted from the bentonite along sections ODDA and O-CD at two times; after the end of the heating period and after the end of the cooling. These core samples were oven dried to give a reliable and independent measure of the water content. 


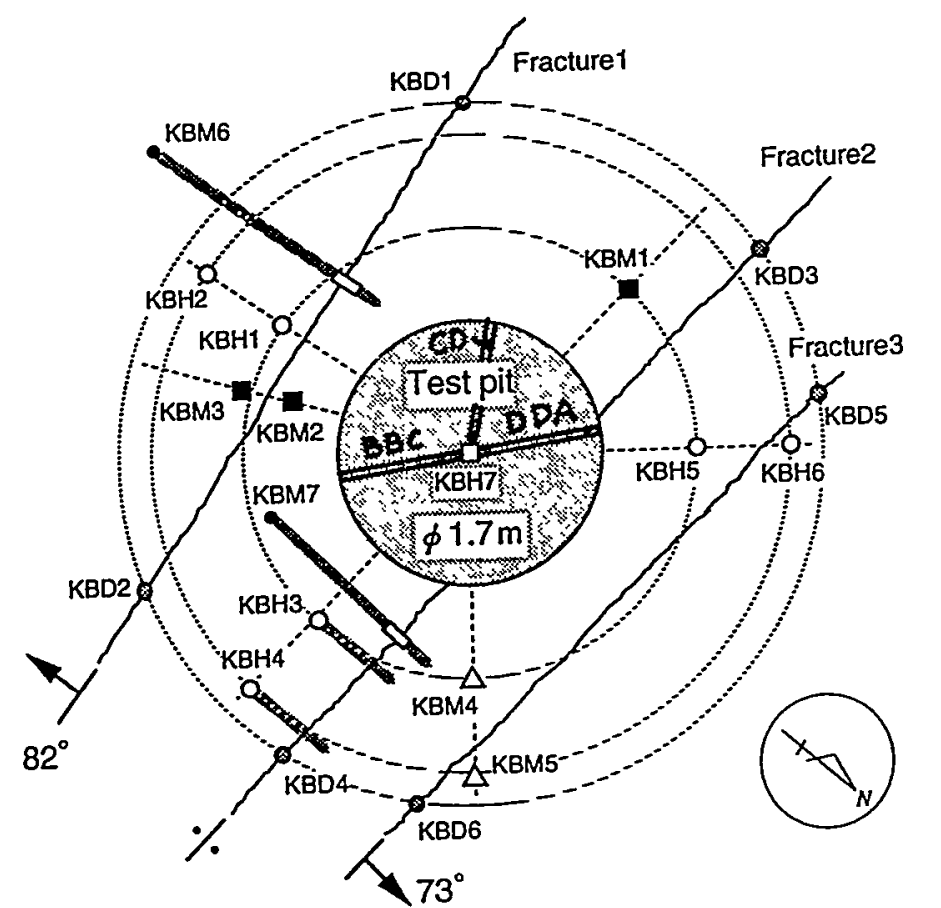

- Pumping up or injection KBD1 6

$\square$ Borehole expansion test $\mathrm{KBH} 7$

- Hydraulic test and pore water pressure $\mathrm{KBH} 1 \sim 6$

- Strain and temperature KBM1 $\sim 3$

$\triangle$ Rock deformation KBM 4,5 $\square$ Joint deformation

- KBM6,7
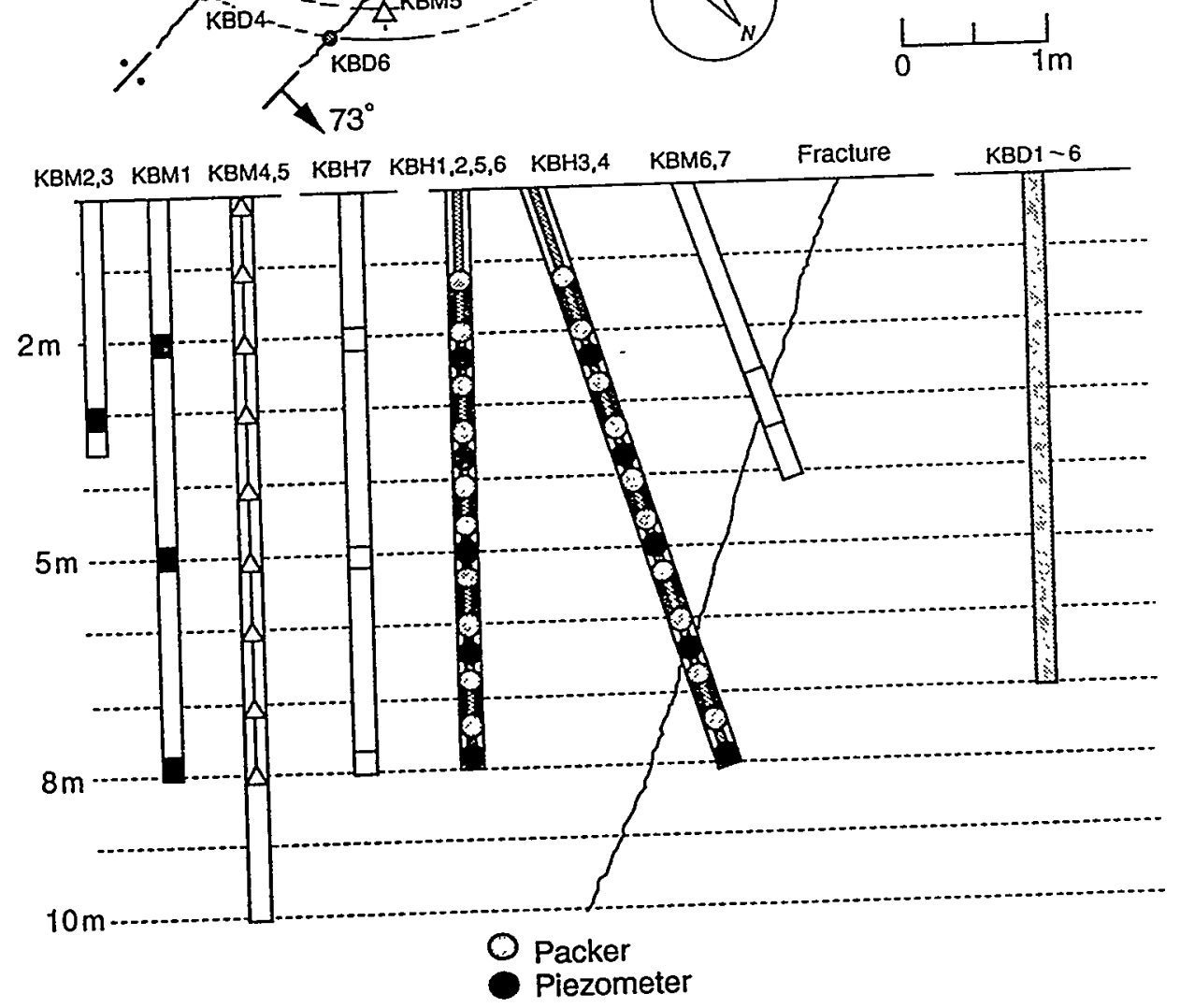

Figure 5.3. Layout of the Test Pit and the boreholes for testing and monitoring of system responses in the rock mass (Fujita et al., 1996c). 


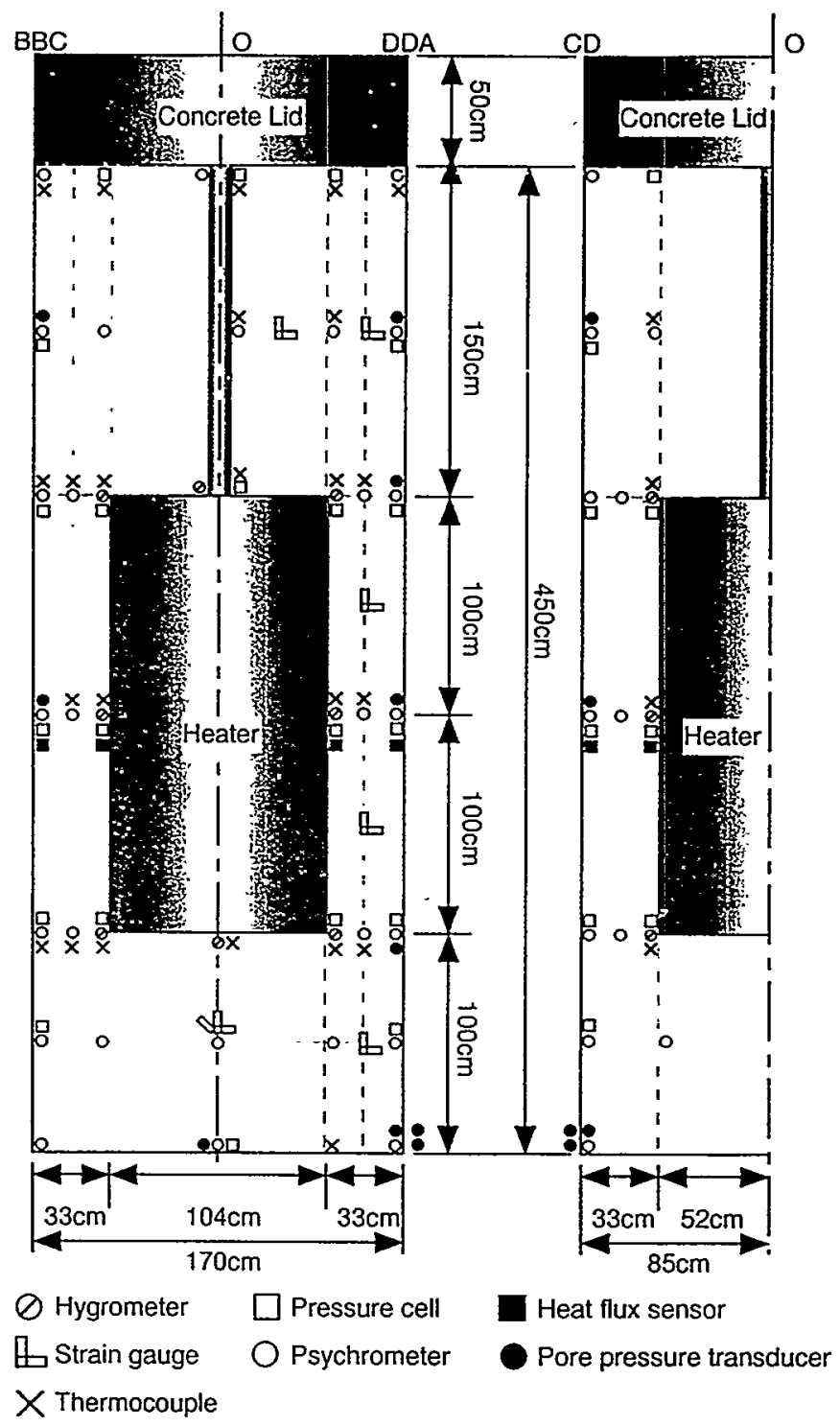

Figure 5.4. Location of sensors in the bentonite buffer mass.

\subsection{Initial conditions}

The initial conditions are the prevailing in situ stress, initial temperature, and initial fluid pressure or saturation. The prevailing in situ stress before excavation of the nearby drifts are known from the regional stress field (Figure 5.1). Away from the Test Drift, the rock was saturated and with an initial pressure of about $0.3 \mathrm{MPa}$. However, near the drifts, the pressure showed a large spatial variation, and the rock was partly unsaturated. Before the heater test, the clay buffer was compacted to a dry-density of $1,6 \mathrm{~kg} / \mathrm{m}^{3}$, and the initial water content was about $16 \%$ (66\% saturation). The initial temperature was about $12.3^{\circ} \mathrm{C}$, both in the bentonite and in the rock mass at the elevation of the drift. 


\section{Modeling conceptualization of the rock at Kamaishi Mine}

This section presents the development of a conceptual model for the rock around the Kamaishi Mine Heater Test and also covers Task 2A modeling for the DECOVALEX project. A conceptualization of a three-dimensional model for the simulation of the final heater test is aided by a number of simple two-dimensional models and a parametric study to determine the influence of discrete fractures. For Task $2 \mathrm{~A}$ we attempted to predict the general hydraulic and mechanical behavior around the Test Pit, giving the outputs within a range of maximum and minimum values.

\subsection{Alternative modeling approaches}

The rock at Kamaishi Mine is hard, crystalline and highly fractured, with an average spacing of 0.1 to 0.4 meters. With these conditions in mind, the following modeling approaches may be used:

1) Anisotropic equivalent properties of a rock mass with ubiquitous fractures.

2) Porous isotropic matrix with discrete fractures.

3) A combination of approach 1 and 2.

The first approach is the most appealing from a practical point of view, because the discretization of the finite-element mesh is much simpler without including the discrete fractures. We may, however, have to include some major fractures to accurately model the near-field behavior. The question is then, which fractures should or can be included in a three-dimensional model?

To find out which fracture should be included in a large-scale three-dimensional model, we started with a few simple two-dimensional calculations for Task 2A. Here, we focused on the near-field consequences of including Fracture 1,2 and 3 into the model. We are seeking answer on how the fractures affect the convergence of the Test Pit and how the inflow and hydromecanical effects in the near-field is affected.

\subsection{Preliminary modeling of mechanical effects of fractures}

A two-dimensional model of $8 \times 8$ meters was constructed for horizontal planes below the drift floor (Figure 6.1). The model contains Fracture 1,2 and 3, but one or several of the fractures may be omitted by changing them to solid material elements. The boundary stresses on the model were estimated using results from a separate two-dimensional simulation (not presented) of the stress redistribution around the drift before excavation of the Test Pit.

A parametric variation was conducted with four sets of mechanical fracture properties. Two extreme cases arise when the fractures have a stiffness as high as the intact rock (equivalent to no fractures) or when the fractures have a very low stiffness. Figure 6.2 and 6.3 compares the modeling results of maximum principal stress and radial displacement convergence for these two extreme cases. Figure $6.2 \mathrm{~b}$ shows that the fractures influence the maximum principal compressive stress magnitude close to each fracture. Furthermore, the stresses tend to be relocated from the right wall of the Test Pit, giving increased stress on the left wall. Figure 6.3 shows that the convergence pattern is 


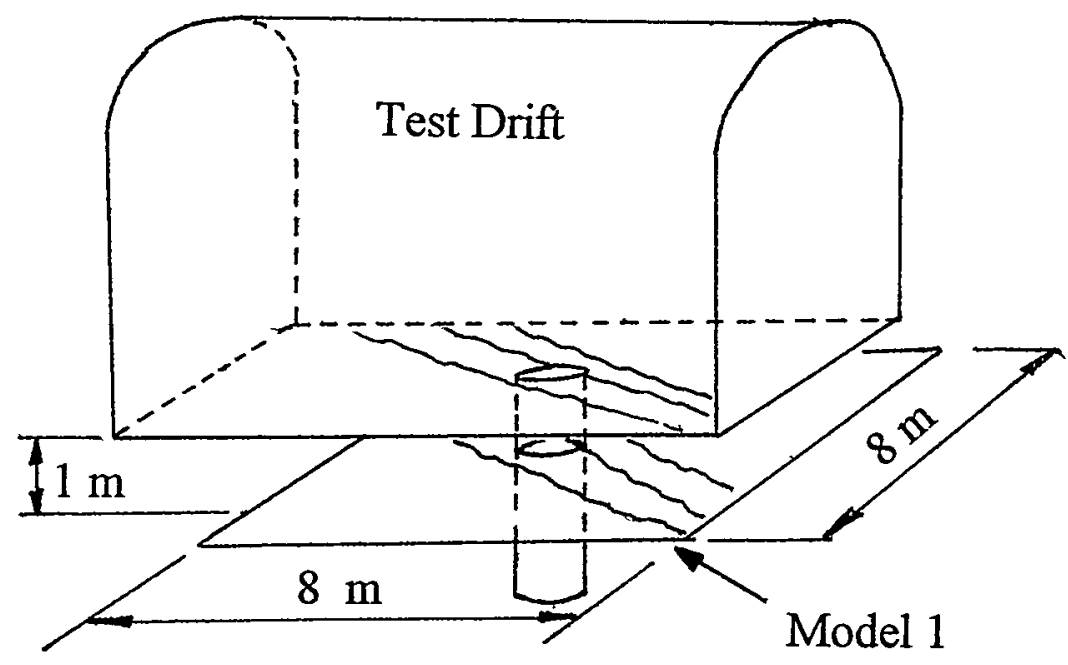

Figure 6.1. Sketch showing a horizontal section of the preliminary two-dimensional model (located below the Test Drift) for investigating the influence of main fractures.

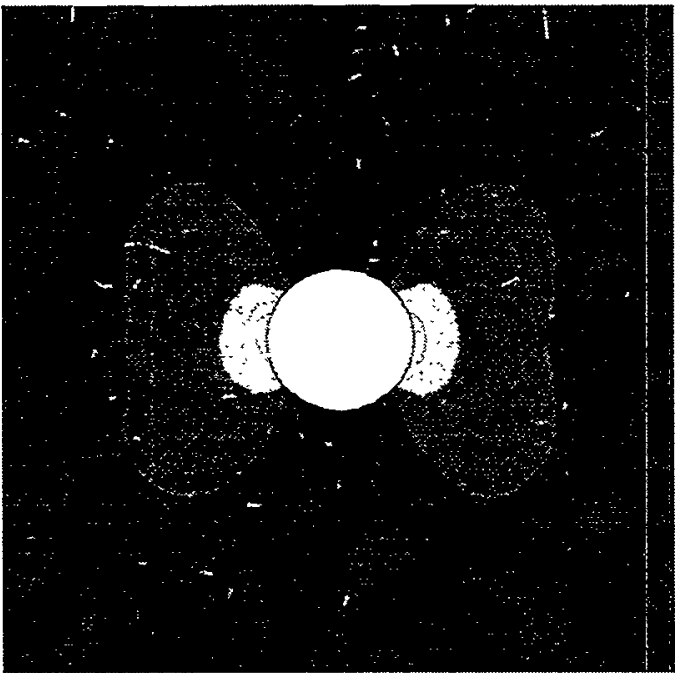

a) Without fractures

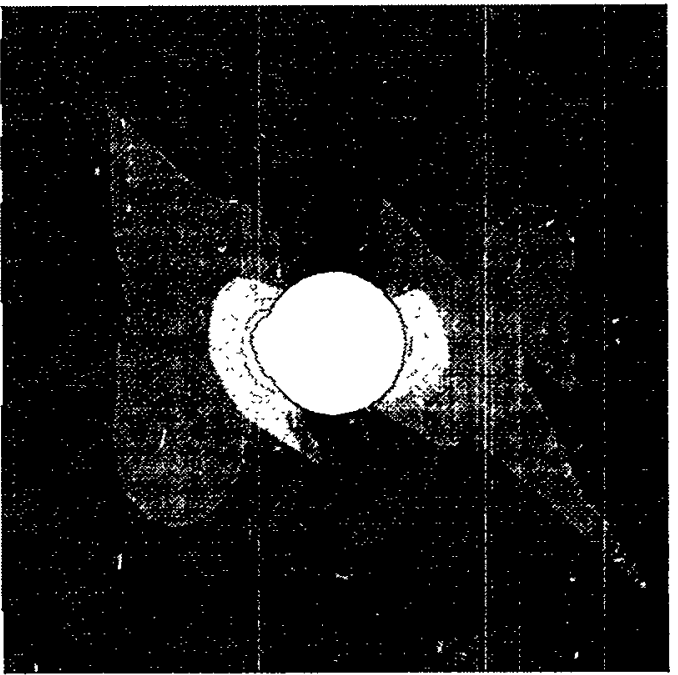

b) With 3 soft fractures

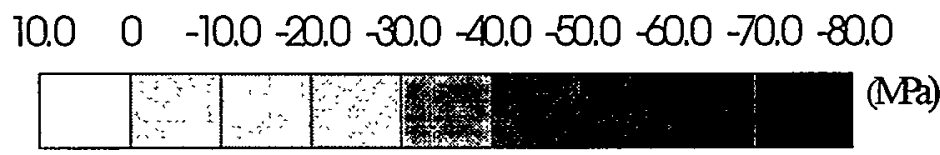

Figure 6.2. Preliminary modeling results on the magnitude of maximum principal stresses in the horizontal section 3 meters below the drift floor. 
strongly influenced by the fracture intersecting the Test Pit and a considerable shear displacement occurs in Fracture 2. When fractures are included, the maximum displacement increases from a few microns to about $0.5 \mathrm{~mm}$.

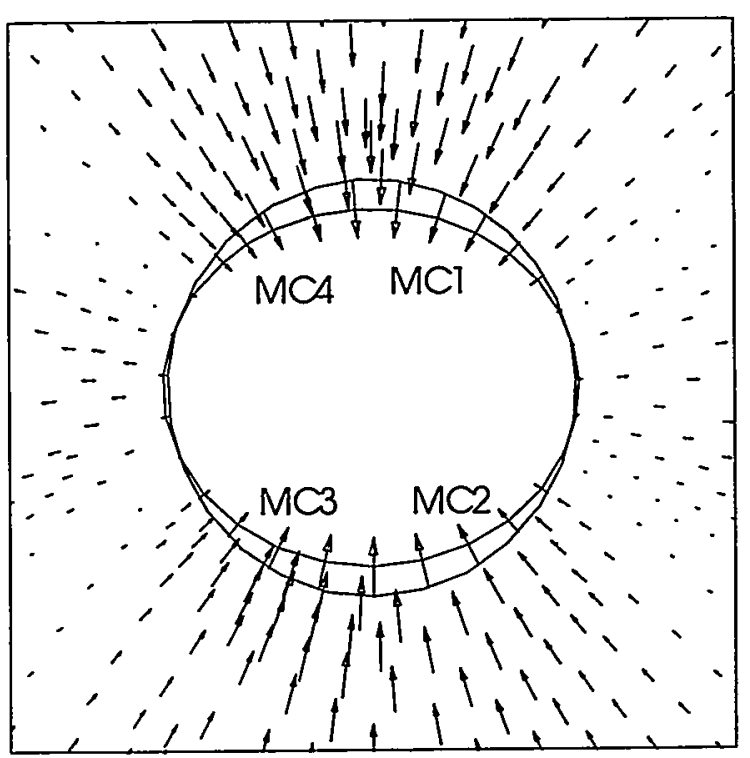

a) Without fractures

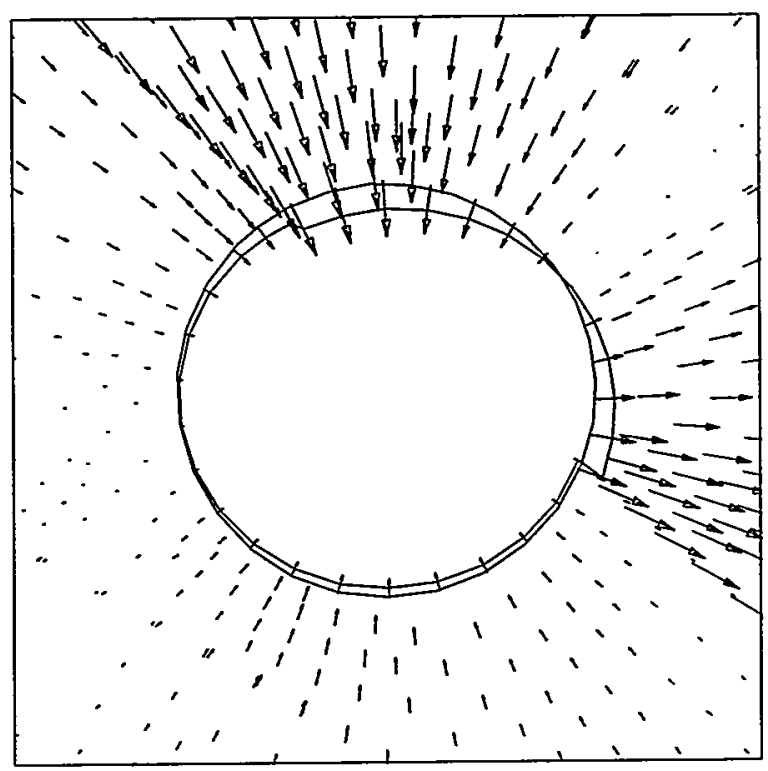

b) With fractures

Figure 6.3. Preliminary analysis of radial convergence of the rock for a model (a) Without fractures and (b) With fractures.

\subsection{Preliminary modeling of fluid flow in Fracture 2}

The inflow into the Test Pit was simulated with a vertical two-dimensional model in the plane of Fracture 2, extended to a constant pressure boundary 25 meters from the Test Pit (Figure 6.4). The pressure at the outer boundary was set to $0.3 \mathrm{MPa}$ and to zero at the walls of the excavation. The fracture aperture after excavation of the Test Pit was obtained from the mechanical calculations of the previous horizontal two-dimensional section and assuming an initial aperture of 50 or $100 \mu \mathrm{m}$. The resulting inflow was 148 liters/day when the initial aperture was $50 \mu \mathrm{m}$ and 1324 liters/day when the initial aperture was $100 \mu \mathrm{m}$ (Figure 6.5). Hence, the initial aperture is a very important parameter. The results of this preliminary modeling indicate that the effects of changed fracture permeability caused by excavation of the Test Pit are small compared to possible variation of the initial fracture permeability. 


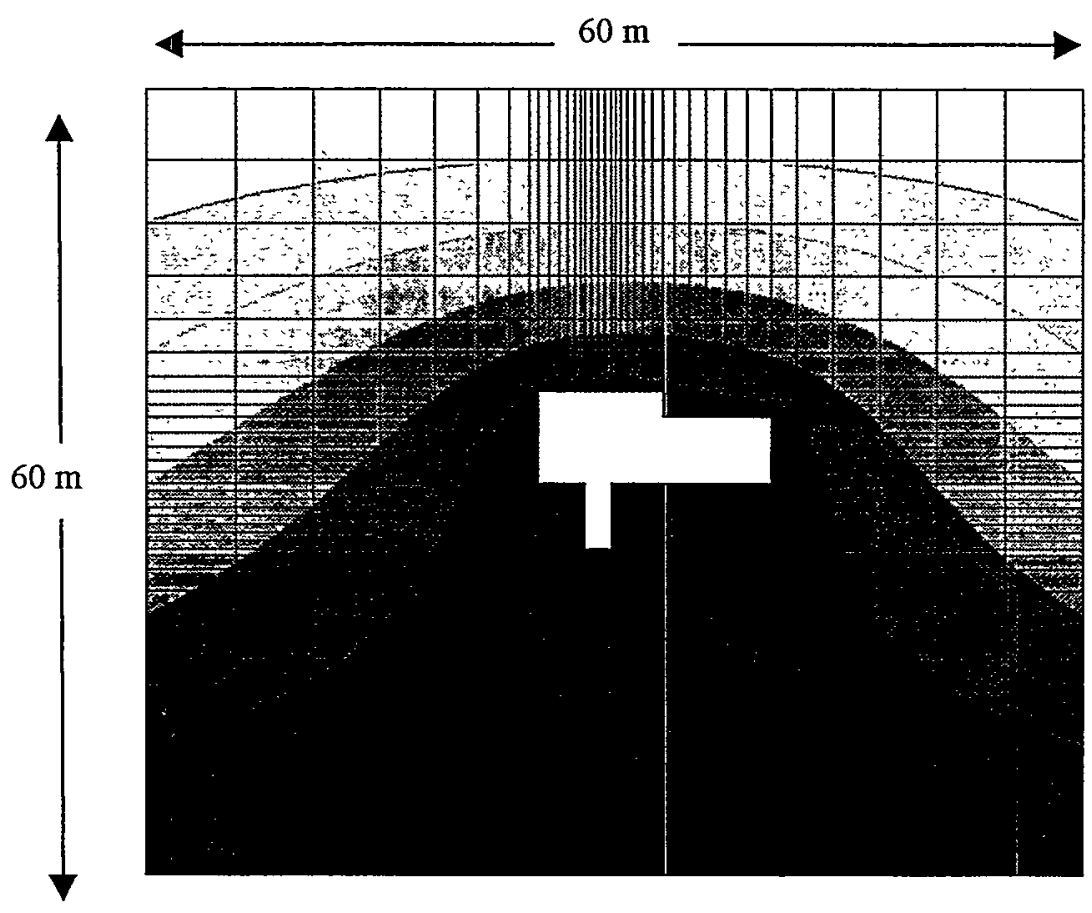

Hydraulic Potential

(m)

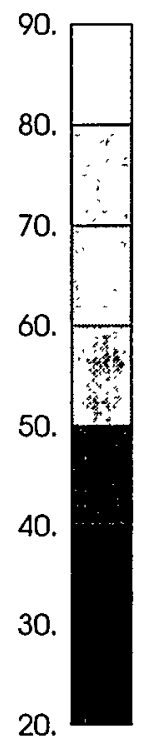

Figure 6.4. Finite element model in the plane of Fracture 2 for preliminary analysis of the water inflow to the Test Pit.

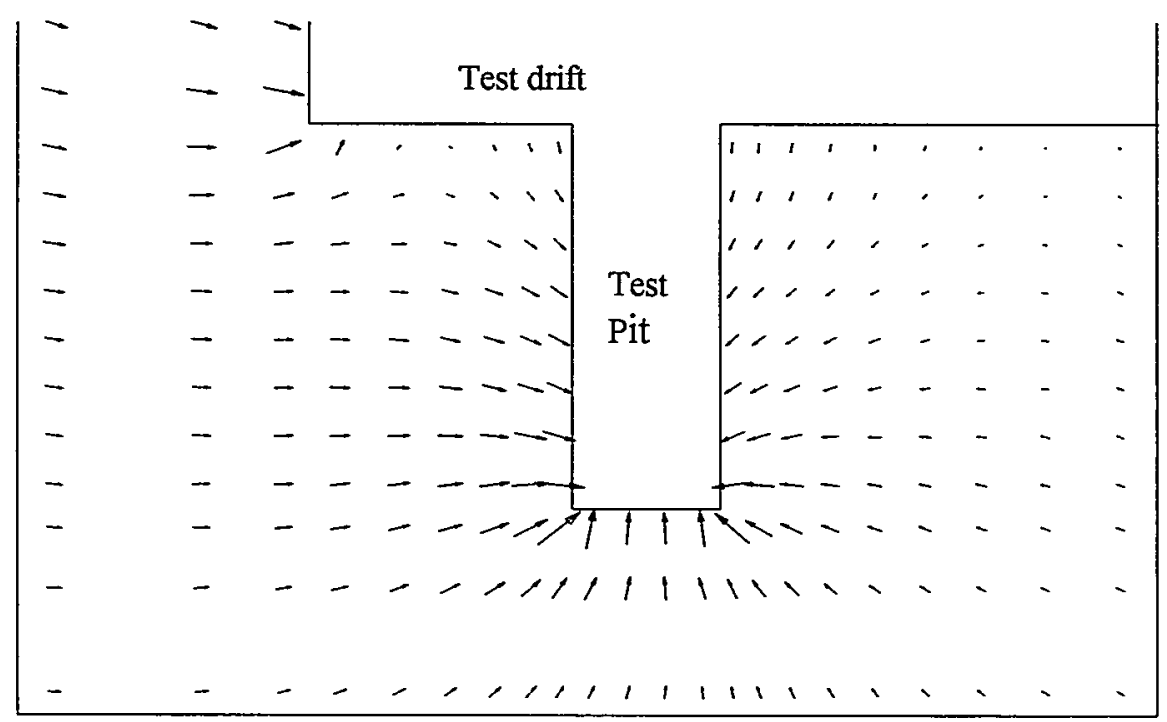

Figure 6.5. Results of preliminary analysis showing the flow pattern in the plane of Fracture 2 near the Test Pit. 


\subsection{Summary of results of Task $2 A$}

The comparison of calculated inflow and mechanical displacement to the field measurements was satisfactory, considering that a simple two-dimensional model was used. The total inflow into the Test Pit was measured to be 280 liters/day, which is within the wide range of the prediction. A statistical analysis of the fracture permeability could have narrowing the range, but it was not attempted in this preliminary study. The field measurement (Figure 6.6) also verified that the inflow was dominated by a few discrete fractures in the near-field. In addition to flow from the intersecting Fracture 2, a large portion of the inflow entered from another fracture (Fracture 4) which was not accounted for in the two-dimensional model.

In general, both modeling and experiments show that the displacement in the rock around the Test Pit is small, less than $1 \mathrm{~mm}$. One main disagreement: the modeling shows that the Test Pit is converging upon excavation, while the experiment indicates that it is expanding. A logical rock-mechanics response is that the Test Pit should converge upon excavation if the stress around it is compression. At this point, no explanation to the apparent expansion of the Test Pit can be given.

\subsection{Conceptualization for a three-dimensional model}

From our two-dimensional modeling, we may conclude that it is essential to include Fracture 1,2 and 4 as discrete features because they dominate the inflow or are important for displacement. In the field, these fractures are partly filled with minerals, curved, and sometimes branching into several parallel fractures. Thus, their properties may vary widely over its plane and therefore cannot be properly modeled with a perfectly planar joint element of homogenous properties. Furthermore, the mechanical monitoring during the experiment is not detailed enough to provide data for a very detailed model with thin joint elements. For instance, the displacement measurement over Fracture 2 is conducted between anchors which are $80 \mathrm{~cm}$ apart, in an interval containing up to 14 fractures. A simpler and more practical approach for modeling may be to simulate the fractures with solid elements of highly anisotropic properties-hence, zones of high permeability and reduced mechanical stiffness.

The concept in the preliminary flow model in Figure 6.4, with a high permeability fracture extending all the way to the outer boundary 25 meters away, is incorrectly leading to a situation where most of the water flow is originating from the far field (see flow pattern Figure 6.5). In the field, the inflow without flooding pool was only 4 liters/minute; with flooding pool, it was up to 280 liters/minute (Figure 6.6). This large difference, showing that most of the water flowing into the Test Pit originates from the flooding pool on the drift floor and flows through a few high-permeability fractures. These fractures seem to form a compartment of high permeability, which is confined in a rock mass of much lower permeability. Such compartmentalization has also been observed in the rock mass at Kamaishi Mine, from extensive hydraulic testing at the nearby KD-90 drift (Doe et al., 1999). Thus, the extensions of the fractures can be limited to the near-field rock around the Test Pit. 


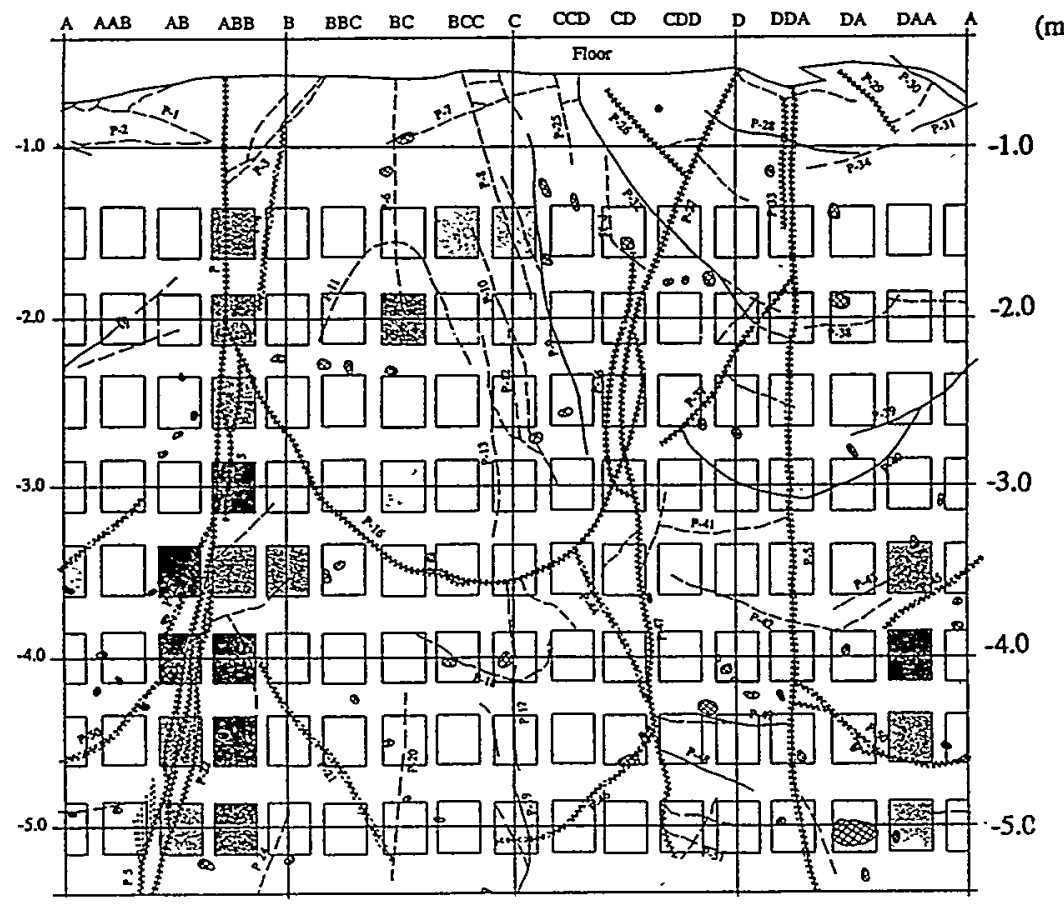

(m)

Water Flux $(\mathrm{cm} / \mathrm{s})$

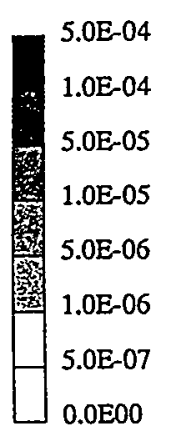

(a) Without flooding pool: Total inflow is 4 liters/minute
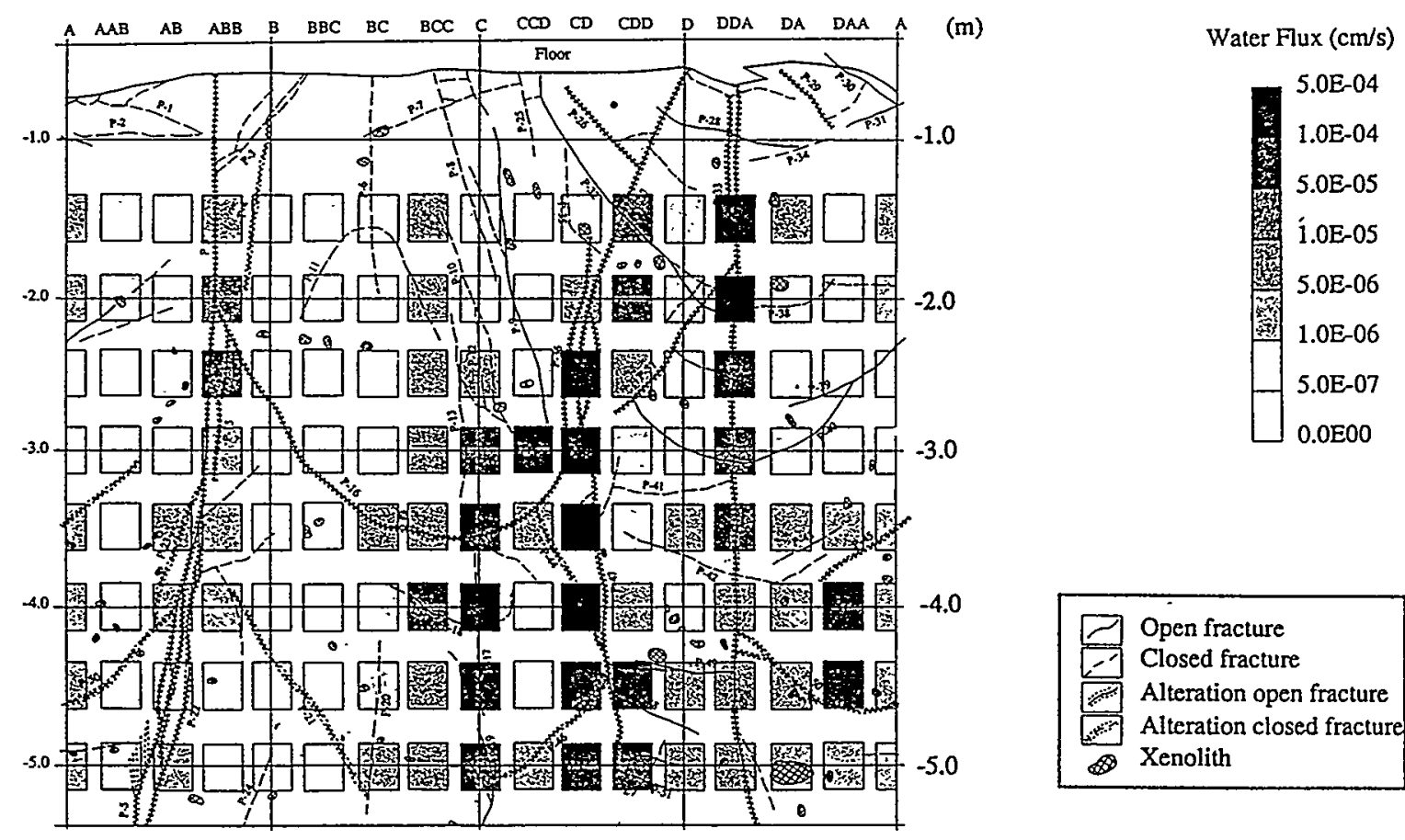

(b) With flooding pool: Total inflow is 183 to 283 liters/minute

Figure 6.6. Inflow distribution on the wall of the Test Pit measured in each zone by the weight gain of an absorbent textile patch that is attached to the rock surface (AAM method). 


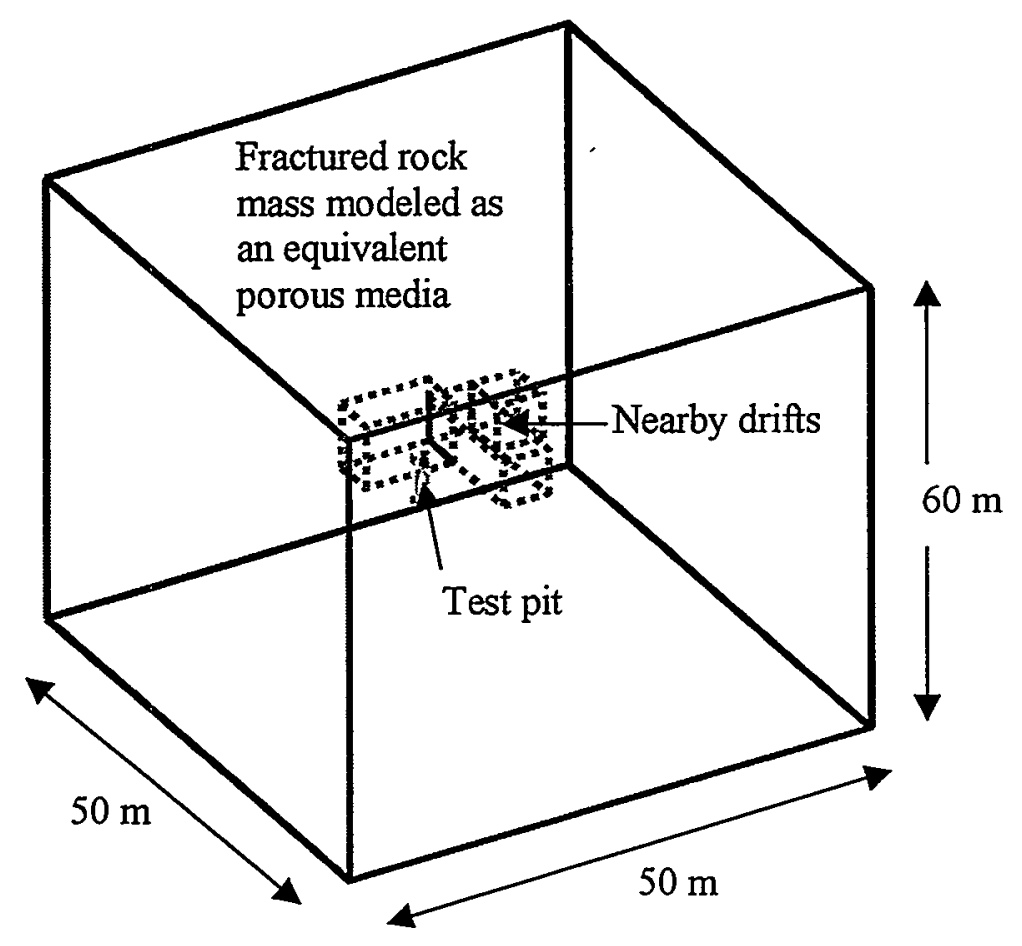

(a) Far field and model size

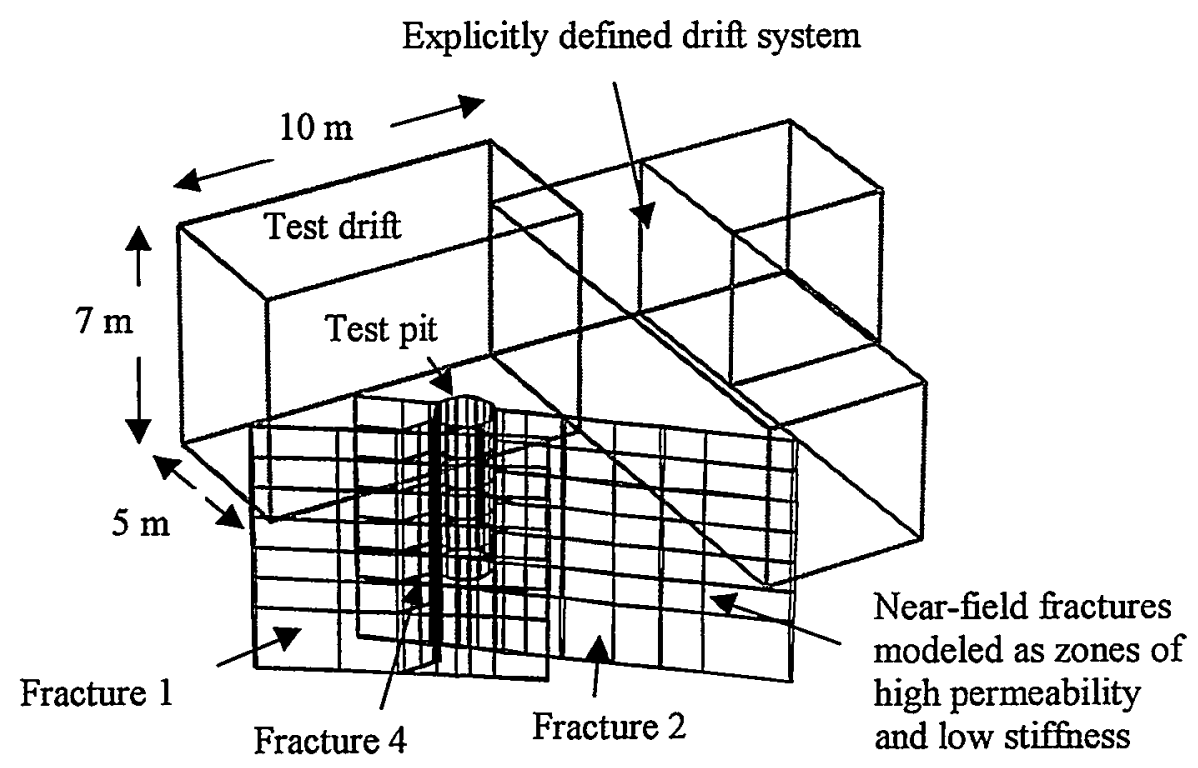

(b) Near-field drifts and fractures

Figure 6.7. Conceptual model for a three-dimensional analysis of the Kamaishi Mine Heater Test 


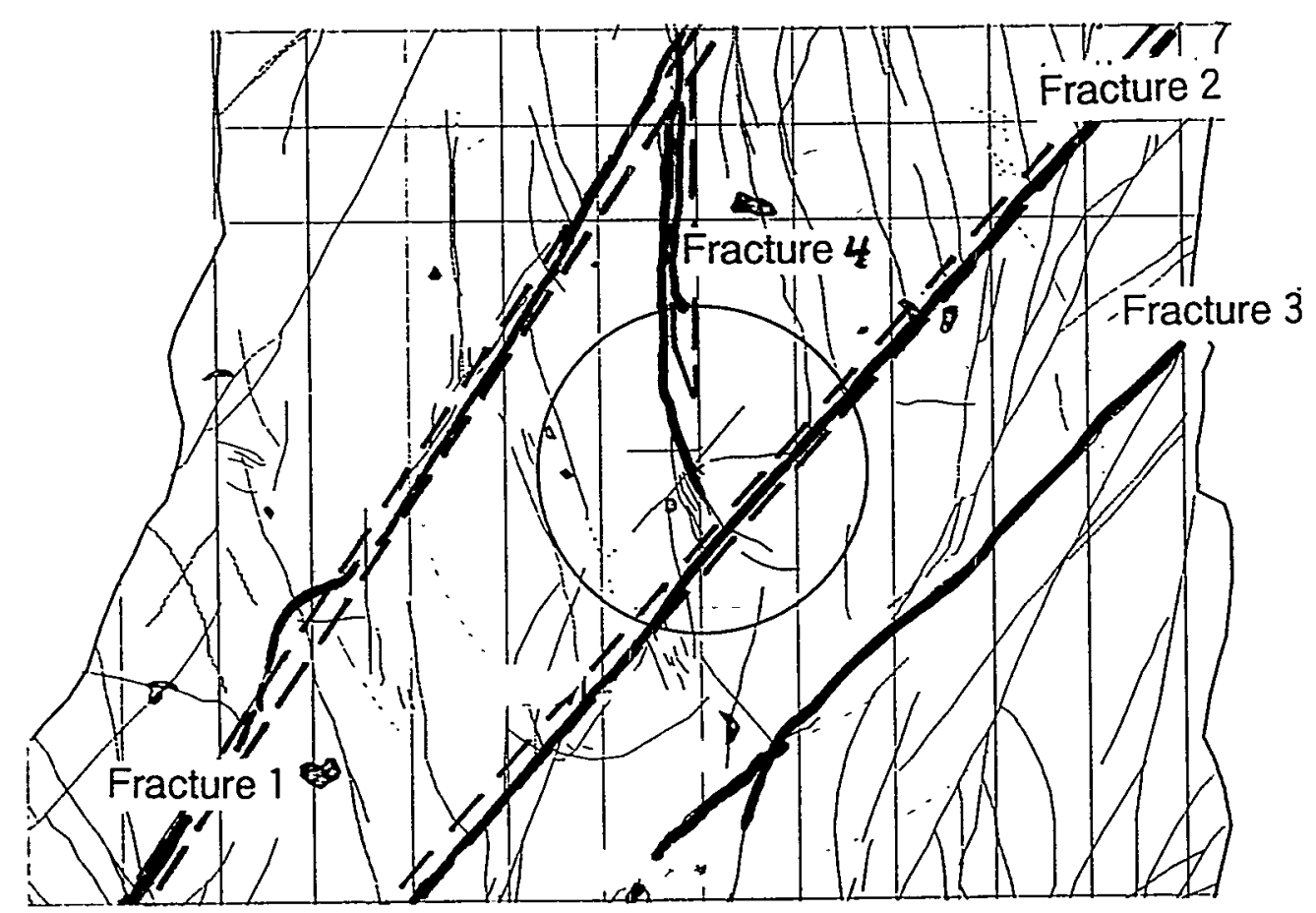

(a) Floor of the Test Drift.

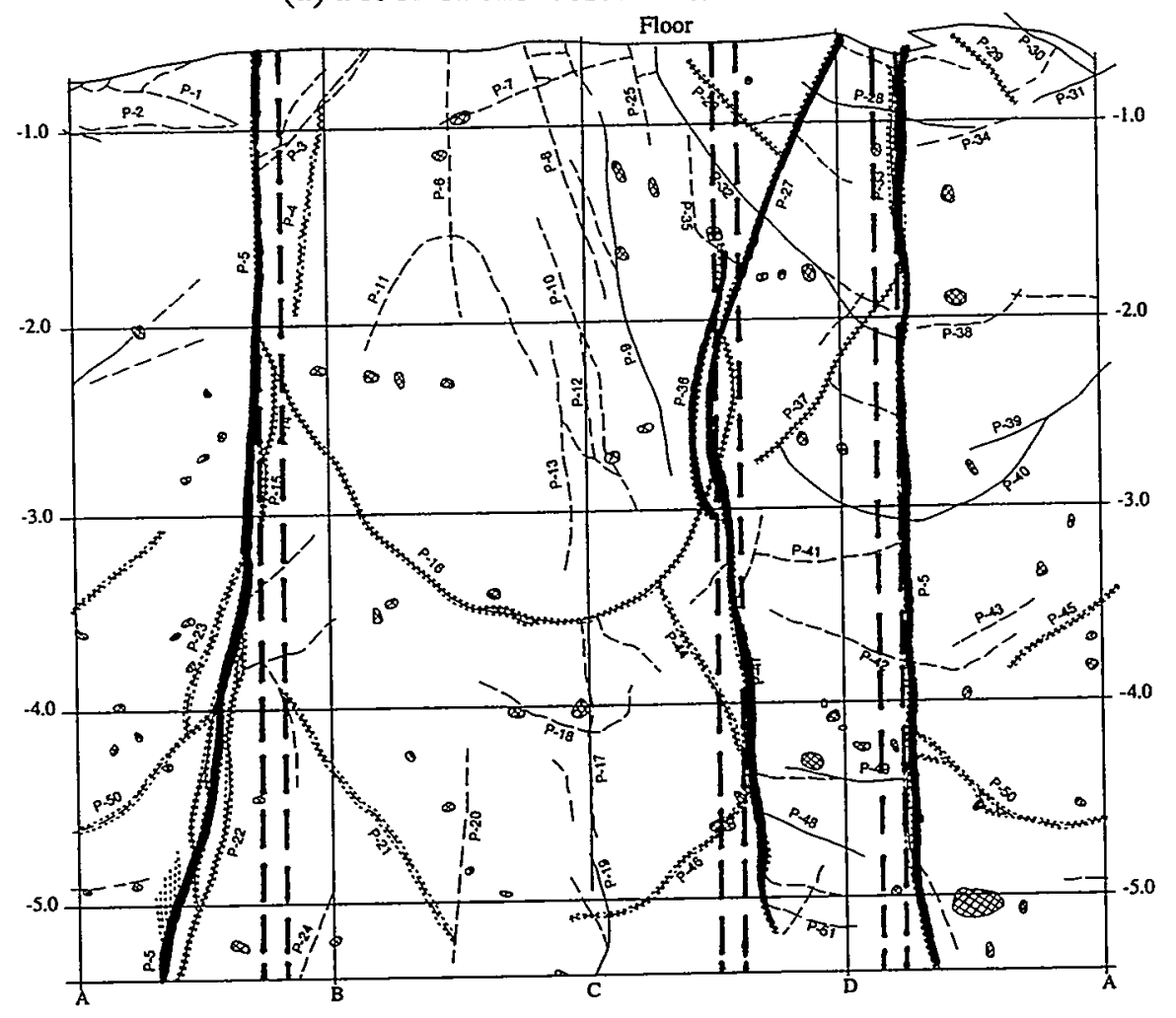

(b) Wall of the Test Pit.

Figure 6.8. Comparison of locations of discrete fractures in model (dashed lines) and fracture traces in the field. 
For a correct stress, fluid flow, and temperature calculation, it is essential to explicitly include the nearby drifts into the model. The model size can be determined without special consideration of the hydraulics because the inflow is dominated by the near-field high permeability fractures and the constant fluid pressure boundary on the floor of the Test Drift. As a result, model size can be determined solely on aspects of mechanical and thermal responses. For example, the distance to the constant stress or no-displacement boundary should be sufficiently large to avoid any boundary affects on the mechanical response near the Test Pit. Owing to those criteria, and the above discussion on the importance of the near-field fractures, a conceptual model is constructed according to Figure 6.7. Figure 6.8 compares the fracture geometry of the model to the fractures mapped in the field. It reveals that the model is a simplification of the reality, because we cannot represent the exact geometry and properties of the fracture. These conditions lead to our choice of a simpler fracture model with zones of high permeability and low mechanical stiffness. 


\section{Calibration of rock mass properties at Kamaishi Mine}

The rock properties in the near-field are calibrated using the measurements of inflow and displacement after excavation of the Test Pit. This calibration is Task $2 \mathrm{~B}$ in the DECOVALEX project, and the calibrated properties will be used for modeling of the heater test and Task $2 \mathrm{C}$ presented in Section 8 of this report.

\subsection{Finite-element model and boundary conditions}

The rock mass is modeled as an equivalent anisotropic continuum with a few of the main fractures introduced according to the conceptual model developed in Section 6 (Figure 6.7). The finite element model, presented in Figure 7.1a, consists of 6,500 elements and 7,400 nodal points, and the dimensions are $60 \times 60 \times 50$ meters. A near-field rock volume with dimensions $5 \times 5 \times 8$ meters is defined where three fractures have been discretized (Figure 7.1b). These represent Fractures 1 and 2, which were also included in the two-dimensional modeling of Task 2 . In addition, Fracture 4 has been included to capture the extra zone of high inflow into the Test Pit.

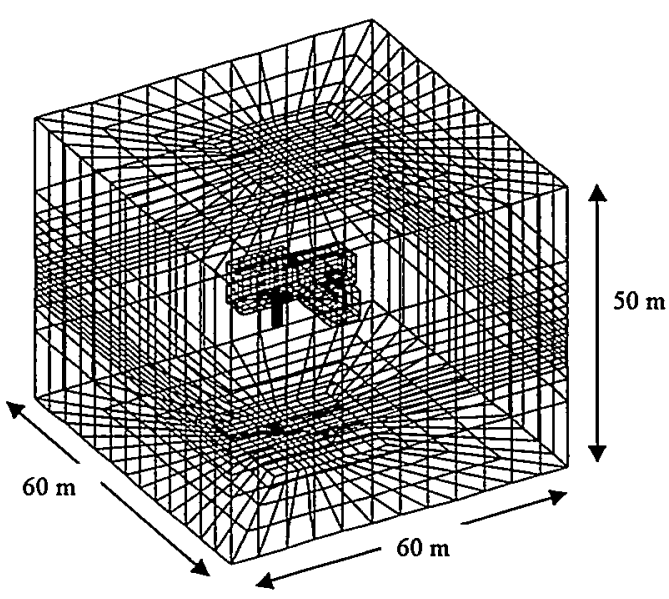

(a) Whole model
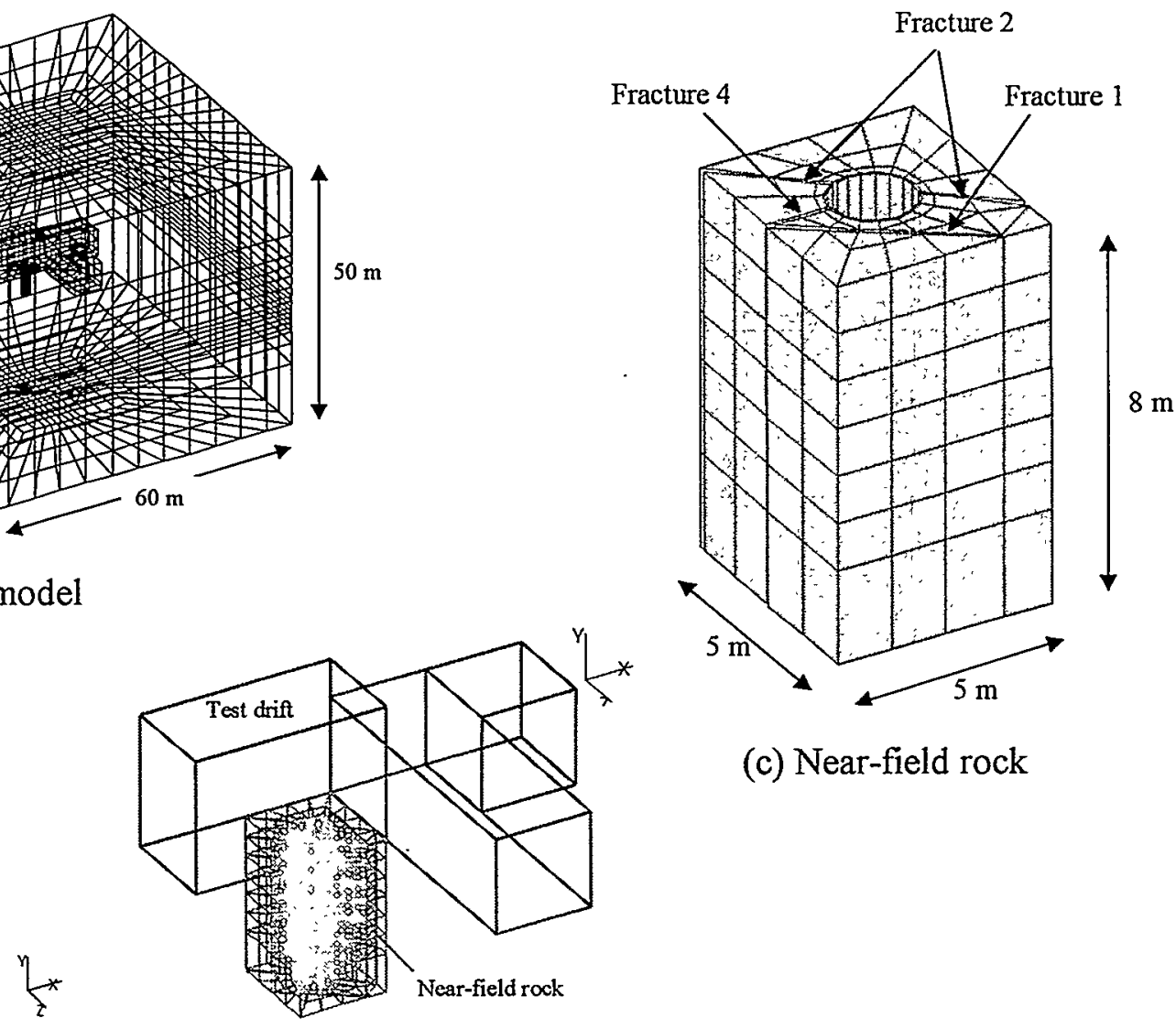

(c) Near-field rock

(b) Location of near-field

Figure 7.1. Finite element model for modeling of excavation and inflow into the Test Pit and for calibration of near-field properties. 
The outer boundaries are restricted from moving and the initial stress field according to field measurements is presented in Figure 3.1c. Fluid pressure on the outer boundaries of the model in set to $0.3 \mathrm{MPa}$, and the pressure in the drifts and the Test Pit is kept equal to zero (Figure 7.2). On the floor of the Test Drift, a constant pressure corresponding to the water column of the 30-cm-deep flooding pool is applied.

The modeling was conducted with the following calculation steps (Figure 7.3):

1) Excavation of the drifts.

2) Partial excavation of the Test Pit down to a depth of 1 meter.

3) Full excavation of the Test Pit down to a depth of 5 meters.

Steps 2 and 3 are modeled to calculate the radial convergence of the Test Pit for comparison to field measurements. In the field, convergence anchors were installed on the Test Pit wall at a depth of 1 meter, and the convergence was measured during the continuing excavation of the Test Pit to a depth of 5 meters. The inflow was measured after Step 3.

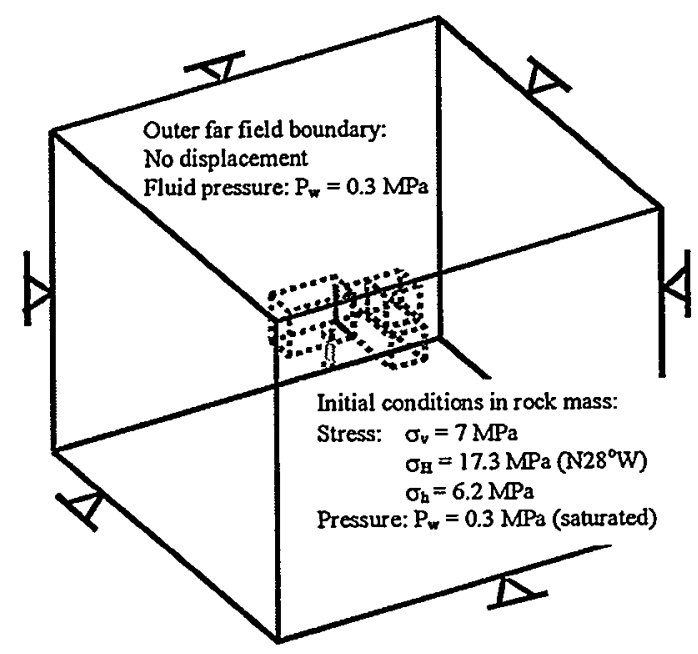

(a) Outer boundaries and rock mass

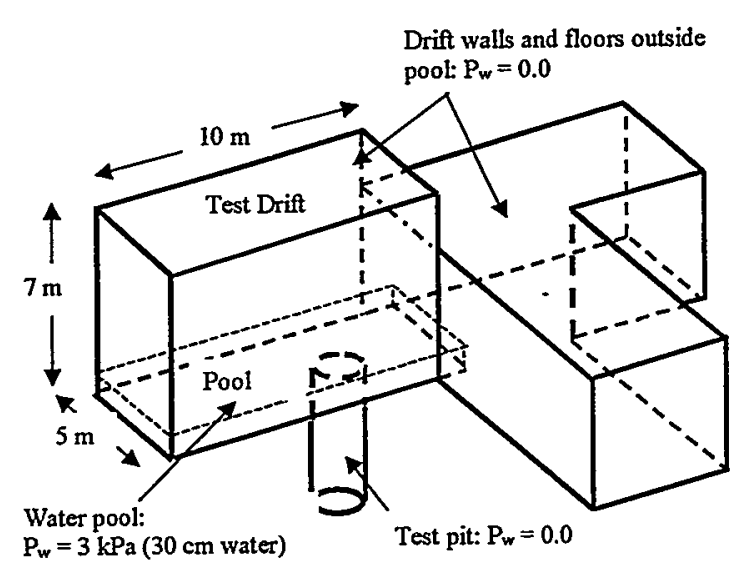

(b) Drifts and test pit.

Figure 7.2. Boundary and initial conditions for the finite element simulation.

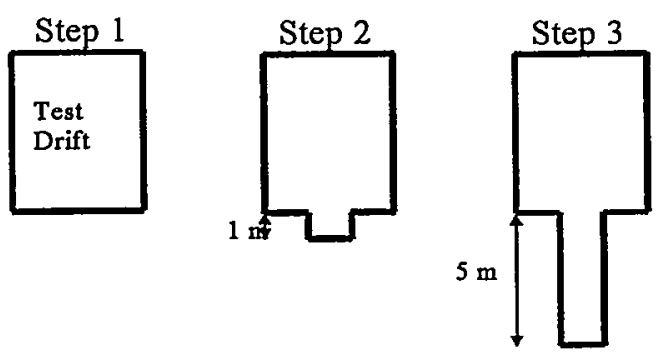

Figure 7.3. Calculation steps for modeling of excavation sequence. 


\subsection{Material properties and calibration method}

Table 7.1 presents far-field properties that are fixed and near-field properties that are initially set to reasonable values as a starting point for further calibration. The deformation modulus of the rock mass is $50 \%$ of the Young's modulus for the intact rock. This is a reasonable value for the rock mass and stress situation at the test site. Similar values of deformation modulus have also been obtained by in situ borehole expansion tests at the test site (Fujita et al., 1996). No experimental tests have been conducted to determine the mechanical properties of the mineral-filled main fractures (Fujita $\mathrm{el} \mathrm{al}$., 1996b). The values of the shear and normal stiffness in Table 7.1 are low but reasonable, considering that the fractures in the field contains filling of soft minerals up to a width of $20 \mathrm{~mm}$.

The far-field hydraulic permeability is fixed according to the cross-hole field measurements conducted at the Kd-90 drift, located about 100 meters away from the test area (Chijumatsu et al., 1997). The hydraulic aperture of $50 \mu \mathrm{m}$ is estimated based on the previous modeling in Task $2 \mathrm{~A}$.

Table 7.1. Initially Values of Parameters for Further Model Calibration.

\begin{tabular}{|l|l|}
\hline \multicolumn{1}{|c|}{ Parameter } & \\
\hline Young's modulus of rock, $\mathrm{E}_{\mathrm{RM}}$ & Value \\
\hline Poisson's ratio of rock, $v_{\mathrm{RM}}$ & $30 \mathrm{Gpa}$ \\
\hline Normal stiffness of fractures, $\mathrm{kn}$ & 0.3 \\
\hline Shear stiffness of fractures, $\mathrm{ks}$ & $30 \mathrm{GPa} / \mathrm{m}$ \\
\hline Biot's effective stress constant, $\alpha$ & $3 \mathrm{GPa} / \mathrm{m}$ \\
\hline Hydraulic permeability of far field rock, $k_{w}$ & 1.0 \\
\hline Hydraulic permeability of near-field rock, $k_{w}$ & $1 \cdot 10^{-15} \mathrm{~m}^{2}$ \\
\hline Hydraulic aperture of fractures, $b_{h}$ & $1 \cdot 10^{-16} \mathrm{~m}^{2}$ \\
\hline
\end{tabular}

It is not possible to calibrate the mechanical properties using stress or displacement because those measurements are not consistent over the drift floor and in some cases actually contradict each other (Fujita $e l$ al., 1997). Therefore, the mechanical modeling will be conducted with fixed mechanical material properties and with comparison of results only in a few measurement points.

The hydraulic properties in the near-field is calibrated using the measurement of inflow into the Test Pit with a flooded floor, which will be the condition at the heater test in Task $2 \mathrm{C}$. The calibration is carried out by variation of the hydraulic permeability of fractures and rock matrix within the near-field block shown in Figure 7.1b. The rock matrix is assumed to have an anisotropic conductivity with its maximum in the southwest direction, which is the dominating fracture orientation in the near field (see Figure 3.1b). The permeabilities of the fractures are calibrated over an upper and lower level (as shown in Figure7.4).

The model is calibrated against the distribution of inflow on the wall of the Test Pit, which was measured by absorbent textile patches (AAM method) attached to the wall. In 
addition to the AAM measurements, the total inflow into the Test Pit was measured with an independent device to be between 183 and 283 liters/day. The former value was obtained in a measurement carried out only one day before the AAM method measurement and is therefore thought to be more consistent. The total inflow collected in all textile patches is only 86 liters/day because they covered only about $50 \%$ of a four meter high section of the five meter high Test Pit wall (Figure 7.5). Therefore, the model is calibrated for the inflow through the 4 meters the AAM covered section, which is about 172 liters/day (Figure 7.5).

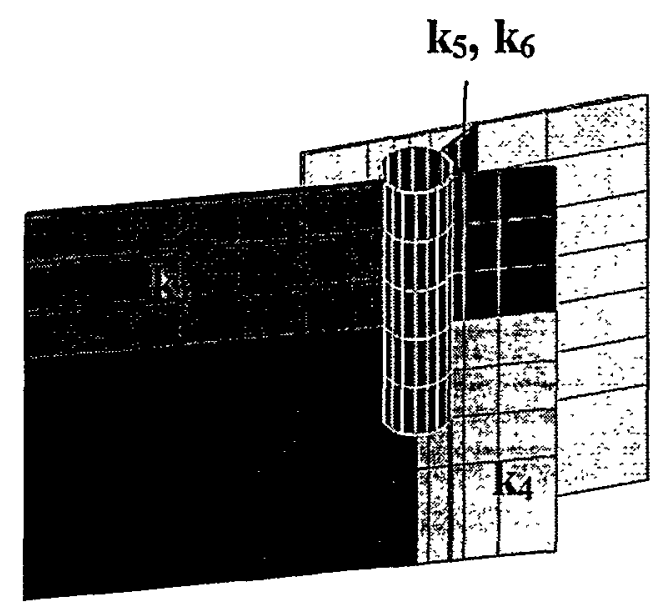

Figure 7.4. Fracture permeability is varied at each fracture that intersects the Test Pit at an upper and lower level.

Total inflow: 183 1/day (July 1) : 283 1/day (July 9)

Total inflow according to AAM method: 86 1/day (July 2)

Textile patches cover $50 \%$ of $21 \mathrm{~m}^{2}$ of the pit wall

Should have $86 \mathrm{y} / \mathrm{day} * 2=172 \mathrm{y} / \mathrm{day}$

from the 4 meters AAM section

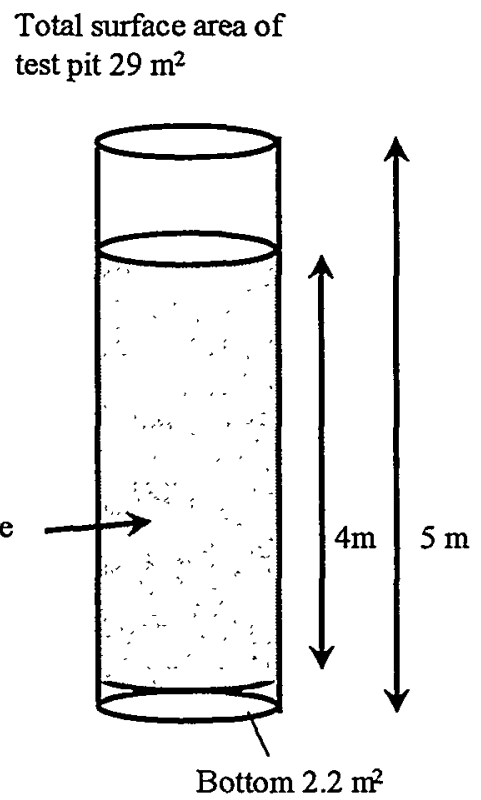

Figure 7.5. Outline of the AAM test area on the wall of the Test Pit. 


\subsection{Results of Rock stress}

Figure 7.6 and 7.7 presents the maximum and minimum principal compressive stresses before and after excavation of the Test Pit. The maximum principal compressive stress increases below the Test Drift as a result of the redistribution of stress around the drift opening. On the floor, the maximum principal compressive stress is therefore about 25 $\mathrm{MPa}$ while the minimum principal stress is smaller than $1 \mathrm{MPa}$. Figures $7.8-7.10$ present vectors and contours of stresses at 3 meters depth below the floor of the Test Drift. A zone with a maximum compressive stress of $45 \mathrm{MPa}$ can be seen at the wall of the Test Pit. This stress is much less than the uniaxial compressive stress of the rock material and should therefore not cause any rock failure. In Figure 7.8, a zone of tensile stress can be seen at the Test Pit wall with stresses up to $4 \mathrm{MPa}$ of tension. Such tensile stress may cause tensile failure and create local extension fractures. In addition, the stress relief in this zone can open existing fractures and increase the rock permeability.

\subsection{Results of Displacements}

Figure 7.11 presents incremental displacement in the near-field rock resulting from the excavation of the Test Drift in Step 1 and from excavation of the Test Pit in Step 3.

Figure 7.11a shows that, when the Test Drift is excavated, the floor is heaving upwards into the drift with a maximum displacement in the order of $2 \mathrm{~mm}$. A vertical shift occurs in the contour plot at Fracture 2 because of a fracture shear that is on the order of $0.1 \mathrm{~mm}$. Figure 7.11b shows that the excavation of the Test Pit causes only local displacements around the Test Pit, mostly in one horizontal direction.

Figure 7.12 shows that the rock converges with a maximum of $1.6 \mathrm{~mm}$ in the direction of the maximum compressive stress. In this maximum displacement direction, displacements can be seen in the rock several meters from the Test Pit wall. Fracture 1 opens near the Test Pit on the order of $0.5 \mathrm{~mm}$. Fracture 2, on the other hand, closes by about $0.7 \mathrm{~mm}$ at the east wall and $0.2 \mathrm{~mm}$ at the west wall. Also, Fracture 4 closes about $0.7 \mathrm{~mm}$. The largest shear displacement is induced in Fracture 4 in the horizontal direction and is about $0.5 \mathrm{~mm}$.

Figure 7.13 and Table 7.2 present an overview of the calculated and measured horizontal displacements at a few points in the near field. The magnitude of the displacements is small in general and less than a few $\mathrm{mm}$ in both modeling and measurements. However, the directions of the displacements do not match except at the joint-deformeter F2. In the modeling, the general mechanical response is that the rock is moving toward and into the excavated opening. The field measurements showed no consistent pattern. At the wall of the Test Pit, the rock is expanding; away from the Test Pit, displacements and strain are very small and appear be dependent on local heterogeneities at the measurements points.

Figure 7.14 presents comparison of interval axial displacements along boreholes KBM4 and KBM5, which are in the vertical direction. The measurements as well as the modeling shows that the borehole is expanding slightly, with incremental displacements (over $1 \mathrm{~m}$ of the borehole) of less than $0.04 \mathrm{~mm}$. The comparison can be considered as satisfactory, at least with respect to the magnitude of the maximum displacement. 


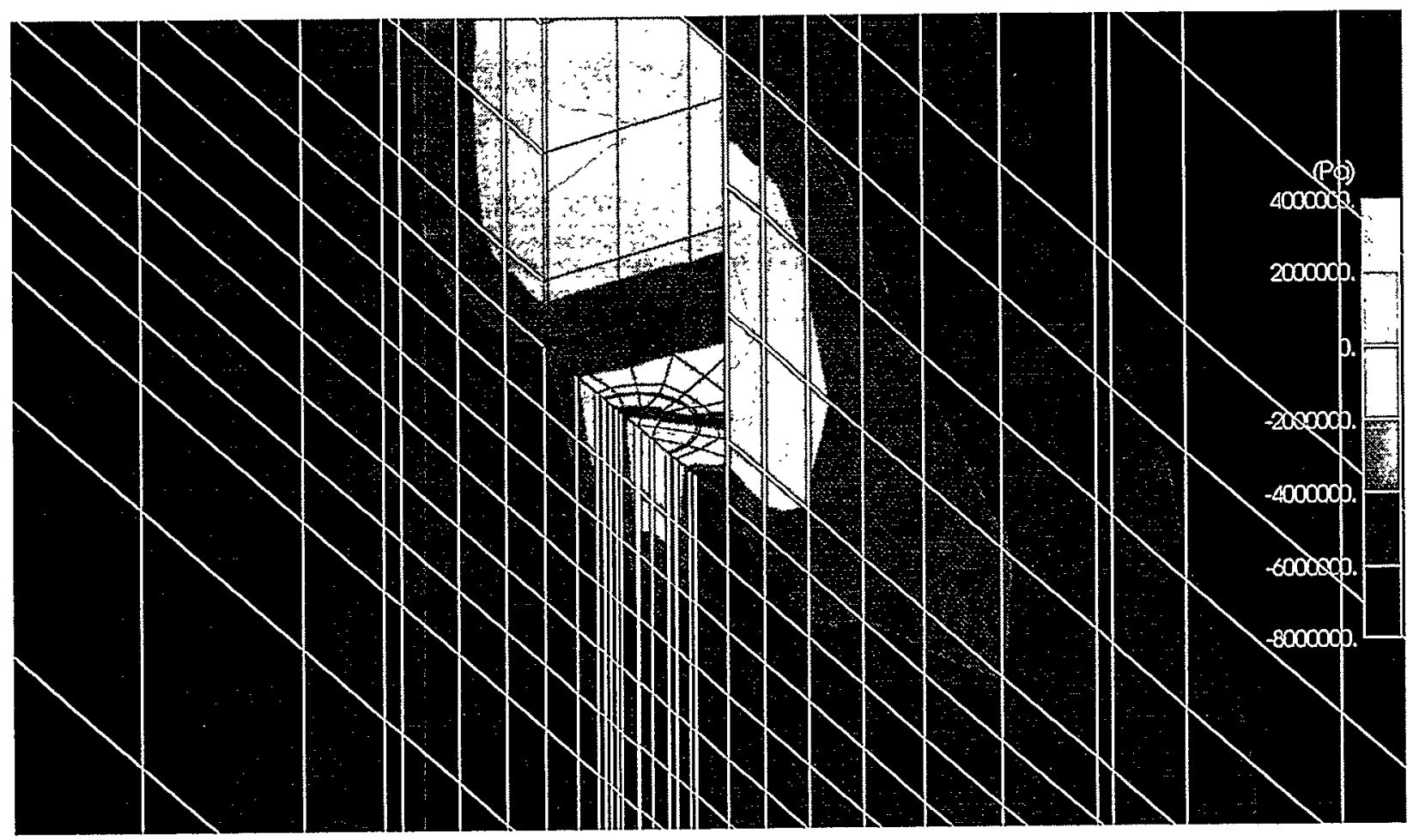

(a) Before excavation of the Test Pit

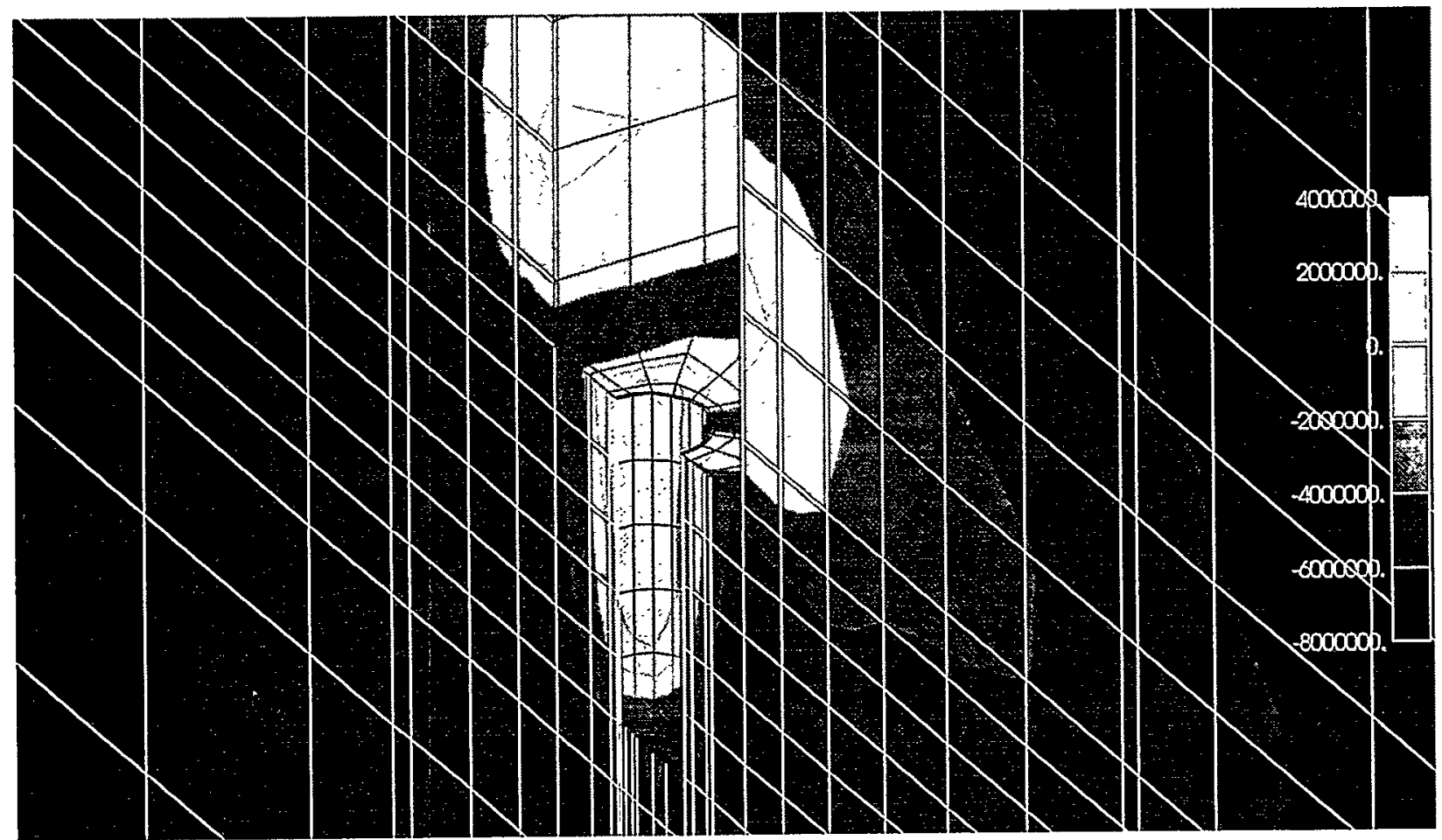

(b) After excavation of the Test Pit

Figure 7.6. Modeling results of minimum principal stress in a vertical section cutting perpendicular to the axis of test drift before and after excavation of the Test Pit. 


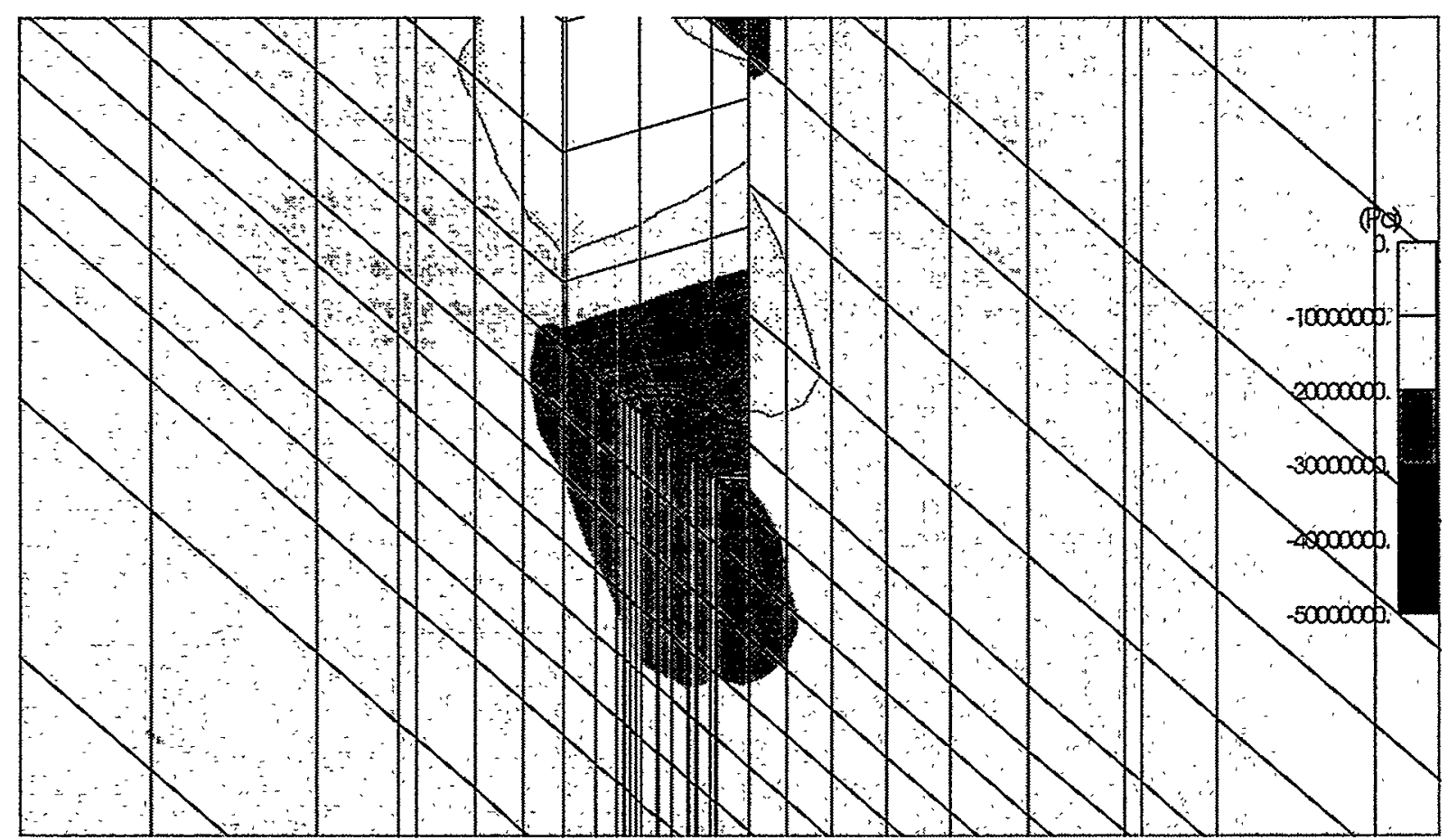

(a) Before excavation of the Test Pit

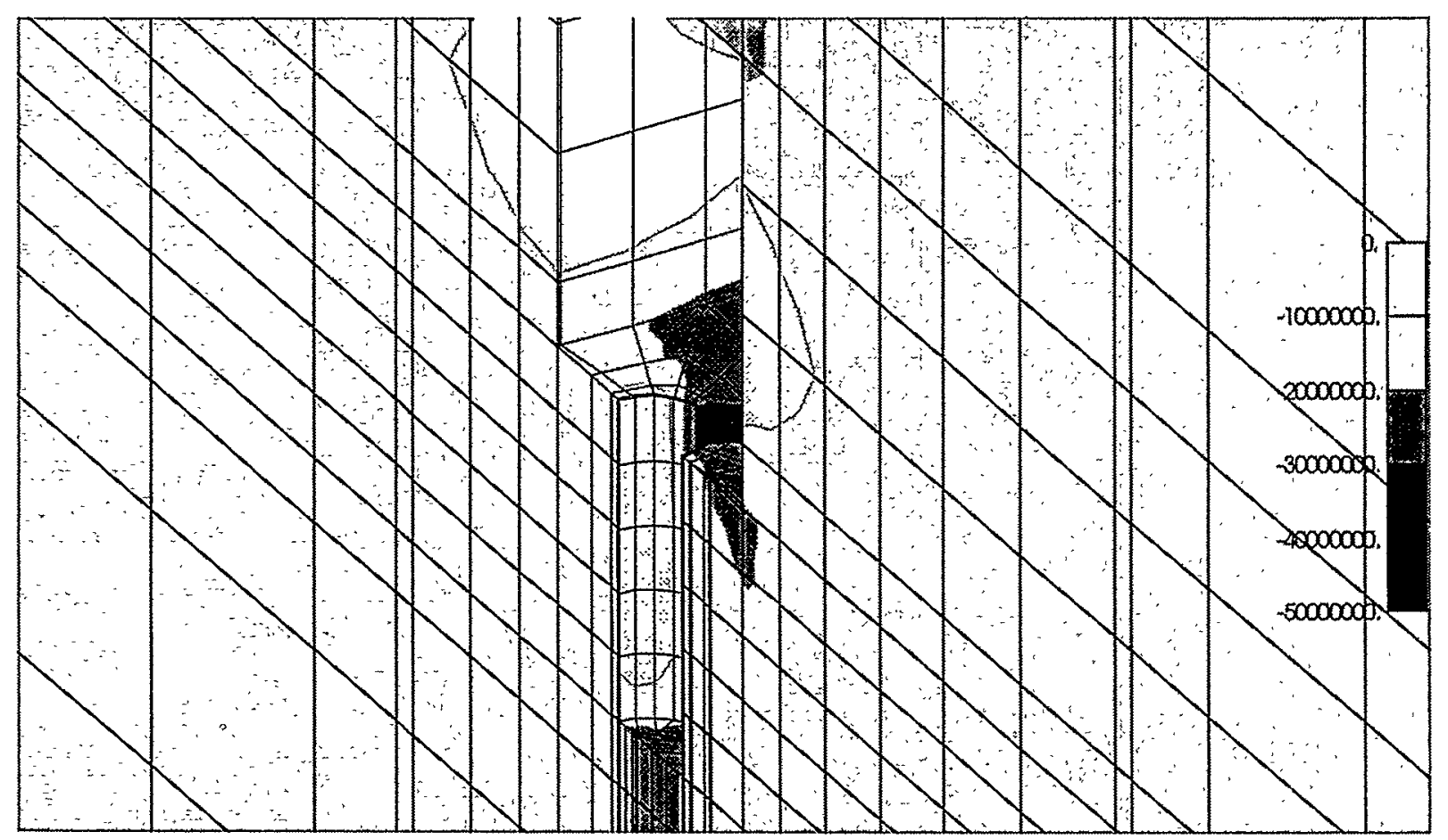

(b) After excavation of the Test Pit

Figure 7.7. Modeling results of maximum principal stress in a vertical section cutting perpendicular to the axis of the Test Drift before and after excavation of the Test Pit. 

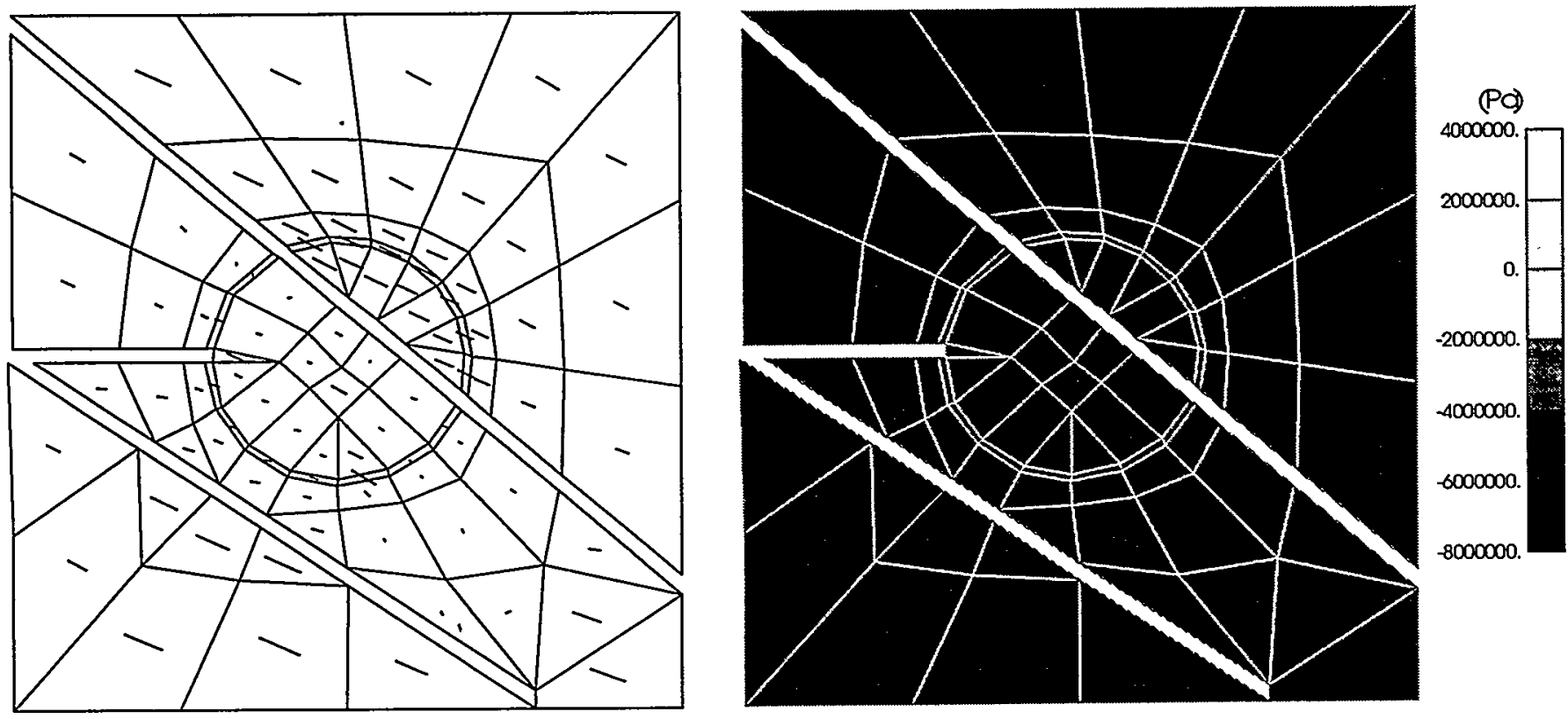

(a) Before excavation of the Test Pit
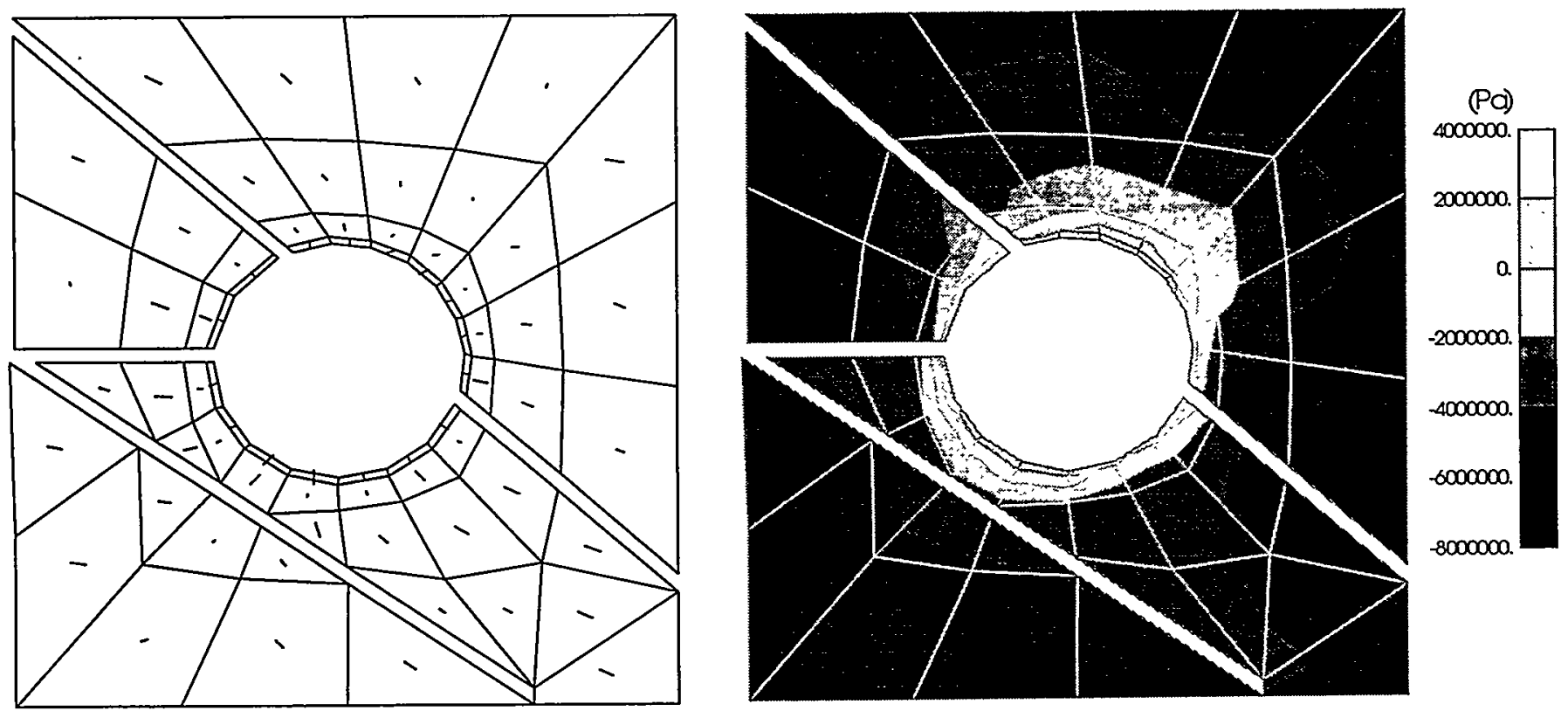

(b) After excavation of the Test Pit

Figure 7.8. Modeling results on a horizontal section at 3 meters below floor of the Test Drift, with vectors and contours of minimum compressive principal stress. 

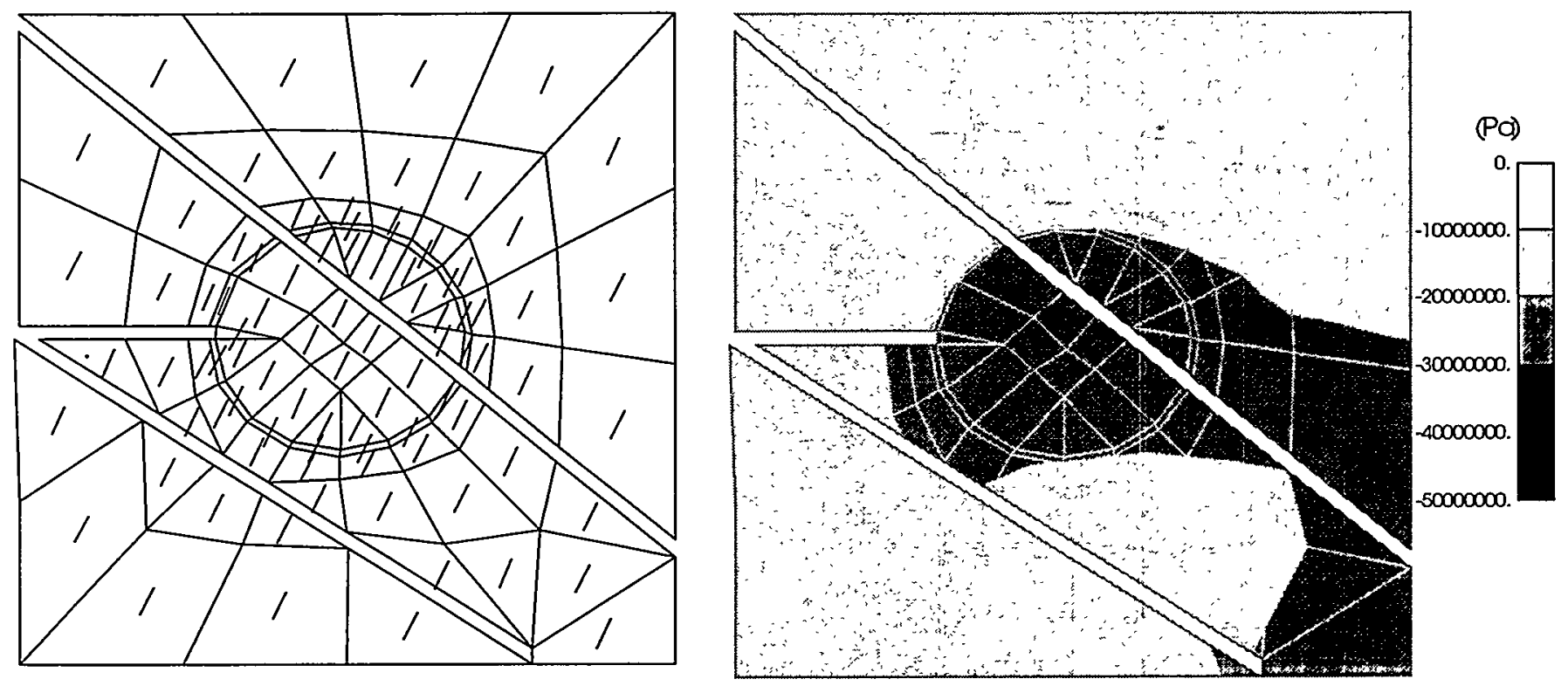

(a) Before excavation of the Test Pit
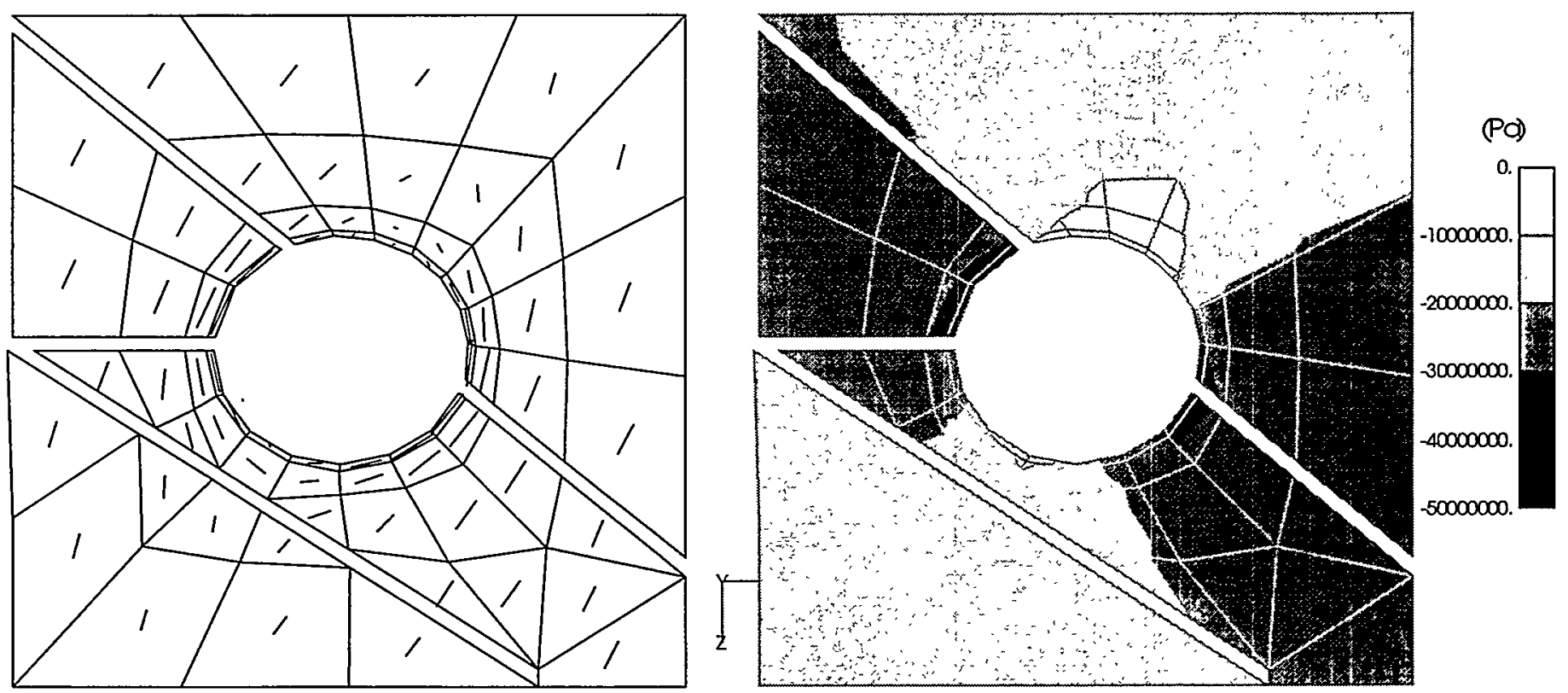

(b) After excavation of the Test Pit

Figure 7.9. Modeling results on a horizontal section at 3 meters below floor of the Test Drift, with vectors and contours of maximum compressive principal stress. 

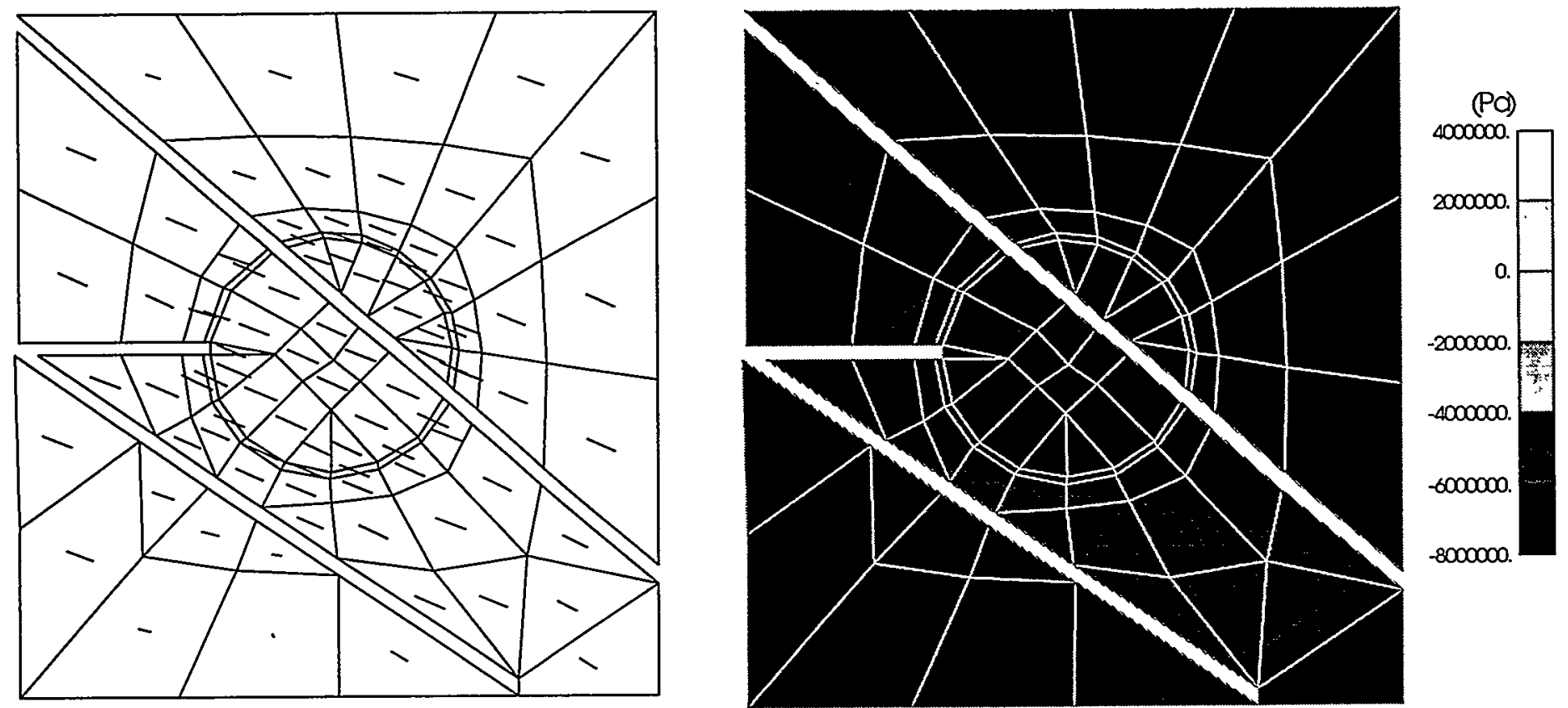

(a) Before excavation of the Test Pit
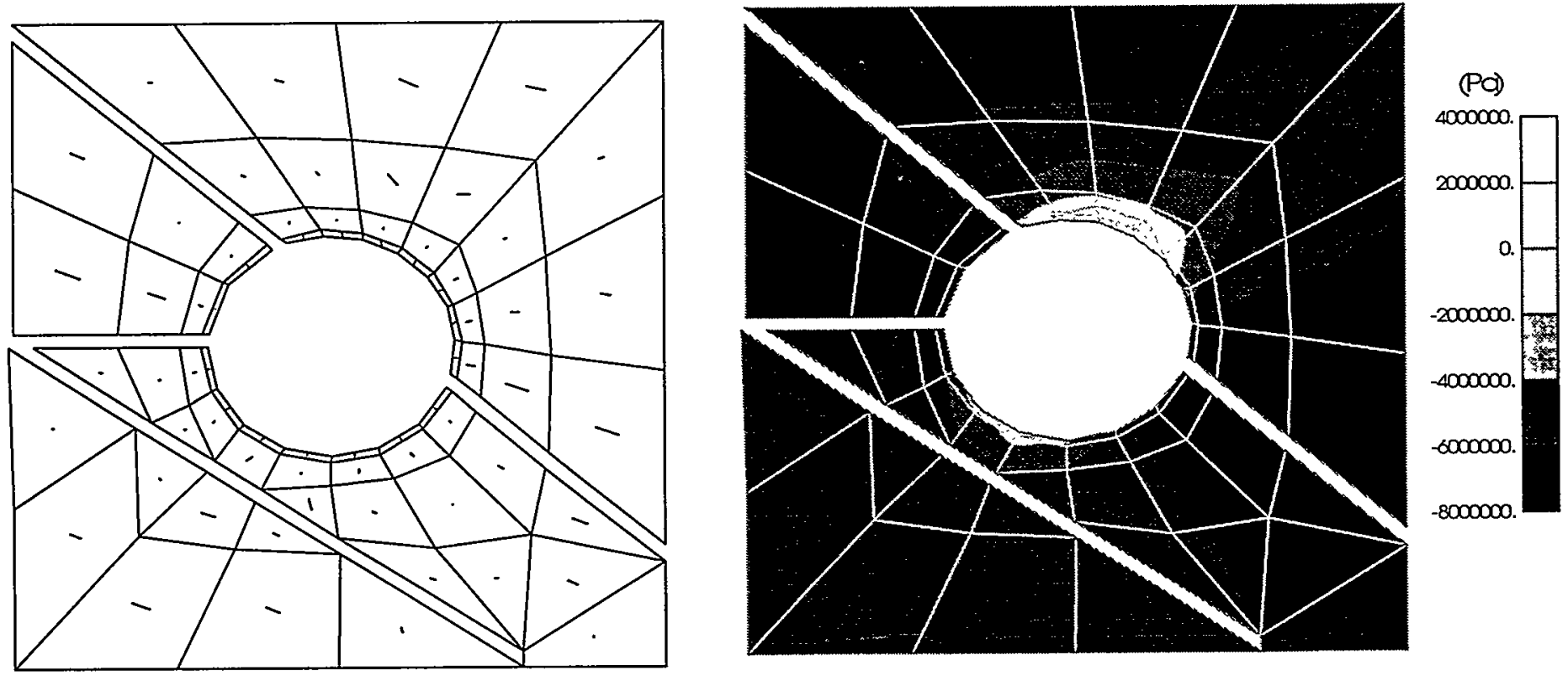

(b) After excavation of the Test Pit

Figure 7.10. Modeling results on a horizontal section at 3 meters below floor of the Test Drift, with vectors and contours of intermediate principal stress. 


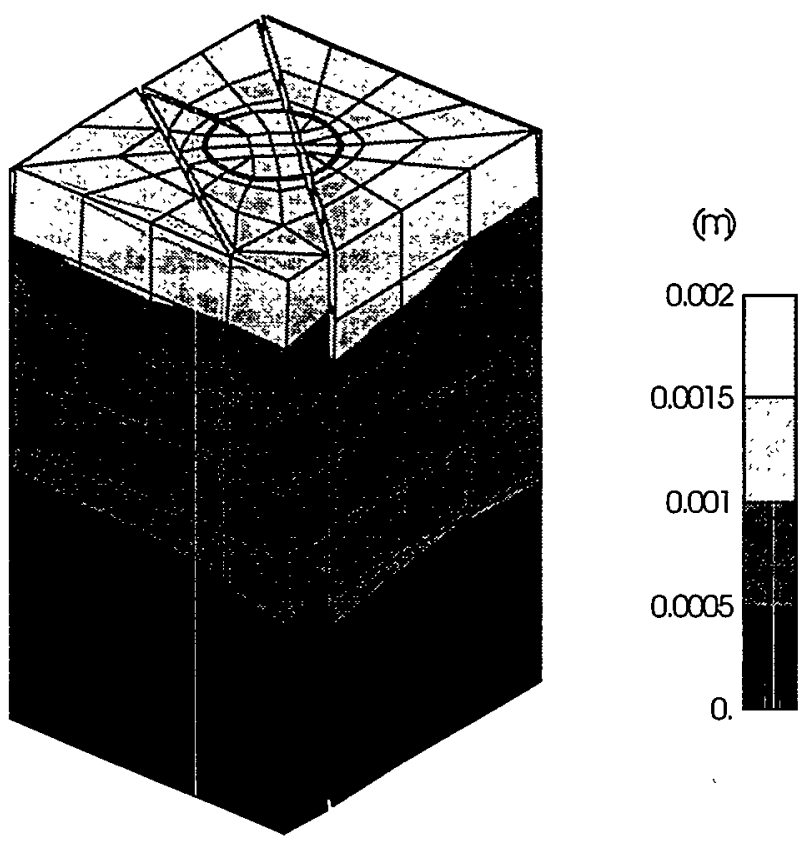<smiles>[Z]C([X])C</smiles>

(a) Before excavation of the Test Pit
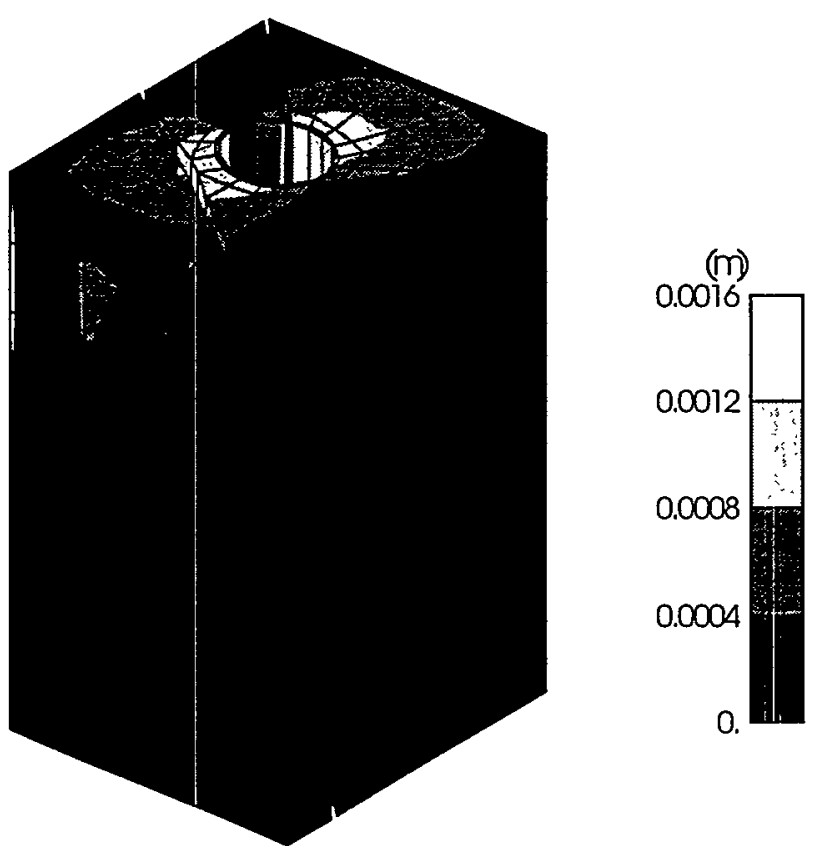<smiles>[X]C([CH])C</smiles>

(b) After excavation of the Test Pit

Figure 7.11. Modeling results of incremental displacement (a) due to excavation of the Test Drift and (b) due to excavation to the Test Pit. 

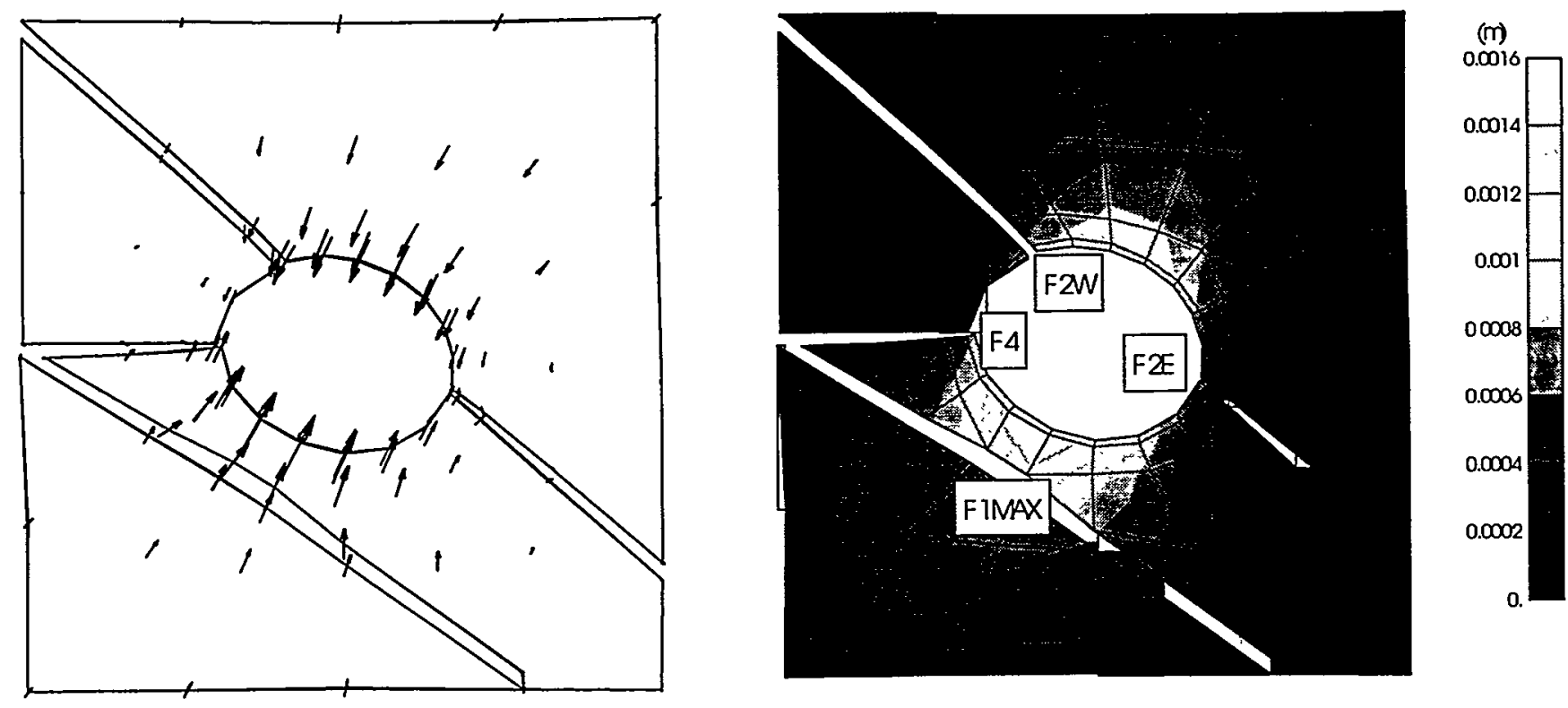

(a) Floor of test drift
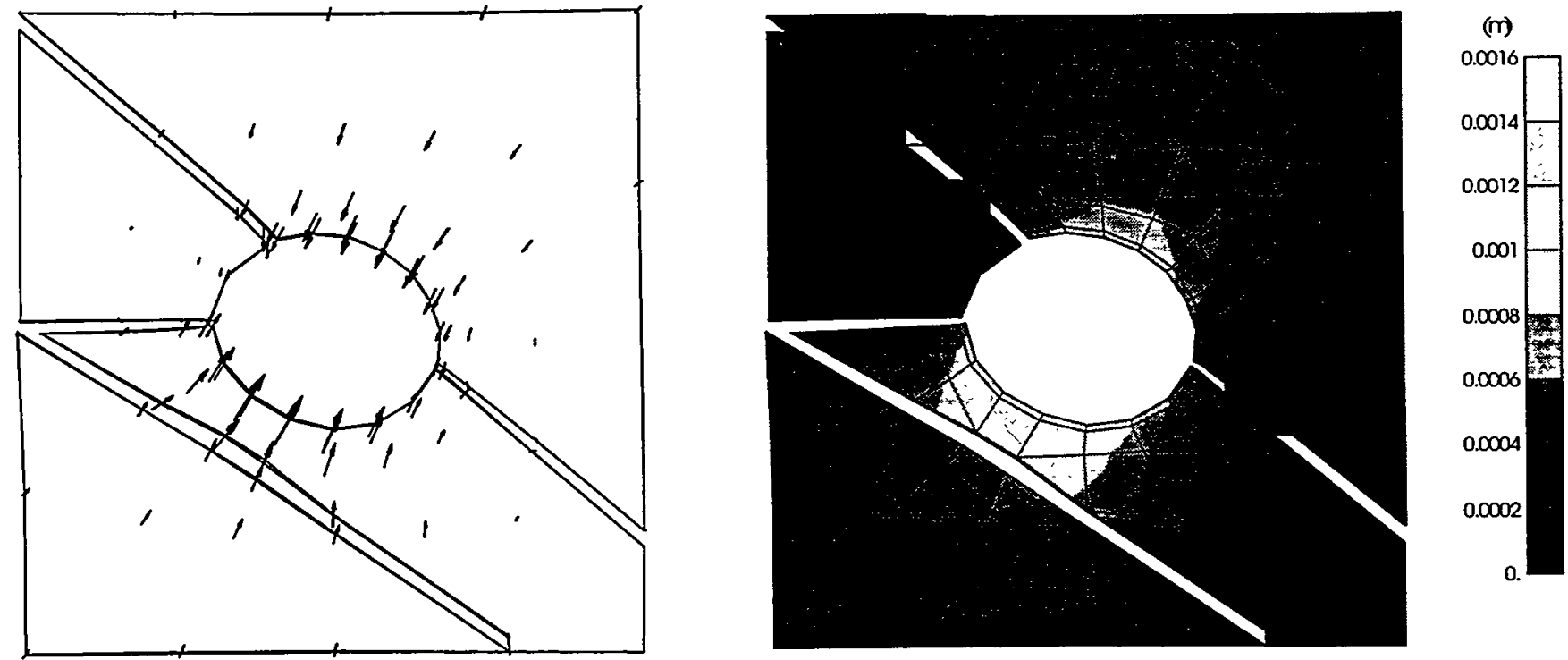

(b) 3 meters below floor

Figure 7.12. Modeling results of incremental displacement due to excavation of the Test Pit. 


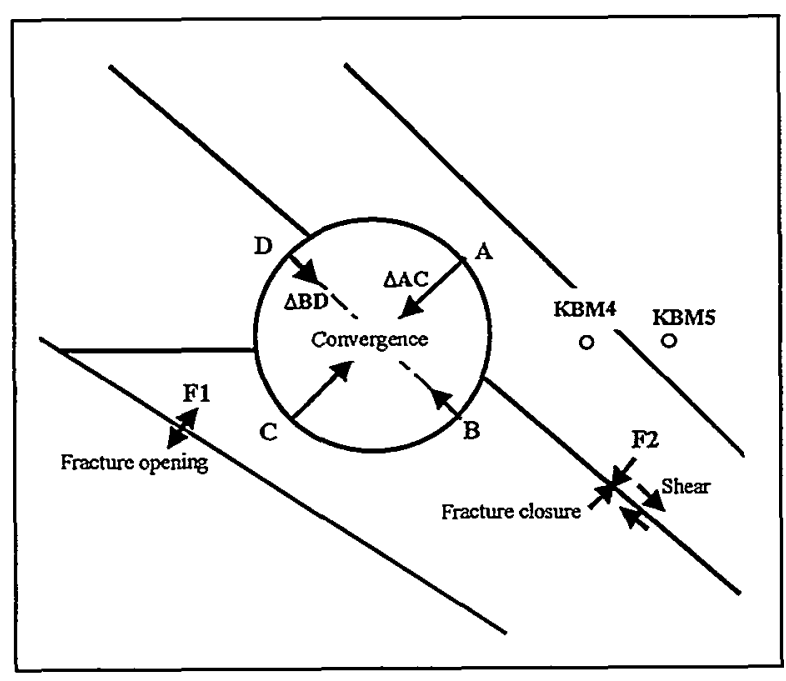

n+ (a) Modeling

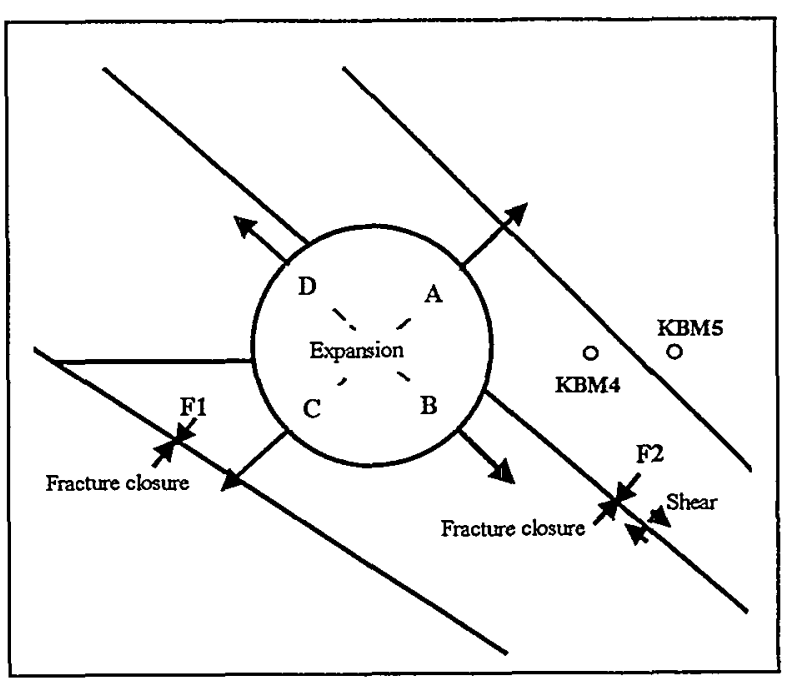

(b) Measurements

Figure 7.13. Directions of calculated and measured horizontal displacements in a few points. Magnitudes of displacements are given in Table 7.2.

Table 7.2. Modeling and Measurement of Displacements (see directions in Figure 7.13).

\begin{tabular}{|l|l|l|l|}
\hline $\begin{array}{l}\text { Measuring } \\
\text { device }\end{array}$ & $\begin{array}{l}\text { Type of } \\
\text { displacement }\end{array}$ & $\begin{array}{l}\text { Modeling } \\
(\mathrm{mm})\end{array}$ & $\begin{array}{l}\text { Measurement } \\
(\mathrm{mm})\end{array}$ \\
\hline $\begin{array}{l}\text { Convergence } \\
\text { (at 0.5 m depth) }\end{array}$ & $\Delta \mathrm{AC}$ & -1.7 & 1.9 \\
\cline { 2 - 4 } $\begin{array}{l}\text { F1 } \\
\text { (at 3 m depth) }\end{array}$ & Normal & -0.4 & 1.2 \\
\cline { 2 - 4 } & Horizontal shear & -0.104 & -0.060 \\
\cline { 2 - 4 } & Vertical shear & 0.039 & Failed \\
\hline \multirow{2}{*}{ F2 $3 \mathrm{~m}$ depth) } & Normal & -0.148 & -0.050 \\
\cline { 2 - 4 } & Horizontal shear & 0.034 & -0.073 \\
\cline { 2 - 4 } & Vertical shear & 0.012 & 0.003 \\
\hline
\end{tabular}




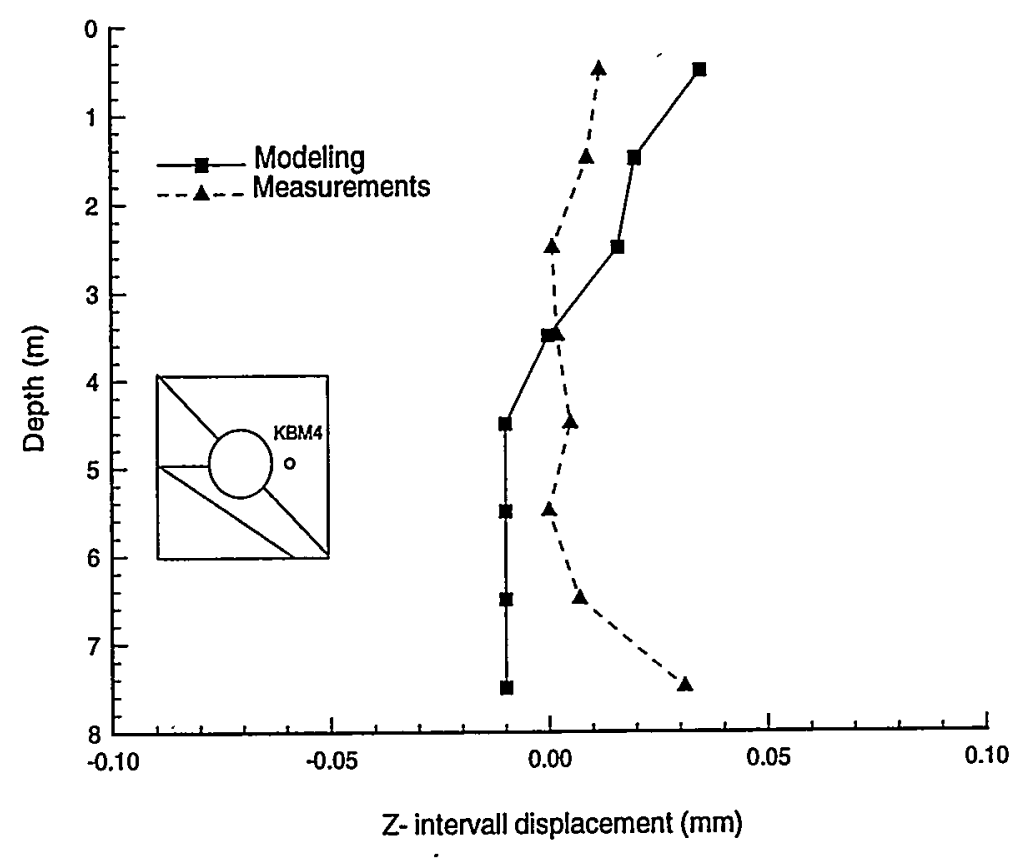

(a) KBM4

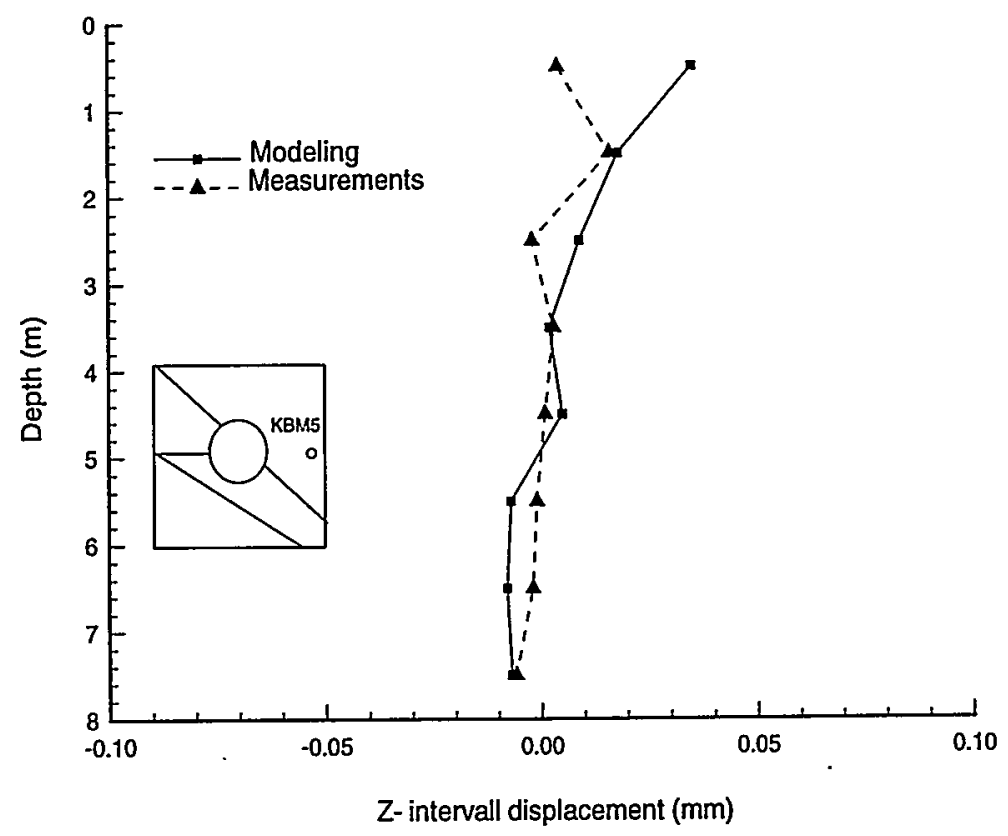

(b) KBM5

Figure 7.14. Comparison between modeling and measurements of axial interval displacement due to excavation of the Test Pit along borehole KBM4 and KMB5. 
A judgement of the modeling performance depends on the reliability of the measurements and the number of comparisons. It is clear that many of the displacement measurements actually contradict each other. Furthermore, the time history of the displacement measurement reveals that a large portion of the displacements in the rock was triggered at the initial stage of the full-face drilling of the Test Pit. This indicates that dynamic effects from the drilling operation may have caused the fractures to slip, creating a more or less randomly distributed displacement field in rock. Thus, the measured displacements in F1 and F2 in Table 7.2 may be triggered by dynamic events rather than by the quasi-static stress redistribution resulting from the excavation. It is, however, quite clear that the measurements show the Test Pit gradually expanding during excavation while modeling shows convergence. From basic rock-mechanics principles, the converging displacement mode obtained by modeling seems to be correct since the rock should be subjected to compressive stress. One possible explanation is that the measurements were only conducted between 4 points, and the displacements in these points may disagree from the general convergence behavior of the Test Pit. Displacement of individual block in the wall of the Test Pit may be important here. However, the measurements are too few and unsystematic to show the overall behavior of the rock near the Test Pit. Therefore, no firm judgment can be made about model performance in this case.

\subsection{Results of fluid flow}

The calibration was conducted according to the procedure presented in Section 7.2 and resulted in a best match for the hydraulic permeabilities in the near-field presented in Table 7.3. Figure 7.15 presents the fluid pressure distribution in a vertical section and the near-field rock for the calibrated model. The figure shows that the fluid pressure gradient is basically directed towards the excavations but is influenced by the high permeability fractures near the Test Pit. Figure 7.16 presents fluid pressure and flow vectors at 3 meters depth. Most of the flow takes place within fractures, which are represented by dark arrows in Figure 7.16. In the rock matrix, the flow is parallel to the direction of material anisotropy and is therefore not exactly perpendicular to the pressure gradient. Figure 7.17 presents the magnitude of flow velocity for the inflow into the Test Pit as a contour output from the modeling. However, for a more accurate comparison, the modeling result is plotted in the same format as the field results in Figure 7.18.

The results of the modeling in Figure 7.18b agree fairly well with the general pattern in Figure 7.18a of high and low inflow zones. However, Figure 7.19 presents a more visible comparison the field and modeling results in a scatter diagram with the area of each circle is here proportional to the square root of the inflow. The figure shows that the dominating inflow sections are at Fracture 2 on the upper west side and on the lower part of Fracture 4. On the other hand, Fracture 2 on the east side, has a much smaller inflow. A relatively permeable zone close to Fracture 4 (line $C$ in Figure 7.18a) could not be captured in the modeling because no discrete fracture has been included in the model at that location. This zone contains no apparent major fracture, but a number of small vertical fractures (Figure 6.6). 


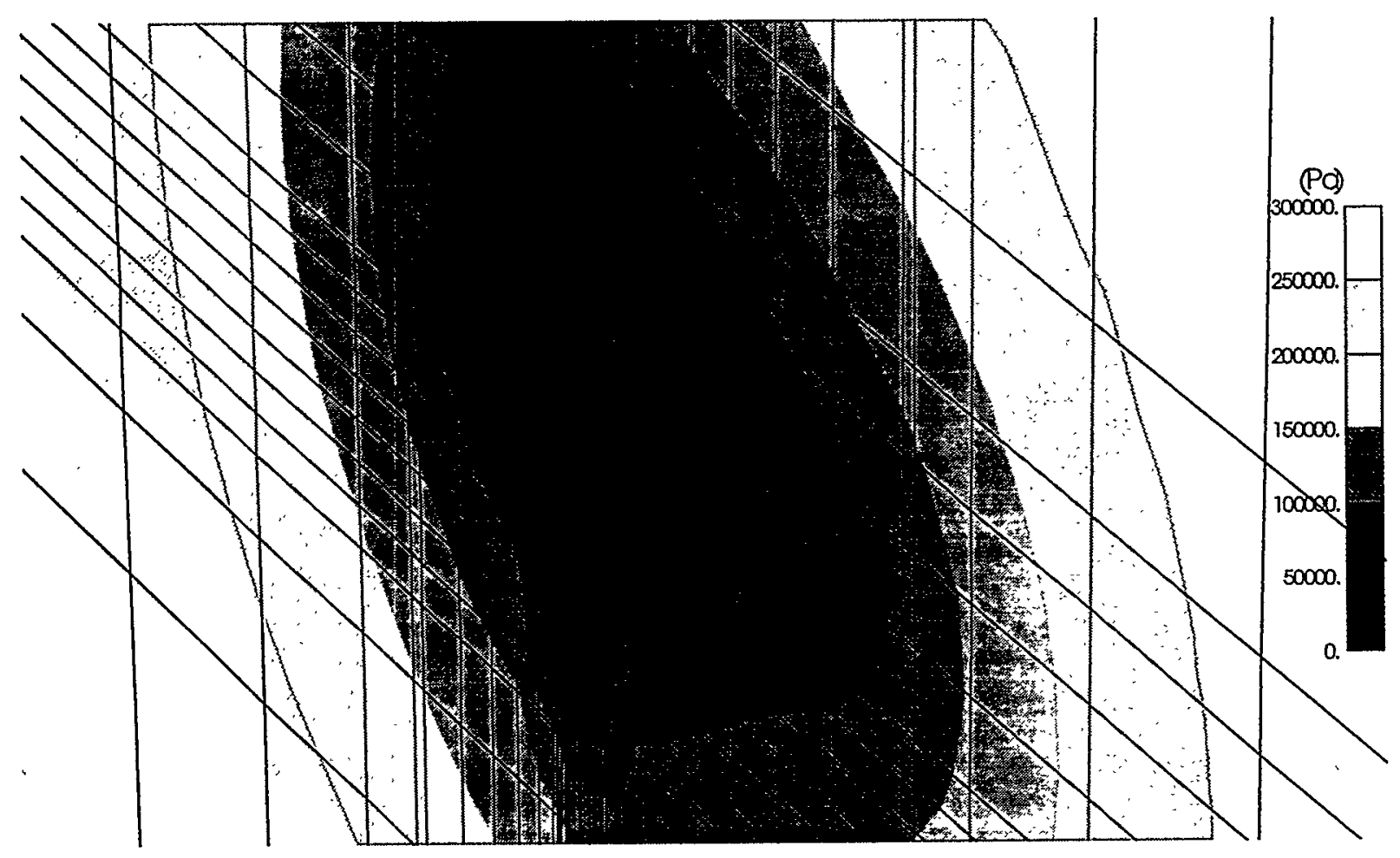

(a) Vertical section

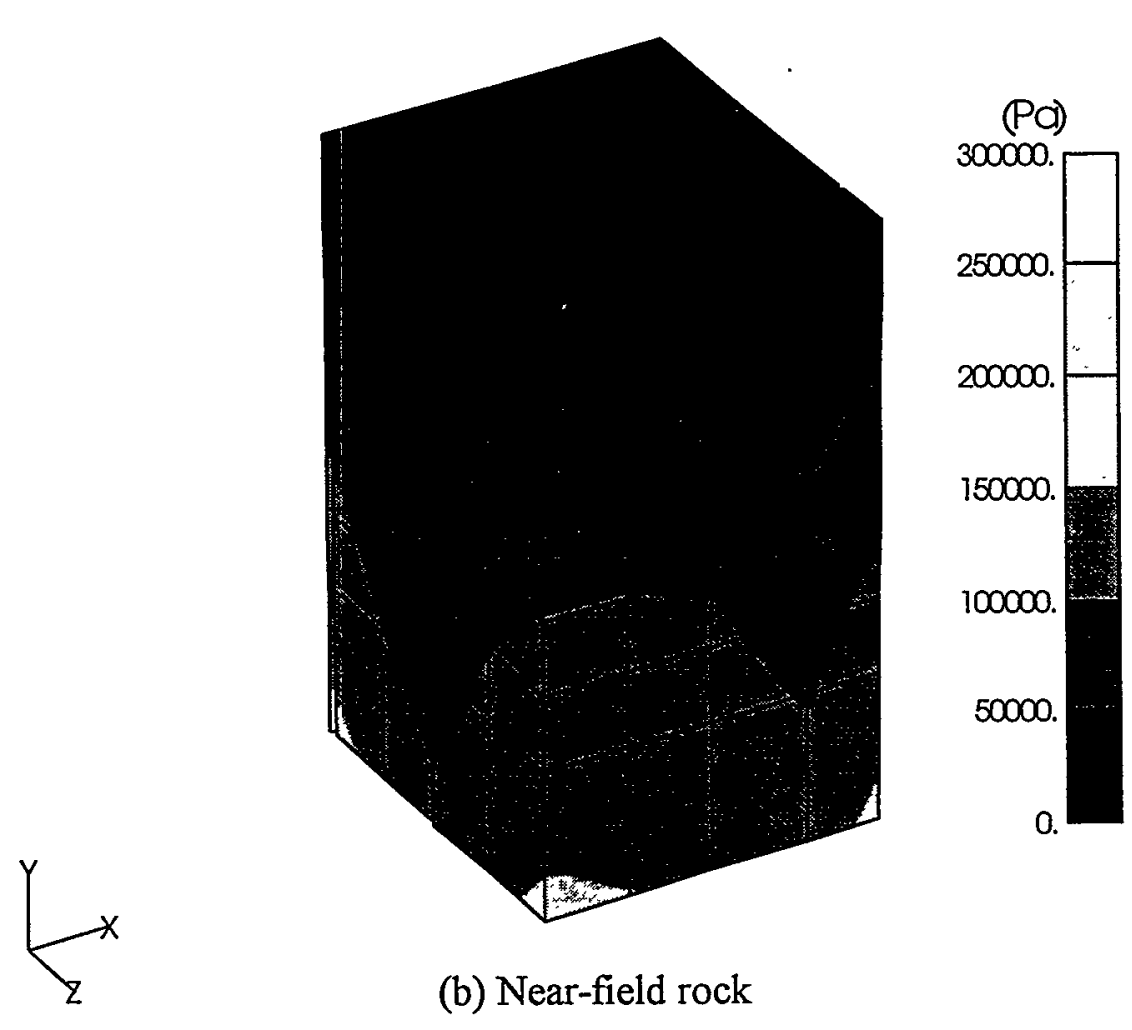

Figure 7.15. Modeling results of fluid pressure after $c$. :avation of the Test Pit and with the drift floor flooded. 

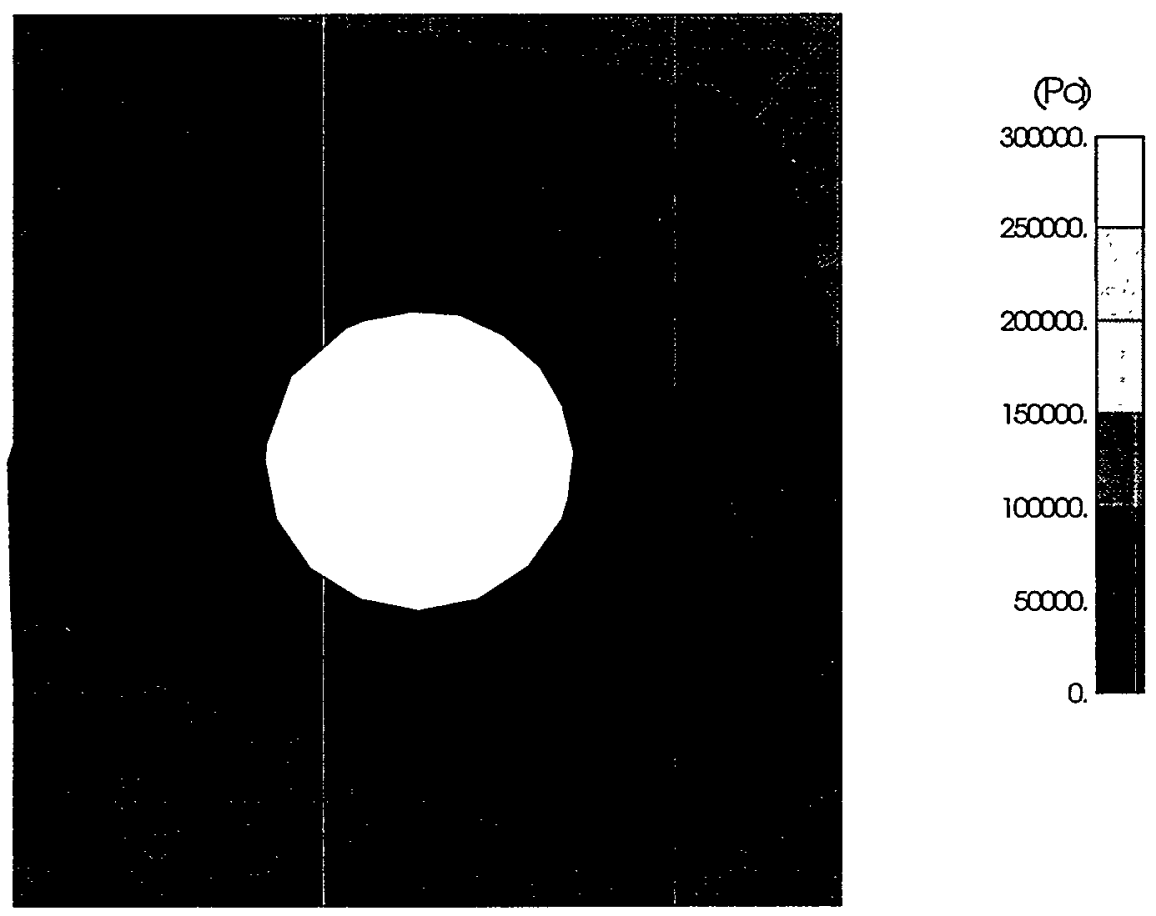

(a) Fluid pressure
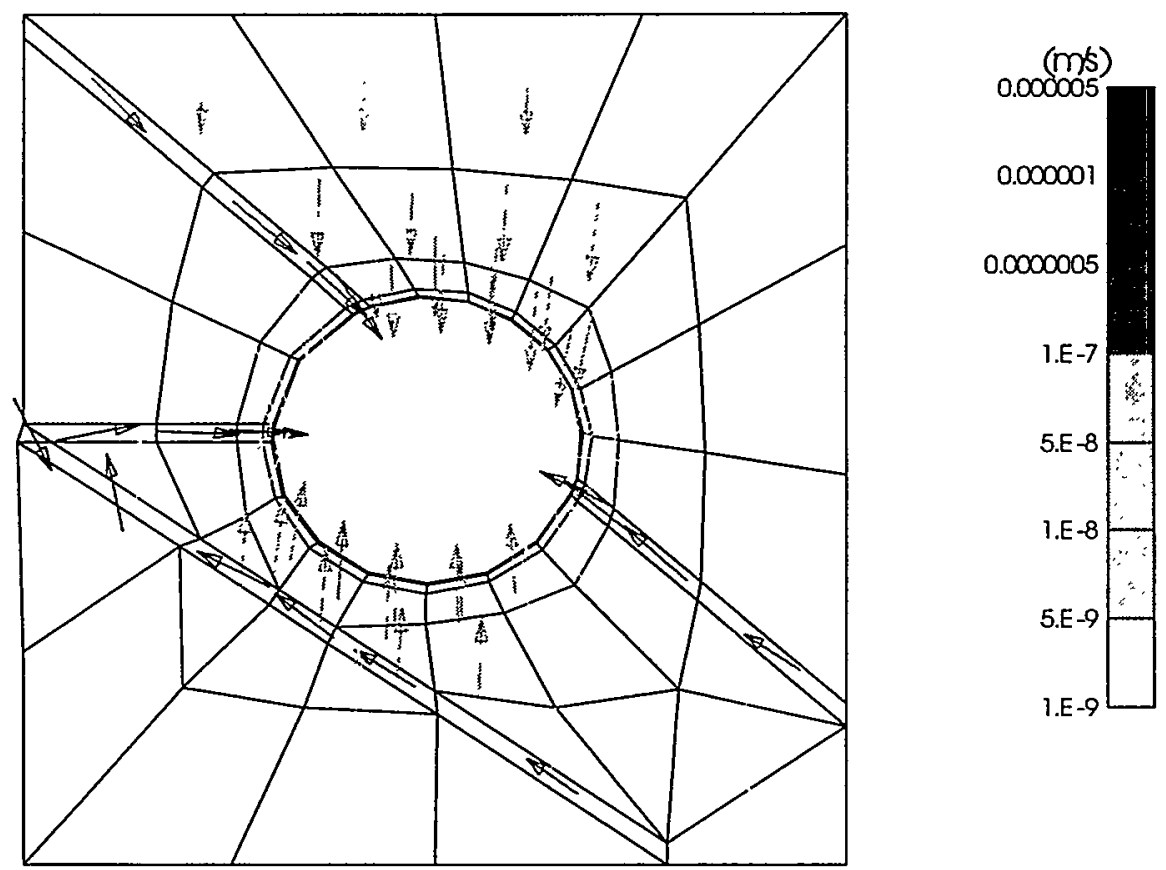

(b) Flow velocity

Figure 7.16. Modeling results of fluid pressure and flow vectors in the near field on a horizontal section at a 3 meters depth 

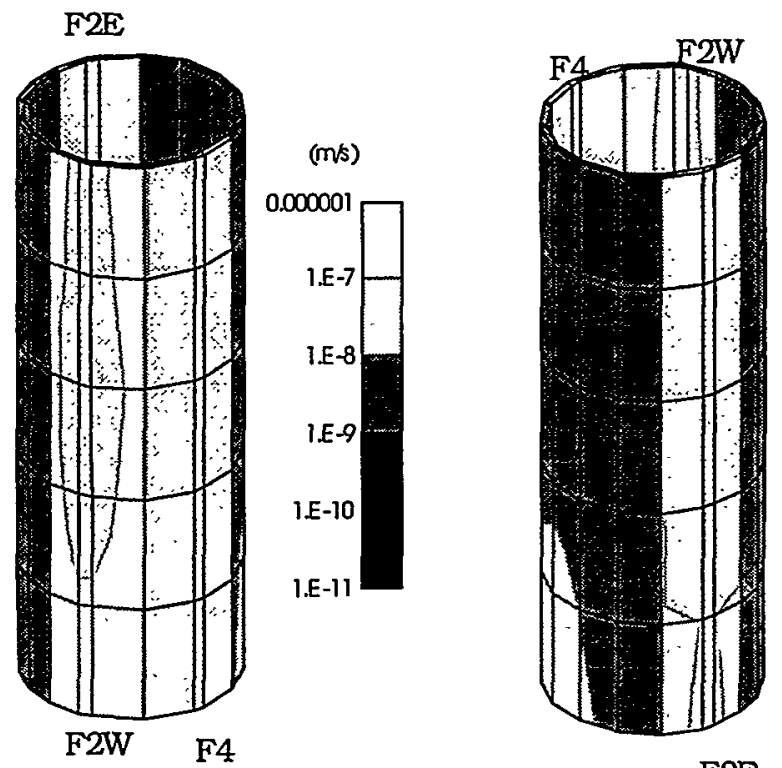

F2E

Figure 7.17. Modeling results of flow velocity into the Test Pit. The two pictures show the same results on the wall of the Test Pit but viewed from different angles.

The numerical modeling showed a zone tensile stress or very low compressive stress in this section of the Test Pit wall (see Figure 7.8 for the zone of low stress between the Test Pit wall and Fracture 1). The low stresses may increase the permeability by the opening of small fractures in this zone, which connects to the major conductor, Fracture 1. Hence, hydromechanical effects may cause the increased inflow along line $\mathrm{C}$ in Figure 7.18. However, there are no mechanical measurements to prove this hypothesis.

Table 7.3. Hydraulic Permeability and Equivalent Apertures Obtained by Calibration against the Inflow to the Test Pit.

\begin{tabular}{|l|l|l|}
\hline \multicolumn{1}{|c|}{ Material } & \multicolumn{1}{|c|}{$\begin{array}{c}\text { Permeability } \\
\left(\mathbf{m}^{2}\right)\end{array}$} & \multicolumn{1}{|c|}{$\begin{array}{c}\text { Equivalent hydraulic aperture } \\
(\mu \mathrm{m})\end{array}$} \\
\hline Far field & $1 \cdot 10^{-15}(\mathrm{fixed})$ & \\
\hline $\begin{array}{l}\text { Near field rock (between } \\
\text { main fractures) }\end{array}$ & $\begin{array}{l}1 \cdot 10^{-16}(\mathrm{k}-\mathrm{max}) \\
1 \cdot 10^{-17}(\mathrm{k}-\mathrm{min})\end{array}$ & \\
\hline Fracture 2 East upper part & $2.3 \cdot 10^{-11}$ & 16 \\
\hline Fracture 2 East lower part & $5.3 \cdot 10^{-12}$ & 8 \\
\hline Fracture 2 West upper part & $1.4 \cdot 10^{-10}$ & 41 \\
\hline Fracture 2 West lower part & $1.2 \cdot 10^{-11}$ & 12 \\
\hline Fracture 4 upper part & $8.0 \cdot 10^{-11}$ & 31 \\
\hline Fracture 4 lower part & $1.1 \cdot 10^{-10}$ & 36 \\
\hline Fracture 1 & $2.1 \cdot 10^{-10}$ (fixed) & 50 (fixed) \\
\hline
\end{tabular}




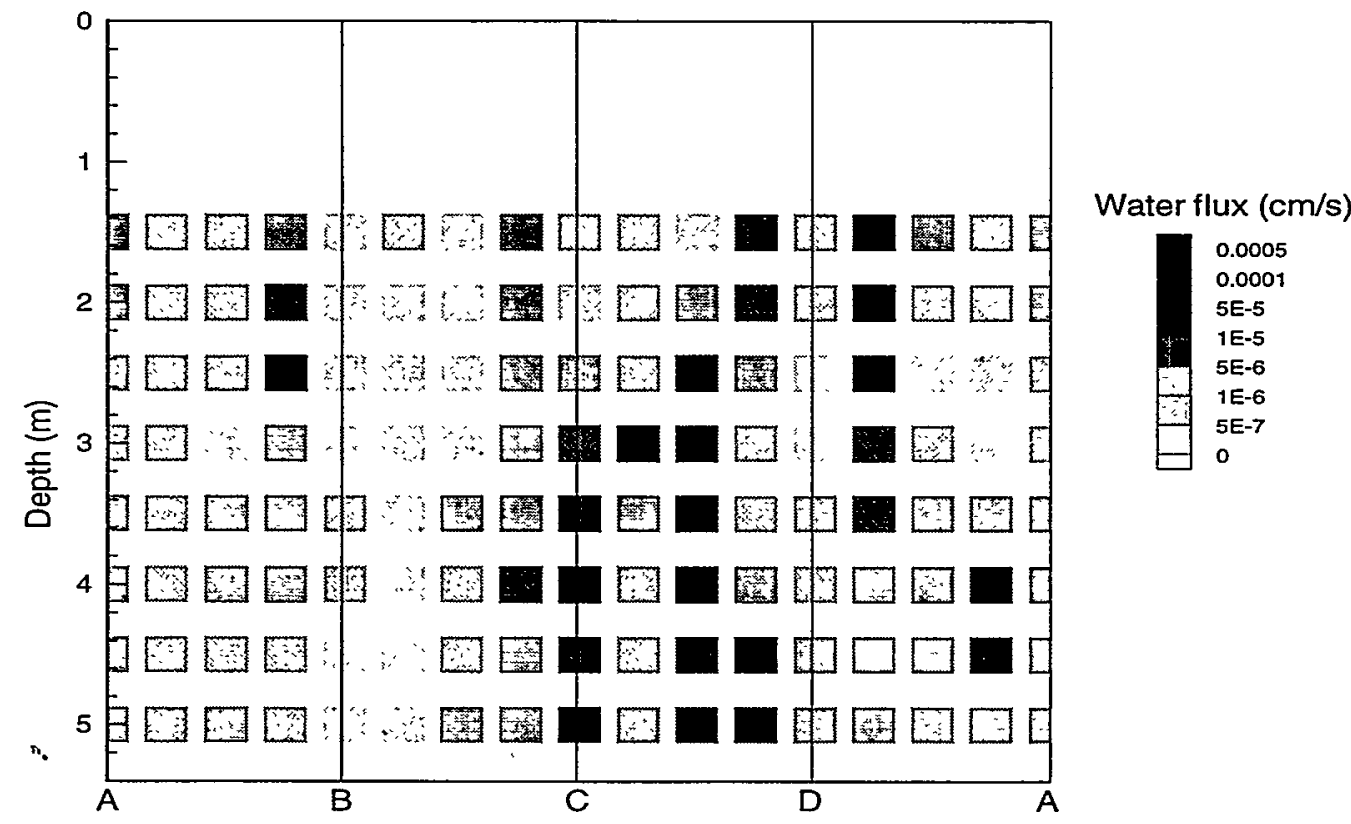

(a) Field measurements

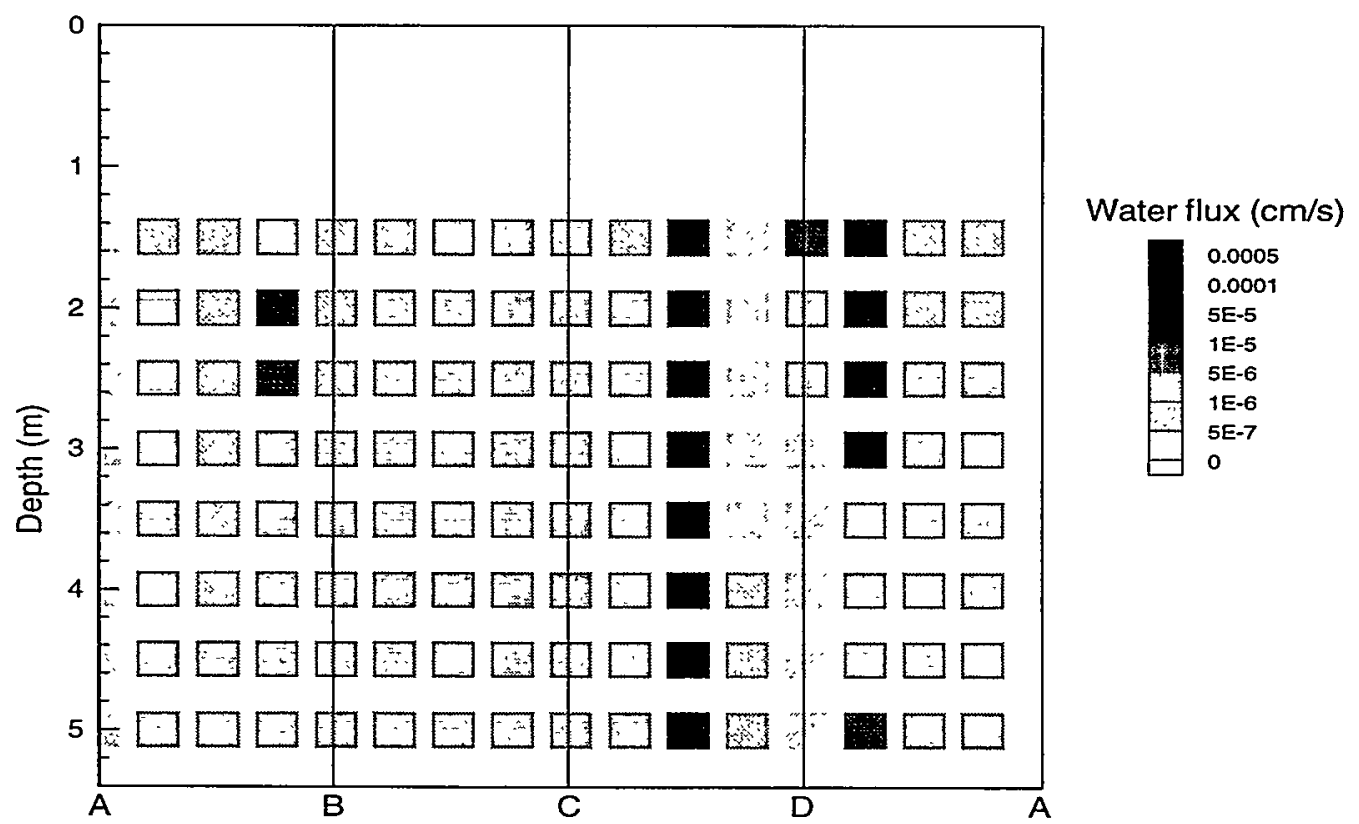

(b) Modeling

Figure 7.18. Comparison of inflow distribution on the wall of the Test Pit. 


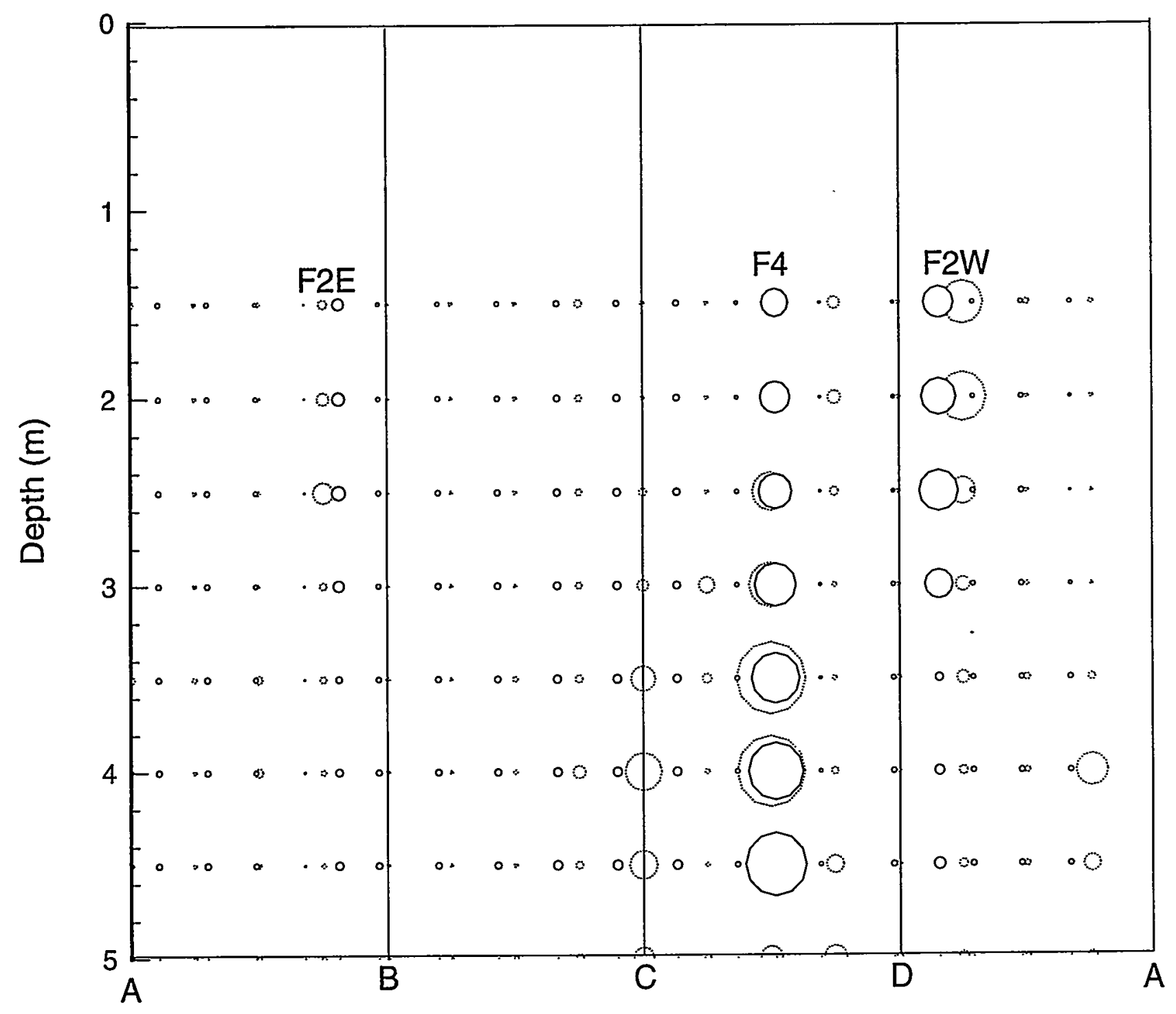

Figure 7.19. Comparison of inflow distribution on the wall of the Test Pit. The area of each circle is proportional to the square root of the flow rate (liters/day). Dashed lined circles are field measurements and solid lined circles are modeling. 


\subsection{Summary of results of Task $2 B$}

It is difficult to derive a general understanding of the rock deformations from the field measurements, and a rather extensive mechanical measurement program was still proven to be insufficient. Both modeling and field experiments show that the displacements are small and in general less than $1 \mathrm{~mm}$, but the comparison between modeling and measurements are inconclusive. In KBM 4 and 5, for vertical displacement, a satisfactory agreement was obtained. On the other hand, at the wall of the Test Pit, a clear discrepancy was found between modeling and field measurements in four points. The conclusion, however, is that there are not enough reliable field measurements to determine the general deformation field in this case, and therefore the modeling performance of mechanical effects cannot be firmly evaluated.

The calibration of the inflow can be considered satisfactory and gives a good model of the permeability in the near field to be used in the final calculation of the heater test in Task $2 \mathrm{C}$. The permeability of the main fractures corresponds to an equivalent parallel plate hydraulic aperture of 8 to $41 \mu \mathrm{m}$. Because of the lack of mechanical measurements backing up the modeling, it is not possible to estimate the importance of hydromechanical effects in the excavation's disturbed zone. However, this field experiment shows that more research is needed on the in situ hydromechanical properties of the large major fractures that dominate fluid flow in crystalline rocks. 


\section{Coupled modeling of the in situ heater test at Kamaishi Mine}

The full-scale heater test is modeled with the newly developed unsaturated version of ROCMAS. All the properties are pre-determined from the laboratory tests and the calibration of rock mass properties in Task $2 \mathrm{~B}$. Task $2 \mathrm{C}$ of DECOVALEX is therefore a prediction of THM behavior during the heater test to be compared with the actual field measurements.

\subsection{Finite element model and boundary conditions}

Task $2 \mathrm{C}$ is modeled with a three-dimensional finite element model of 11,158 elements and includes 13 materials (Figure 8.1). The geometry including drifts and fractures is exactly the same as used in Task 2B for calibration of the rock mass permeability, but the number of elements has been increased on account of the emplacement of the buffer and heater in the Test Pit and necessary refinement of the mesh. The boundary and initial conditions are presented in Figure 8.2. The temperature at the heater is set to $100^{\circ} \mathrm{C}$ at mid-elevation, on the inside surface of the heater, which results in a temperature of $98^{\circ} \mathrm{C}$ at mid-elevation, outer surface of the heater, and about $85-90^{\circ} \mathrm{C}$ at upper and lower ends of the heater. The temperature is constant and equal to $12.3^{\circ} \mathrm{C}$ on the floor directly below the water pool. For remaining surfaces of the drifts a constant heat transfer coefficient of $10 \mathrm{w} / \mathrm{m}^{\circ} \mathrm{C}$ is assumed. The water pressure is initially assumed to be $0.1 \mathrm{MPa}$ in the rock, which implies full saturation, while the bentonite-buffer is partially saturated at $68 \%$.

\subsection{Material properties}

The predictive modeling of the in situ heater test is conducted using values of material properties obtained from the previous modeling and laboratory testing. These include calibrated hydraulic permeability of rock and rock fractures from Task 2B (Section 7) and bentonite properties obtained from the modeling of the laboratory tests (Section 3). Additional properties are provided by JNC, either from laboratory testing on rock sampled at Kamaishi Mine (Table 5.1) or from previous laboratory experiments on bentonite clays. The mechanical rock properties and the saturated permeability of the rock and rock fractures are given in Table 7.1 and 7.3. The properties of the bentonite are given in Table 8.1, and additional material properties are given in Table 8.2. 


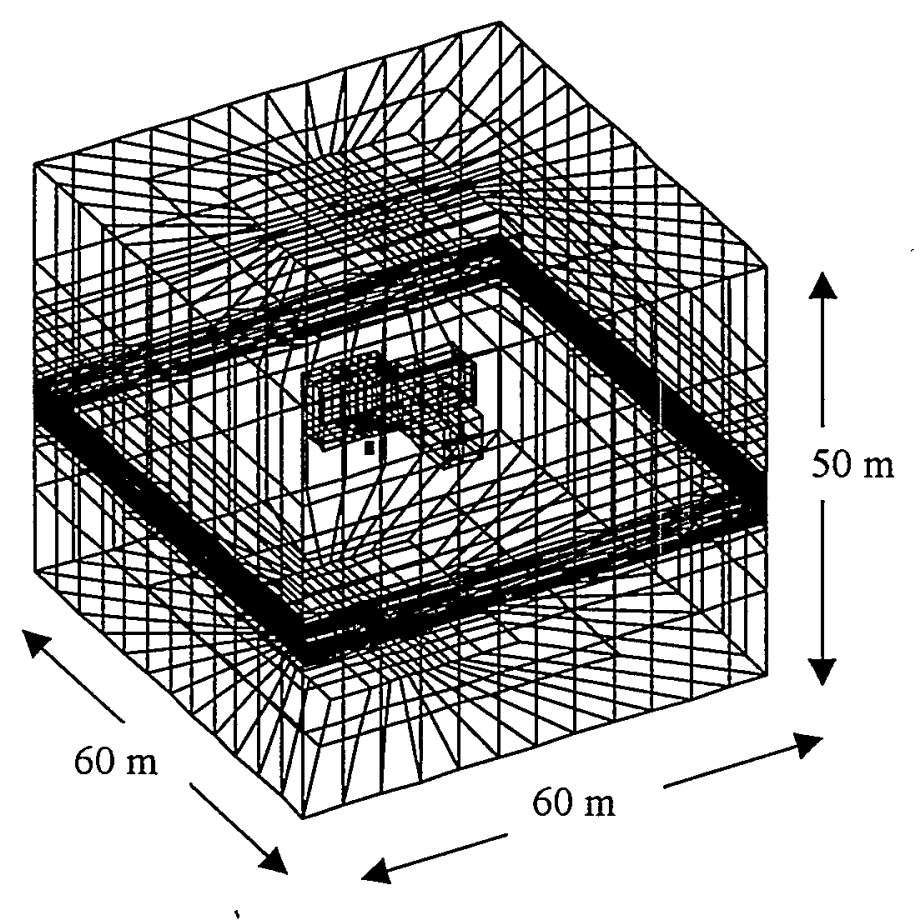

List of materials:

1) Far-field rock mass

2) Near-field rock

3) Fracture 1

4) Fracture 2 upper part East

5) Fracture 2 lower part East

6) Fracture 2 upper part West

7) Fracture 2 lower part West

8) Fracture 4 upper part

9) Fracture 4 lower part

10) Benotnite

11) Heater

12) Heater guide

13) Concrete lid

(a) Whole model

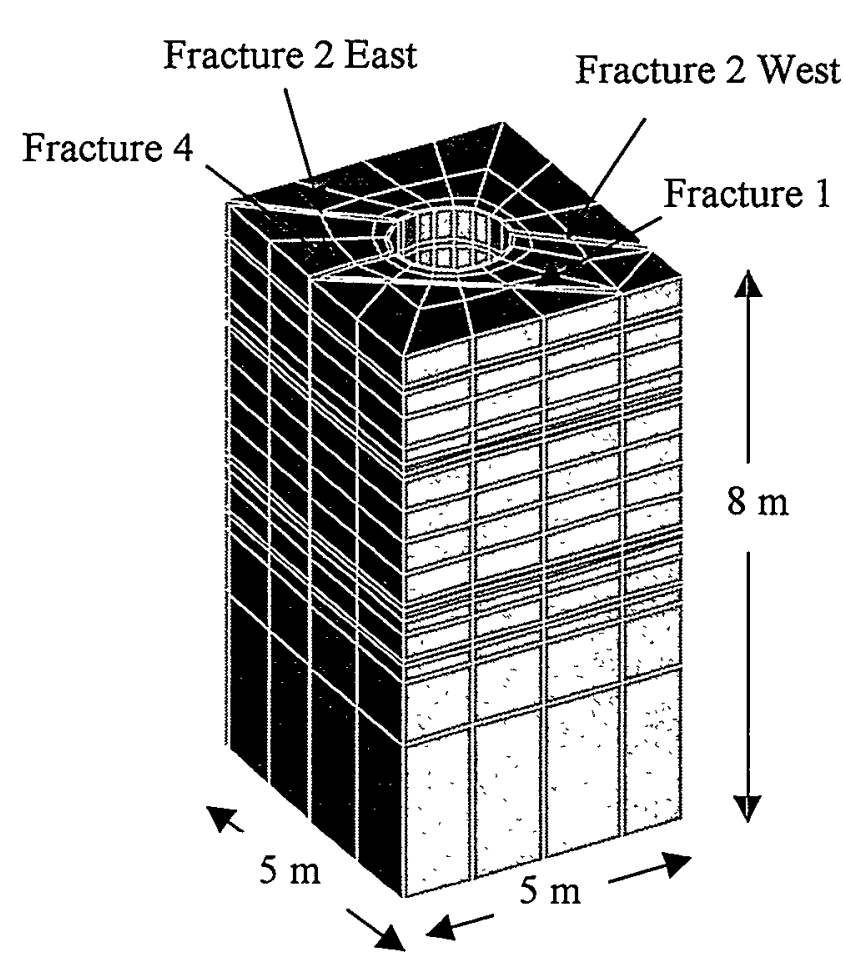

(b) Near-field rock and fractures

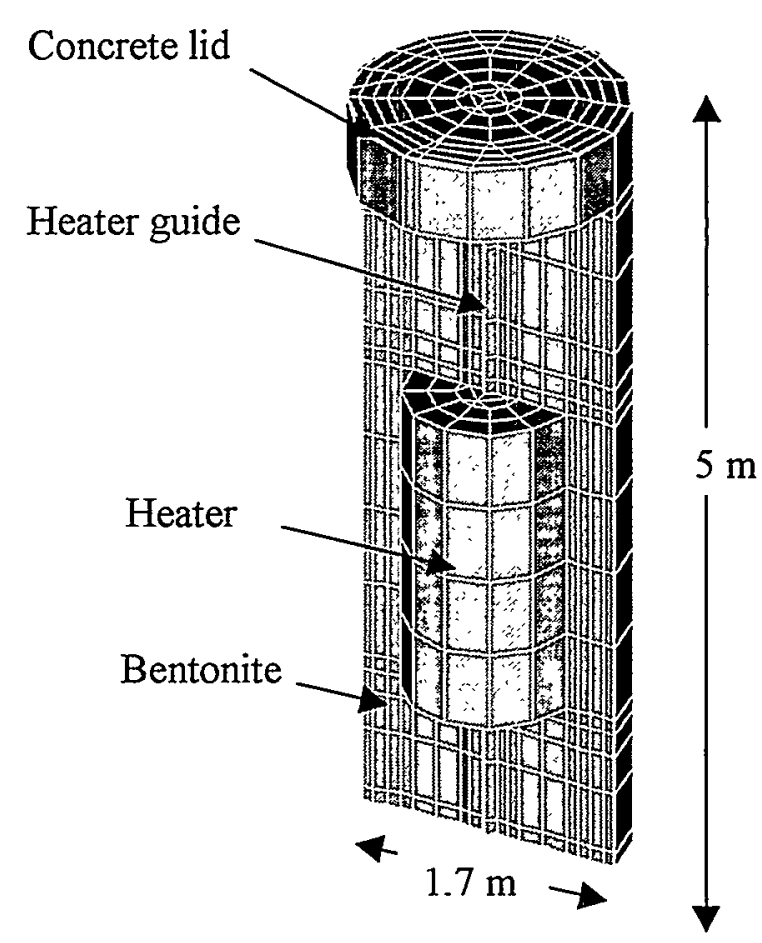

(c) Materials emplaced in the Test Pit.

Figure 8.1. Finite element model of the Kamaishi mine heater test for modeling of Task 2C. a) A wire-frame view of the whole model with 11158 elements and 12192 nodes; (b) Detailed view of near-field rock and fractures intercepting the borehole; (c) Detailed view of the heater and bentonite inside the Test Pit. 


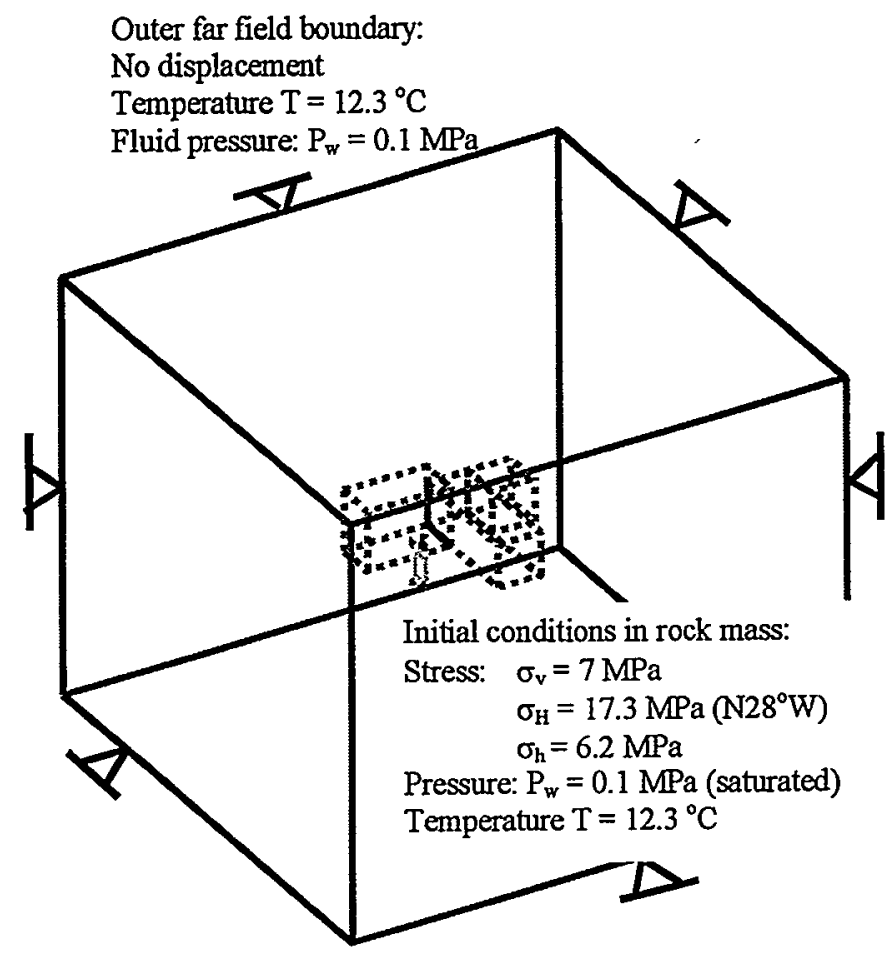

(a) Outer boundaries and rock mass

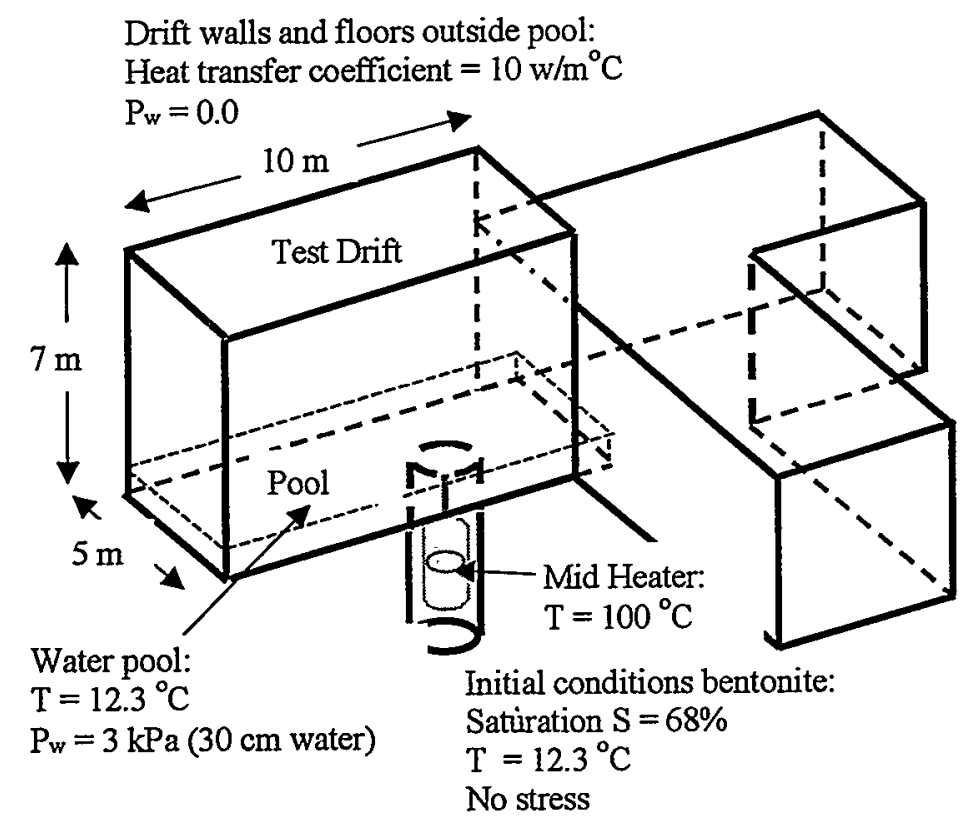

(b) Drifts and test pit

Figure 8.2. Boundary and initial conditions for the finite simulation of Task 2C. 
Table 8.1. Material Properties of the Bentonite-Water System Determined from Laboratory Experiments and Used for Modeling of the Heater Test (Task 2C).

\begin{tabular}{|c|c|c|c|}
\hline Material & Parameter & Value & Source \\
\hline \multirow[t]{11}{*}{ Bentonite } & Dry density, $\rho_{d}\left[\mathrm{~kg} / \mathrm{m}^{3}\right]$ & $1.6 \cdot 10^{3}$ & Direct lab test ${ }^{1}$ \\
\hline & Saturated permeability, $k_{w S}\left[\mathrm{~m}^{2}\right]$ & $1.6 \cdot 10^{-20}$ & Direct lab test ${ }^{1}$ \\
\hline & Relative permeability, $k_{r}[-]$ & (Figure 9) & Modeling lab test ${ }^{2}$ \\
\hline & Porosity, $\phi[-]$ & 0.389 & Direct lab test $t^{1}$ \\
\hline & Biot's effective stress parameter, $\alpha[-]$ & 0.0 & Modeling lab test ${ }^{2}$ \\
\hline & Moisture swelling coefficient, $\xi[-]$ & 0.011 & Modeling lab test ${ }^{2}$ \\
\hline & Thermal expansion, $\beta\left[1 /{ }^{\circ} \mathrm{C}\right]$ & $1.0 \cdot 10^{-6}$ & Direct lab test $t^{1}$ \\
\hline & Young's Modulus, $E$ [Gpa] & 0.1 & Direct lab test ${ }^{1}$ \\
\hline & Poisson ratio, $v[-]$ & 0.3 & $\mathrm{PNC}^{3}$ \\
\hline & Dry specific heat, $C_{v s}\left[\mathrm{~J} / \mathrm{kg} \cdot{ }^{\circ} \mathrm{C}\right]$ & 426 & $\mathrm{PNC}^{3}$ \\
\hline & Thermal conductivity, $K_{m}+L D_{T v}\left[\mathrm{~W} / \mathrm{m} \cdot{ }^{\circ} \mathrm{C}\right]$ & $0.5+1.2 \cdot \mathrm{S}$ & Direct lab test $^{1}$ \\
\hline \multirow[t]{5}{*}{ Fluid } & Thermal expansion coefficient, $\beta_{\mathrm{T}}\left[1 /{ }^{\circ} \mathrm{C}\right]$ & $4.0 \cdot 10^{-4}$ & Standard table ${ }^{4}$ \\
\hline & Specific heat, $C_{v w}\left[\mathrm{~J} / \mathrm{kg} \cdot{ }^{\circ} \mathrm{C}\right]$ & 4180 & Standard table ${ }^{4}$ \\
\hline & Viscosity, $\eta_{w}\left[\mathrm{Ns} / \mathrm{m}^{2}\right]\left(\right.$ at $25^{\circ} \mathrm{C}$ ) & $1.070 \cdot 10^{3}$ & Standard table ${ }^{4}$ \\
\hline & Compressibility, $\beta_{p}[1 / \mathrm{Pa}]$ & $4.4 \cdot 10^{-10}$ & Standard table ${ }^{4}$ \\
\hline & Density, $\rho_{w 0}\left[\mathrm{~kg} / \mathrm{m}^{3}\right]\left(\right.$ at $\left.25^{\circ} \mathrm{C}\right)$ & 997.0 & Standard table ${ }^{4}$ \\
\hline \multirow[t]{5}{*}{ Vapor-air } & Mass flow times tortousity factors, $\nu_{\nu} \times \tau_{\nu}[-]$ & 0.67 & Modeling lab test ${ }^{2}$ \\
\hline & Thermal diffusion enhancement factor, $f_{T_{v}}[-]$ & 1.0 & Modeling lab test ${ }^{2}$ \\
\hline & Vapor specific heat, $C_{v s}\left[\mathrm{~J} / \mathrm{kg} \cdot{ }^{\circ} \mathrm{C}\right]$ & 1900 & Standard table $\mathrm{e}^{4}$ \\
\hline & Latent heat of vaporization, $L_{o}[\mathrm{~J} / \mathrm{kg}]$ & $2.4 \cdot 10^{6}$ & Standard table ${ }^{4}$ \\
\hline & Specific gas constant of water vapor, $R\left[\mathrm{~J} / \mathrm{kg}^{\circ} \mathrm{C}\right]$ & 461.5 & Standard table $e^{4}$ \\
\hline
\end{tabular}

1) The parameter has been directly measured in a laboratory experiment and is reported in Fujita el al (1997b) and Chijimatsu et al. (1996d).

2) The parameter has been determined by modeling (using ROCMAS) of a laboratory experiment reported in Fujita et al., $1997 \mathrm{~b}$.

3) The parameter has been given by PNC but has not been determined by the laboratory experiments reported in Fujita et al. (1997b) and Chijimatsu et al. (1996d).

4) The parameter is obtained from standard thermodynamic or thermophysical tables. 
Table 8.2 Properties of Additional Materials for Modeling of the Heater Test (Task2C).

\begin{tabular}{|c|c|c|c|}
\hline Material & Parameter & Value & Source \\
\hline \multirow[t]{6}{*}{ Rock mass } & Density, $\rho_{3}\left[\mathrm{~kg} / \mathrm{m}^{3}\right]$ & 2700 & Direct lab test ${ }^{1}$ \\
\hline & Porosity, $\phi[-]$ & 0.03 & Direct lab test ${ }^{1}$ \\
\hline & Biot's effective stress parameter, $\alpha[-]$ & 1.0 & Assumed $^{2}$ \\
\hline & Wet specific heat, $C_{\nu}\left[\mathrm{J} / \mathrm{kg} \cdot{ }^{\circ} \mathrm{C}\right]$ & 833 & Direct lab test $^{1}$ \\
\hline & Thermal conductivity, $K_{m}\left[\mathrm{~W} / \mathrm{m} \cdot{ }^{\circ} \mathrm{C}\right]$ & 2.7 & Direct lab test $^{1}$ \\
\hline & Thermal expansion, $\beta\left[1 /{ }^{\circ} \mathrm{C}\right]$ & $8.21 \cdot 10^{-6}$ & Direct lab test ${ }^{1}$ \\
\hline \multirow[t]{9}{*}{ Concrete lid } & Density, $\rho_{3}\left[\mathrm{~kg} / \mathrm{m}^{3}\right]$ & 2300 & $\mathrm{PNC}^{3}$ \\
\hline & Hydraulic permeability, $k_{w}\left[\mathrm{~m}^{2}\right]$ & $1.0 \cdot 10^{-21}$ & $\mathrm{PNC}^{3}$ \\
\hline & Porosity, $\phi[-]$ & 0.01 & $\mathrm{PNC}^{3}$ \\
\hline & Young's modulus, $E$ [GPa] & 25 & $\mathrm{PNC}^{3}$ \\
\hline & Poisson's ratio, $v[-]$ & 0.167 & $\mathrm{PNC}^{3}$ \\
\hline & Biot's effective stress parameter, $\alpha[-]$ & 1.0 & Assumed $^{2}$ \\
\hline & Wet specific heat, $C_{v}\left[\mathrm{~J} / \mathrm{kg}^{\circ} \mathrm{C}\right]$ & 460 & $\mathrm{PNC}^{3}$ \\
\hline & Thermal conductivity, $K_{m}\left[\mathrm{~W} / \mathrm{m}^{\circ} \mathrm{C}\right]$ & 1.88 & $\mathrm{PNC}^{3}$ \\
\hline & Thermal expansion coefficient, $\beta\left[1{ }^{\circ} \mathrm{C}\right]$ & $1.0 \cdot 10^{-6}$ & $\mathrm{PNC}^{3}$ \\
\hline \multirow{9}{*}{$\begin{array}{l}\text { Heater and } \\
\text { heater guide }\end{array}$} & Density, $\rho_{3}\left[\mathrm{~kg} / \mathrm{m}^{3}\right]$ & 7800 & $\mathrm{PNC}^{3}$ \\
\hline & Hydraulic permeability, $k_{w}\left[\mathrm{~m}^{2}\right]$ & $1.0 \cdot 10^{-27}$ & $\mathrm{PNC}^{3}$ \\
\hline & Porosity, $\phi[-]$ & $1.0 \cdot 10^{-4}$ & $\mathrm{PNC}^{3}$ \\
\hline & Young's modulus, $E$ [GPa] & 200 & $\mathrm{PNC}^{3}$ \\
\hline & Poisson's ratio, $v[-]$ & 0.3 & $\mathrm{PNC}^{3}$ \\
\hline & Biot's effective stress parameter, $\alpha[-]$ & 1.0 & Assumed $^{2}$ \\
\hline & Wet specific heat, $C_{v}\left[\mathrm{~J} / \mathrm{kg}^{\circ} \mathrm{C}\right]$ & 750 & $\mathrm{PNC}^{3}$ \\
\hline & Thermal conductivity, $K_{m}\left[\mathrm{~W} / \mathrm{m}^{\circ} \mathrm{C}\right]$ & 100.0 & $\mathrm{PNC}^{3}$ \\
\hline & Thermal expansion coefficient, $\beta\left[1 /{ }^{\circ} \mathrm{C}\right]$ & $1.64 \cdot 10^{-6}$ & $\mathrm{PNC}^{3}$ \\
\hline
\end{tabular}

1) The parameter has been directly measured in a laboratory experiment and is reported in Fujita el al (1997b) and Chijimatsu et al. (1996d).

2) The parameter has been assumed to a reasonable value.

3) The parameter has been given by PNC but has not been determined by the laboratory experiments reported in Fujita et al. (1997b) and Chijimatsu et al. (1996d). 


\subsection{Results of temperature in buffer and rock}

Figures 8.3 and 8.4 present modeling results of temperature in the buffer and rock around

the Test Pit at three different times. These are (a) at 30 days; (b) at 258 days, which is the end of the eight and a half month heating period; and (c) at 438 days, which is the end of the six month cooling period. Figure 8.3 shows that the temperature in the buffer appears to have reached a steady state already after 30 days; and therefore the temperature distribution is almost equal at 30 and 258 days. However, Figure 8.4 shows that the temperature in the rock mass is not steady after 30 days and that the contour line for 12.5 ${ }^{\circ} \mathrm{C}\left(0.2{ }^{\circ} \mathrm{C}\right.$ above initial temperature $)$ is still propagating away from the heat source. At 30 days, this contour line has reached about 5 meters from the heater and after 258 days about 10 meters. At 258 days, the temperature on the drift-walls is slightly elevated while the temperature on the floor below the water pool is constant at $12.3^{\circ} \mathrm{C}$. At 438 days, when the heater has been turned off for 6 months, the temperature in the buffer is almost back to the initial value of $12.3^{\circ} \mathrm{C}$. However, there is still a zone of slightly elevated temperature around the heater with the $12.5^{\circ} \mathrm{C}$ contour line extending 9 meters away from the heater. This zone is slowly contracting because of the cooling from the water pool and walls of the Test Drift.

Figure 8.5 presents comparison of the temperature history predicted with ROCMAS and the actual field measurements in the bentonite. At the top of the buffer (BT1 and BT2), the agreement is excellent. At the mid heater elevation (BT3, BT4 and BT5), the agreement is very good, especially at BT5 and BT4. At BT3 (near the rock and benonite interface) the modeling shows a slower temperature increase during the first 50 days than the experimental results. After 100 days and towards the end of the heating period, the modeling shows a gradual decline in temperature with time. This temperature decline is caused by the fact that the bentonite becomes dryer near the heater, reducing its thermal conductivity (a function of water content). At the bottom of the Test Pit (BT6 and BT7) the agreement is good, although the modeling shows a slightly slower rate of temperature decline during the cooling phase.

Figures $8.6-8.8$ present predicted and measured temperature in the boreholes located in the rock at 30 and 60 centimeters from the wall of the Test Pit. The agreement between modeling and field measurements can be considered as satisfactory, although a perfect match was not obtained for all measurement points. The results in points closest to the heater (RH5, RH11 and RH 14) were those that showed the largest discrepancy between modeling and measurements. This discrepancy may be caused by local inhomogeneities in the thermal properties of the rock from the influence of fractures or local unsaturated rock conditions. Such local inhomogeneities are less important away from the heat source, where the average bulk properties of the rock mass between the monitoring point and the heat source determine the temperature response. The overall temperature agreement is good, but with a tendency toward a slower rate of temperature decline during cooling in the modeling. 

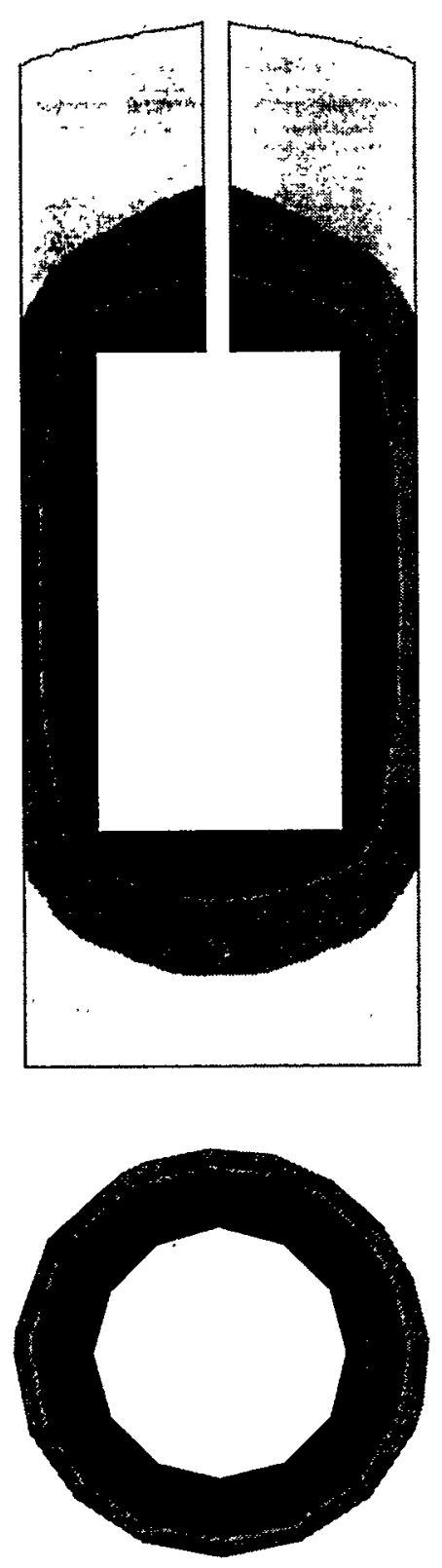

(a) 30 days
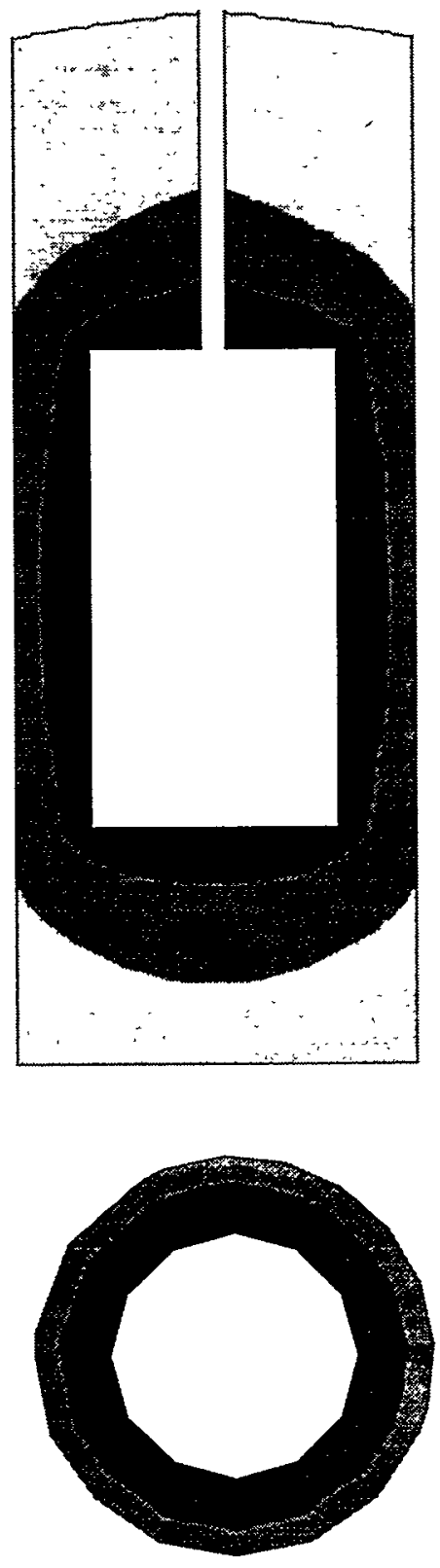

(b) 258 days

$\left({ }^{\circ} \mathrm{C}\right)$

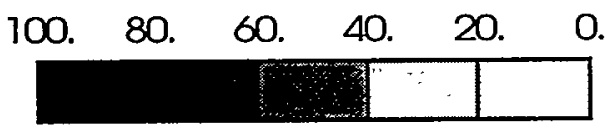

(c) 438 days 

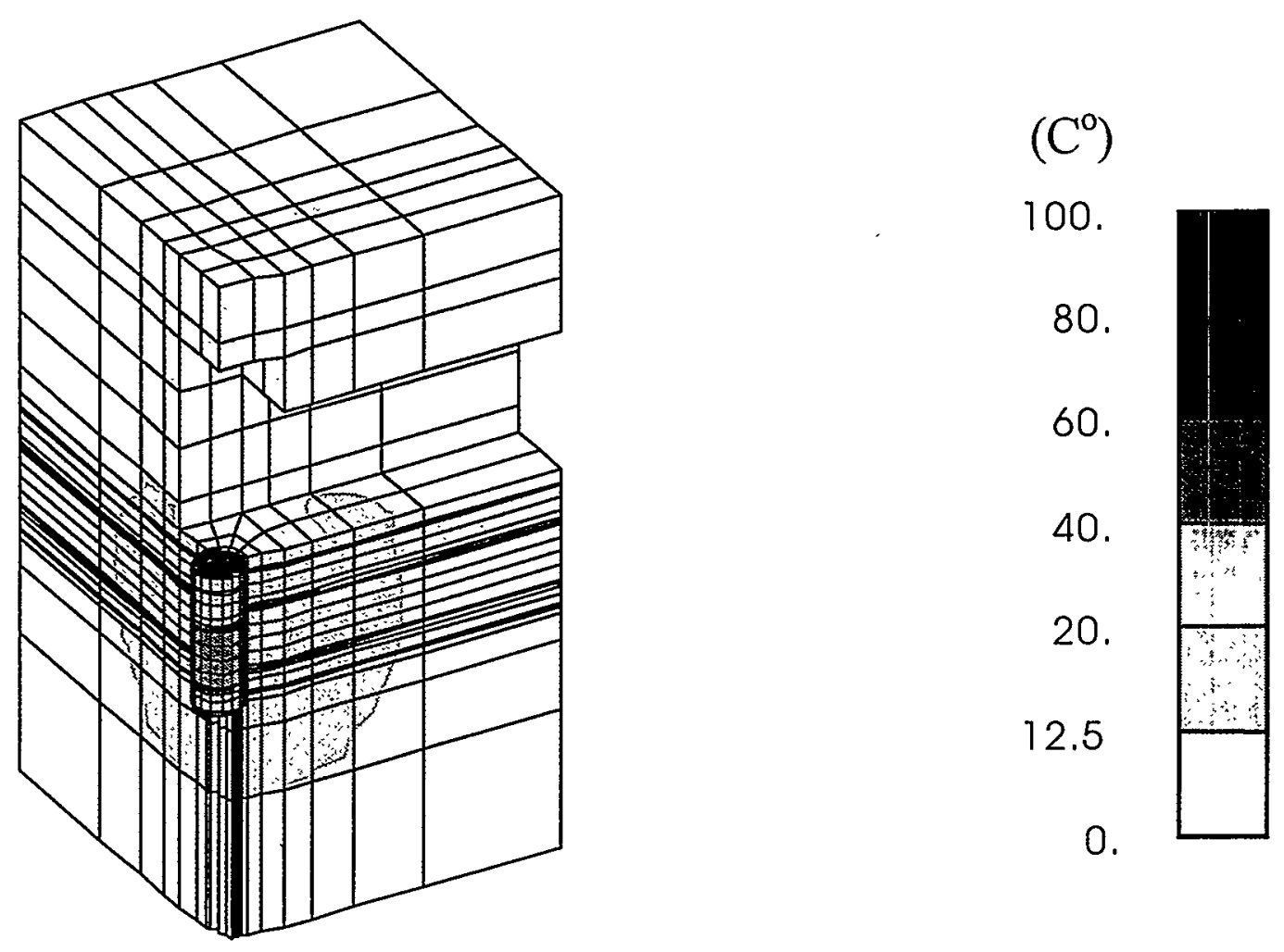

(a) 30 days

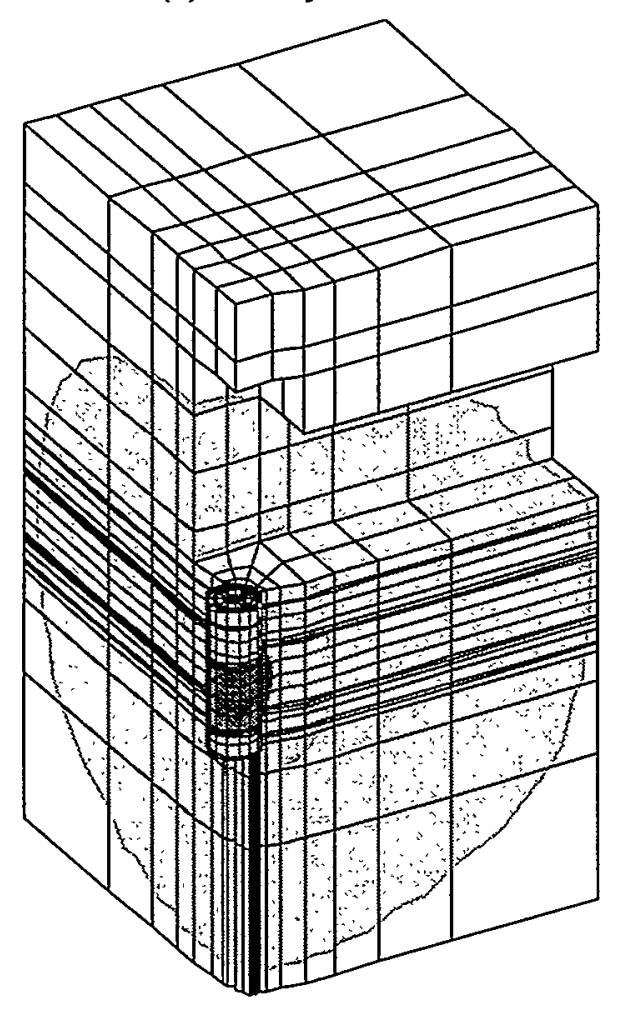

(b) 258 days

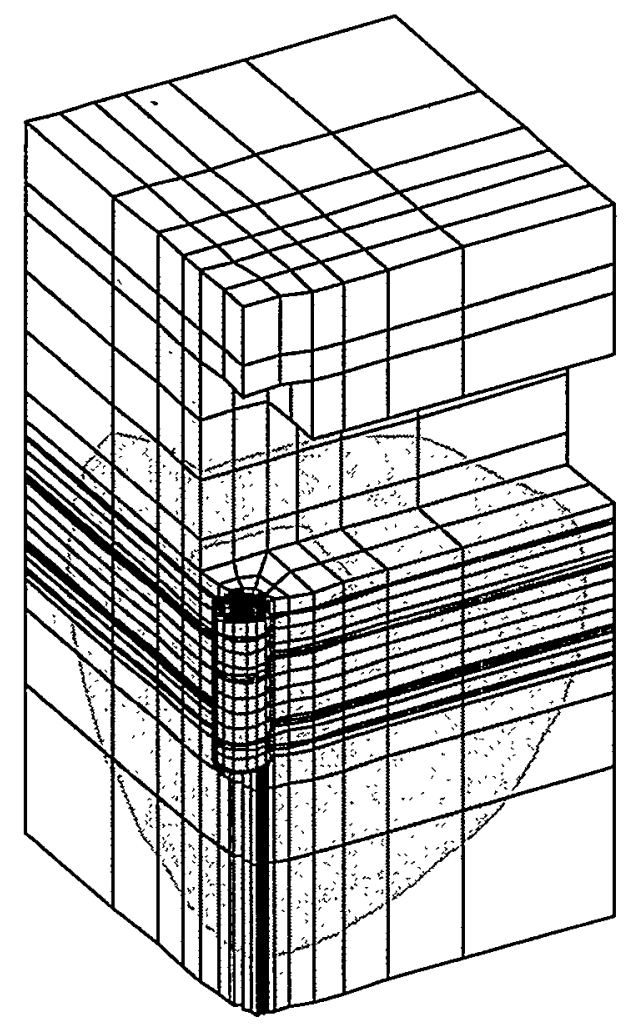

(c) 438 days

Figure 8.4. Modeling results of temperature in the rock mass after (a) 30 days, (b) 258 days (end of heating period) and (c) 438 days (end of cooling). 

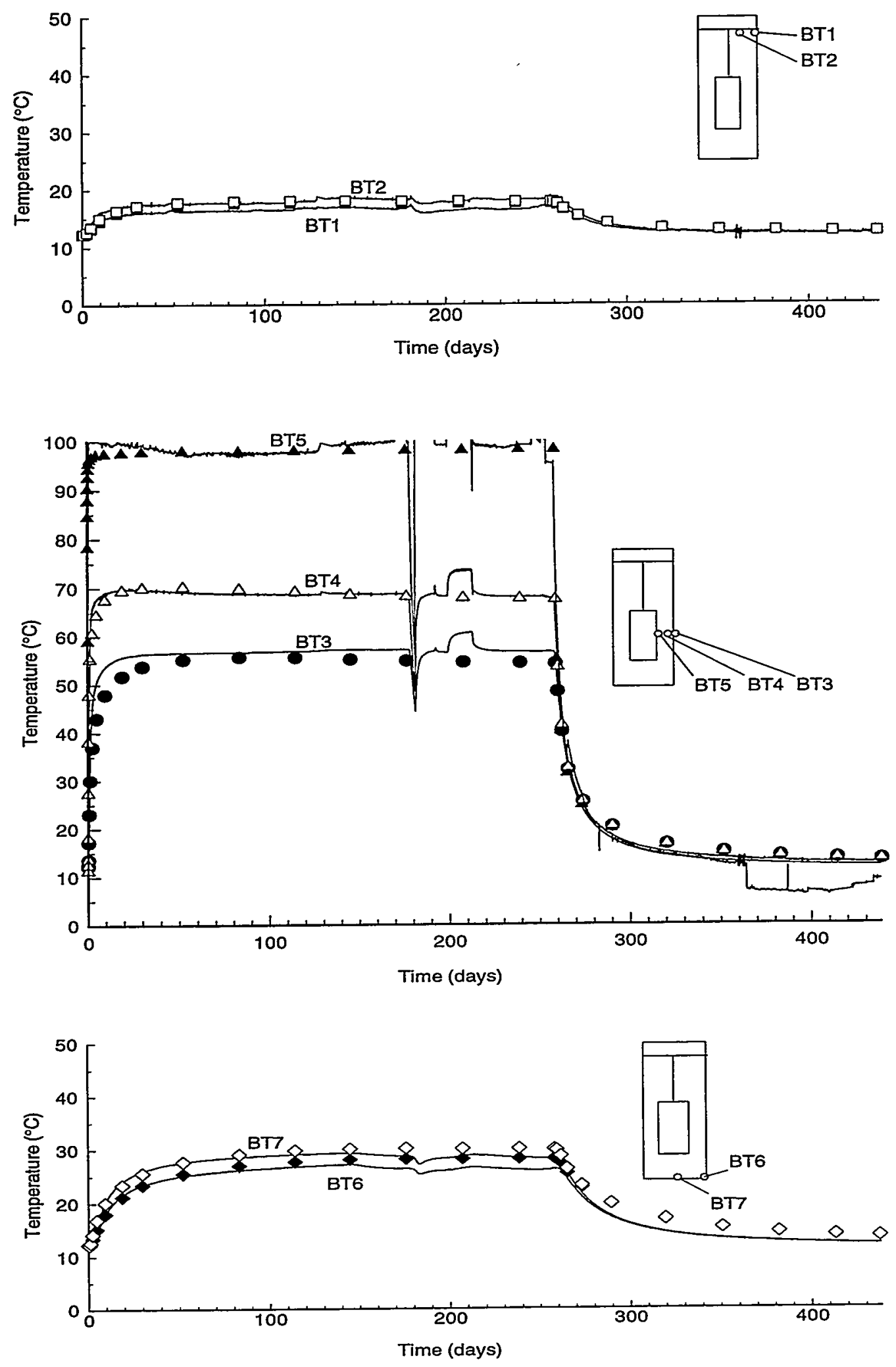

Figure 8.5. Temperature history at seven points in the bentonite. Comparison of experimental results (lines) and modeling with ROCMAS (symbols). 


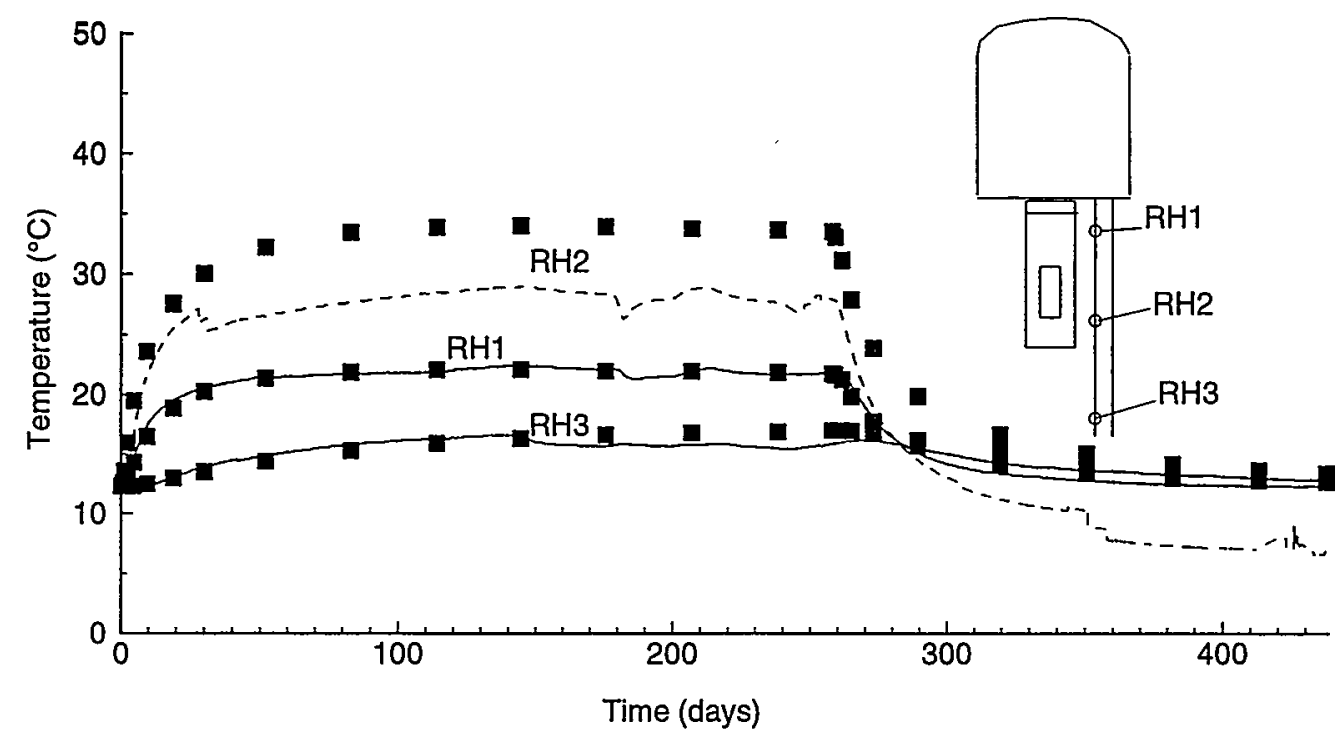

(a) Borehole BH1

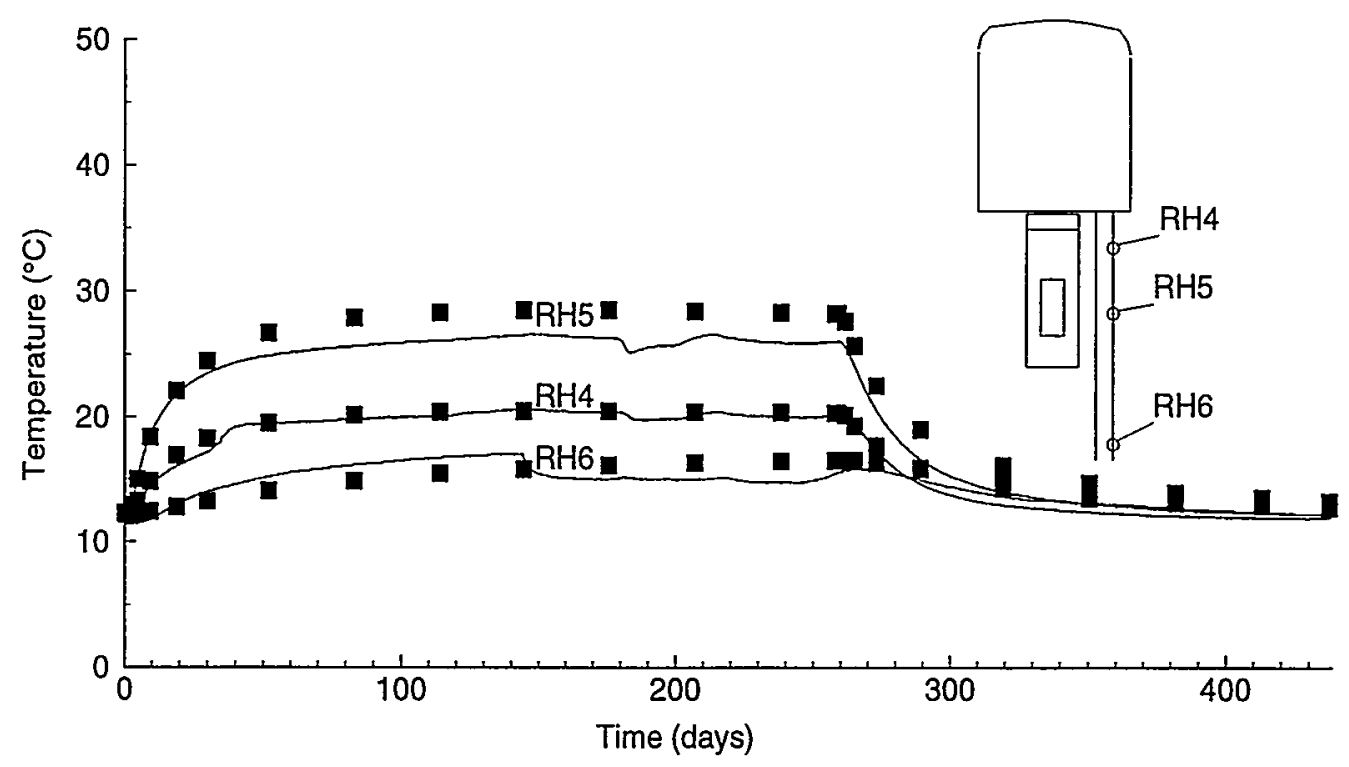

(b) Borehole BH2

Figure 8.6. Temperature history at six points in the rock mass located in (a) borehole $\mathrm{BH} 1$, and (b) borehole $\mathrm{BH} 2$. Comparison of experimental results (lines) and modeling with ROCMAS (symbols). 


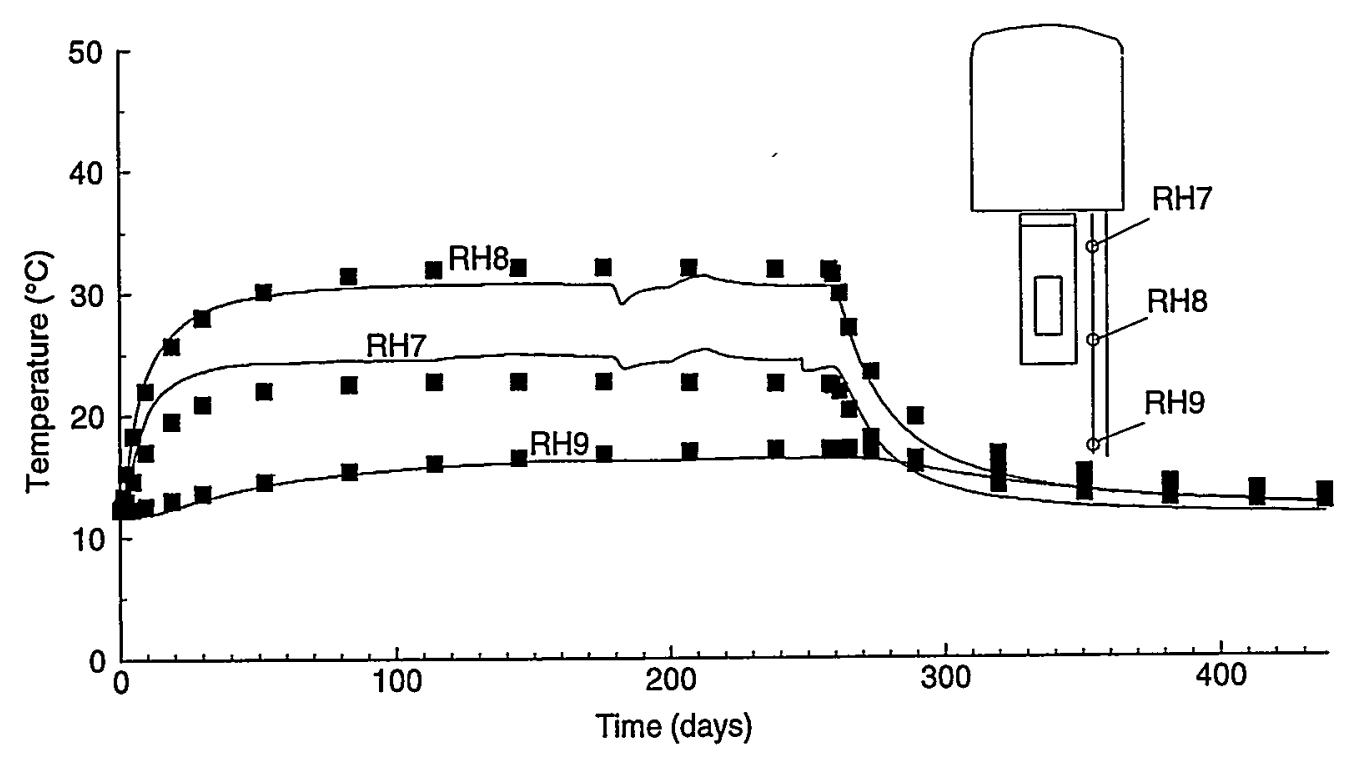

(a) Borehole BH3

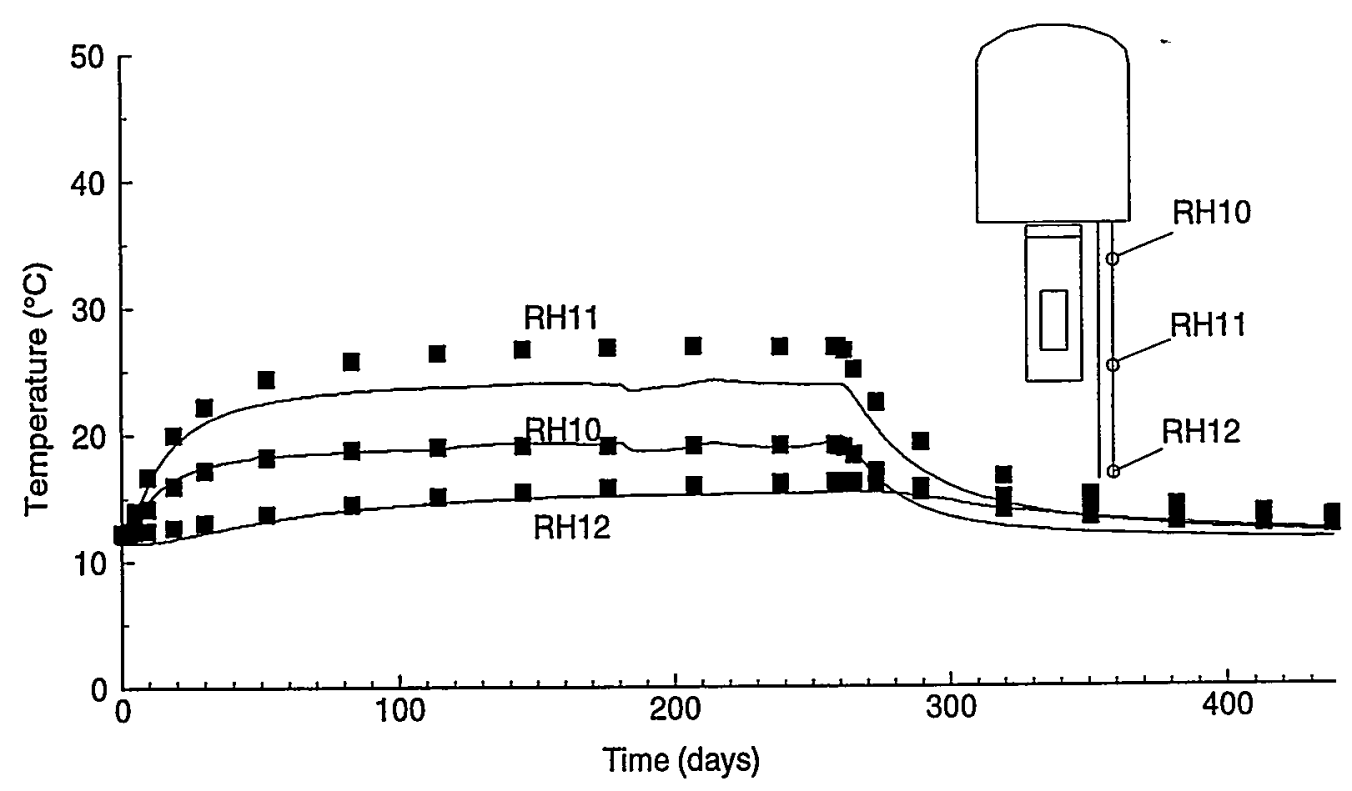

(b) Borehole BH4

Figure 8.7. Temperature history at six points in the rock mass located in (a) borehole $\mathrm{BH} 3$, and (b) borehole BH4. Comparison of experimental results (lines) and modeling with ROCMAS (symbols). 


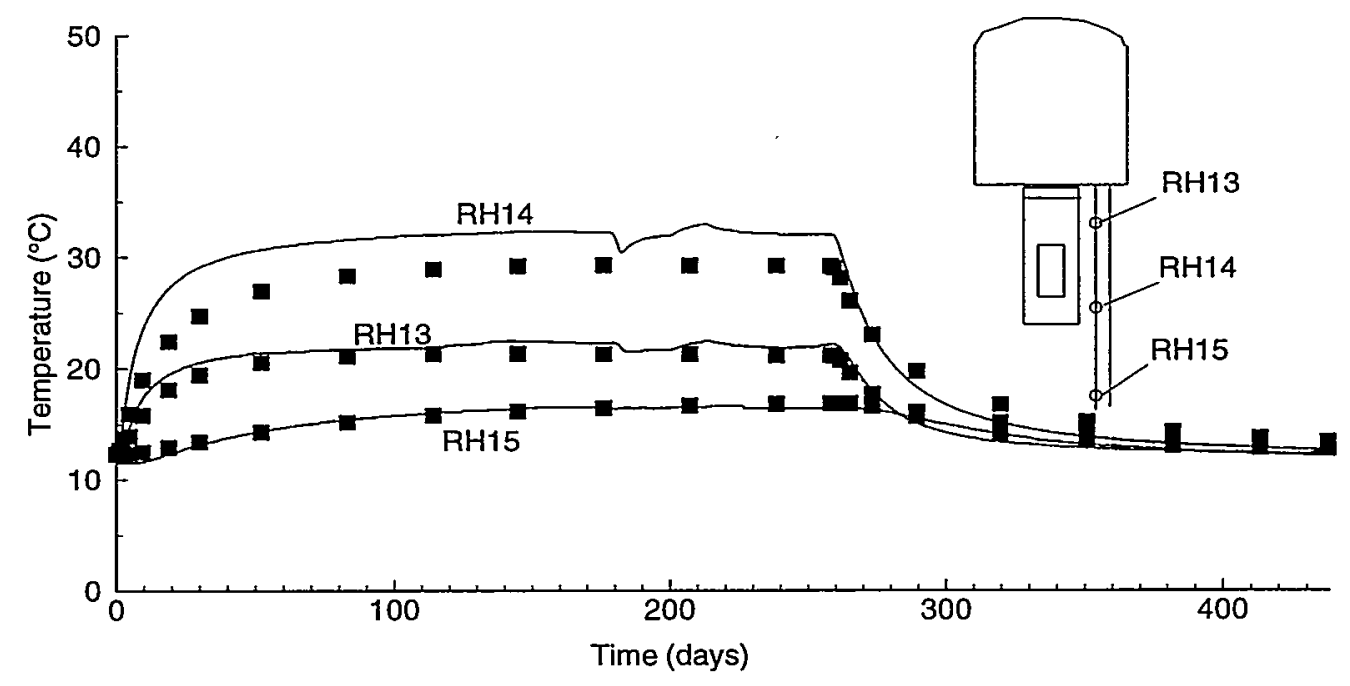

(a) Borehole $\mathrm{BH} 5$

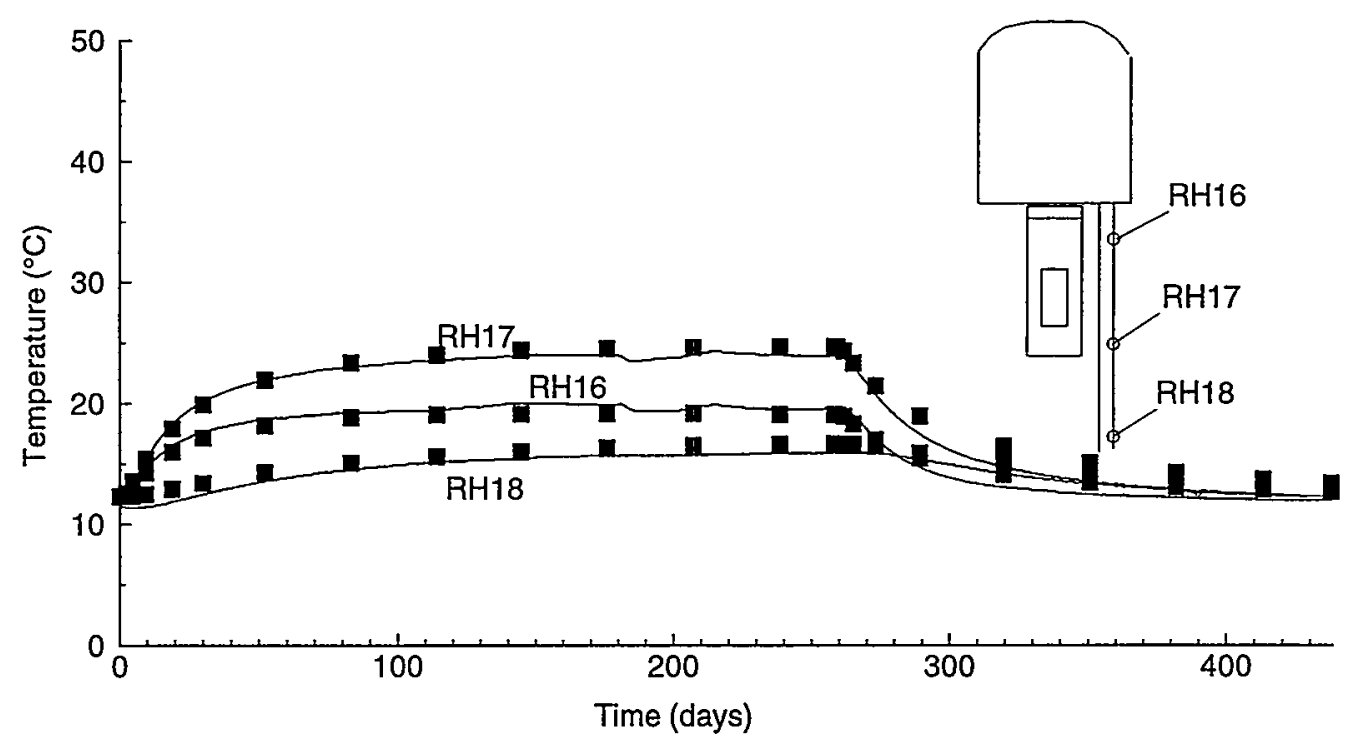

(b) Bohehole BH6

Figure 8.8. Temperature history at six points in the rock mass located in (a) borehole $\mathrm{BH} 5$ and (b) borehole BH6. Comparison of experimental results (lines) and modeling with ROCMAS (symbols). 


\subsection{Results of water content in buffer and rock}

Figure 8.9 presents modeling results of water content after one month, at the end of the heating phase (258 days), and at the end of cooling phase (438 days). Two main processes control the water content distribution in this case. First, there is vapor flow from the inner hot region toward the cooler outer region of the bentonite. Second, there is a liquid flow from the fully saturated rock-bentonite interface into the dryer regions of the bentonite. At 30 days, a small region in the bentonite near the heater surface has been dried, because of vaporization of liquid water and transport of vapor through molecular diffusion toward cooler regions, where the vapor is condensed into liquid water. A condensation zone can be seen in Figure 8.9 (30 days) as dark spots of increased liquid water content about 10 centimeters outside the dried region. The zone of increased water content moves slowly outwards from the heater and finally joins the liquid water flowing in from the fully saturated rock-bentonite interface. At the end of the heating period (Figure 8.9, 258 days), the region near the heater has been dried to a water content of less than 5\%. At the end of the cooling period (Figure 8.9, 438 days), water has flowed back towards the heater where the water content now is more than $5 \%$ but less than $10 \%$. Liquid water is continuously infiltrating from the rock to the bentonite during the entire 14 month of the heater test. However, at the end of the cooling, the water content is unchanged at its initial value of $16.5 \%$ in large regions of the bentonite above and below the heater. The results in Figure 8.9 show that fractures have no affect on the resaturation with the model parameters assumed. This indicates that rock permeability is sufficiently high so that enough water can be provided to the bentonite, and that the resaturation is controlled by the permeability of the bentonite.

Figure 8.10 compares the time history of water content at monitoring points in the bentonite. The agreement between the prediction and the measurements are satisfactory, with all the general trends captured in the modeling. Near the heater (BW5), the water content gradually decreases to about $3 \%$ at the end of the heating phase and thereafter increases slowly during the cooling phase. At the midsection between the heater and the rock (BW4), the water content increases during the first month of heating and thereafter decreases. This temporary increase of the water content results from the moving condensation zone described above and seen as dark spots at 30 days in Figure 8.9. At the rock-bentonite boundary BW3 (located in the bentonite 1 centimeter from the rock), the water content increases fast towards full saturation. However, at other measurement points near the rock interface (BW1 and BW6), the resaturation appears to be slower in the field than predicted by the numerical modeling. The overall agreement, though, is satisfactory considering the uncertainty in the psychrometric monitoring of the water content. For example, the decline in water content monitored in BW2 after 250 days is probably a measurement error, since core sample data from the same location shows that the water content stays constant at about $16 \%$ (Figure $8.9 \mathrm{a}$ ). 

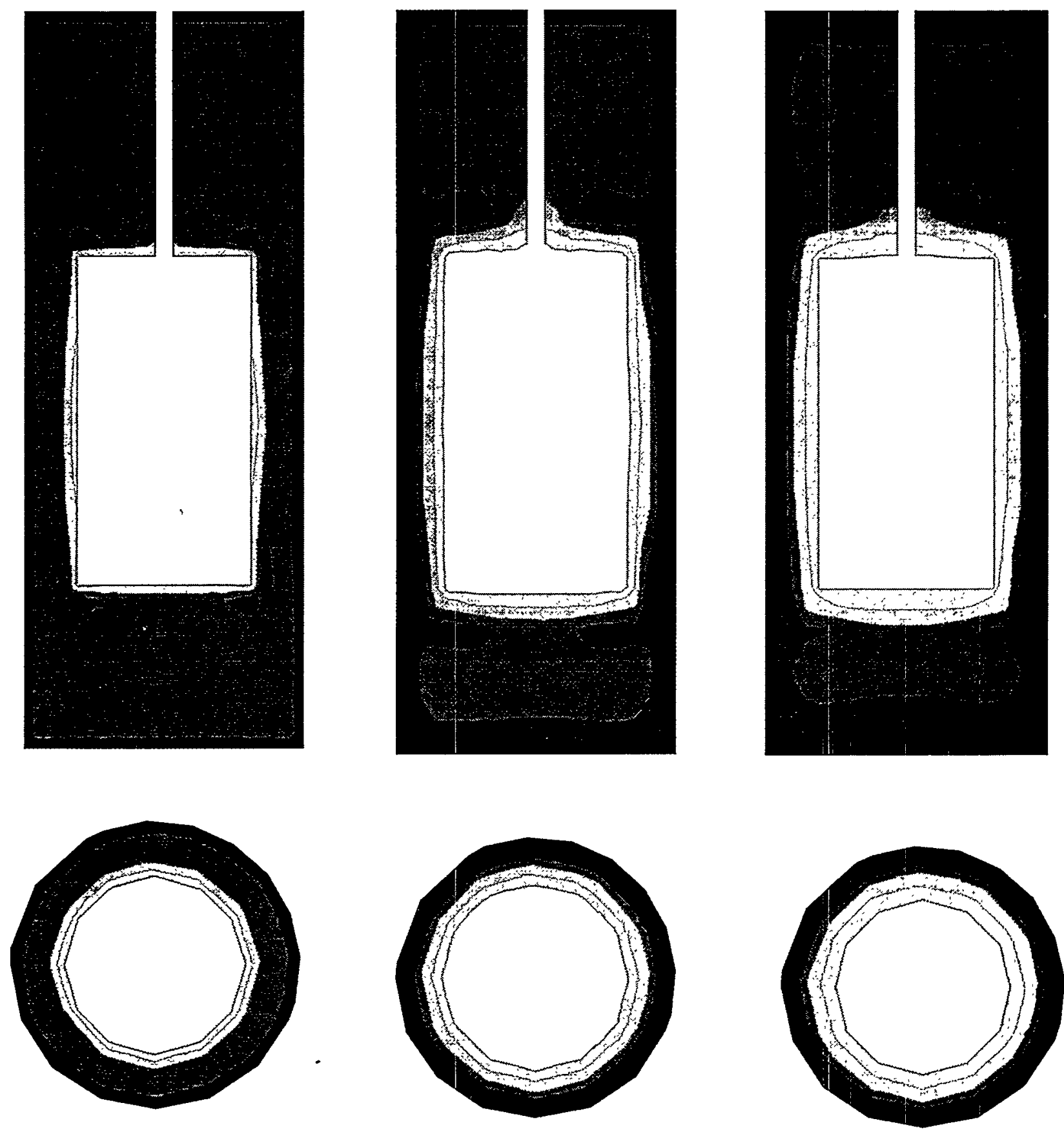

(a) 30 days

(b) 258 days

(c) 438 days

25. 20. $15 . \quad 10 . \quad 5.0 .0(\%)$

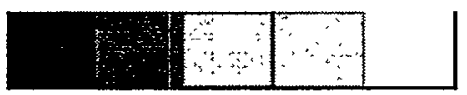

Figure 8.9. Modeling results for contours of water content in the bentonite for Task $2 \mathrm{c} 2$ after (a) 30 days, (b) 258 days (end of heating period) and (c) 438 days (end of cooling period). 


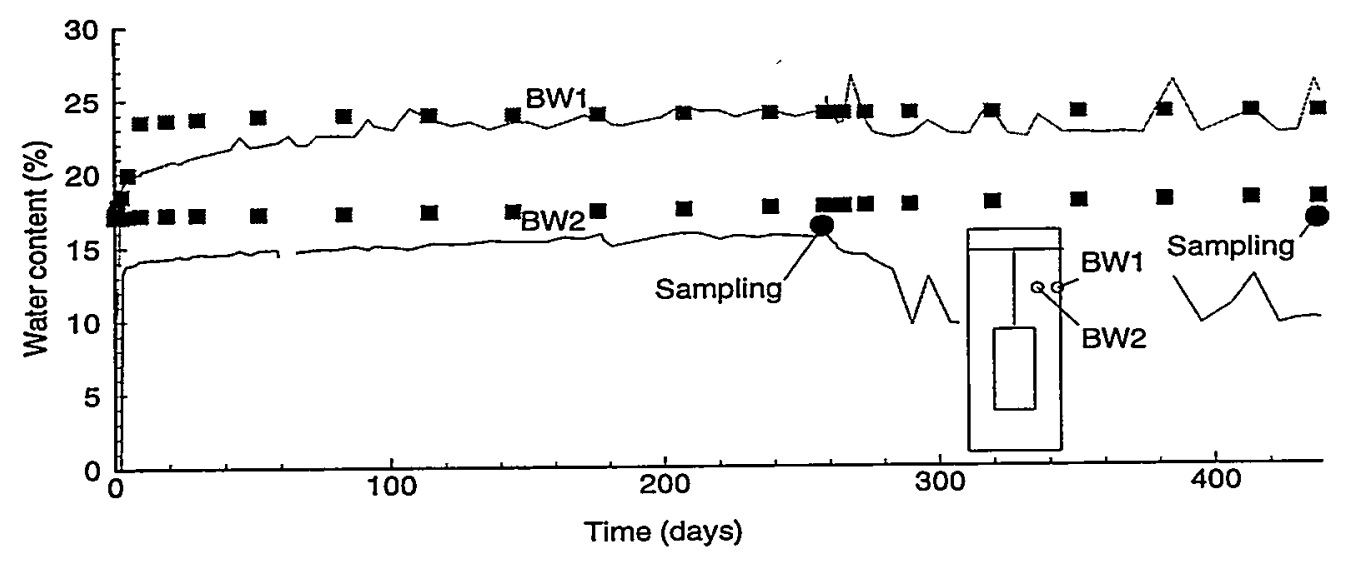

(a)

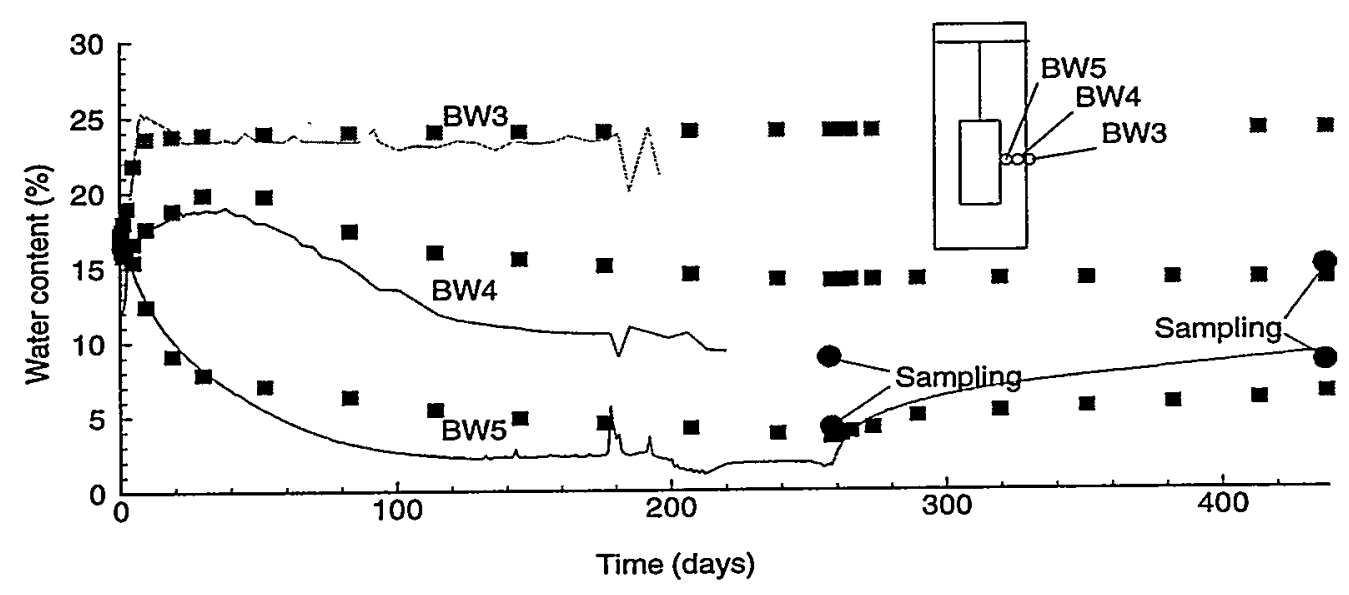

(b)

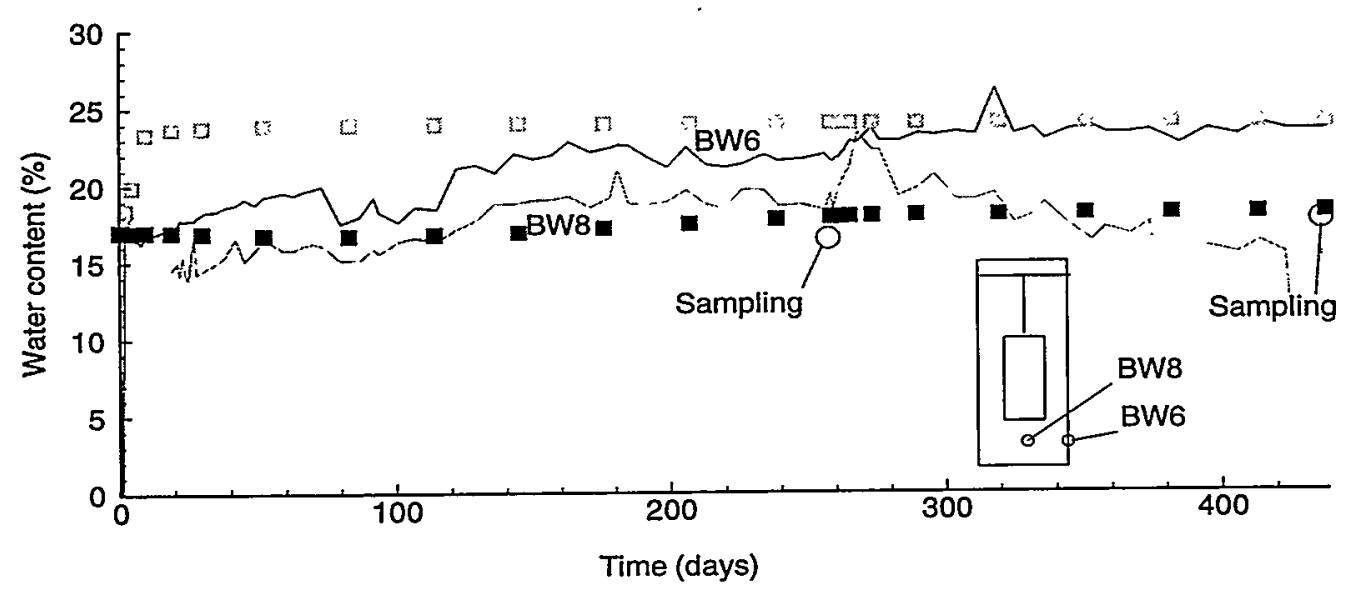

(c)

Figure 8.10. History of water content at 7 points in the bentonite: Comparison of experimental results (lines) and modeling with ROCMAS (symbols). 

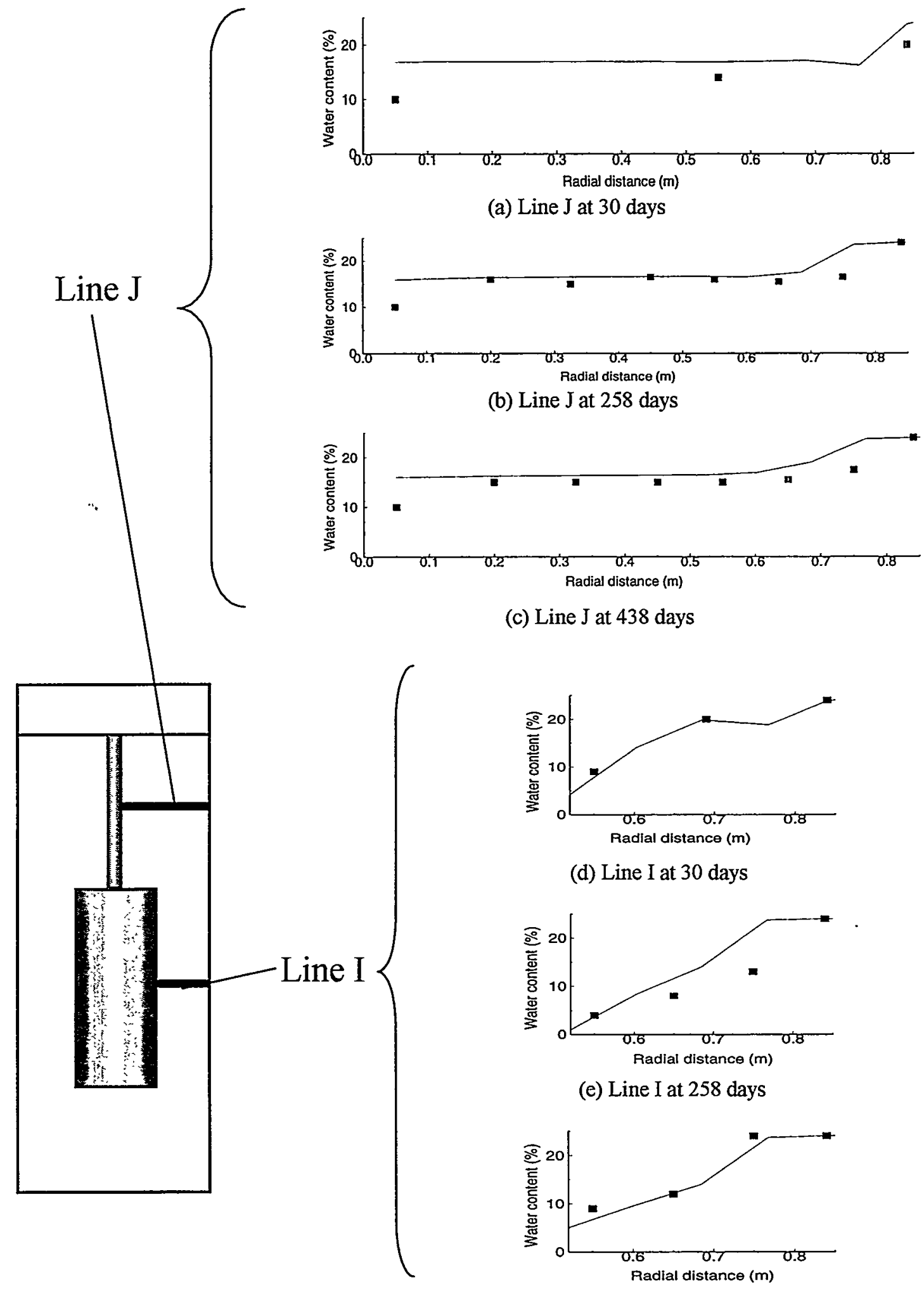

(a) Line $J$ at 30 days

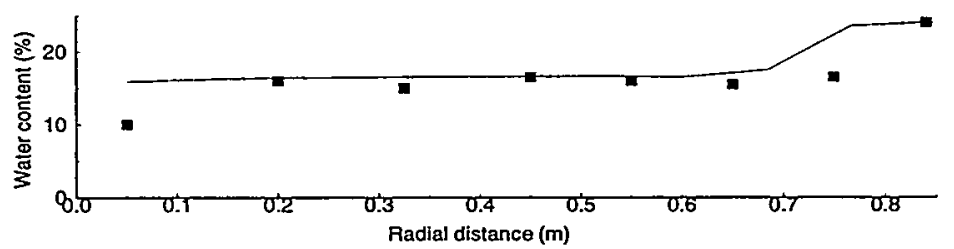

(b) Line $\mathrm{J}$ at 258 days

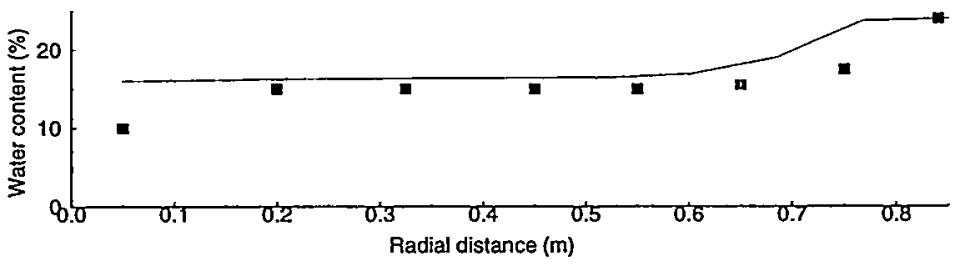

(c) Line $J$ at 438 days

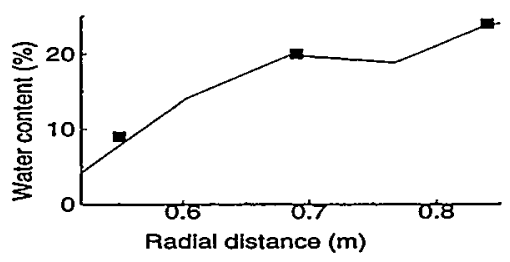

(d) Line I at 30 days

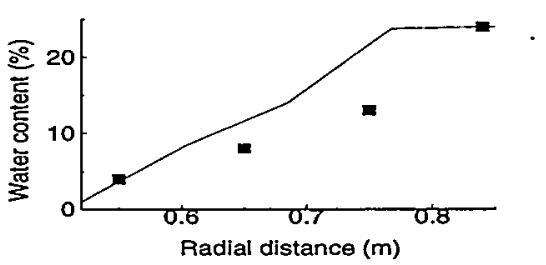

(e) Line I at 258 days

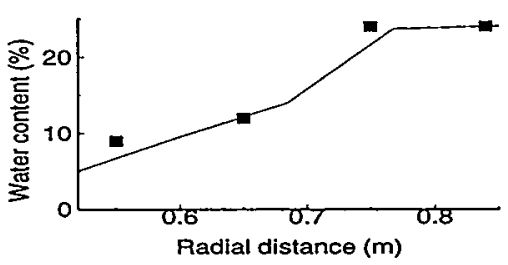

(f) Line I at 438 days

Figure 8.11. Water content versus radial distance from the center of the Test Pit along two lines across the bentonite: Comparison of modeling (lines) and measurements (symbols). 
Figure 8.11 presents a comparison of the model prediction and the measurements of water content along two lines. Most measurements presented in this figure have been determined by core sampling, but a few points at 30 days and those at the rock-bentonite interface are psychrometric monitoring data. At mid-elevation of the heater (Line I in Figure 8.11), the agreement is excellent, except at 258 days near the rock-bentonite interface. The result in Figure 8.11e indicates again that the liquid flow from the boundary is higher in the modeling than in the measurements. The same trend can be seen on Line $\mathrm{J}$ (Figure 8.11a and b), where the water content near the rock boundary is overpredicted by the modeling, possibly because the permeability of the rock is too high in the modeling. The rock permeability between fractures was estimated by the calibration in Task $2 \mathrm{~B}$ to be between $1 \cdot 10^{-17}$ to $1 \cdot 10^{-16} \mathrm{~m}^{2}$. $\mathrm{NNC}$ has also measured the permeability of samples of intact rock to be about $1 \cdot 10^{-20} \mathrm{~m}^{2}$, i.e., three to four orders of magnitude smaller. Using such a low value of rock permeability, the infiltration to the bentonite is reduced and the experimental results are a better match. However, the experimental measurements are conducted in section O-DDA, located near Fracture 2, which has a very high permeability (see Figure 3.3 for location of section 0-DDA near Fracture 2). Therefore, it seems that the hypothesis of very low rock permeability does not apply in this case. An alternative explanation to the delayed wetting at the rock-bentonite interface is that there is a sealing effect at the interface itself. Such sealing properties of the rockbentonite interface have been observed at similar field experiments at (for example) the Underground Research Laboratory (URL) in Canada (personal communication with Prof. R. Young, University of Wales, Canada) and should be further investigated.

\subsection{Results of stress in buffer and rock}

The mechanical response of the buffer and rock mass system is complex, dependent on thermal expansion of the rock, thermal expansion of the heater and bentonite, and swelling of the bentonite. Figure 8.12 and 8.13 presents the modeling results of maximum and minimum compressive stresses in the bentonite. The general response is that the stress becomes tensile immediate around the heater, but compressive near the rockbentonite interface. The stress becomes tensile near the heater when water is driven out and the bentonite is dried out, with corresponding shrinkage. Near the bentonite-rock interface, on the other hand, the bentonite swells from the increased water content, and compressive stresses are created.

Figures 8.14 and 8.15 present comparison of experimental results and modeling predictions at a few monitoring points within the buffer. The experimental results of stress in the buffer are very scattered, and severe problems occurred in sensors located at the bentonite-rock interface due to the surface roughness of the rock. The experimental results of each monitoring point in Figure 8.14 and 8.15 are from 3 different locations in the bentonite at the same radial distance and height but at a different angle (see Figure 3.3 for locations of Sections BBC, DDA and CD). The experimental responses vary widely and are dependent on the angular location in the bentonite. However, a few characteristic types of behavior can be observed. Near the heater (BP3, BP5, BP7), sharp and complex responses occur in both the modeling and experimental data. On the other hand, away from the heater near the bentonite-rock interface (BP1 and BP9), the general response is slower, with little or slightly increased compressive stress. 

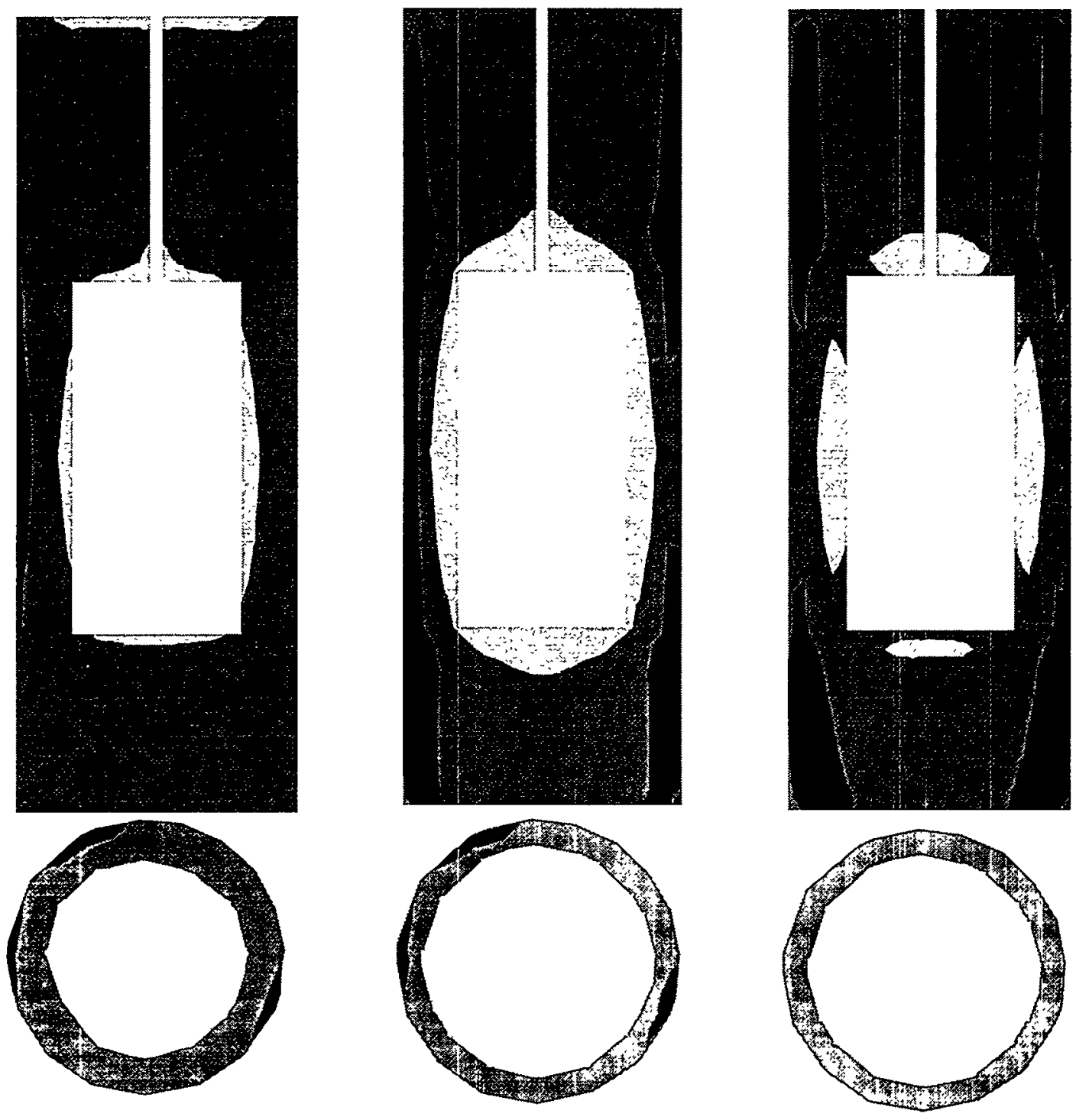

(a) 30 days

(b) 258 days

(c) 438 days

\section{$0.4 \quad 0.0-0.4-0.8(\mathrm{MPa})$}

Figure 8.12. Modeling results of maximum compressive stress contours (tension positive) in the bentonite for Task $2 \mathrm{c} 2$ after (a) 30 days, (b) 258 days (end of heating period), and (c) 438 days (end of cooling period). 

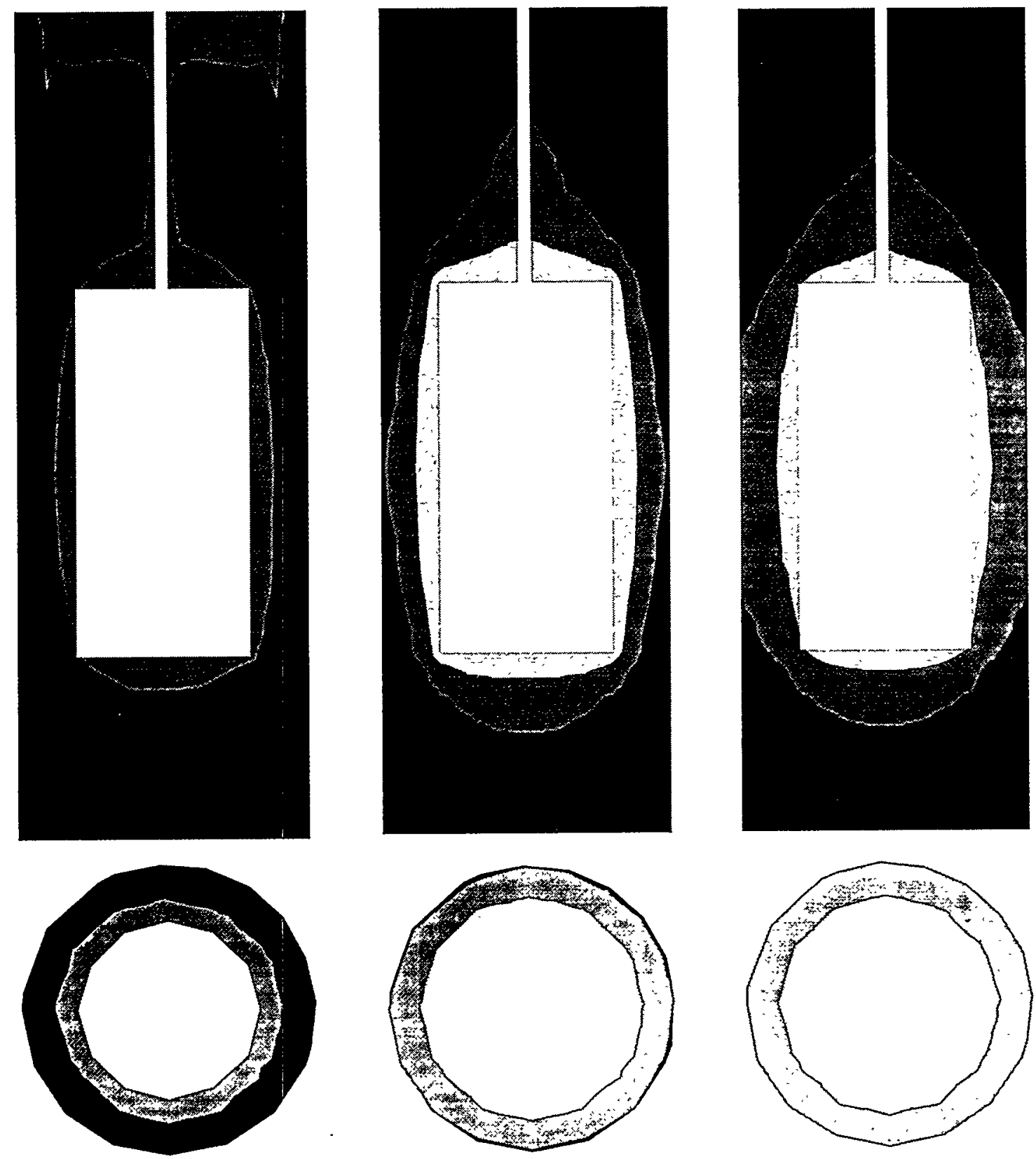

(a) 30 days

(b) 258 days

(c) 438 days

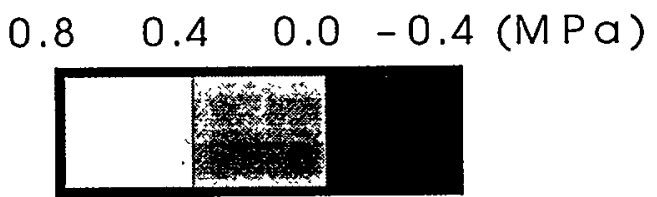

Figure 8.13. Modeling results of minimum compressive stress (tension positive) contours in the bentonite for Task2c2 after (a) 30 days, (b) 258 days (end of heating period), and (c) 438 days (end of cooling period). 

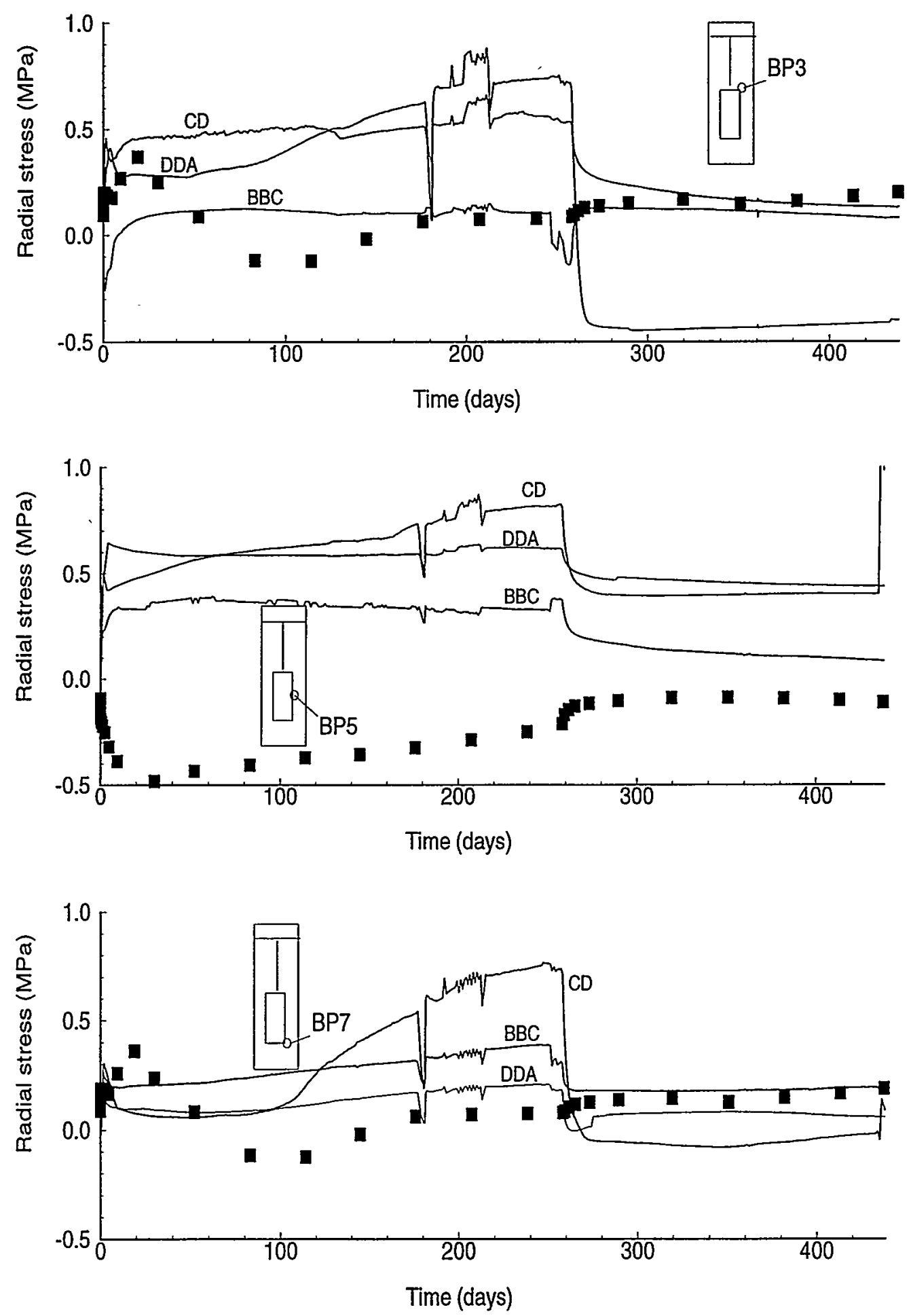

Figure 8.14. Total stress history (compression positive) for monitoring points at the heater surface. 

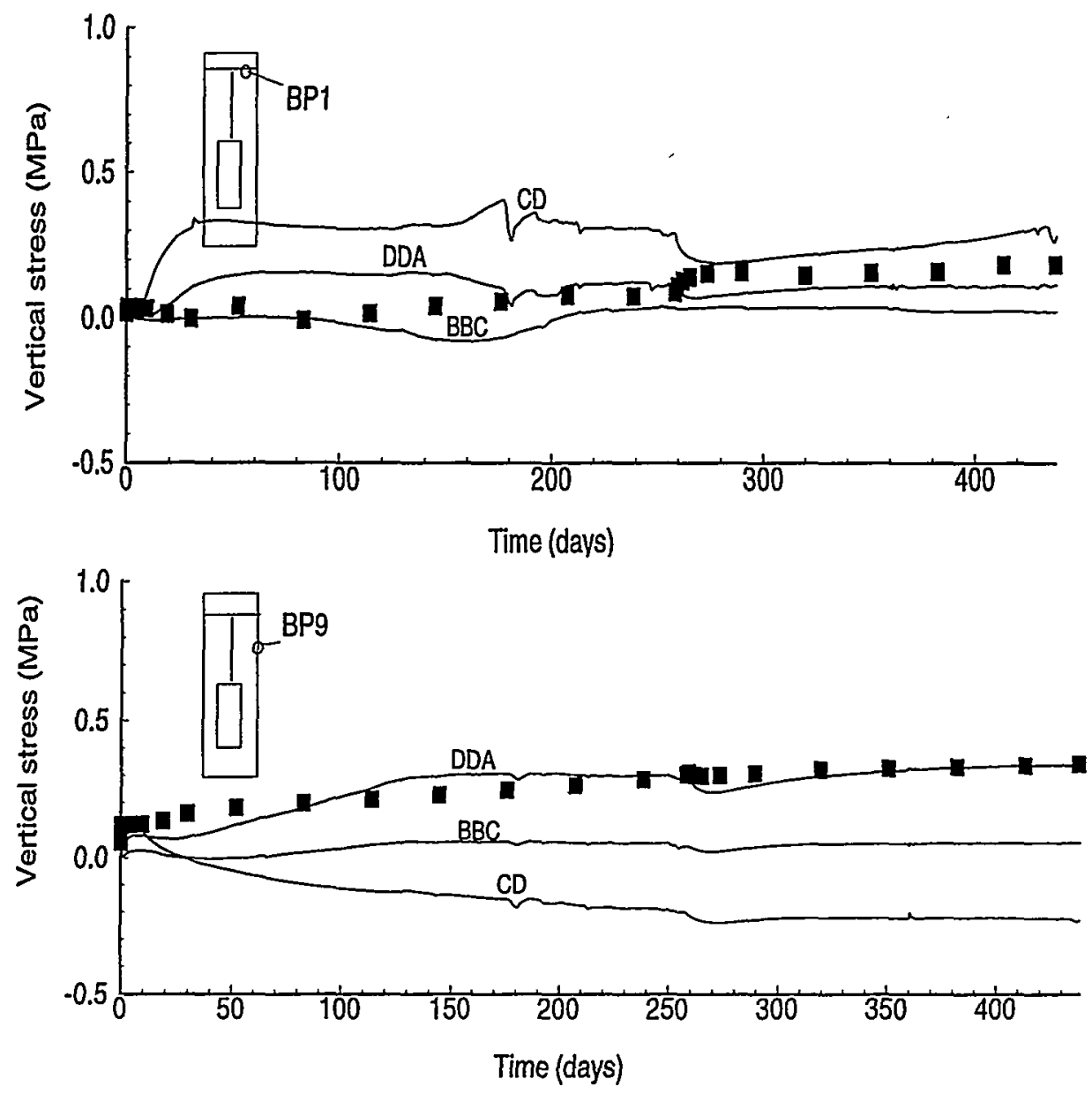

Figure 8.15. Total stress history (compression positive) for monitoring points at the rockbentonite interface.

Considering the scattered experimental results at each point, the modeling results can be considered as satisfactory regarding the magnitude of stress, although it must be acknowledged that the response at each point cannot be predicted in detail. There is, however, one important difference between modeling and experimental results. In BP5, the modeling predicts that the stress becomes tensile from the drying of the bentonite. The experimental results, on the other hand, show that the stress becomes compressive near the heater. In general, though, the swelling pressure in this heater test is low, with the total stress roughly in the interval -0.5 to $0.5 \mathrm{MPa}$. Thus, there is no dominating signature of the swelling pressure in the total stress of the buffer. Instead, the stress depends partly on thermal expansion of buffer and rock, and partly on the swelling of the buffer.

The heating creates thermal stresses of up to $12 \mathrm{MPa}$ in the rock adjacent to the wall of the Test Pit (Figure 8.16). These thermal compressive stresses will tend to relieve some of the tensile stresses created at the Test Pit wall after excavation. Also, thermal expansion and thermal stresses are closing the fractures in the near field. 


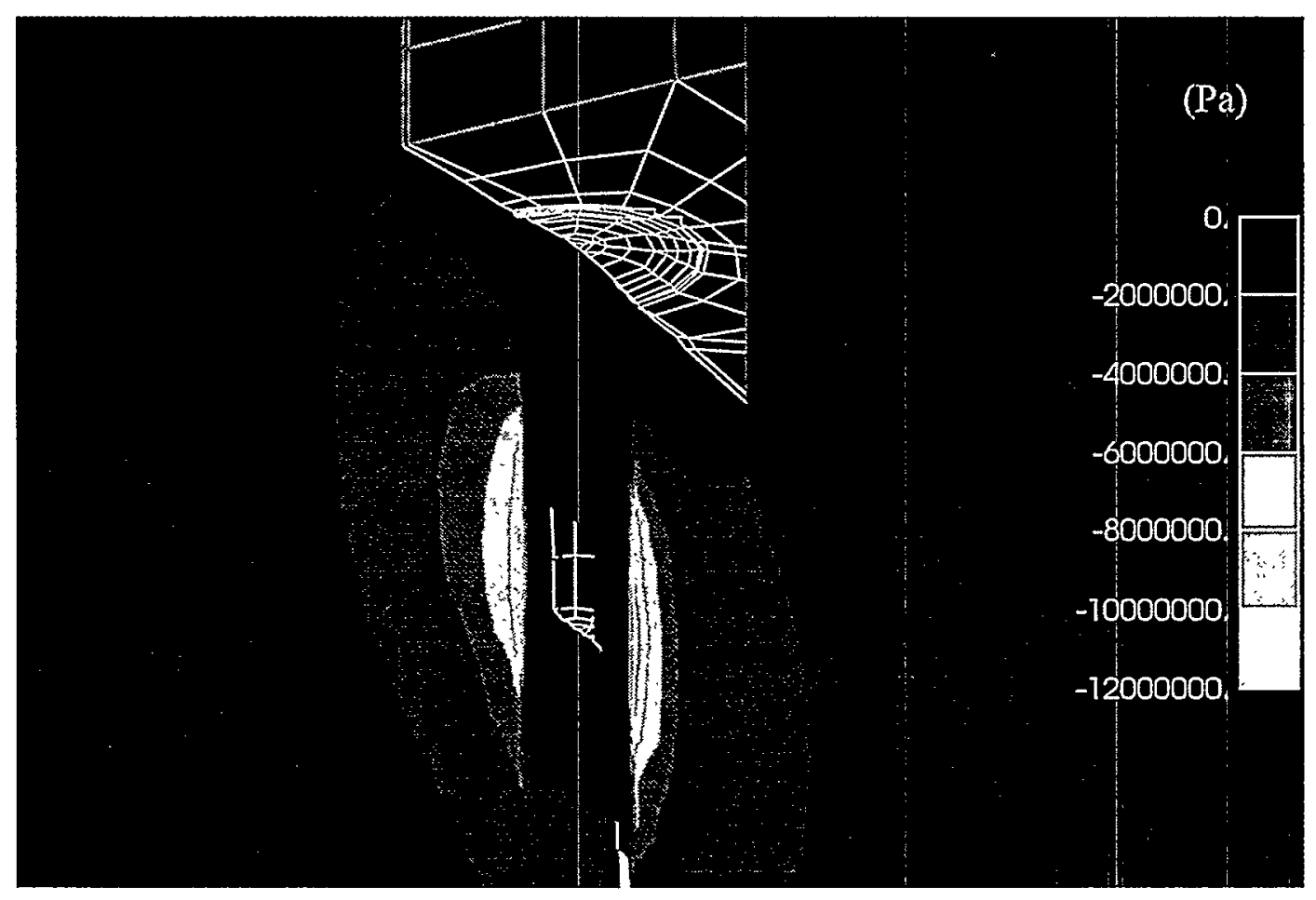

(a) Vertical section through the Test Drift and test pit

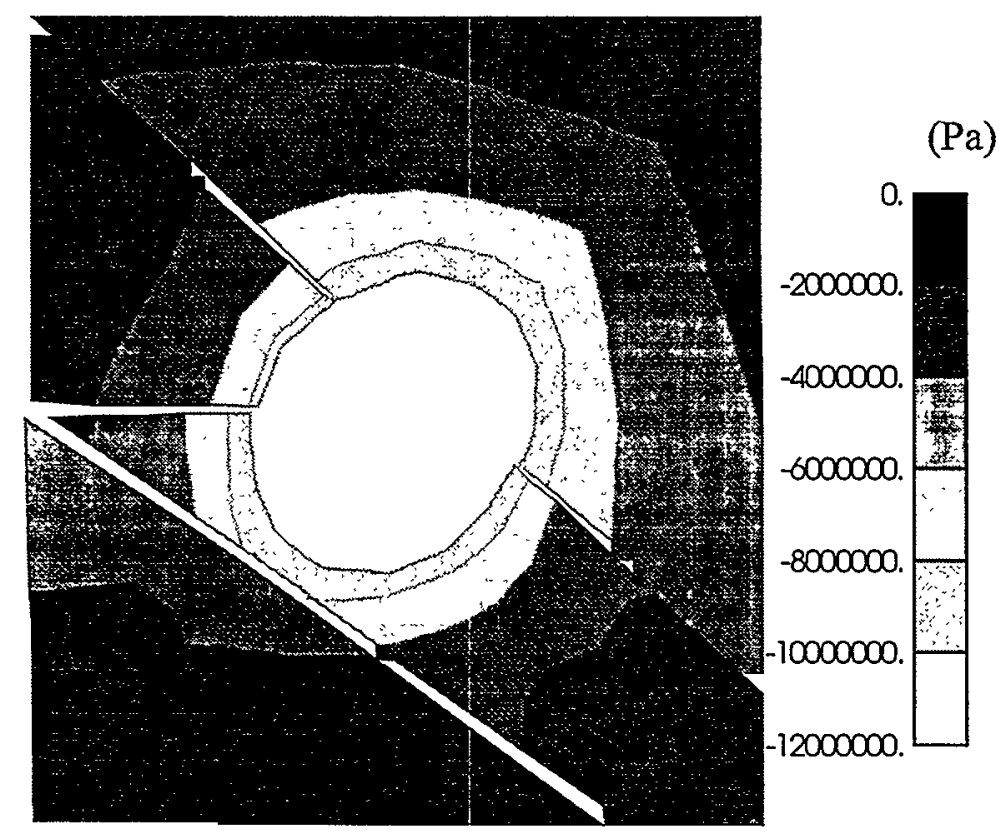

(b) Horizontal section at 3 meters below the Test

Figure 8.16. Modeling results of maximum principal stress at 258 days as a result of thermal expansion of the rock 


\subsection{Results of displacement in buffer and rock}

The general displacement pattern in the buffer during the heater test is an expansion in the vertical direction and compression or expansion in radial direction dependent on location. Figure 8.17 shows that at 30 days, the main deformations result from the expansion of the heater and rock, with the displacements in general less than $0.4 \mathrm{~mm}$. At 258 days, the displacement response appears to be dominated by the drying and shrinking of the bentonite near the heater, and the first column of elements in the bentonite along the heater surface are compressed in the radial direction. At the same time, the elements at the rock-bentonite interface expand slightly. The maximum displacements are now up to $1 \mathrm{~mm}$ in the bentonite immediate below the heater and at the periphery surface of the heater. After 438 days, a large deformation still remains, especially immediate below the heater.

The general deformation pattern obtained in the modeling agrees well with the strain measurements (not shown). The measurements also indicate expansion in the vertical direction and compression in the radial direction near the heater. In addition, after completion of the field experiment, fracturing in the bentonite could only be observed below the heater. This location is also where the modeling shows the largest remaining deformation at 438 days (Figure 8.17). One reason for the vertical expansion of the bentonite may be that the rock is expanding and the floor of the Test Drift is heaving (Figure 8.18). In general, the rock is expanding upwards into the drift with a maximum displacement of about $0.6 \mathrm{~mm}$. Figure 8.19 shows that at 3 meters below the floor of the Test Pit, the rock is expanding and the fractures are closing. At this level, the displacements are only up to $0.3 \mathrm{~mm}$.

Figure 8.20 presents a comparison between modeling and experiments of vertical displacements in the rock along boreholes KBM4 and 5. The agreement is good, for both magnitude and its distribution along the borehole.

\subsection{Summary of results of Task $2 \mathrm{C}$}

Modeling of the full-scale heater experiment is a challenging test of the robustness and applicability of ROCMAS for practical field problems. Task $2 \mathrm{C}$ was performed based on two model calibrations: the calibration for the rock property field by Task $2 \mathrm{~B}$ and calibration of the bentonite behavior using laboratory experiments. Therefore, Task $2 \mathrm{C}$ is a prediction of the fully coupled THM behavior of the heater-bentonite-rock system and the interaction between the different components. Because of the complexity and uncertainties in the material behavior, fracture geometry and properties, scale and time effects, and reliability of sensors and data for long-time experiments, good agreement between predicted and measured results should not be expected for all sensors. Despite these limitations, good agreement was achieved for most of the predicted variables in the buffer, especially temperature and water content distribution and rock temperature (Table 8.3). The results do, however, show that the liquid flow from the rock into the bentonite was overestimated by the numerical modeling. One possible explanation is that a sealing effect occurs at the rock-bentonite interface, retarding the wetting of the bentonite from the saturated rock surface. 

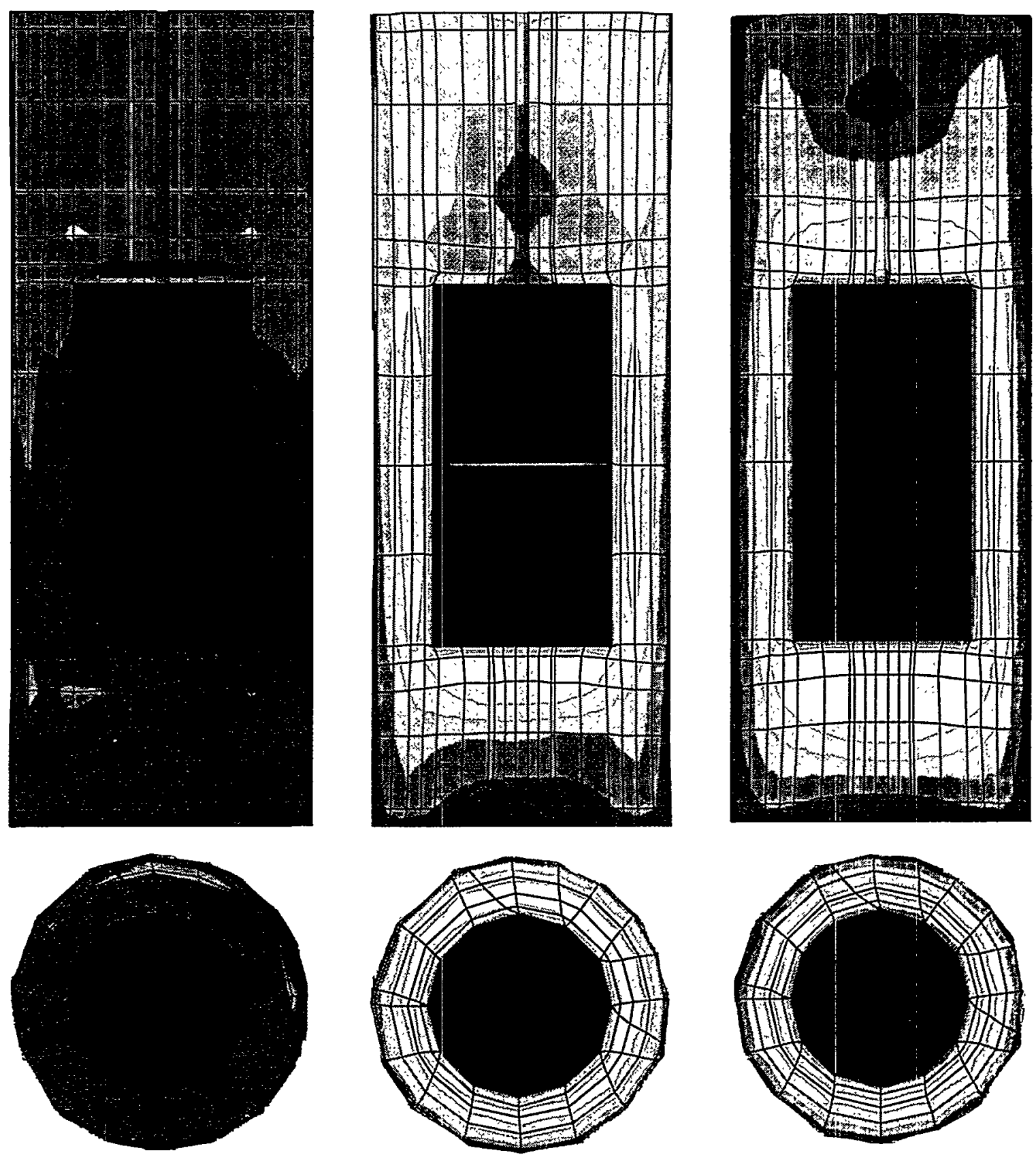

(a) 30 days

(b) 258 days

(c) 438 days

\section{$\begin{array}{lllllll}1.0 & 0.8 & 0.6 & 0.4 & 0.2 & 0.0 & (\mathrm{~mm})\end{array}$}

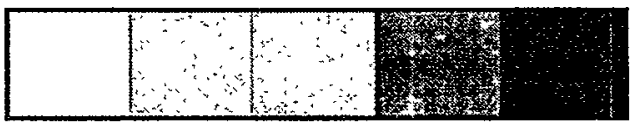

Figure 8.17. Displacement contours and deformed mesh in the bentonite for Task $2 \mathrm{c} 2$ after (a) 30 days, (b) 258 days (end of heating period), and (c) 438 days (end of cooling period). 


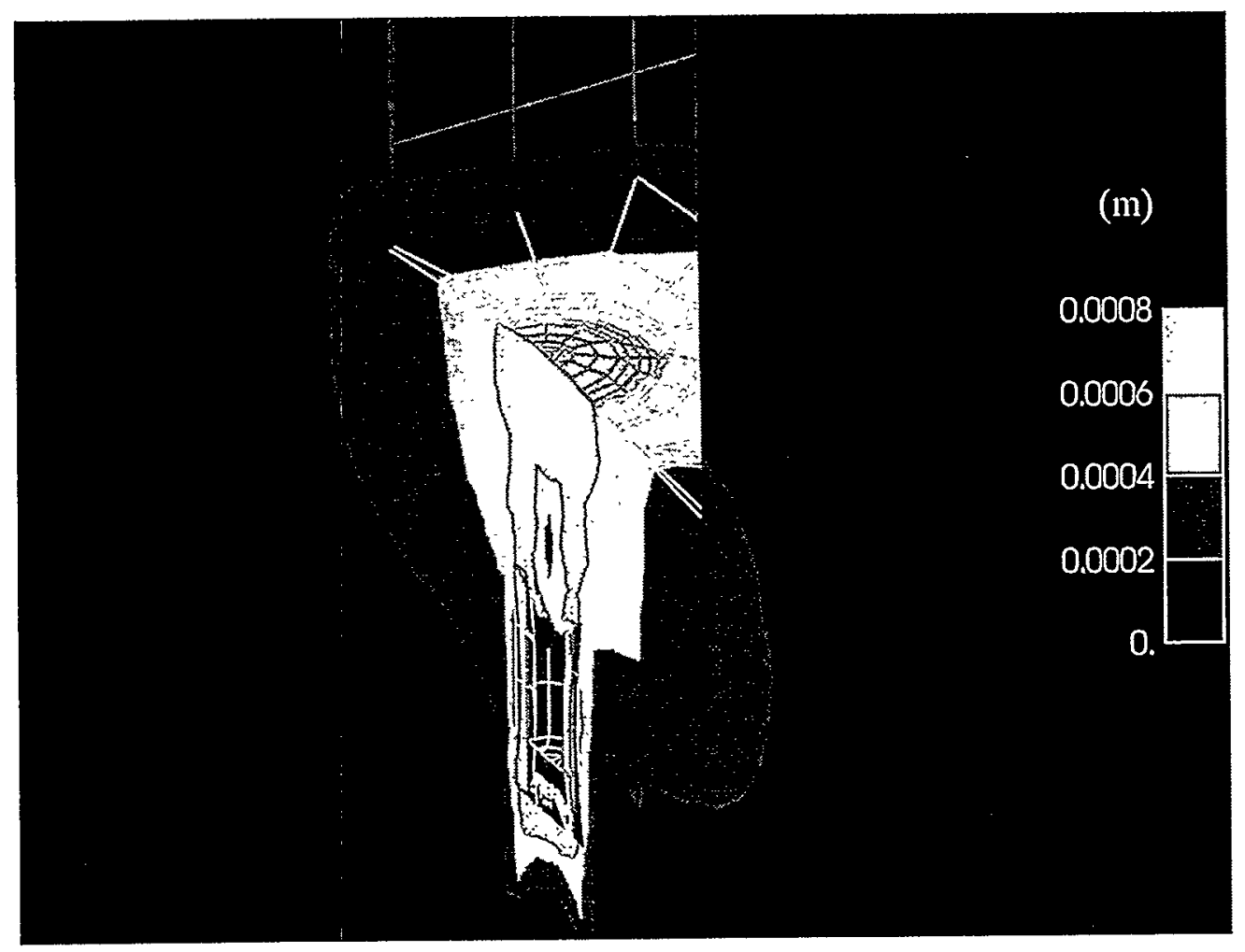

(a) Vertical section through test drift and deposition hole

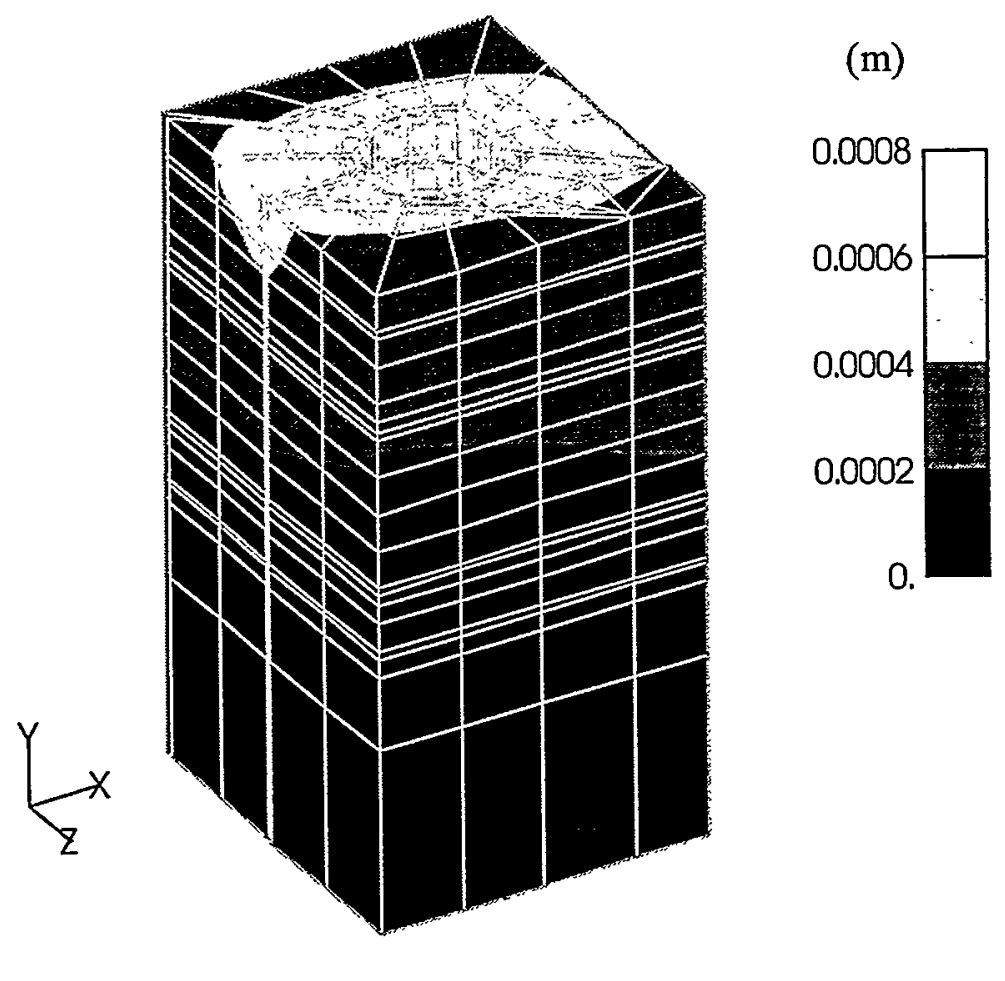

(b) Near field rock

Figure 8.18. Modeling results of incremental displacement in the rock at 258 days resulting from heating and thermal expansion of the rock. 

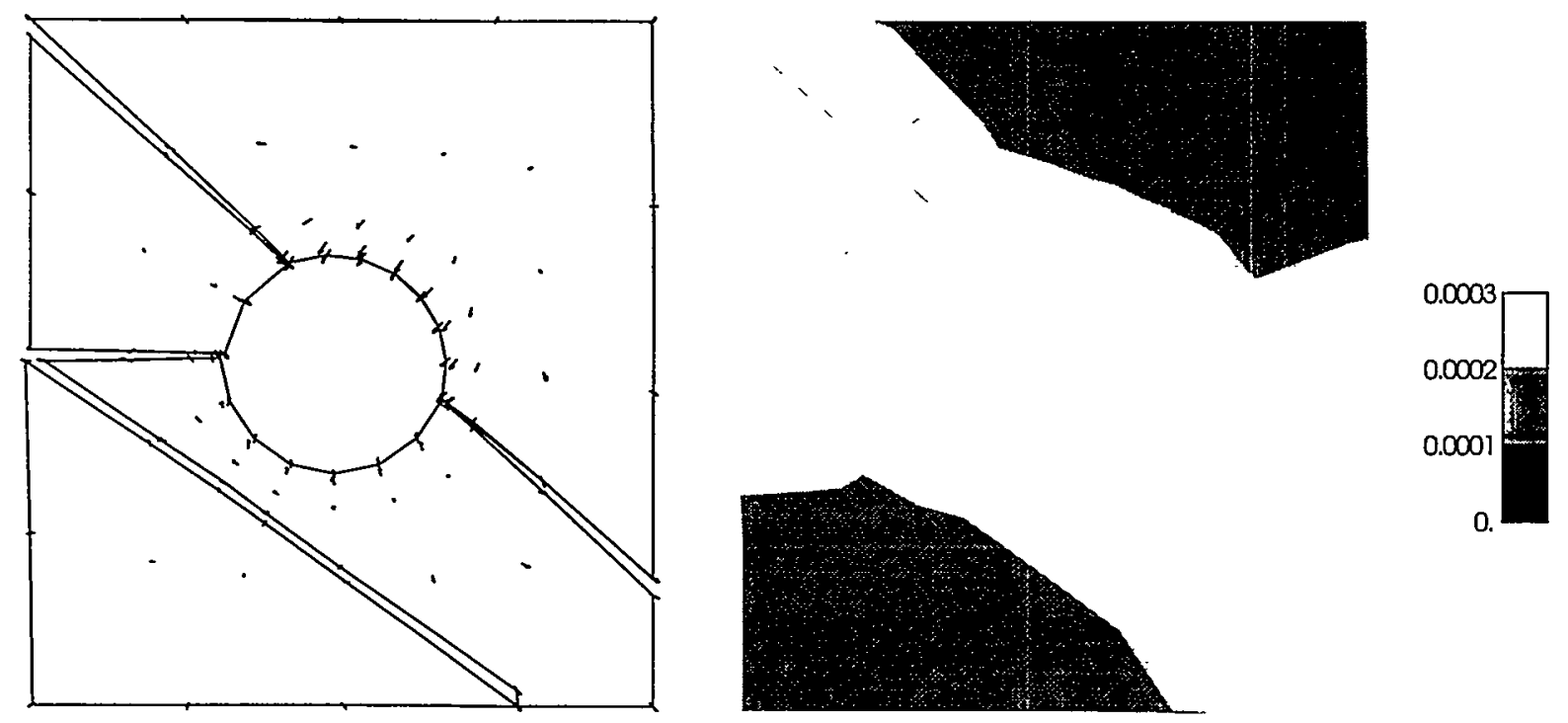

Figure 8.19. Modeling results of horizontal section at 3 meters below the Test Drift with vectors and contours of incremental displacement at 258 days resulting from heating and thermal expansion.

The agreement of swelling pressure in the bentonite may be regarded as satisfactory because both the modeling and measurements showed that the stresses are low in this case $(<0.5 \mathrm{MPa})$, and at the same time, the general responses of strain could be predicted by modeling. However, the details of the very complex responses of swelling pressure, which seemed to depend on local condition at the sensors, could not be captured in the modeling. The concept of the effective stress law is one source of uncertainty at low saturation. This uncertainty was amplified by the laboratory experiment for calibration of the swelling properties being conducted only at a degree of saturation above $66 \%$, while saturation at the heater test was as low as $10 \%$. Further improvement of mechanical modeling could include no tension behavior, when drying takes place at a water content below the bentonites' shrinking limit. This will prevent high tensile stresses from developing during the drying.

Good agreement exists regarding vertical displacement along boreholes KBM4 and KBM5, which are the only reliable displacement measurements in this case. Both modeling and measurements show that the rock is expanding upwards into the Test Drift, with a maximum incremental displacement (over 1 meter) on the order of $0.1 \mathrm{~mm}$. The mechanical measurements are, however, too few to draw any firmer conclusions about the model prediction of displacement. 
The overall conclusion from Task $2 \mathrm{C}$ is that the agreement between model and experiments are satisfactory or good, with remaining uncertainties in the mechanics of the buffer and the hydraulics of the rock-bentonite interface.

Table 8.3. Summary of Agreement Between Model Prediction and Measurements and Suggestions for Possible Improvements of the Modeling.

\begin{tabular}{|c|c|c|}
\hline Process & Agreement & Possible Improvements \\
\hline $\begin{array}{l}\text { Temperature in buffer } \\
\text { and rock }\end{array}$ & Very good & No \\
\hline Water content in buffer & Good general response & $\begin{array}{l}\text { Reduce infiltration from rock } \\
\text { by: } \\
\text { 1) Reduced rock permeability } \\
\text { 2) Considering sealing effect } \\
\text { at interface }\end{array}$ \\
\hline Fluid pressure in rock & Satisfactory & $\begin{array}{l}\text { Slight reduction of pressure } \\
\text { by reducing far field fluid } \\
\text { pressure boundary condition }\end{array}$ \\
\hline $\begin{array}{l}\text { Swelling pressure in } \\
\text { buffer }\end{array}$ & $\begin{array}{l}\text { Both model and field } \Rightarrow \text { low } \\
\text { swelling stress }(<0.5 \mathrm{MPa}) \text {. } \\
\text { Uncertain at low saturation }\end{array}$ & $\begin{array}{l}\text { 1) Tensile failure model for } \\
\text { the bentonite } \\
\text { 2) Temperature effects on } \\
\text { swelling pressure. } \\
\text { 3) Need more laboratory } \\
\text { data for low saturation. }\end{array}$ \\
\hline Displacement in rock & $\begin{array}{l}\text { Good for the limited data } \\
\text { available. Small displacements }\end{array}$ & $\begin{array}{l}\text { Need more displacement } \\
\text { measurements. }\end{array}$ \\
\hline
\end{tabular}




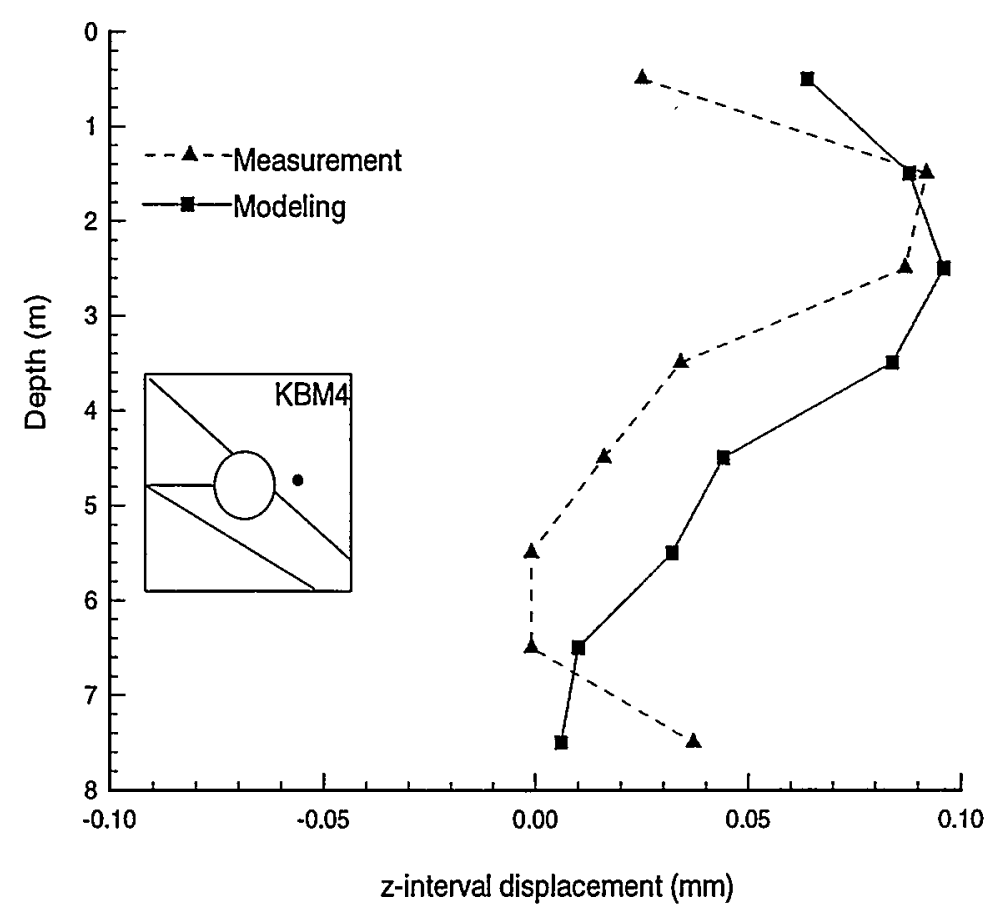

(a) KBM4

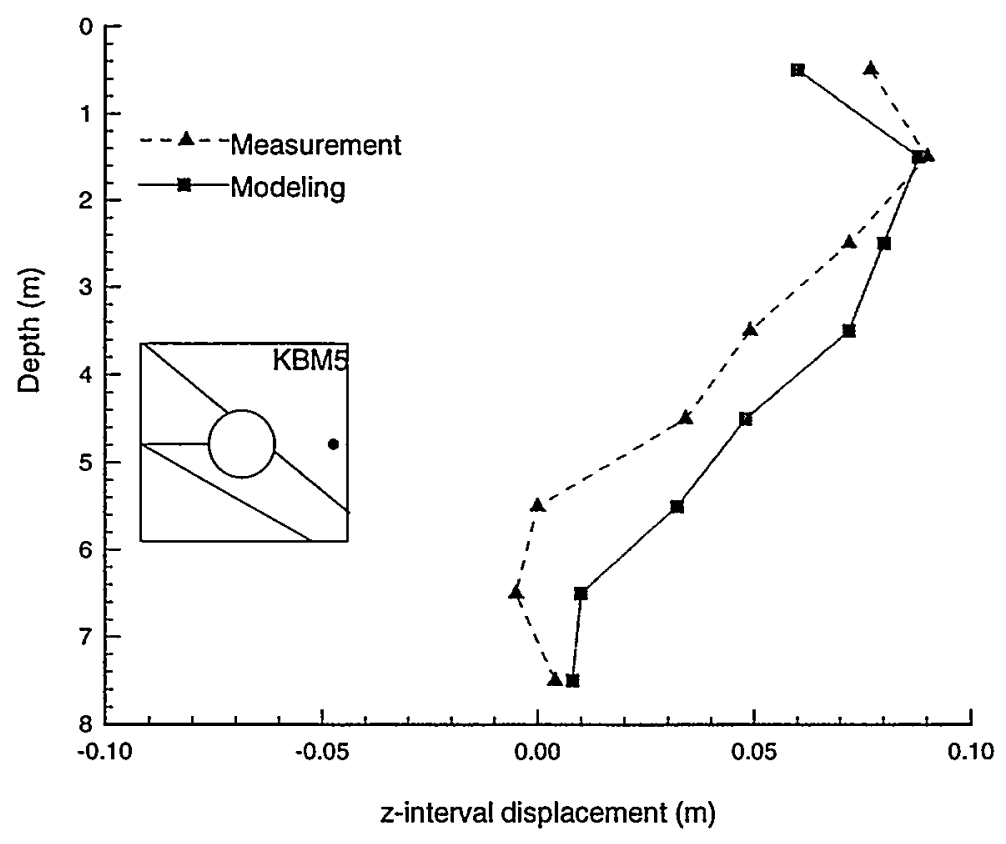

(b) KBM5

Figure 8.20. Comparison between modeling and measurements of axial interval displacement due to heating along borehole KBM4 and KBM5. 


\section{Overview of Coupled THM processes at Kamaishi Mine}

The following is an illustrated overview of the thermal, hydraulic, and mechanical processes and the coupling between these at Kamaishi Mine. These observations are site specific but are of general interest for nuclear waste repositories in fracture crystalline rocks.

At Kamaishi Mine, the stress and fluid pressure is low, and the rock mass is highly fractured. The mechanical and hydraulic responses are thus complex and very sensitive to local material inhomogeneities such as fractures. In addition, the rock mass near the drifts is unsaturated, probably a result of drift ventilation.

In the near-field rock, the fluid flow is dominated by a few shear-fractures that are forming a compartment of high permeability.

These fractures have shown past shearing and are reported to be filled with minerals up to $20 \mathrm{~mm}$ and having a visible aperture of about $1 \mathrm{~mm}$. An equivalent hydraulic aperture of the fractures was backcalculated to be in the order of 0.01 to 0.04 $\mathrm{mm}$ assuming a homogeneous fracture model.

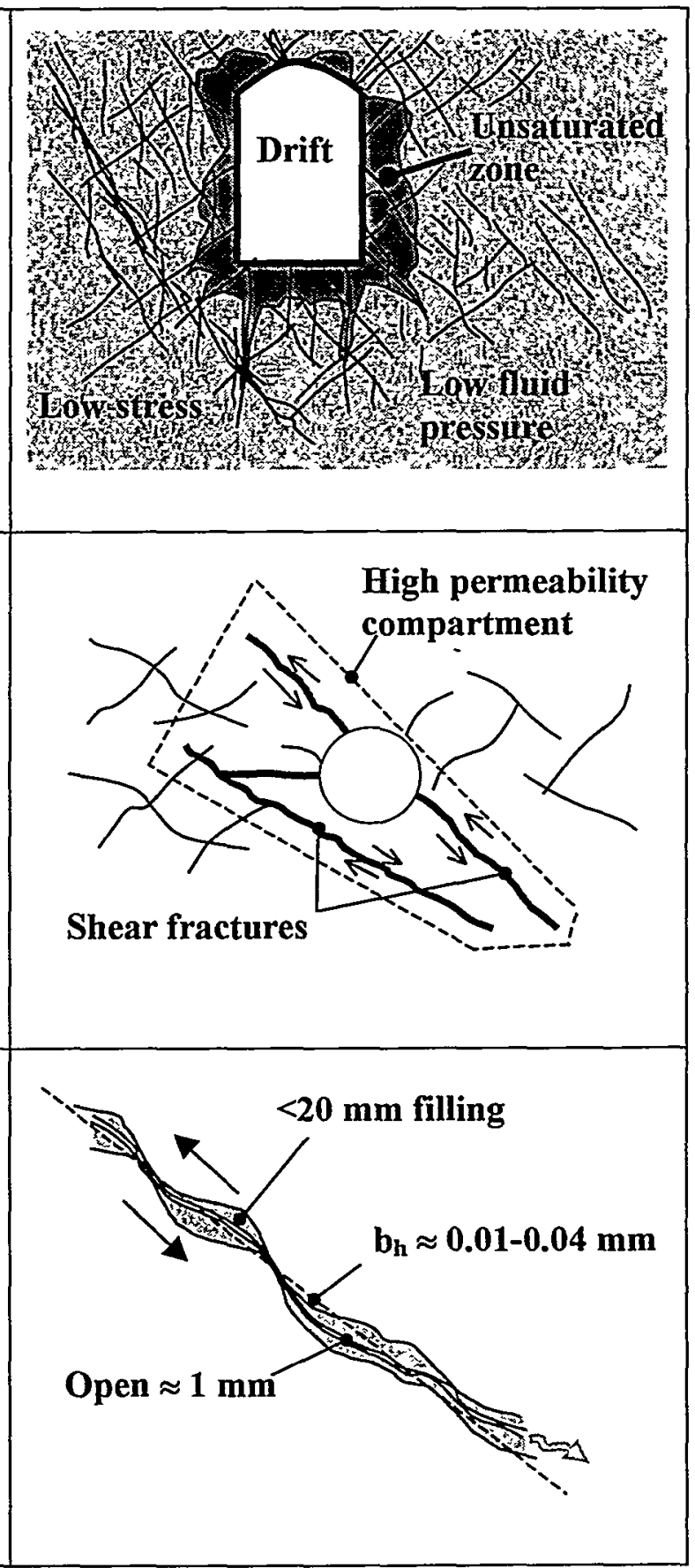


Hydraulic injection tests show that these fracture planes are partially filled, with areas open to flow forming flow channels. Thus, they are highly heterogeneous from a hydraulic point of view.

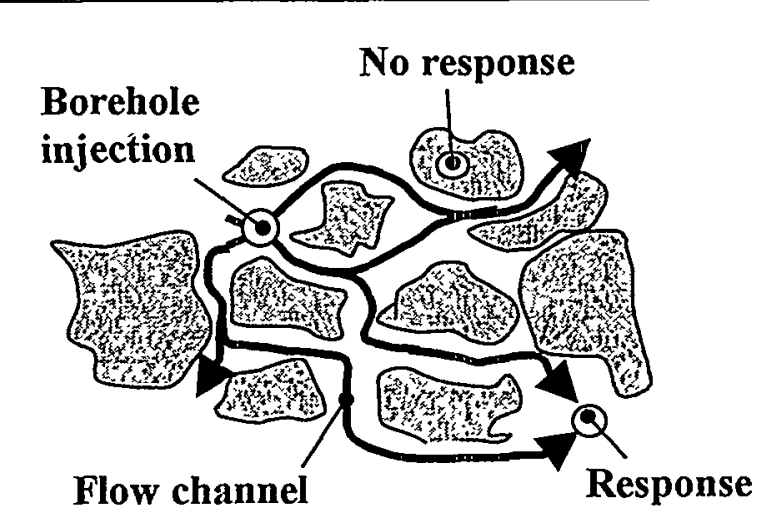

These fractures are curved, branching, and have a variable width of mineral filling. The mechanical stiffness of fractures is not known but are likely to vary over the fracture plane. Hence, the fracture mechanical properties are heterogeneous.

During drilling of the Test Pit, the displacements away from the wall of the Test Pit are small (about $0.1 \mathrm{~mm}$ ) and are inconsistent with each other. Dynamic effects from the full-face drilling may have triggered the displacements because this is a low-stress environment.

The field measurements surprisingly indicate that at least part of the Test Pit is expanding during the full-face drilling of it.
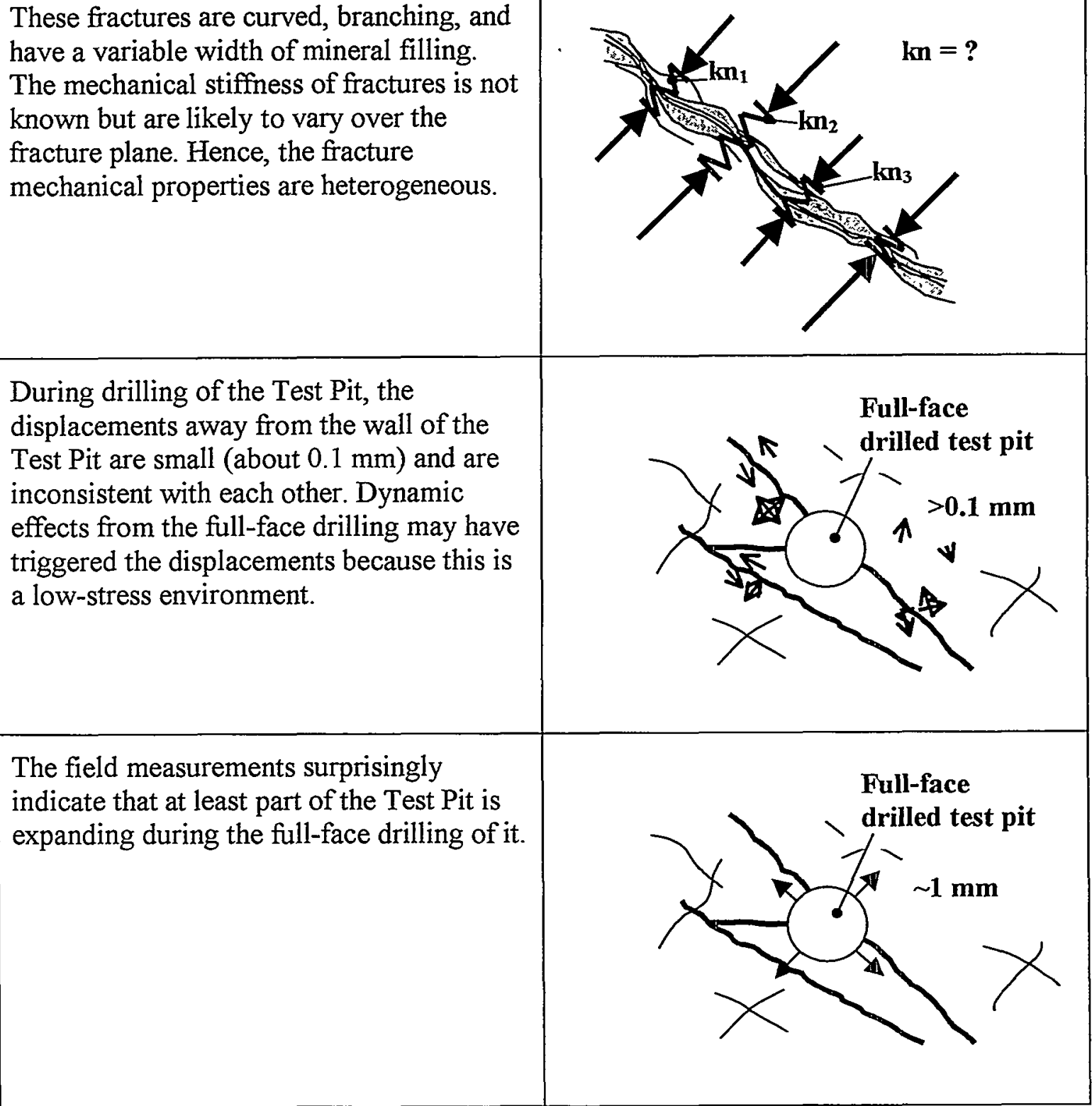


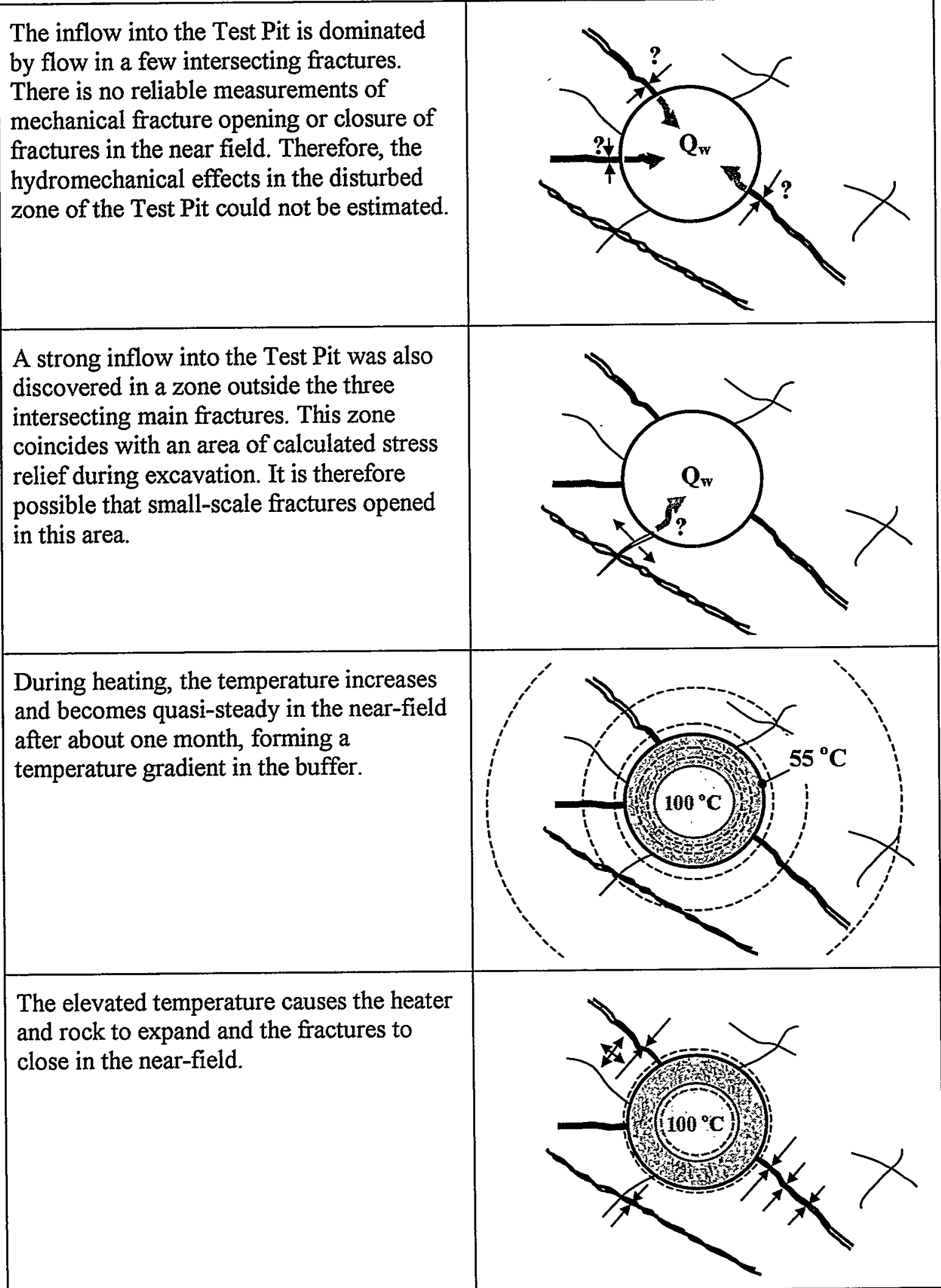




The increased temperature near the heater
causes vaporization of liquid water. This
vapor is transported outwards along the
thermal gradient by molecular diffusion in
air-filled pores. At the same time, liquid
water is infiltrating from the fully saturated
rock towards dryer regions of the bentonite.




\section{Scientific achievements in DECOVALEX Task 2}

The modeling of the Kamaishi Mine Heater Test has required research teams in DECOCALEX to model coupled THM processes on a practical field-scale problem. The problem includes large rock masses as well as detailed near-field processes in discrete rock fractures and the bentonite buffer. Solving this realistic problem has boosted strong code developments within the DECOVALEX group for analysis of all the important processes. In this project, the newly developed three-dimensional version of ROCMAS for unsaturated media was (for the first time) applied to a large-scale problem including over 60,000 unknowns and transient simulation times of over a year. The code was validated against laboratory experiments and successfully applied to predict THM responses at Kamaishi Mine. 


\section{Lessons learned from modeling of Kamaishi Mine Heater Test}

The Kamaishi Mine heater test has provided very valuable experience in analysis of coupled THM processes for a problem similar to that posed by a real nuclear waste repository. Especially valuable was the international cooperation of several research teams within DECOVALEX for solving the problems. Each research team contributed and learned from each other, and pushed the work to a higher scientific level. In Task 2 there was good cooperation between the research teams and great administrative and technical support from JNC and the DECOVALEX secretariat. The following are a few important scientific lessons learned from the project (Jing et al., 1999):

- Our current capability of modeling coupled hydro-mechanical processes in fractured rocks with complex fracture geometry is still rather limited, basically because of a lack of knowledge about the fracture geometry and uncertainty about fracture in situ properties.

- Our current knowledge about the de-saturation in rock and the EDZ issue is rather limited for predictions of high confidence.

- Despite great progress in characterization and parameterization of bentonite used in Task $2 \mathrm{C}$, our current knowledge about physical behavior of partially saturated swelling clays, such as in the areas of effective stress behavior, vapor flow, and water retention processes, is still very limited.

- Our current knowledge on the rock-buffer interaction, especially the hydraulic interactions, is limited for confident numerical predictions.

- Very limited effect on the hydraulic behavior of the buffer from the surrounding rock and rock fractures could be observed by the measurements. This may be due to the following reasons:

- The in situ experiment was not maintained long enough for the possible larger hydro-mechanical interaction between the rock and buffer at the longer period could not be observed.

- The hydraulic conductivity of rock is much higher than that of the buffer, so that whether fractures in the rock are considered or not resulted in little difference in hydraulic behavior of the buffer.

- The rock fractures near the buffer might have been sealed by buffer material during installation of the buffer.

- Very limited mechanical effects on the buffer from the surrounding rock was also observed, which may be caused by:

- The low stress field in the test area makes the rock mechanically inactive, besides the fact that thermal expansion and stresses induced by heating have also limited effect because of low power input and temperature gradient.

- Pointwise measurement of mechanical behavior may not be nearly enough to capture essential aspects and pattern of the mechanical responses.

- Reliability of the field measurements over a long time needs to be verified and improved for reliable numerical verifications, especially the on-site sampling and calibration of sensors and material.

- Proper design and implementation for the study and characterization of the rockbuffer interface, with and without fractures in rock. 


\section{Suggestions for future in situ heater tests}

Based on the above conclusions and lessons learned, the following recommendations are proposed to improve numerical modeling capabilities for fractured rocks and buffer material for nuclear waste repositories and for future projects addressing THM processes:

- Modeling should be concentrated on representing and predicting the general overall system response. In the Kamaishi Mine as well as at other sites of fractured rocks, we will not be able to predict the behavior at every single point. The presence of fractures implies that there is a substantial spatial variation in the responses of (for example) fluid flow and displacements. Every fracture cannot be included in a model and we cannot know the exact location or property of all the fractures. With this in mind, we believe the effort should be to model and predict the general behavior of the rock mass and possible estimate maximum values (for example, maximum displacement). A modeling of this problem should therefore include a stochastic approach considering heterogeneity, not only on hydraulic properties but also on the mechanical and hydromechanical properties.

- Field measurements should be designed to show the general overall system response. Because the system response shows a larger spatial variation, a few point measurements have little value, especially when comparing the results to a numerical model. For example, point measurements of rock strain showed a large variation, depending on their location. The measurements are too few to make a statistical evaluation of the general response, and the point responses are of little value for modelers. The expansion of the Test Pit was only measured between four points and could not be confirmed by any independent measurement. This leaves room for doubt about the quality of these measurements. The displacements of Fracture 1 and 2 were also measured only in one point of the fracture plane. The response may depend on the local condition at that specific point on the fracture plane, and it may not be a general response of the fracture. To obtain the general response of displacement, measurements systematically aligned along lines on surfaces or along boreholes are preferred. For instance, the vertical displacements along the axial directions of KBM4 and KBM5 were useful.

- Criteria should be developed during the projects that clarify what is a good or a bad prediction. For example, the displacement could not be predicted in each and every point of the rock mass. The measurements showed that the Test Pit was expanding while the modeling shows convergence. It was therefore considered a bad prediction. However, one should keep in mind that although the direction disagrees, these displacements are on the order of $1 \mathrm{~mm}(0.1 \%$ of the pit diameter) or less and are probably not relevant for the stability of the construction. They would not jeopardize the integrity of a nuclear waste canister. Furthermore, the modeling predicted correctly that the maximum displacement would be on the order of $1 \mathrm{~mm}$. In view of this the model prediction could be considered as satisfactory. On the other hand, if the 1-mm displacement is concentrated in a fracture, the permeability of that fracture may change by several orders of magnitude. Thus, it must be clarified in the project what is to be expected of the modeling teams, and criteria should be developed (by the project) defining what is a good or bad prediction. 
- The quality of measurements or data should be judged and resolved during the project. The quality of the data should be judged to remove any uncertainties regarding their accuracy. For example, if there are doubts about the measurements of the pit expansion, this should be clearly stated, and these measurements could be removed from comparison. Every attempt should be made to resolve such doubts. In this case, one could perform over-coring stress measurements in the floor of the Test Drift to see whether there is tension stress in the area causing the expansion. A second example is the laboratory test of the swelling pressure, which showed a peculiar temperature dependency. The general opinion was that these experimental results are wrong, but the reason was not resolved, which causes uncertainties.

- Further research is needed on in situ properties and modeling of major fractures. The three dominating fractures in the near field of the deposition hole were reported to be shear fractures with up to $20 \mathrm{~mm}$ of filling, with a visual aperture on the order of $1 \mathrm{~mm}$. In our modeling, we could back-calculate hydraulic apertures of about 8 to 40 microns from the inflow measurements. These fractures are very different from fractures that are commonly tested in laboratory drill core samples. We do not even know the order of magnitude of stiffness in these large-scale fractures. Therefore, rather than developing more sophisticated joint models for detailed behavior of small-scale fractures, we need to learn the basic behavior of the large scale features that can be incorporated in a numerical model. In a field test like this, it is not sufficient to measure the fracture.

- Further research is needed in modeling of the bentonite mechanical behavior at low saturation. The laboratory test for swelling pressure was performed for saturation above $66 \%$. This test could be simulated with the various computer codes in the project. However, in the heater test, the saturation was below $66 \%$ in a large part of the bentonite and it was down to $10 \%$ near the heater. The modelers' predictions of the mechanical response near the heater varied widely. One reason is that all the models were calibrated against the laboratory experiments performed at high saturation, and apparently these experimental results are not relevant for lowsaturation condition. Thus, if possible, the swelling pressure test also could have been conducted at lower saturation.

- Further research is needed on the rock-bentonite interface behavior. The apparent delay of the infiltration from the rock to the bentonite in the Kamaishi experiment suggests that there is a sealing effect in the interface. Such a sealing effect could be studied in small-scale laboratory tests and numerical modeling.

- Aspects of unsaturated rock resulting from drift ventilation should be analyzed. The rock mass was not fully saturated around the Test Drift, and there was a large spatial variation in water level in the near-field rock, below the Test Drift. The large variation in fluid pressure is probably caused by fractures that are or are not connected to the drift. Ventilation of a drift can create a negative water pressure, and the rock dries from the drift boundary. The drying takes place first in highpermeability fractures and can thereby create the variation in near-field fluid pressure seen at Kamaishi Mine. 


\section{Concluding remarks}

The ROCMAS code has been developed to handle the problem of coupled THM responses in unsaturated clay and rock under thermal load. The new development of ROCMAS was successfully tested for modeling of laboratory experiments conducted in bentonite clay and for a blind prediction of a full-scale heater-bentonite and fractured rock problem. Modeling of the Kamaishi Mine in situ heater experiment was a challenging test of the robustness and applicability of ROCMAS for practical field problems. The results show that temperature and water content, both in the bentonite and rock, can be modeled with confidence. Uncertainty remains, however, in modeling the mechanical behavior of bentonite at low saturation and also in the treatment of the rockbentonite interface.

\section{Acknowledgments}

Financial support by a grant from the Swedish Nuclear Power Inspectorate is gratefully acknowledged. Work is also partially supported by the Office of Science, Office of Basic Energy Sciences, Engineering and Geosciences Division of the Department of Energy, under contract No. DE-AC03-76SF00098 and by the National Energy Research Scientific Computational Center (NERSC) through Contract DE-AC03-76SF00098. 


\section{References}

Biot M. A. General theory of three dimensional consolidation. J. Applied Physics, 12, 155-164 (1941).

Chijumatsu M., Fujita T., Sugita Y., Ishikawa H. and Moro Y. Coupled thermo-hydromechanical experiment at Kamaishi mine. Instrumentation. Power reactor and nuclear fuel development corporation (PNC). TN8410 96-056 (1996a).

Chijumatsu M., Fujita T., Sugita Y. and Ishikawa H. Coupled thermo-hydro-mechanical experiment at Kamaishi mine. Initial data around the T-H-M experiment area. Power reactor and nuclear fuel development corporation (PNC). TN8410 96-057 (1996b).

Chijumatsu M., Fujita T., Sugita Y., Ishikawa H. and Kobayashi A. Coupled thermohydro-mechanical experiment at Kamaishi mine. Hydraulic tests. Power reactor and nuclear fuel development corporation (PNC). TN8410 96-058 (1996c).

Chijumatsu M., Fujita T., Sugita Y. and Ishikawa H. Coupled thermo-hydro-mechanical experiment at Kamaishi mine. Laboratory rock property tests. Power reactor and nuclear fuel development corporation (PNC). TN8410 96-060 (1996d).

Chijumatsu M., Fujita T., Sugita Y. and Ishikawa H. Coupled thermo-hydro-mechanical experiment at Kamaishi mine. Measurements of inflow rate into the Test Pit. Power reactor and nuclear fuel development corporation (PNC). TN8410 97-070 (1997).

Doe T. Evaluating fracture network geometry from hydraulic data at underground test facilities. Proceeding of the International Symposium on dynamics of fluids in fractured rocks-Concepts and resent advances (Ed. Faybishenko) pp. 66-68 (1999).

Fujita T., Sugita Y., Sato T., Ishikawa H. and Mano T. Plan of coupled Thermo-hydromechanical experiement at Kamaishi Mine. Proposal for DECOVALEX II. Power Reactor and Nuclear Fuel Development Corporation (PNC). (1995).

Fujita T., Sugita Y., Sato T., Ishikawa H. and Mano T. Coupled thermo-hydromechanical experiment at Kamaishi mine. Plan. Power reactor and nuclear fuel development corporation (PNC). TN8020 94-005 (1996a).

Fujita T., Sugita Y., Chijimatsu M. and Ishikawa H. Coupled thermo-hydro-mechanical experiment at Kamaishi mine. Mechanical properties of fracture. Power reactor and nuclear fuel development corporation (PNC). TN8410 96-059 (1996b).

Fujita T., Sugita Y., Chijimatsu M. and Ishikawa H. Coupled thermo-hydro-mechanical experiment at Kamaishi mine. Fracture characteristics. Power reactor and nuclear fuel development corporation (PNC). TN8410 96-061 (1996c). 
Fujita T., Chijimatsu M., Sugita Y., and Ishikawa H. Coupled thermo-hydro-mechanical experiment at Kamaishi mine. Measurement data related to excavation of test pit. Power reactor and nuclear fuel development corporation (PNC). TN8410 (1997a).

Fujita T., Chijimatsu M., Ishikawa H., Suzuki H. and Matsumoto K. Coupled thermohydro-mechanical experiment at Kamaishi mine. Fundamental properties of bentonite OT-9607. Power reactor and nuclear fuel development corporation (PNC). TN8410 97071 (1997b).

Jing L., Stephansoon O., Börgesson L., Chijimatsu M., Kautsky F. and Tsang C.-F. DECOVALEX II Project - Technical Report - Task 2C. Swedish Nuclear Power Inspectorate, SKI Report 99:23 (1999).

Milly P.C.D., Moisture and heat transport in hysteretic, inhomogenuous porous media: a matric head-based formulation and a numerical model. Water Resources Research, 18(3), 489-498, (1982).

Noorishad J. and Chin-Fu Tsang. ROCMAS simulator; A thermohydromechanical computer code. In Coupled thermo-hydro-mechanical processes of fractured media (Stephansson, Jing and Tsang, Eds), 551-558 Elsevier (1996).

Phillip J.R. and de Vries D.A. Moisture movement in porous material under temperature gradients. EOS Trans., AGU, 38(2) 222-232 (1957).

Rutqvist J., Noorishad J., Stephansson O. and Tsang C.-F. Determination of fracture storativity in hard rocks using high pressure testing. Water Resources Research. 34 (10) 2551-2560 (1998).

Rutqvist J. and Stephansson O. Cyclic hydraulic jacking to determine virgin stress normal to a fracture. Int. J. Rock mech. Min. Sci. \& Geomech. Abstr. 33, 695-711 (1996).

Rutqvist J. Determination of hydraulic normal stiffness of fractures in hard rock from hydraulic well testing. Int. J. Rock mech. Min. Sci. \& Geomech. Abstr 32, 513-523 (1995).

Rutqvist J., Noorishad J., Stephansson O. and Tsang C. -F. Theoretical and field studies of coupled hydromechanical behaviour of fractured rocks - 2. Field experiment and modelling. Int. J. Rock mech. Min. Sci. \& Geomech. Abstr. 29, 411-419 (1992).

SKB. Final storage of spent nuclear fuel - KBS-3 - I General. Swedish Nuclear Fuel and Waste Management Company (SKB), Stockholm, Sweden. ISSN 0349-6015 (1983).

Vargaftik N. B. Tables of the thermophysical properties of liquids and gases. Published by John Wiley and Sons, New York (1975). 